\title{
MEDIDAS LINEARES EM RADIOGRAFIAS PANORÂMICAS DIGITALIZADAS, FORNECIDAS POR DOIS PROGRAMAS DE IMAGEM PARA PLANEJAMENTO NA IMPLANTODONTIA: CORRELAÇÃO E ANÁLISE CRÍTICA
}

Tese apresentada à Faculdade de Odontologia de Bauru da Universidade de São Paulo, como parte dos requisitos para obtenção do título de Doutor em Odontologia, na área de Estomatologia

(Edição Revisada)

Bauru 2004 


\section{MEDIDAS LINEARES EM RADIOGRAFIAS PANORÂMICAS DIGITALIZADAS, FORNECIDAS POR DOIS PROGRAMAS DE IMAGEM PARA PLANEJAMENTO NA IMPLANTODONTIA: CORRELAÇÃO E ANÁLISE CRÍTICA}

FLÁVIA NOEMY GASPARINI KIATAKE FONTÃO

Tese apresentada à Faculdade de Odontologia de Bauru da Universidade de São Paulo, como parte dos requisitos para obtenção do título de Doutor em Odontologia, na área de Estomatologia

(Edição Revisada)

Orientador: Professor Dr. Luiz Eduardo Montenegro Chinellato

Bauru

2004 


\begin{tabular}{|l}
\hline F736m $\begin{array}{l}\text { Fontão, Flávia Noemy Gasparini Kiatake } \\
\text { Medidas lineares em radiografias panorâmicas digitalizadas, fornecidas }\end{array}$ \\
por dois programas de imagem para planejamento na Implantodontia: \\
correlação e análise crítica./ Flávia Noemy Gasparini Kiatake Fontão - \\
Bauru, 2004. \\
157 p. 30 il.; 30 cm \\
\\
Tese (Doutorado) - Faculdade de Odontologia de Bauru, USP. \\
Orientador: Prof. Dr. Luiz Eduardo Montenegro Chinellato
\end{tabular}

Aprovado pelo Comitê de Ética em pesquisa da Universidade do Sagrado
Coração.
Protocolo $n^{\circ} 0086 / 2004$
Data: $21 / 10 / 2004$

Autorizo, exclusivamente para fins acadêmicos e científicos, a reprodução total ou parcial desta dissertação/tese, por processos fotocopiadores elou meios eletrônicos.

Assinatura do autor:

Data: 


\section{DADOS CURRICULARES}

\section{FLÁVIA NOEMY GASPARINI KIATAKE FONTÃO}

09 de julho de 1967

Nascimento

Bauru - SP

Maria Alba Gasparini Kiatake

Filiação

Braz Keichu Kiatake

$1985-1988$

Curso de Odontologia - Faculdade de Odontologia de Lins - Instituto Americano de Lins da Igreja Metodista.

$1989-1992$

Ingresso no Magistério - Faculdade de Odontologia de Lins - Instituto Americano de Lins da Igreja Metodista.

$1992-1996$

Curso de Pós-Graduação em Diagnóstico Bucal, em nível de Mestrado - Faculdade de Odontologia de Bauru, Universidade de São Paulo 
1994

Início de Atividades Docentes no Curso de Odontologia da Universidade do Sagrado Coração.

$2000-2004$

Curso de Pós-Graduação em Estomatologia, em nível de Doutorado - Faculdade de Odontologia de Bauru, Universidade de São Paulo.

Associações

ABO -Associação Brasileira de Odontologia.

ABRO - Associação Brasileira de Radiologia Odontológica.

APCD - Associação Paulista de Cirurgiões-Dentistas do Estado de São Paulo.

SOBE - Sociedade Brasileira de Estomatologia. 
Dedico este trabalho à SABEDORIA INFINITA

Senhor!

Fazei-me instrumento de Vossa paz:

Onde houver ódio, que eu leve o amor Onde houver ofensa, que eu leve o perdão Onde houver discórdia, que eu leve a união

Onde houver dúvida, que eu leve a fé

Onde houver erro, que eu leve a verdade Onde houver desespero, que eu leve a esperança Onde houver tristeza, que eu leve alegria

Onde houver trevas, que leve a luz

\section{Ó Mestre!}

Fazei que eu procure mais

Consolar, que ser consolado

Compreender, que ser compreendido

Amar, que ser amado

Pois é dando que se recebe

É perdoando que se é perdoado

E é morrendo que se vive

Para a vida Eterna

Amém 


\section{Dedico este trabalho}

\section{A todos vocês, com muito carinho e amor,}

Aos meus pais Alba e Braz, exemplos de amor e dedicação aos filhos. Guardo em meu coração os seus sábios ensinamentos e, sobretudo, os seus testemunhos de vida como pais e como casal cristão. Devo a vocês mais esta conquista. Não tenho palavras para expressar o quanto os amo!

Ao meu querido esposo Roberto, o meu agradecimento pela sua compreensão, apoio, carinho e estímulo, tão necessários para a concretização dos meus ideais, pelo companheirismo e partilha de nossa vida, o meu amor eterno. Você é um anjo bom que ilumina minha vida.

"Você caiu do céu, um anjo lindo que apareceu..."

Com carinho

Aos meus filhos Júlia e Otávio, que são verdadeiros tesouros da minha vida, na alegria de seus sorrisos encontro a razão maior na busca de meus ideais. Deus é a maior testemunha de quanto vocês foram desejados e são amados!

Aos meus queridos sogros Marlene e Roberto agradeço-lhes de coração, pelo incentivo e carinho com que sempre trataram a mim e a meus filhos. Sem a sua inestimável ajuda, essa caminhada seria muito mais dificil.

Deus os abençoe sempre! 
Aos meus irmãos Angela e Luiz Gustavo, meus cunhados Fausto, Sandra, Rosana e Vicente, pela presença fraterna, solidariedade, carinho e confiança que sempre me dedicaram

À Teina, tia querida, que desde o início da minha vida acadêmica incentivou e encorajou para o meu aperfeiçoamento na vida profissional

À Vovó Carmem (in memorian) pela sua grande sabedoria, nascida de sua simplicidade e humildade, através da qual me passou profundas lições de vida 


\section{Minha admiração e agradecimentos}

Dr. Luiz Eduardo Montenegro Chinellato, em primeiro lugar a manifestação de minha admiração e respeito, pela sua renomada competência e reconhecida capacidade profissional. Ao longo de toda esta pesquisa, pudemos sentir a sua presença e a sua orientação, que a tornaram possivel. A sua orientação não se restringiu à parte profissional, mas você com muito carinho me passou sábios conselhos de vida. Sua amizade, compreensão e apoio me trouxeram muita segurança e confiança. Por tudo, o meu reconhecimento e a minha gratidão.

Dr. Casati, é maravilhoso conviver com um grande mestre, que "no campo do mundo é um semeador e cuja missão é semear sempre, a semente abundante - um pensamento, um sorriso, uma promessa de alento, um aperto de mão, um conselho, uma orientação, um pouco de água". Para mim, o senhor é um exemplo de pessoa humana admirável e mestre por excelência, cujo o caminho pretendo seguir. Juntamente com a nossa querida Dona Terezinha, e seus filhos, formam uma família maravilhosa que mora no meu coração. Deus os abençoe sempre!

Dr. Tavano, o segredo de seu imenso sucesso como mestre e pesquisador universalmente reconhecido é a sua disponibilidade em ajudar as pessoas. A sua amizade, sua presença amiga a me mostrar caminhos, a sua disposição e disponibilidade de partilhar experiências e projetos, e sua enorme visão de talento fez crescer em mim a grande admiração e respeito que eu já lhe dedicava. Por tudo isso, sou-lhe imensamente grata. 
Dra. Ana Lúcia Alvares Capelozza, querida amiga, cuja alegria de viver contagia e ilumina a todos, faz de você, além de profissional competente, uma semeadora de paz e felicidade. Você é um exemplo de que se pode transformar o mundo, deixando-o muito melhor e mais gostoso de se viver, com o sorriso nos lábios e um acolhimento caloroso.

Dr. José Humberto Damante. A sua amizade sempre afirmada foi fator importantíssimo nesta minha jornada pelo curso de doutorado. Em todos os momentos pude sentir, de maneira silenciosa mas efetiva, a sua aprovação, o seu amparo, o seu encorajamento, a sua presença fraterna. A você, o meu reconhecimento e gratidão eterna

Dra. Izabel Regina Fisher Rubira Bullen, agradeço de coração, o carinho, a atenção e os sábios conselhos $e$ sugestões em tantas ocasiões de nossa convivência

Dra. Nancy Alfieri Nunes. Você querida mestra, a quem devo a minha iniciação na carreira docente e cujo incentivo e estímulo me conduziram a este curso de Pós-Graduação. Em você, querida amiga, cuja a simplicidade e humildade escondem uma enorme competência $e$ capacidade, procurei sempre me espelhar em minha vida profissional e pessoal. Sua abertura de coração firmada na Sabedoria Infinita, faz de você uma pessoa muito especial, cuja a luz ilumina todos aqueles que têm o privilégio de privar de sua amizade e partilha de vida 
Aos professores do Departamento de Estomatologia $e$ Cirurgia da Faculdade de Odontologia de Bauru da Universidade de São Paulo, Dra. Ana Lúcia Alvares Capelozza, Dra. Izabel Regina Fisher Rubira Bullen, Dr. José Humberto Damante, Dr. Luiz Eduardo Montenegro Chinellato, Dr. Eduardo Sant'Anna, Dr. Júlio Gurgel e Dr. Osny Ferreira Júnior. Nesta minha caminhada pelo curso, professores e mestres merecem todo o meu reconhecimento pelo muito que fizeram em favor de meu crescimento como pessoa e como profissional. Agradeço a acolhida, o carinho e os bons momentos de convivência.

Às professoras companheiras de disciplina Izabel Maria March Carvalho e Márcia Ferreira Vasconscelos Malmström, minhas grandes amigas, irmãs de coração, agradeço por assumirem com tanta competência e disponibilidade minhas atividades profissionais no momento de minha ausência. A certeza da amizade sincera, a certeza de poder contar sempre, em quaisquer circunstâncias, com o apoio, incentivo e auxílio de vocês, deram-me a confiança e tranqüilidade necessárias para levar adiante o meu curso. Que Deus as abençoe e lhes dê toda felicidade! Por tudo isso sou-lhes imensamente grata

Às minhas super amigas de Pós-graduação Mariela $e$ Luciana, que muito me ajudaram não só nas atividades do curso, mas estiveram presentes, partilhando com o coração, os grandes momentos de minha vida. Pelo carinho incondicional e convivência amiga, peço a Deus que as ilumine sempre! Os fortes laços de amizade que criamos permanecerão vivos em nossas vidas.

Aos amigos, colegas de Pós-Graduação (Mestrado), Cláudio, Fernando, Flávio, Josiane, Luiz Fernando e Nicole, pelos preciosos momentos de convivência, pelos sorrisos, e pela amizade fraterna, meus agradecimentos e alegres lembranças 
Aos meus irmãos em Cristo, da Equipe Nossa Senhora do Bom Parto e ao meu amigo Padre Enedir, a minha gratidão pela amizade desinteressada, ajuda mútua e a partilha de vida, que faz da nossa equipe um lugar de profundo encontro e comunhão de irmãos que se amam. A certeza de que "Quando dois ou três estiverem reunidos em Meu Nome, Eu estou no meio deles", nos mantêm sempre unidos.

Aos funcionários do Departamento de Estomatologia $e$ Cirurgia da Faculdade de Odontologia de Bauru da Universidade de São Paulo, Camila, Cristina, Fernanda, José Messias e Josi agradeço pela inestimável colaboração e pelo atenção constante

Às amigas Marilia e Walderez pela acolhida e sincera amizade demonstrada em todos os momentos de convivência

Aos amigos professores e funcionários da Universidade do Sagrado Coração pelo incentivo e amizade

Ao Professor Dr. José Roberto Pereira Lauris, do Departamento de Odontologia Social da Faculdade de Odontologia de Bauru da Universidade de São Paulo, pela confecção da análise estatística deste trabalho

À bibliotecária Valéria, da Biblioteca da Faculdade de Odontologia de Bauru da Universidade de São Paulo, pela revisão das Referência Bibliográficas

Aos funcionários da Biblioteca da Faculdade de Odontologia de Bauru da Universidade de São Paulo, em todos os momentos, auxiliaram nos levantamentos bibliográficos 
À Professora Angela Elys Gasparini Kiatake Bianchini, pela dedicação e eficiência na revisão do texto

Ao Tecnólogo Fausto Bianchini Filho pelo excelente trabalho de confecção dos gráficos

Aos mestres Sandra Capuano e Luis Gustavo Kiatake pela criteriosa revisão de computação gráfica

À Professora Gisele Dalben, pela correta versão do resumo para a Lingua Inglesa

Aos técnicos André e José Roberto pela revisão da formatação das tabelas

Aos Professores Dr. Mário Gongora e Dr. Sérgio Takeo Kofuji, do Laboratório de Sistemas Integráveis da Escola Politécnica da Universidade de São Paulo, pela cessão do Paquímetro digital Mitutoyo, utilizado nesta pesquisa

À CDT, na pessoa do Diretor Científico Dr. Mike Bueno, pela cessão do Programa Planimp, utilizado nesta pesquisa

À Radiomemory, na pessoa do chefe do Departamento Comercial Senhor Alexandre Oliveira, pela cessão do Programa Radioimp, utilizado nesta pesquisa

A todos que de uma forma ou de outra, me incentivaram, o meu sincero agradecimento e desejo de que Deus os abençoe e torne plena suas vidas de graças e sabedoria 


\section{Meus sinceros agradecimentos, admiração e respeito}

À Faculdade de Odontologia de Bauru da Universidade de São Paulo, na pessoa de sua Diretora, Dra. Maria Fidela de Lima Navarro

À Comissão de Pós-Graduação da Faculdade de Odontologia de Bauru da Universidade de São Paulo, na pessoa do Professor Dr. José Carlos Pereira

À Universidade do Sagrado Coração, na pessoa da Magnífica Reitora Irmã Jacinta Turolo Garcia

À Faculdade de Odontologia da Universidade do Sagrado Coração, na pessoa da Digníssima Diretora do Centro de Ciências Biológicas e Profissões de Saúde, Irmã Marisabel Leite, pela confiança que deposita em mim e pelo carinho com que me trata

À Faculdade de Odontologia de Lins, e a todos os meus professores e amigos pela minha formação acadêmica 


\section{Digna Banca Examinadora}

Professores ilustres que com grande disponibilidade, aceitaram o convite para compor a Banca Examinadora e, dessa maneira, me honraram sobremaneira. A vós confio meu trabalho, fruto de muito estudo, dedicação e esforço, e da participação de tantos professores e alunos desta Universidade

Assim, meu agradecimento todo especial 


\section{SUMÁRIO}

LISTA DE FIGURAS......................................................................

LISTA DE TABELAS.........................................................................xiii

LISTA DE ABREVIATURAS E SÍMBOLOS....................................xxvii

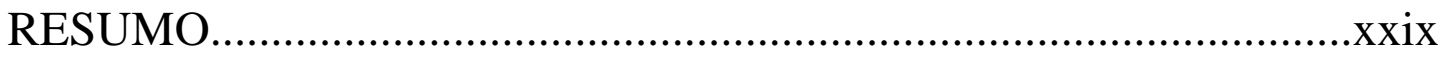

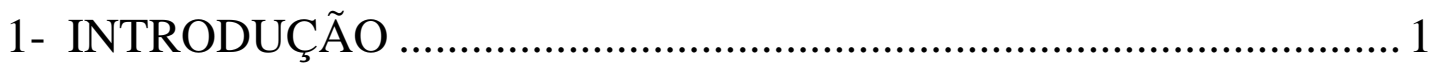

2- REVISÃO DE LITERATURA ........................................................... 5

2.1- Radiologia em Implantodontia.......................................................... 6

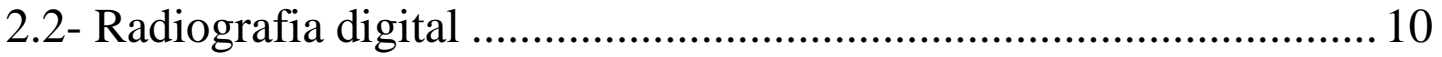

2.3- Programas de imagem....................................................................... 24

2.3.1- Mensurações de distâncias lineares ................................................ 25

2.3.2 - Programas de imagem para o planejamento pré-cirúrgico

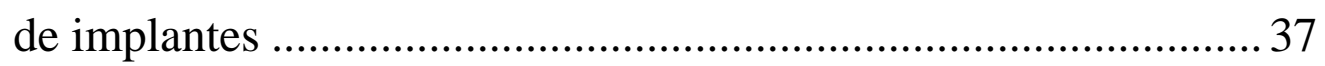

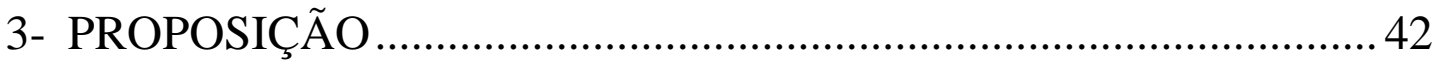

4- MATERIAL E MÉTODOS ............................................................ 44

4.1- Radiografias panorâmicas ................................................................... 45

4.2- Distâncias anatômicas .................................................................... 46

4.3- Digitalização das radiografias panorâmicas ..................................... 50

4.4- Mensurações lineares das distâncias anatômicas................................ 53

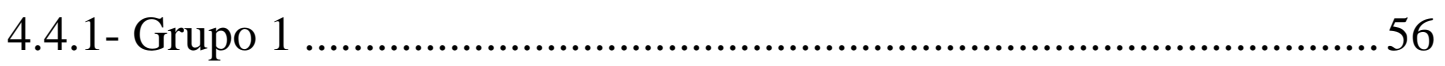

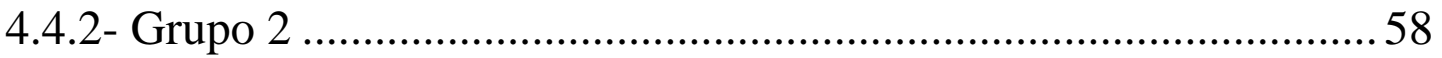

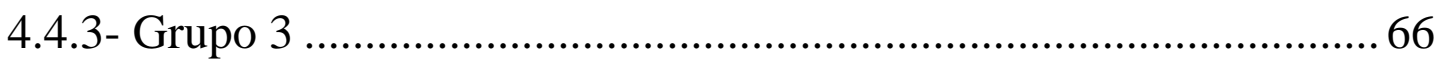

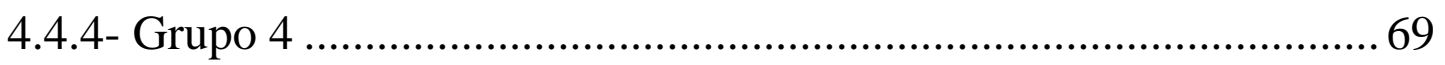

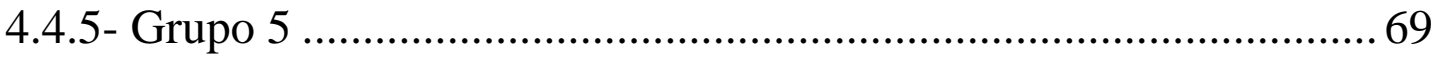

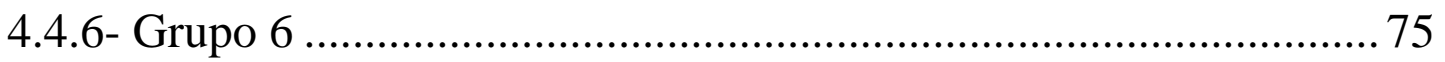

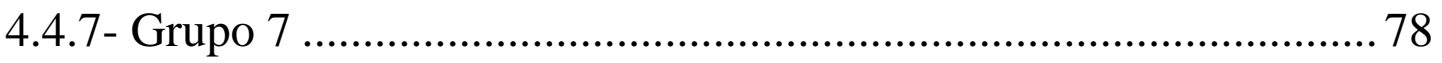




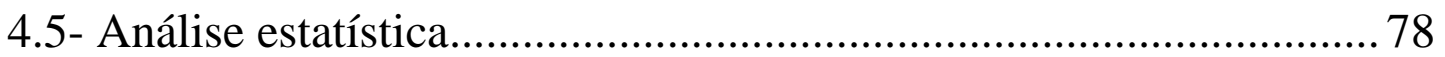

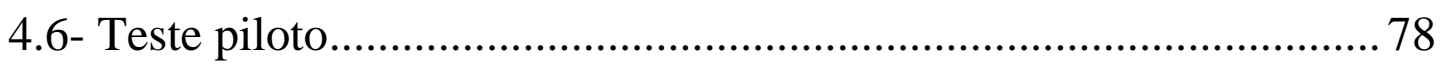

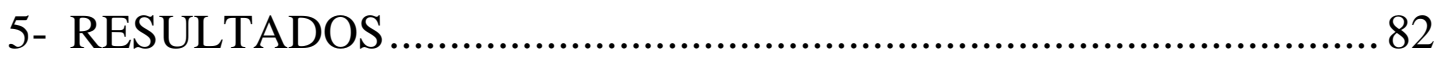

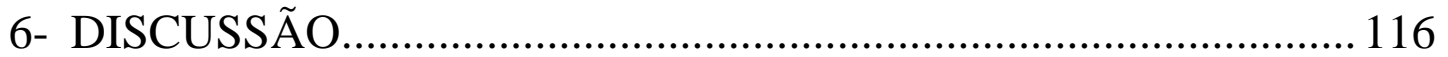

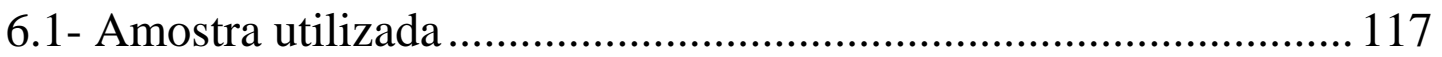

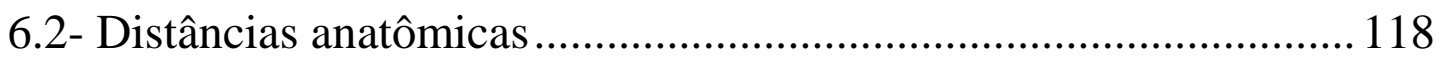

6.3- Digitalização das radiografias panorâmicas .................................... 119

6.4- Mensuração das distâncias anatômicas.......................................... 122

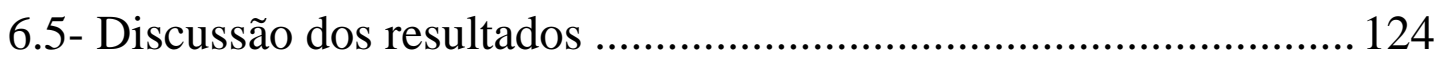

6.5.1- Análise dos gráficos ................................................................. 124

6.5.2- Comparação entre medidas digitais e as medidas manuais ......... 129

6.5.3 - Comparação entre os sitemas de calibração dos programas....... 133

6.5.4 - Comparação entre os programas Radioimp e Planimp................ 134

6.5.4.1- Em relação aos seus sistemas de calibração .............................. 134

6.5.4.2- Em relação aos seus sistemas de medição ................................. 135

6.5.5 - Comparação entre os métodos de aquisição de imagem:

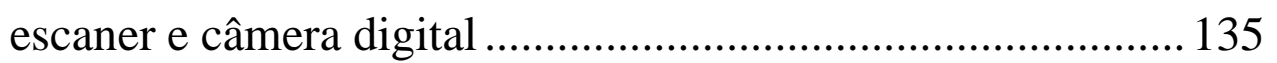

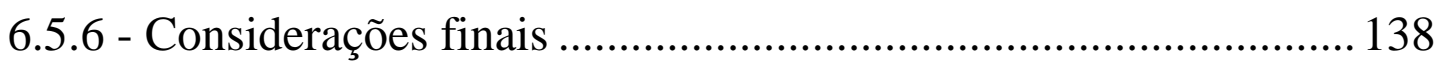

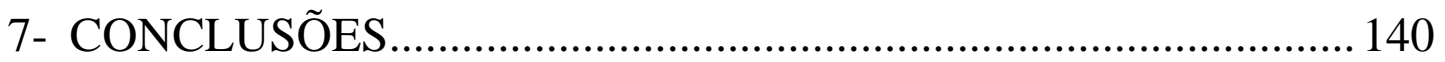

REFERÊNCIAS BIBLIOGRÁFICAS ................................................ 142

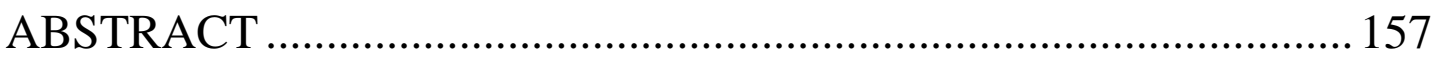

ANEXOS 


\section{LISTA DE FIGURAS}

FIGURA 1 - Pontos de referência delimitando as 14 distâncias anatômicas

FIGURA 2 - Escaner HP Scanjet 4 C/T com leitor de transparência, utilizado para digitalização das radiografias 52

FIGURA 3 - Câmera digital FinePix S602 posicionada na estativa, no momento da digitalização das radiografias 52

FIGURA 4 - Exemplos de laudos fornecidos por programas de imagem para planejamento de implantes: I Radioimp e II Planimp. 55

FIGURA 5 - Negatoscópio MB e paquímetro digital Mitutoyo $150 \mathrm{~mm}$, utilizados para mensuração das distâncias anatômicas, nas radiografias (grupo 1)

FIGURA 6 - Demonstração na tela do monitor com imagens dos passos seguidos para calibração da imagem e obtenção das medidas do grupo 2 (radioimp/calibração por resolução/escaner): I) abertura do programa, II) busca da imagem radiográfica 
FIGURA 7 - Demonstração na tela do monitor com imagens dos passos seguidos para calibração da imagem e obtenção das medidas do grupo 2 (radioimp/calibração por resolução/escaner). III) seleção do tipo de calibração, IV calibração por resolução 61

FIGURA 8 - Demonstração na tela do monitor com imagens dos passos seguidos para calibração da imagem e obtenção das medidas do grupo 2 (radioimp/calibração por resolução/escaner): V) identificação dos dados do paciente, VI) ferramentas para tratamento da imagem 64

FIGURA 9 - Demonstração na tela do monitor com imagens dos passos seguidos para calibração da imagem e obtenção das medidas do grupo 2 (radioimp/calibração por resolução/escaner). VII) medição com a ferramenta distância, VIII) obtenção das 14 medidas

FIGURA 10 - Demonstração na tela do monitor com imagens dos passos seguidos para calibração da imagem e obtenção das medidas do grupo 3 (radioimp/calibração referencial/escaner). I) seleção do tipo de calibração, II) calibração da imagem pelo método referencial 68 
FIGURA 11 - Demonstração na tela do monitor com imagens dos passos seguidos para calibração da imagem e obtenção das medidas do grupo 5 (Planimp/calibração por resolução/escaner). I) abertura do programa e identificação do paciente, II) busca da imagem.

FIGURA 12 - Demonstração na tela do monitor com imagens dos passos seguidos para calibração da imagem e obtenção das medidas do grupo 5 (Planimp/calibração por resolução/escaner). III) seleção do tipo de calibração, IV) calibração por resolução 72

FIGURA 13 - Demonstração na tela do monitor com imagens dos passos seguidos para calibração da imagem e obtenção das medidas do grupo 5 (Planimp/calibração por resolução/escaner). V) medição das distâncias anatômicas, VI) obtenção das 14 medidas 74

FIGURA 14 - Demonstração na tela do monitor com imagens dos passos seguidos para calibração da imagem e obtenção das medidas do grupo 6 (Planimp/calibração referencial/escaner). I) seleção do tipo de calibração, II) calibração referencial 
FIGURA 15 - Teste piloto: exemplos de mensuração da espessura da imagem da régua digitalizada. I) distância lente-filme de $20 \mathrm{~cm}$ sem zoom, II) distância lente/filme de 50 cm com zoom 81

FIGURA 16 - Comparativo das médias dos valores (em mm) das médias das medidas da distância D1-MSD (Molar Superior Direito) obtidas pelos sete grupos. 86

FIGURA 17 - Comparativo das médias (em mm) das medidas da distância D2-PMSD (Pré-Molar Superior Direito) obtidas pelos sete grupos 88

FIGURA 18 - Comparativo das médias (em mm) das medidas da distância D3-CSD (Canino Superior Direito) obtidas pelos sete grupos 90

FIGURA 19 - Comparativo das médias (em mm) das medidas da distância D4-ICS (Incisivo Central Superior) obtidas pelos sete grupos 92

FIGURA 20 - Comparativo das médias (em mm) das medidas da distância D5-CSE (Canino Superior Esquerdo) obtidas pelos sete grupos 94

FIGURA 21 - Comparativo das médias (em mm) das medidas da distância D6-PMSE (Pré-Molar Superior Esquerdo) obtidas pelos sete grupos 96 
FIGURA 22 - Comparativo das médias (em mm) das medidas da distância D7-MSE (Molar Superior Esquerdo) obtidas pelos sete grupos 98

FIGURA 23 - Comparativo das médias (em mm) das medidas da distância D8-MID (Molar Inferior Direito) obtidas pelos sete grupos 100

FIGURA 24 - Comparativo das médias (em mm) das medidas da distância D9-PMID (Pré-Molar Inferior Direito), obtidas pelos sete grupos 102

FIGURA 25 - Comparativo das médias (em mm)das medidas da distância D10-CID (Caninor Inferior Direito), obtidas pelos sete grupos 104

FIGURA 26 - Comparativo das médias (em mm) das medidas da distância D11-ICI (Incisivo Central Inferior) obtidas pelos sete grupos 106

FIGURA 27 - Comparativo das médias (em mm) das medidas da distância D12-CIE (Canino Inferior Esquerdo), obtidas pelos sete grupos 108

FIGURA 28 - Comparativo das médias (em mm) das medidas da distância D13-PMIE (Pré-Molar Inferior Esquerdo) obtidas pelos sete grupos 
FIGURA 29 - Comparativo das médias (em mm) das medidas da distância D14-MIE (Molar Inferior Esquerdo), obtidas pelos sete grupos

FIGURA 30 - Comparativo entre os valores (em mm) da média geral das 14 distâncias anatômicas referentes a cada um dos sete grupos 


\section{LISTA DE TABELAS}

TABELA 1 - Valores (em mm) das médias, desvios padrão e p referentes ao teste de análise de variância, com nível de significância a 5\%, das medidas obtidas pelos sete grupos, para a distância D1-MSD (Molar Superior Direito)

TABELA 2 - Valores (em mm) das médias, desvios padrão e p referentes ao teste de análise de variância, com nível de significância a 5\%, das medidas obtidas pelos sete grupos, para a distância D2-PMSD (Pré-Molar Superior Direito) 88

TABELA 3 - Valores (em mm) das médias, desvios padrão e p referentes ao teste de análise de variância, com nível de significância a 5\%, das medidas obtidas pelos sete grupos, para a distância D3-CSD (Canino Superior Direito)

TABELA 4 - Valores (em mm) das médias, desvios padrão e p referentes ao teste de análise de variância, com nível de significância a 5\%, das medidas obtidas pelos sete grupos, para a distância D4-ICS (Incisivo Central Superior) 
TABELA 5 - Valores (em mm) das médias, desvios padrão e p referentes ao teste de análise de variância, com nível de significância a 5\%, das medidas obtidas pelos sete grupos, para a distância D5-CSE (Canino Superior Esquerdo)

TABELA 6 - Valores (em mm) das médias, desvios padrão e p referentes ao teste de análise de variância, com nível de significância a 5\%, das medidas obtidas pelos sete grupos, para a distância D6-PMSE (Pré-Molar Superior Esquerdo) 96

TABELA 7 - Valores (em mm) das médias, desvios padrão e p referentes ao teste de análise de variância, com nível de significância a 5\%, das medidas obtidas pelos sete grupos, para a distância D7-MSE (Molar Superior Esquerdo) 98

TABELA 8 - Valores (em mm) das médias, desvios padrão e p referentes ao teste de análise de variância, com nível de significância a 5\%, das medidas obtidas pelos sete grupos, para a distância D8-MID (Molar Inferior Direito) 100

TABELA 9 - Valores (em mm) das médias, desvios padrão e p referentes ao teste de análise de variância, com nível de significância a 5\%, das medidas obtidas pelos sete grupos, para a distância D9-PMID PréMolar Inferior Direito) 102 
TABELA 10 - Valores (em mm) das médias, desvios padrão e p referentes ao teste de análise de variância, com nível de significância a 5\%, das medidas obtidas pelos sete grupos, para a distância D10-CID (Caninor Inferior Direito)

TABELA 11 - Valores (em mm) das médias, desvios padrão e p referentes ao teste de análise de variância, com nível de significância a 5\%, das medidas obtidas pelos sete grupos, para a distância D11-ICI (Incisivo Central Inferior)

TABELA 12 - Valores (em mm) das médias, desvios padrão e p referentes ao teste de análise de variância, com nível de significância a 5\%, das medidas obtidas pelos sete grupos, para a distância D12-CIE (Canino Inferior Esquerdo).

TABELA 13 - Valores (em mm) das médias, desvios padrão e p referentes ao teste de análise de variância, com nível de significância a 5\%, das medidas obtidas pelos sete grupos, para a distância D13-PMIE (Pré-Molar Inferior Esquerdo)

TABELA 14 - Valores (em mm) das médias, desvios padrão e p referentes ao teste de análise de variância, com nível de significância a 5\%, das medidas obtidas 
pelos sete grupos, para a distância D14-MIE (Molar Inferior Esquerdo)

TABELA 15 - Valores (em mm) das médias das medidas obtidas pelos sete grupos, para as 14 distâncias anatômicas 


\section{LISTA DE ABREVIATURAS E SÍMBOLOS}

AAOMR - American Academy of Oral and Maxillofacial Radiology

ALARA - As Low As Reasonably Achievable

bits - Binary digits

Ca - Câmera digital

CCD - Charge-Coupled-Device (dispositivo acoplado de carga)

$\mathrm{CD}$ - compact disc

CDT - Consultoria Desenvolvimento e Treinamento em Informática

CID - Canino Inferior Direito

CIE - Canino Inferior Esquerdo

cm - centímetro

CSD - Canino Superior Direito

CSE - Canino Superior Esquerdo

D - distância

Dpi - dots per inch (pontos por polegada)

EAO - European Association for Osseointegration

Esc - escaner

GB - gigabyte (capacidade de armazenamento)

HD - disco rígido

HP - Hewllett Packard

ICI - Incisivo Central Inferior

ICS - Incisivo Central Superior

JPEG - Joint Photographic Experts Group

$\mathrm{kB}$ - kilobyte(capacidade de armazenamento)

$\mathrm{KVp}$ - quilovoltagem pico

MB - megabytes (capacidade de armazenamento) 
MID - Molar Inferior Direito

MIE - Molar Inferior Esquerdo

M.L.P.I - Método de Localização Para Implantes

mm - milímetro

MSD - Molar Superior Direito

MSE - Molar Superior Esquerdo

PCIM - ponto Cortical Interna da Mandíbula

PCM - ponto Canal Mandibular

PENA - ponto Espinha Nasal Anterior

PFM - ponto Forame Mentual

PFP - ponto entre forame mentual e Plano sagital mediano

Pixel- picture element (elemento de imagem)

Plan - Planimp

PMID - Pré-Molar Inferior Direito

PMIE - Pré-Molar Inferior Esquerdo

PMSD - Pré-Molar Superior Direito

PMSE - Pré-Molar Superior Esquerdo

PRAI - ponto Rebordo Alveolar Inferior

PRAS - ponto Rebordo Alveolar Superior

PSM - ponto Soalho do Seio Maxilar

PY - ponto Y de Ennis

Radio - Radioimp

RAM - memória aleatória

SMPTE - Sociedade da Imagem em Movimento e Engenheiros de Televisão

TV2-DL - teste padrão de registro operacional

$\mu \mathrm{m}$ - micrometro 
RESUMO 


\section{RESUMO}

O objetivo da presente pesquisa foi avaliar, comparativamente, as medidas lineares em radiografias panorâmicas obtidas em programas de imagem para planejamento pré-cirúrgico em implantes (Radioimp e Planimp), com as obtidas pelo método manual, utilizando um paquímetro digital. Outro objetivo foi analisar os dois métodos de digitalização utilizados: escaner e câmera digital A amostra constou de 50 radiografias panorâmicas de pacientes edêntulos, nas quais foram marcados pontos de referência para delimitar 14 distâncias anatômicas em cada radiografia. As radiografias foram digitalizadas por meio de um escaner HP Scanjet 4C/T (Hewllett Packard) e uma câmera digital FinePix S602 (Fujifilm). As mensurações lineares das distâncias anatômicas foram realizadas pelo método manual (paquímetro digital) e pelo método digital (programas Radioimp e Planimp). Os dados obtidos foram submetidos à análise estatística de variância, com nível de significância de 5\%. Esta análise estatística mostrou que não houve diferença significante entre as medidas manuais e digitais. A partir dos resultados concluiu-se que os programas Radioimp e Planimp apresentaram desempenhos adequados para a calibração da imagem radiográfica, bem como para a mensuração de distâncias lineares. Os sistemas de digitalização de imagens utilizados (escaner e câmera digital) não apresentaram diferenças significativas, sendo adequados para uso com esses programas. 
1- INTRODUÇÃO 


\section{1- INTRODUÇÃO}

Após a descoberta do Professor Per-Ingvar Branemark na década de 1960, de que o titânio inserido em tecido ósseo se tornava permanentemente integrado a ele, o uso de implantes osseointegráveis cresceu rapidamente no mundo. Atualmente são considerados métodos bem-sucedidos na reposição de dentes, alcançando índices de sucesso de $90 \%$ ou mais. Assim, surgiu na Odontologia uma nova fase relacionada à reabilitação bucal (CHILVARQUER ${ }^{22}$, 1998; TYNDALL et al. ${ }^{70}$, 2000).

Para a realização de um planejamento em Implantodontia o exame radiográfico é de fundamental importância, sendo seus objetivos por permitir a visualização global do complexo maxilomandibular, a orientação sobre as possíveis regiões a serem implantadas, a avaliação da qualidade dos tecidos, a proservação e documentação de cada caso.

As radiografias pré-operatórias têm a finalidade de fornecer a topografia da região anatômica a ser avaliada, incluindo a quantidade e qualidade do tecido ósseo, bem como a localização das estruturas anatômicas adjacentes. Auxiliam também na observação de eventuais processos patológicos na área receptora de implantes.

As radiografias panorâmicas, nos relatos de vários autores, têm um papel fundamental na fase pré-operatória para o planejamento de implantes osseointegráveis. $\quad$ (CHILVARQUER ${ }^{21}$, 1993; CHILVARQUER $^{22}$, 1998; DULA et al. ${ }^{29}$, 2001).

Essas radiografias oferecem uma visão abrangente da maxila e da mandíbula, dos dentes presentes, do formato do seio maxilar, da fossa nasal, de assimetrias e lesões ósseas. Por meio de suas informações é possível delinear os reparos anatômicos de interesse, resultando em um traçado radiográfico panorâmico para implantes (CHILVARQUER ${ }^{23}$, 
2002). As radiografias panorâmicas são de obtenção e interpretação relativamente fáceis, com baixo custo, produzindo uma baixa dose de radiação ao paciente (DULA et al. $^{29}$, 2001; HARRIS et al. ${ }^{42}$, 2002; TYNDALL et al. $\left.^{70}, 2000\right)$. Apresentam como desvantagens a distorção causada por erros de posicionamento do paciente e a ausência de informação da espessura vestíbulo-lingual dos rebordos alveolares (MONTEBELO FILHO $^{54}$, 2000; REISKIN ${ }^{60}$, 1998; TYNDALL et al. $^{70}$, 2000). Por essas razões, muitos pesquisadores não recomendam o uso isolado da técnica panorâmica para planejamento pré-cirúrgico de implantes osseointegráveis para todas as regiões de maxila e mandíbula (BOUSERHAL et al. ${ }^{11}$, 2002; CHILVARQUER ${ }^{23}$, 2002; DULA et al. $^{29}$, 2001; 1995; HARRIS et al. $^{42}$, 2002; MONTEBELO FILHO ${ }^{54}$, 2000; TYNDALL et al. $\left.{ }^{70}, 2000\right)$.

Dentro do protocolo para implantes osseointegráveis, CHILVARQUER $^{23}$ em 2002, incluiu a "radiografia panorâmica com traçado radiográfico", como técnica pré-operatória necessária para uma visualização globalizada do complexo maxilomandibular. Tal técnica visa delinear os principais reparos anatômicos e estimar medidas das distâncias anatômicas de interesse.

Freqüentemente, o traçado radiográfico para planejamento de implantes é realizado manualmente, diretamente em papel acetato transparente superposto à radiografia, vista através de um negatoscópio. As mensurações das distâncias anatômicas, na grande maioria das vezes, são realizadas com o auxílio de réguas milimetradas.

Em função da grande evolução na área da Implantodontia e da crescente demanda de pacientes que atualmente recebem implantes, programas de imagem têm sido desenvolvidos para o planejamento précirúrgico de implantes osseointegráveis, a fim de se garantir a qualidade e precisão das medições, aliadas à facilidade e rapidez da operação. 
Os programas de imagem realizam medições necessárias e oferecem sugestões de tipos e tamanhos de implantes, em imagens capturadas por escaner, câmera digital ou sensores digitais. Eles possuem várias ferramentas de desenho, efeitos, tratamento de imagem e mensurações, possibilitando a confecção de traçados radiográficos de alto padrão técnico e estético. A padronização dos relatórios emitidos, no formato de fichas, pelos diversos programas, possibilita o arquivamento de dados de forma mais organizada e acessível. Além disso, os programas possuem um sistema de calibração da magnificação da imagem, com a finalidade de garantir a precisão das medidas.

Atualmente, estão sendo comercializados alguns programas de imagem para o planejamento pré-cirúrgico de implantes (CDT ${ }^{17}, 2004$; RADIOMEMORY $^{58}$, 2004) desenvolvidos no Brasil. Verificamos que não existem pesquisas avaliando esses programas quanto aos seus desempenho e confiabilidade.

Diante disso, nos propusemos avaliar dois programas de imagem para planejamento de implantes odontológicos, recentemente lançados no Brasil: o Radioimp - Radiomemory, Belo Horizonte, Minas Gerais, Brasil - ( RADIOMEMORY ${ }^{58}$, 2004) e o Planimp - CDT, Cuiabá, Mato Grosso, Brasil - (CDT $\left.{ }^{17}, 2004\right)$. 
2- REVISÃO DE LITERATURA 


\section{2- REVISÃO DE LITERATURA}

Com a finalidade de embasar o nosso trabalho e nos aprofundarmos no contexto do assunto, procedemos a uma revisão de literatura. Concentramos nosso estudo na literatura referente à Radiologia em Implantodontia, radiografia digital e programas de imagem.

\section{1- Radiologia em Implantodontia}

A Radiologia, dentro da Implantodontia, exerce papel de grande importância, visto que, por meio dela, podemos avaliar a região anatômica a ser implantada, a quantidade e a qualidade do tecido ósseo, localizar e delimitar estruturas anatômicas adjacentes, e descobrir possíveis processos patológicos na área receptora de implantes. Ela nos permite, ainda, a proservação e uma documentação adequadas. Em virtude de todas essas aplicações, é indispensável aos profissionais na avaliação e planejamento para a instalação de implantes.

Os autores são concordes quanto aos critérios de seleção de uma técnica radiográfica. Devem ser levados em consideração fatores como distorção, reprodutilibilidade, dose de radiação e custo financeiro (ABRAHAMS $^{1}$, 1993; BOUSERHAL et al. ${ }^{11}$, 2002; DULA et al. ${ }^{29}$, 2001, HARRIS et al. ${ }^{42}$, 2002; TYNDALL et al. ${ }^{70}$, 2000).

Dentre as modalidades radiográficas úteis para a Implantodontia podemos citar as técnicas intrabucais, panorâmicas, cefalométricas e tomografias (MILES; VAN DIS ${ }^{53}$, 1993).

Para muitos autores, a radiografia panorâmica tem especial papel na Implantodontia, e faz parte dos protocolos de planejamento para 
implantes, pois permite a visualização global do complexo maxilomandibular. Além disso, é uma técnica de fácil execução resultando em uma radiografia, que pode ser interpretada por qualquer profissional devidamente treinado. A partir dela, é possível delinear as estruturas anatômicas, resultando em um traçado radiográfico panorâmico para implantes (CHILVARQUER ${ }^{23}$, 2002; DULA et al. $^{29}, \quad 2001$; FREDERIKSEN $^{37}$, 1995; HARRIS et al. $^{42}$, 2002; REISKIN ${ }^{60}$, 1998; TYNDALL et al. $\left.{ }^{70}, 2000\right)$.

Em 2000, a American Academy of Oral and Maxillofacial Radiology (AAOMR) ${ }^{70}$ fez uma revisão da literatura a respeito das modalidades radiográficas (radiografias intrabucais, panorâmicas, cefalométricas, tomografia convencional e computadorizada) disponíveis para avaliação pré-cirúrgica do local receptor de implantes, relatando as suas aplicações, vantagens e desvantagens em relação à dose de radiação e custo financeiro. A Academia recomenda a utilização da radiografia panorâmica em todos os casos para avaliação do local de implante (desde espaços unitários até áreas totalmente edêntulas; áreas de trauma significante e de enxertos). Essa radiografia é útil para avaliar se o local do implante é adequado, pois fornece uma visão ampla da maxila e mandíbula. Complementando o exame panorâmico, radiografias periapicais podem ser realizadas em áreas isoladas para esclarecer algum ponto duvidoso. Além dessas técnicas radiográficas, o protocolo pré-operatório inclui imagens de corte seccional, sendo a tomografia convencional recomendada para a maioria dos casos. A tomografia computadorizada, por requerer uma alta dose de radiação e apresentar um elevado custo financeiro, deve ser indicada apenas para casos especiais ou pacientes edêntulos.

MONTEBELO $^{54}$ em 2000, após comparar imagens de um crânio seco, obtidas de forma padronizada por várias técnicas radiográficas, concluiu que as medidas que mais se aproximaram das dimensões reais 
foram as da tomografia computadorizada (Denar Quint Sectograph), seguida pela tomografia convencional (Denar Quint Sectograph), cefalométrica, periapical (paralelismo), panorâmica (Instrumentarium OP 100), panorâmica (Ortopantomograph Siemens), tomografia convencional (Instrumentarium OP 100). Nesse trabalho, o autor apresenta as aplicações, vantagens e desvantagens de cada técnica radiográfica e demonstra que nenhum procedimento radiográfico isolado produz imagens ideais para todas as etapas do planejamento pré-cirúrgico.

DULA et al..$^{29}$ em 2001, realizaram uma avaliação dos critérios de escolha para as principais técnicas radiográficas utilizadas no planejamento pré-cirúrgico em Implantodontia, com base nas necessidades clínicas do paciente e no risco biológico envolvido. Nesse sentido, os autores consideram a radiografia panorâmica como um exame amplo, com visão abrangente, que permite a avaliação de várias estruturas anatômicas e oferece a possibilidade de mensurações verticais com acurácia suficiente quando o fator de magnificação do aparelho é conhecido. No geral, recomendam a radiografia panorâmica como exame padrão para o plano de tratamento de implantes, pelo fato de proporcionar um baixo risco biológico e, ao mesmo tempo, oferecer uma visão ampla e uma acurácia média para a determinação do comprimento do implante em maxila e mandíbula. As radiografias periapicais devem ser utilizadas, se necessário, para complementar os achados obtidos na panorâmica. Outros métodos baseados em cortes seccionais podem ser aplicados somente em circunstâncias especiais, indicando a tomografia convencional para pequenas áreas de interesse e a tomografia computadorizada para grandes áreas de maxila e mandíbula.

Em 2002, membros da European Association for Osseointegration $(E A O)^{42}$ em um workshop realizado no Trinity College Dublin, estabeleceram diretrizes para o uso de diagnóstico por imagem em 
Implantodontia. O objetivo desse guia é oferecer recomendações para as variadas situações clínicas, que garantirão informações radiográficas essenciais, obtidas com uma dose de radiação tão baixa quanto razoavelmente possível (princípio ALARA: As Low As Reasonably Achievable). Devido à utilização rotineira de técnicas sofisticadas (tomografias), sem a adequada análise do risco benefício, a EAO acredita que esse fato possa levar a um aumento significante da carga de radiação nos pacientes submetidos a implantes. Eles advertem que técnicas como a tomografia convencional e a computadorizada só devem ser indicadas quando, após a realização dos exames radiográficos convencionais, houver dúvidas em relação à localização de estruturas anatômicas nobres, bem como em casos particulares, que são detalhadamente descritos no guia.

KALIL $^{45}$ em 1998, concorda que a radiografia panorâmica sobrecontornada em papel acetato transparente facilita na aferição e visualização das distâncias das estrutruras ósseas, tornando mais prático o planejamento cirúrgico de implantes osseointegráveis. Em seu trabalho, o autor propõe a confecção de um traçado radiográfico na imagem panorâmica, determinando algumas distâncias anatômicas denominadas: distância naso-sinusal, rebordo-nasal, rebordo-sinusal, rebordo-alveolar inferior e rebordo-basal anterior mandibular.

CHILVARQUER $^{23}$ em 2002, incluiu a "radiografia panorâmica com traçado radiográfico" como técnica pré-operatória necessária para uma visualização globalizada do complexo maxilomandibular. Dentre os reparos importantes a serem delineados na região mandibular, incluiu o canal mandibular, a emergência do forame mentual e o contorno de todo o rebordo remanescente, inclusive os dentes; para a região maxilar: o contorno das cavidades sinusais, a espinha nasal anterior, o palato duro e o contorno do rebordo remanescente e, também, os dentes. Após executadas as possíveis mensurações no sentido vertical e as 
possíveis deduções das distorções intrínsecas da técnica panorâmica, realizam-se cortes tomográficos axiais e laterais para análise vestíbulolingual. A tomografia computadorizada pode ser indicada para pacientes totalmente edêntulos, devido à possibilidade de reformatar todos os dados obtidos em três planos espaciais.

COSTA et al. ${ }^{26}$ em 2004, com o propósito de descrever um protocolo de trabalho destinado ao planejamento radiográfico para a Implantodontia, abordaram de forma sistemática, a utilização das diferentes técnicas radiográficas no planejamento pré-cirúrgico, visando a colocação e controle de implantes osseointegráveis. Lembram os autores que a radiografia panorâmica poderá ser indicada, apesar dos fatores limitantes ao seu uso, uma vez que as ampliações médias variam para cada tipo de equipamento, devendo ser individualizadas. É indicada no pré-operatório para pesquisas de dentes inclusos, relação de oclusão futura com os dentes antagonistas, estimativas das resultantes de forças e relacionamento dos sítios dos implantes com os dentes vizinhos. Nesse estudo, concluíram que os exames ideais são a tomografia convencional para um a sete implantes e a tomografia computadorizada para oito ou mais implantes.

\section{2- Radiografia digital}

A Radiologia é constantemente pesquisada com o intuito de se obter cada vez mais detalhes e maior precisão no diagnóstico. No final dos anos 70, a difusão e a facilidade que a Informática trouxe, possibilitaram o uso da digitalização de imagens radiográficas convencionais. Os sistemas de digitalização de radiografias pelo método direto, surgiram no final da década de 80. Este método permite a obtenção de uma imagem radiográfica 
sem a utilização de um filme convencional, que é substituído por sensores ou placas ópticas (DUNN; KANTOR ${ }^{31}$, 1993; FUJITA et al. ${ }^{38}, 1988$; GRÖNDAHL $^{39}$, 1992; SANDERINK ${ }^{61}$, 1993; SARMENTO et al. ${ }^{62}, 2000$; SEWELL; FENYO PEREIRA; VAROLI ${ }^{67}, 1997$; WATANABE et al. $^{79}$, 1999; WENZEL; GRÖNDAHL ${ }^{82}$, 1995).

Assim foram aparecendo, com o passar dos anos, programas de imagens que tornaram possível avaliar, medir, e quantificar áreas do filme radiográfico, após sua reprodução digital (SARMENTO; PRETTO; COSTA $^{64}$, 1999; VERSTEEG; SANDERINK; VAN DER STELT ${ }^{75}$, 1997).

Digitalizar uma imagem, tornando-a uma matriz, significa transformá-la em dados numéricos e colocá-los na memória de um computador. Isto é feito por um processo chamado amostragem. A amostragem consiste em dividir a imagem original em pequenos quadrados e retângulos (amostras) e associar a cada um deles um número que representa a cor daquele pedaço da imagem. Isso faz com que se represente a imagem como um conjunto de números que pode ser armazenado na memória de um computador. A cada quadrado, que pode ser considerado um ponto da imagem devido ao seu tamanho reduzido, dá-se o nome de pixel. Uma imagem digital de boa qualidade é formada de centenas de milhares de pixels, cada um deles contendo um número com a informação da cor daquele ponto na imagem. Desse modo, o número de tons de cinza disponíveis determina a densidade da imagem e, em geral, o padrão para a radiografia intrabucal é a digitalização da imagem em 256 tons de cinza, onde o valor 0 (zero) representa o preto e o valor 255, representa o branco. Os demais tons de cinza estão entre os dois valores (VAN DER STELT ${ }^{72}$, 2000).

As imagens digitais podem ser obtidas por meio de dois métodos, o indireto e o direto (BROOKS; MILES ${ }^{13}$, 1993; FARMAN et 
al. $^{34}$, 1998; FERREIRA ${ }^{35}$, 1996; GRÖNDAHL ${ }^{39}$, 1992; SANDERINK ${ }^{61}$, 1993; WENZEL ${ }^{82}$, 1995).

Pelo método indireto, a imagem pode ser capturada de uma radiografia convencional por meio de escaneres de alta resolução ou câmeras de vídeo (ATTAELMANAN; BORG; GRÖNDAHL ${ }^{5}, 2000$; BÓSCOLO et al. $^{10}$, 2001; BROOKS; MILES ${ }^{13}$, 1993; CAPELOZZA ${ }^{15}$, 2001; CHEN; CHIANG ${ }^{19}$, 1997; CHEN; HOLLENDER ${ }^{20}$, 1995; DUNN; KANTOR $^{31}$, 1993; HILDEBOLT et al. $^{43}, 1990$; KASSEBAUM et al. $^{46}$,1998; KURITA et al. ${ }^{49}$, 2001; OHKI; OKANO; NAKAMURA ${ }^{56}$, 1994; SARMENTO; PINHO; RIVAS ${ }^{63}$, 2002; SHROUT et al. ${ }^{68}$, 1993; VISSER; AYABAKAN ${ }^{77}$, 1995; ZENÓBIO; FERREIRA ${ }^{78}$, 1997)

No método direto utilizam-se sensores colocados diretamente dentro da boca. Há sensores do tipo Charge-Coupled-Device (CCD dispositivo de carga acoplada) e do tipo placa fotoestimulável. O sensor $C C D$, por meio de um cabo, envia o sinal elétrico produzido pelos raios $\mathrm{X}$ ao microcomputador. O sinal obtido do CCD, após a exposição à radiação, é armazenado e convertido pixel por pixel em 256 níveis de cinza (ALVARES; TAVANO ${ }^{3}$, 2002; BORG; GRÖNDAHL ${ }^{9}$, 1996; GROSSI; TAVANO $^{40}, 1997$; MOYSTAD et al. $\left.{ }^{55}, 1996\right)$. O outro sistema de captação direta da imagem utiliza uma placa fotoestimulável do mesmo tamanho do filme radiográfico intrabucal, não existindo fio conector ao aparelho como no sistema anterior. Neste sistema, o sinal luminoso captado pela placa, após exposição aos raios $\mathrm{X}$, é ativado por luz laser e enviado ao microcomputador. O sensor intrabucal, o hardware e o software associados substituem o filme e o processamento radiográfico (ALVARES; FREITAS; CAPELOZZA $^{2}$, 2000; HAITER et al. ${ }^{41}$, 2001; KURITA et al. ${ }^{49}, 2001$; SARMENTO et al. $^{62}$, 2000; VALE; BRAMANTE ${ }^{71}$, 2002).

Câmeras fotográficas digitais têm sido utilizadas para aquisição de imagens clínicas intra e extrabucais, e de imagens 
radiográficas. Diversas são as aplicações para essas imagens: preparação de material didático como eslaides e pôsters, fotos para publicação, orientação ao paciente sobre o plano de tratamento, processamento de imagens para diagnóstico, mensurações computadorizadas e teletransmissão (BENGEL ${ }^{8}$, 2000; FOTOGRAFIA DIGITAL ${ }^{36}$, 2004; CHEN; CHIANG ${ }^{19}$, 1997; DUNN; BECKLER ${ }^{30}$ 2001; IMAGENS DIGITAIS ${ }^{44}$, 2004; WATANABE et al. $\left.^{79}, 1999\right)$.

Em trabalho publicado em 1999, WATANABE et al. ${ }^{79}$ apresentaram diferentes métodos recentes de diagnóstico por meio de imagem digitalizada. Os autores citam como equipamentos de digitalização o escaner, sistemas de vídeo, fotografia digital e radiografia digital. $\mathrm{Na}$ Odontologia, as principais aplicações da imagem digital são as documentações digitais, a possibilidade de processamento de imagens digitais para fins de diagnóstico e as mensurações computadorizadas.

Atualmente, muitos profissionais utilizam a câmera digital para digitalização de radiografias, porém, a literatura nesse campo é escassa, acarretando uma falta de padronização para sua utilização na digitalização de radiografias. Daí a necessidade de se realizar mais trabalhos visando sanar essa lacuna.

WENZEL ${ }^{81}$ em 1987, estudou o efeito de variar a resolução de profundidade da escala de cinza e filtragem da imagem de radiografias periapicais para detectar lesões ósseas. As radiografias foram digitalizadas por câmera CCD gerando uma matriz de 512x512 pixels e resolução da escala de cinza variável de 256 (8 bits) a 32 tons de cinza (5 bits). Concluiu-se que quando se utilizou a resolução de 256 tons de cinza (8 bits) o diagnóstico foi equivalente à radiografia original. A mesma autora (WENZEL ${ }^{80}$ ), em 1988 , testou o efeito de três tipos de tratamento de imagem: filtros, alteração de contraste e pseudocolorização. Os estudos 
deixaram evidente que a detecção de lesões ósseas na mandíbula pode ser melhorada pelo tratamento de imagem.

FUJITA et al. ${ }^{38}$, em 1988 observaram uma melhora da qualidade da imagem de radiografias intrabucais, com o uso de um sistema de processamento digital da imagem. A qualidade e a visibilidade de detalhes das radiografias digitalizadas foram melhores do que nas radiografias originais. Os autores concluíram que o diagnóstico radiográfico pode ser melhorado com o uso deste sistema.

KASSEBAUM et al. $^{46}$ em 1989, realizaram um estudo subjetivo para determinar a resolução espacial apropriada para digitalização de radiografias odontológicas, utilizando o sistema de câmera de vídeo (Kodak Ektascan Image Transmission System). Neste sistema, as radiografias são colocadas sobre um negatoscópio onde a luz é focada diretamente para um tubo foto-sensível ou um sensor $C C D$, permitindo uma digitalização com uma matriz de 512x512 pixels e 8 bits. Radiografias panorâmicas, periapicais e interproximais foram digitalizadas utilizando-se diferentes parâmetros de resolução espacial (pixels de 200, 300 e 400 m). Oito examinadores avaliaram subjetivamente a detectabilidade de patologias periapicais, cáries proximais e anormalidades ósseas nas imagens radiográficas digitalizadas. Os resultados mostraram que a precisão de diagnóstico das radiografias originais foi superior às imagens digitalizadas. Observou-se, também, um aumento na precisão de diagnóstico das modalidades digitais quando o tamanho do pixel foi diminuído ou quando a resolução foi melhorada, embora não houvesse diferença estatisticamente significante entre as diferentes resoluções. Com base nesses achados, os autores concluíram que as imagens digitais das radiografias estudadas, forneceram adequada precisão de diagnóstico para avaliação de lesões periapicais, cáries proximais e anormalidades ósseas. 
HILDEBOLT et al. $^{43}$ em 1990, relataram que a imagem digitalizada possui uma resolução espacial e uma resolução de contraste. A resolução espacial é definida pelo número de pixels existentes na imagem, ou seja, quanto maior o número de pixels, maior a resolução espacial. O tamanho do pixel está diretamente relacionado com a resolução da imagem, ou seja, quanto menor o tamanho do pixel, maior a resolução e mais detalhes serão visualizados. A resolução espacial pode ser medida em uma unidade chamada dpi (dots per inch), que significa pontos por polegada. Cada pixel possui um valor correspondente a uma tonalidade de cinza, que pode variar de zero (preto) até 255 (branco), passando por valores intermediários de cinza que podem ser exibidos. Assim, quanto menor a quantidade de tons de cinza intermediários, maior o contraste da imagem. Nesta pesquisa os autores compararam dois sistemas de digitalização indireta: uma câmera de vídeo (Dage-MTI) acoplada a um conversor analógico para digital, incorporado a um sistema computadorizado de formação de imagem, e um escaner de eslaide de $35 \mathrm{~mm}$ com sensor CCD (Barneyscan). Foram avaliados os desempenhos radiométricos e geométricos para estudos quantitativos da doença periodontal. Um penetrômetro foi radiografado em filmes periapicais com diferentes tempos de exposição. Após processadas, as radiografias foram digitalizadas pelos sistemas descritos. A resolução espacial para o sistema de vídeo é de 512x512 pixels e a do escaner é de 1520x1024. Cada sistema operou com 256 níveis de cinza (8 bits). Com o objetivo de medir as distorções geométricas dos sistemas, foi empregado um teste padrão de registro operacional (TV2-DL) disponível pela Sociedade da Imagem em Movimento e Engenheiros de Televisão (SMPTE). O padrão consiste de 148 anéis dispostos em uma grade de 17 colunas e 14 fileiras. Os números de pixels situados entre os anéis foram medidos no sentido vertical e horizontal. Os resultados mostraram que a distorção causada pelo sistema 
de vídeo $(0,06 \mathrm{~mm})$ permaneceu dentro dos limites aceitáveis para mensuração de perda óssea. Por outro lado, a distorção apresentada pelo escaner de eslaide foi maior (0,15 mm). Em relação à resolução, contraste, nitidez e ruído, os autores concluíram que o escaner de eslaide foi superior ao sistema de vídeo.

Em 1993, SHROUT et al. ${ }^{68}$, estudaram algumas características da qualidade da imagem, como a resolução, o contraste, a distorção e o ruído. A resolução refere-se à habilidade de distinguir pequenos objetos muito próximos entre si como entidades separadas. O contraste significa o quanto as áreas claras e escuras podem ser distinguidas. Distorção refere-se à correspondência geométrica entre pontos em um objeto e a imagem digitalizada destes pontos. Ruído é uma flutuação indesejável das intensidades dos pixels. Representa uma variação da densidade que escurece a imagem. Neste trabalho, os autores se propuseram avaliar um escaner de eslaide recentemente lançado no mercado: Nikon LS-3510 AF, utilizando sensor $C C D$. Sua performance radiométrica e geométrica de digitalização foi comparada com outros dois sistemas já estudados, o escaner de eslide da Barneyscan e o sistema de vídeo Dage-MTI. Um penetrômetro foi radiografado em filmes periapicais com diferentes tempos de exposição. Após processadas, as radiografias foram digitalizadas com 8 bits, e avaliadas pelo teste padrão de registro operacional (TV2-DL), sendo a mesma metodologia empregada por HILDEBOLT et al. ${ }^{43}$ em 1990. Os resultados mostraram que as radiografias digitalizadas pelo escaner Nikon apresentaram uma distorção muito pequena $(0,016 \mathrm{~mm}$ por pixel). $\mathrm{O}$ escaner Nikon teve desempenho superior para o contraste em relação aos outros sistemas, pois reproduziu uma escala maior de densidades ópticas clinicamente relevantes (que vai de 0,3 a 2,0). Em relação ao ruído, os autores observaram que o escaner estudado apresentou níveis 
insignificantes de ruído quando comparados ao sistema de vídeo, conseqüentemente não alterando a qualidade da imagem.

BROOKS; MILES ${ }^{13}$ em 1993, discutiram as novas modalidades de captura de imagens utilizadas em Odontologia. A imagem radiográfica de um filme convencional pode ser convertida para um sinal digital, utilizando-se para isto, um escaner de alta resolução. Este escaner deve ser composto de um leitor de transparência que faz o papel de um negatoscópio, incidindo uma luz através da imagem, permitindo assim a digitalização e, em seguida, esta imagem é enviada a um monitor e analisada ou modificada por programas específicos. Com a imagem armazenada em um computador, um grande número de operações pode ser realizado. Uma das mais úteis operações é a comparação de imagens, chamada de subtração digital. O computador pode comparar as duas imagens, pixel por pixel, e jogar a diferença de densidade para uma nova imagem. Alguns usos para este tipo de informação incluem a progressão da doença durante o período de avaliação do tratamento periodontal e terapia endodôntica. Além destas informações, imagens digitais obtidas diretamente por $C C D$ têm como vantagens uma diminuição da dose de radiação em aproximadamente $80 \%$, eliminação do processamento químico, possibilidade de reconstrução da imagem e capacidade de armazenamento no computador.

DUNN; KANTOR ${ }^{31}$ em 1993, discutiram os fatos e as ficções que existem em torno das radiografias digitais. Entre os tópicos discutidos, os autores fizeram referência ao processamento da imagem digital, à utilidade destes processamentos, à capacidade de interpretação do examinador e à quantificação da informação nas imagens digitais. Neste último tópico, foi mostrado que as imagens digitais facilitam medições nas radiografias. Foi salientado também que, nas radiografias digitais indiretas, a imagem digital não pode ser melhor do que a radiografia convencional 
que a originou. Os autores concluíram que a imagem digital ainda se encontra em fase de desenvolvimento e avaliação, tendo muitos benefícios em potencial a serem explorados.

OHKI; OKANO; NAKAMURA ${ }^{56}$ em 1994, realizaram um estudo subjetivo para detecção de cáries incipientes, comparando as imagens de filmes digitalizados por meio de três tipos de equipamentos de digitalização: um escaner a tambor (Abe-Sekkei), um escaner a laser (AbeSekkei), e uma câmera de vídeo (Hamamatsu Photo.). No escaner a tambor (Microdensitômetro), o filme radiográfico é posicionado sobre uma superfície ou circundando um tambor (drum scanner) e uma fonte de luz percorre a radiografia enquanto a superfície se move ou o tambor rota, produzindo uma imagem bidimensional. No escaner a laser, a radiografia é mecanicamente movida e percorrida por uma fonte de laser estreita de baixa potência. Em ambos os sistemas a intensidade de luz transmitida é captada por um fotomultiplicador e convertida para as densidades do filme. As imagens digitais, variando em tamanho de pixel e nível de cinza, foram avaliadas por dez profissionais. Com base nos resultados, os autores concluíram que as imagens digitalizadas pelo escaner a tambor foram as que apresentaram maior precisão de diagnóstico para cáries incipientes. Em relação ao tamanho do pixel, não houve diferença significante entre as imagens digitalizadas com pixel de $50 \mu \mathrm{m}$ a $100 \mu \mathrm{m}$. A imagem com pixel de $100 \mu \mathrm{m}$ tem a vantagem de requerer menor espaço para armazenamento. Os autores também consideraram que a escala de cinza pode ser reduzida de 256 para 32 tons, sem perda da qualidade da imagem, se baseando no fato de o olho humano só conseguir distinguir até 50 tons de cinza. A escala de 16 tons de cinza (4 bits) e pixels com tamanho maior que $100 \mu \mathrm{m}$, na consideração dos autores, parecem insuficientes para o diagnóstico.

CHEN; HOLLENDER ${ }^{20}$ em 1995, analisaram a performance física de digitalização do escaner de superfície plana com leitor de 
transparência em relação ao alcance dinâmico e reprodutibilidade. O escaner de superfície plana, quando associado a um leitor de transparência que faz o papel do negatoscópio, com a incidência de uma luz por trás da imagem, permite a digitalização de filmes radiográficos. Para essa pesquisa, utilizou-se a imagem radiográfica de um penetrômetro que foi exposto sobre um filme panorâmico Kodak T-MAT G. O escaner Artix ArtiScan operou com resolução de 200 dpi e 8 bits de escala de cinza. As radiografias do penetrômetro foram digitalizadas em várias posições e orientações no escaner, variando-se também as configurações do aparelho (tempo de escaneamento e interrupção entre as digitalizações ligando e desligando o aparelho). Os valores de densidades de pixel das radiografias digitalizadas, obtidas a partir do programa de imagem Aldus Photostyler, foram comparados com os valores obtidos por meio de um densitômetro a laser, diretamente dos filmes originais. Os autores observaram que esse tipo de escaner apresentou um alcance dinâmico bem menor em relação à radiografia original e que os resultados de reprodução só puderam ser adquiridos quando as imagens foram escaneadas sempre na mesma posição de escaneamento, sem mudança na configuração do escaner. Diante disto, concluíram que esse tipo de escaner de superfície plana pode ser utilizado para digitalização de filmes odontológicos, desde que as configurações de escaneamento e a posição do filme sejam cuidadosamente padronizadas.

VISSER; AYABAKAN ${ }^{77}$ no ano de 1995, realizaram um estudo das propriedades físicas da imagem por meio de um escaner de alta resolução (Nikon) para digitalização de filmes intrabucais. As imagens foram analisadas em relação à resolução espacial, distorção e ruído. A distorção da imagem foi avaliada por meio de uma grade de precisão óptica de escaneamento. A grade de precisão é constituída de uma lente plana com linhas de diferentes tamanhos. Os resultados revelaram que o escaner 
estudado não apresentou uma distorção mensurável e demonstrou uma alta resolução espacial.

Em 1997, CHEN; CHIANG ${ }^{19}$, avaliaram o desempenho físico de um escaner tipo cilíndrico (VXR-12, Vidar System) em relação ao alcance dinâmico, reprodutibilidade e homogeneidade das imagens de filmes periapicais. O escaner tipo cilíndrico foi desenvolvido inicialmente para digitalização de filmes médicos. No processo de digitalização um cilindro movimenta a radiografia sobre a lâmpada fluorescente. Para essa pesquisa, utilizou-se a imagem radiográfica de um penetrômetro em filme periapical que foi digitalizado com resolução de 300 dpi, e 8 bits, em várias posições e orientações sobre o escaner. O programa Paint Shop Pro registrou os valores de densidades ópticas que foram comparados com os valores da radiografia convencional. Os autores concluíram que os valores digitais repetitivos demonstraram que a distorção não era significante, e que a imagem digitalizada apresentou um alcance dinâmico semelhante à do filme convencional. O alcance dinâmico do escaner tipo cilíndrico foi maior que no escaner de superfície plana, portanto é possível a utilização do escaner tipo cilíndrico para radiografias odontológicas.

Para comparar a técnica periapical do paralelismo com os sistemas de imagens digitalizadas, de maneira que estes recursos sejam usados de forma segura e generalizada, ZENÓBIO; FERREIRA ${ }^{78}$ em 1997, obtiveram uma radiografia pela técnica do paralelismo, que foi submetida à digitalização, utilizando um escaner. Determinou-se a área de interesse para análise e a colorização para definir as estruturas de maior radiolucidez e radiopacidade, empregando o seguinte esquema de cores: vermelho radiolúcido; amarelo - radiopacidade parcial e verde - radiopaco. Concluíram que o processo de digitalização de imagens possibilita a identificação mais precisa da perda óssea, sendo o mesmo, uma boa opção para o diagnóstico. Segundo os autores, apesar do desenvolvimento e 
aperfeiçoamento desta tecnologia, a aproximação da relação custo/benefício do uso deste sistema, sua viabilidade e praticidade quando comparados com o sistema convencional, ainda dificultam sua utilização na clínica Odontológica.

No ano de 2000, ATTAELMANAN; BORG; GRÖNDAHL ${ }^{5}$ realizaram um estudo para determinar os parâmetros ideais para digitalização e apresentação de imagens radiográficas periapicais. Para isto, radiografias periapicais foram digitalizadas pelo escaner Arcus II utilizando 8 bits e três resoluções diferentes (200, 400 e 600 dpi). As radiografias foram escaneadas com e sem uso de máscaras. As imagens obtidas foram apresentadas com um monitor Nokia com 256 cores, variando-se o tamanho da imagem. Utilizando os programas LabView e Imaq Vision, sete observadores experimentados analisaram subjetivamente a qualidade das imagens para identificação de estruturas anatômicas. Após a avaliação, observou-se que os melhores resultados foram alcançados quando os filmes foram digitalizados com máscara e com resolução de 200 e 400 dpi. As opções de apresentação se mostraram ideais com 256 cores e tamanho de imagem de 1152x854 pixels.

KRUPINSKI et al. ${ }^{48}$ em 2000, testaram o uso de uma câmera digital amadora para digitalizar imagens radiográficas e transmití-las via rede de telemedicina, a fim de serem avaliadas por parte de um centro de especialistas. As radiografias de 40 casos de traumas ósseos, de um centro médico rural no Arizona, foram digitalizadas por meio de uma câmera digital Canon PowerShot 600, com sensor de imagem CCD de resolução de 570.000 pixels, com 24 bits, e uma velocidade do obturador de 1/30 a 1/500 segundos. Essa câmera tem três modos de resolução: fino (832x608 pixels), normal (640x480 pixels) e econômico (320x240 pixels), correspondentes a arquivos de tamanhos de 150 kB, 75 kB e 43 kB, respectivamente. Após a digitalização, as imagens foram transmitidas para o site do núcleo do 
programa de telemedicina. Dois cirurgiões ortopédicos e dois radiologistas reavaliaram os casos, analisando as radiografias convencionais sobre um negatoscópio, e observando as imagens digitais por meio de um monitor colorido. Os revisores também avaliaram a qualidade das imagens. Os resultados mostraram que não houve diferença significante na precisão de diagnóstico entre o filme convencional e a interpretação da imagem digital na telemedicina. Houve elevada concordância entre o diagnóstico realizado por meio das modalidades estudadas. A qualidade da imagem foi classificada como excelente para ambas condições de visualização. Os autores concluíram que a câmera digital pode ser utilizada, efetivamente, para digitalização de radiografias, bem como sua transmissão e visualização via rede de telemedicina.

No ano de 2001, em seu trabalho, DUNN; BECKLER ${ }^{30}$ fazendo uma comparação entre a tecnologia da fotografia digital e a convencional, destacaram as vantagens da digital. Ela possibilita uma disponibilidade da imagem para uso imediato e, pela sua visualização instantânea, oferece a oportunidade de repetir a foto, no ato, caso ela não tenha ficado satisfatória. Ao mesmo tempo, proporciona a transmissão de dados para outro profissional ou laboratório. Salientam, ainda, que em virtude das práticas odontológicas estarem sendo cada vez mais computadorizadas e que, no futuro, a documentação digital será um procedimento padrão, e seria prudente que os profissionais se preparassem para esse fato.

Em 2001, BÓSCOLO et al. $^{10}$, realizaram um estudo comparativo avaliando a qualidade de três sistemas radiográficos digitais (Sens-A-Ray, CDR e Digora), com o filme digitalizado Ekta-speed Plus EP-21. Os objetos de análise (regiões anatômicas de peças maceradas e penetrômetro) foram radiografados com 50, 60 e $70 \mathrm{kVp}$ e diferentes tempos de exposição e as radiografias digitalizadas com 600 dpi e 8 bits, 
por meio do escaner Hewlett Packard Scanjet $4 \mathrm{C} / \mathrm{T}$, e analisadas pelo programa Corel Photo-Paint. As imagens aquiridas pelos aparelhos digitais diretos foram analisadas nos programas próprios dos sistemas. Para análise de todas as imagens, os avaliadores utilizaram uma escala de classificação de 0 a 4. Os resultados mostraram que o maior número de imagens em condições de diagnóstico foi apresentado pelo sistema Digora, seguido em ordem decrescente pelo filme digitalizado, filme Ekta-speed, CDR e SensA-Ray.

No mesmo ano, CAPELOZZA ${ }^{15}$ realizou uma pesquisa com o objetivo de avaliar a imagem digital indireta utilizando o escaner Genius Collor-Page-Vivid Pro II Film (resolução de 600x1200 dpi) e o programa Adobe Photoshop 5.0, e compará-la com a imagem radiográfica convencional, na interpretação de lesões do periápice. Vinte e cinco imagens de lesões periapicais foram interpretadas por dez cirurgiõesdentistas, analisando as radiografias convencionais (com lupa) e as imagens digitais (com os recursos imagem invertida, imagem em relevo, brilho, contraste e zoom). Os resultados mostraram que não houve diferença estatisticamente significante entre a imagem convencional e a digitalizada na interpretação de lesões apicais. A autora concluiu que embora os recursos oferecidos pelo programa tenham melhorado a interpretação das lesões, os resultados não demonstraram maior acerto no diagnóstico final das periapicopatias.

KURITA et al. ${ }^{49}$ em 2001, compararam o sistema indireto de obtenção de radiografias digitalizadas por meio de escaner, com as radiografias panorâmicas convencionais, na visualização das alterações ósseas peri-implantares. Quatorze radiografias panorâmicas de pacientes que possuíam implantes na região posterior de mandíbula foram digitalizadas por um escaner Hewlett Packard - Scanjet $4 \mathrm{C} / \mathrm{T}$, com resolução de 300 dpi, observando-se 56 implantes. Por meio do programa 
Corel Photo Paint 5.0 foram feitos recortes de parte das imagens das panorâmicas. Em seguida as imagens totais e parciais foram manipuladas com ampliação, inversão de contraste, realce em relevo, e colorização da imagem por meio do programa do Sistema Digora. Os resultados mostraram que a radiografia panorâmica convencional permite uma visualização de regular a boa das alterações ósseas peri-implantares. A radiografia panorâmica convencional mostrou-se melhor que todos os tipos de imagens digitalizadas manipuladas.

Em 2002, SARMENTO; PINHO; RIVAS ${ }^{63}$ estudaram a amplitude dinâmica de radiografias digitalizadas em relação ao tempo de exposição utilizado para sua obtenção e ao tamanho de captura da imagem pelo escaner. Hemimandíbulas de ratos foram radiografadas com filmes periapicais com tempo de exposição de 0,5 e 0,7 segundos. As radiografias foram capturadas por um escaner a laser com leitor de transparência (Scanjet 6100 CT - HP), e as imagens foram digitalizadas com resolução espacial de 75 dpi (pixel de $340 \mu \mathrm{m}$ ), 8 bits, no modo escala de cinza, e salvas com diferentes tamanhos $(1 \mathrm{x}, 2 \mathrm{x}$ e $4 \mathrm{x})$. Os tons mais claros e mais escuros do histograma de cada imagem foram mensurados pelo programa Adobe Photoshop 5.5. A amplitude dinâmica foi calculada pela diferença entre os dois valores obtidos. Diante dos resultados, as autoras concluíram que um tempo de exposição mais alto e uma maior ampliação, produziram imagens digitalizadas de maior amplitude dinâmica.

\section{3- Programas de imagem}

Com o avanço da Informática, inúmeros programas de imagem têm sido desenvolvidos com o objetivo de oferecer meios de manipulação e processamento de imagens digitais, permitindo que suas informações sejam 
melhor detectadas e observadas. Por meio desses programas, há possibilidade de se trabalhar com várias modalidades de imagens radiográficas (intra e extrabucais) adquiridas direta ou indiretamente. Além da possibilidade de processamento de imagens digitais, os programas permitem a integração e facilitam a comunicação. Transferências de imagens a longas distâncias podem ser realizadas para consulta a especialistas e centrais de informações para educação. A telecomunicação, com o intercâmbio de imagens digitalizadas, além de útil, poupa tempo quando se deseja uma segunda opinião ou comunicação com empresas. O procedimento leva apenas alguns minutos ou segundos, sem perda de qualidade da imagem (VERSTEEG; SANDERINK;VAN DER STELT ${ }^{75}$, 1997).

Diversos são os recursos oferecidos pelos programas: as imagens podem ser manipuladas por meio de ferramentas especiais, tais como ajuste de brilho, contraste, aplicação de pseudo-coloração, imagem em relevo, imagem negativa, ampliação de uma área de interesse, histograma, medição de distâncias lineares e angulares (VERSTEEG; SANDERINK;VAN DER STELT ${ }^{75}$, 1997, MC DONNELL ${ }^{52}, 1995$, LAURIS $^{51}$, 1997).

Muitos pesquisadores utilizaram-se de ferramentas de análise contidas nos programas de imagem para realizar mensurações de distâncias lineares nas diversas áreas da Odontologia: na Implantodontia, Periodontia, Endodontia, Ortodontia e outras.

\subsection{1- Mensuração de distâncias lineares}

SCARFE; NORTON; FARMAN ${ }^{66}$ em 1995, compararam a
precisão de medida de distâncias lineares realizadas nos sistemas 
digitais RVG-S (RadioVisioGraphy) e Flash Dent (Villa Sistemi Medicali), com as medidas obtidas no filme radiográfico periapical Ekta-speed EP-21 da Kodak, com auxílio de régua ou grade milimetrada. Utilizou-se como amostra um objeto com dimensões previamente conhecidas e registradas, sendo o mesmo, radiografado com tempos de exposição de 0,04 segundos para o sensor do RVG-S, 0,08 segundos para o sensor Flash Dent e 0,12 segundos para o filme Ekta-speed EP-21. As medidas dos filmes foram obtidas com grade milimetrada de $3 \times 4 \mathrm{~cm}$ e com régua milimetrada. As medidas das imagens do RVG-S foram realizadas com o programa do próprio sistema, cujas imagens eram superpostas com grade milimetrada. As medições algorítmas do Flash Dent, foram obtidas com o programa próprio do sistema realizadas com o cursor do mouse, clicando-se nos pontos a serem medidos. Os resultados mostraram que as medidas digitais (Flash Dent e RVG-S) foram menores que as obtidas com a régua no filme periapical. Em comparação com o objeto teste, as medidas realizadas com o Flash Dent e as medidas feitas com régua no filme periapical foram as mais acuradas, apresentando variações inferiores a $0,5 \mathrm{~mm}$, consideradas clinicamente insignificantes. Com isso, os autores sugeriram que as medidas digitais são, no mínimo, tão boas, ou até melhores, que aquelas obtidas com réguas milimetradas para a obtenção de medidas dimensionais.

CONOVER; HILDEBOLT; YOKOYAMA-CROTHERS ${ }^{26}$ em 1996, realizaram um estudo com o objetivo de comparar medidas lineares tomadas diretamente sobre radiografias convencionais, radiografias indiretamente digitalizadas e imagens digitais obtidas de placas de armazenamento de fósforo. Para orientar as mensurações das distâncias lineares, pontos de referências radiopacos foram determinados sobre hemimandíbulas secas, no sentido vertical, horizontal e oblíquo, com a finalidade de avaliar as possíveis distorções das imagens radiográficas. As radiografias foram realizadas utilizando-se um suporte especialmente 
confeccionado para garantir a padronização. Inicialmente, os espécimes foram radiografados com filmes oclusais Ekta-speed da Kodak, no aparelho Gendex 770 com uma distância foco-filme de $48 \mathrm{~cm}$, sendo as radiografias processadas automaticamente. Depois foram digitalizadas com 12 bits e resolução espacial de $50 \mu \mathrm{m}$, por meio do Personal Densitometer (Molecular Dynamics). Utilizando um sistema de radiografia digital, os espécimes foram radiografados por meio de placas de armazenamento de fósforo (HRV, Fuji Photo film) que foram expostas aos raios $\mathrm{X}$ de forma padronizada. As placas foram submetidas a um sistema de leitura de placa, por meio de um escaner de laser-neon (Molecular Dynamics) e resultaram em imagens digitais de 12 bits e $200 \mu \mathrm{m}$ de resolução espacial. As mensurações das distâncias lineares das imagens digitais foram obtidas por meio do programa DIPStation 1.0.6 (Hayden Image Processing Group). Com o auxílio de um paquímetro foram realizadas mensurações diretamente sobre as radiografias convencionais e também sobre os espécimes (consideradas medidas reais). Após a comparação, os resultados revelaram que as medidas das imagens dos filmes escaneados foram maiores que as obtidas manualmente sobre as radiografias ( $1 \mathrm{~mm})$, sem acusar diferença estatística significante. No geral, as medidas realizadas nas imagens escaneadas foram as que mais se aproximaram das medidas reais das hemimandíbulas, seguidas, na ordem decrescente, das medidas das imagens digitais do sistema de armazenamento de fósforo e das medidas dos filmes convencionais. Contudo, essas diferenças não foram estatisticamente significantes. Por fim, os pesquisadores concluíram que as imagens radiográficas digitalizadas por meio do método direto e indireto, quando analisadas por meio de programas de imagem, são alternativas viáveis na realização de mensurações de distâncias lineares.

VELDERS; SANDERINK; VAN DER STELT ${ }^{73}$ em 1996, compararam medições do comprimento de limas endodônticas em imagens 
radiográficas de filmes periapicais Ultra-speed DF-58 da Kodak com imagens dos aparelhos digitais Sidexis e Digora, utilizando diferentes tempos de exposição. Limas endodônticas (números 10, 15, 20 e 25), colocadas nos canais de pré-molares de mandíbulas secas, foram radiografadas com diferentes tempos de exposição. As medidas nas imagens radiográficas periapicais foram feitas com régua milimetrada, com precisão de 0,5 mm, enquanto que as medidas nas imagens digitais foram obtidas com recursos do programa de imagem Emago, com 0,1 mm de precisão. Os resultados revelaram que as imagens digitais (Sidexis e Digora) apresentaram-se maiores (diferença de 0,2 $\mathrm{mm}$ ) que as imagens do filme periapical Ultra-speed DF-58. Segundo os autores, este fato pode ter sido causado pelo método de mensuração utilizado no filme, já que a régua apresenta uma precisão de 0,5 mm, enquanto que o programa, de 0,1 mm. De um modo geral, as médias dos comprimentos da raiz do pré-molar e das limas não diferiram entre as imagens digitais.

VERSTEEG et al. ${ }^{74}$ em 1997, realizaram uma pesquisa com a finalidade de comparar medidas lineares obtidas sobre imagens digitalizadas pelos sistemas Sens-A-Ray e Vixa e radiografias convencionais periapicais (Ekta-speed Plus da Kodak). As mensurações de diferentes distâncias da ponta da lima ao limite apical de molares e prémolares de uma mandíbula seca, foram realizadas por um grupo de estudantes e um grupo de especialistas. As medidas dos filmes convencionais foram obtidas com auxílio de um paquímetro digital. Utilizando o programa Emago (dental software, SODS), as distâncias das imagens digitais foram mensuradas por meio de ferramentas de medidas. Os resultados mostraram que as medidas digitais do sistema Vixa não exibiram diferença estatística significante em relação às medidas do filme Ekta-speed Plus, obtidas por meio do paquímetro digital. Por outro lado as medidas digitais do Sens-A-Ray foram menores em relação às medidas do 
paquímetro. Os autores concluíram que estimar distâncias sobre imagens digitalizadas é comparável às medidas sobre radiografias convencionais, ou mesmo melhor.

CEDERBERG et al. ${ }^{16}$ em 1998, compararam a visualização de limas endodônticas entre o sistema digital Digora e o filme Ekta-speed Plus da Kodak. As mensurações da ponta da lima ao ápice radicular foram obtidas pelo sistema Digora por meio de suas ferramentas de medida e, para o filme, foram utilizadas uma régua milimetrada e lupa de aumento de sete vezes. Os resultados revelaram que as médias dos comprimentos das limas, nas imagens digitais Digora, foram levemente maiores em relação às encontradas nas imagens periapicais do filme, com diferença de 0,2 mm, não sendo estatisticamente significante. Os autores concluíram que o sistema Digora exibiu uma performance similar ao filme para mensuração endodôntica, tendo a vantagem de poder reduzir a dose de radiação ao paciente.

SCARFE et al. ${ }^{65}$ em 1999, compararam radiografias digitais com radiografias convencionais na mensuração de lesões periapicais. Antes de serem removidas cirurgicamente, as lesões periapicais foram radiografadas por dois métodos: sistema digital Visualix-2, (Dentsply/Gendex) e filme convencional Ekta-speed Plus da Kodak. Para as medições nas imagens digitais, foi utilizado o programa VixWin versão 1.2 (Dentsply/Gendex), com precisão de $0,1 \mathrm{~mm}$, enquanto que as medições dos filmes Ekta-speed Plus foram feitas com auxílio de uma régua milimetrada (precisão de 0,5 mm). Após as comparações, os autores observaram que as medidas obtidas pelas imagens digitais foram levemente maiores que as obtidas manualmente sobre as radiografias (6\%), enquanto que ambas foram subestimadas em relação ao tamanho real das lesões.

ARAÚJO FILHO et al. ${ }^{4}$ em 1999, realizaram uma comparação "in vivo" da odontometria obtida por meio de radiografia digital direta e 
radiografia convencional. As radiografias foram obtidas de pacientes que necessitavam de tratamento endodôntico. As tomadas digitais foram feitas pela técnica do paralelismo, onde determinou-se o comprimento de trabalho por meio do sistema Sens-A-Ray. As mensurações no filme Ektaspeed Plus da Kodak, foram realizadas com auxílio de uma régua milimetrada e lupa. Os resultados mostraram que as medidas digitais (SensA-Ray) foram menores que as obtidas no filme convencional (diferença de 0,12 mm), não havendo diferença estatística significante. Os autores observaram que embora a análise estatística tenha mostrado que o sistema digital apresenta confiabilidade, é necessário que o profissional adapte sua acuidade visual e se familiarize mais com as imagens digitais.

EICKHOLZ et al. ${ }^{32}$ em 1999 realizaram uma pesquisa cujo objetivo foi comparar medidas lineares de imagens radiográficas digitalizadas de perda óssea interproximal, com as medidas transoperatórias. Anteriormente à cirurgia, os pacientes portadores de doença periodontal foram radiografados por uma técnica padronizada. Em seguida, as radiografias foram capturadas por meio de um escaner de superfície plana da Friacom (resolução 600x1200 dpi e 10 bits). As mensurações foram efetuadas com o programa Friacom, após aplicação de diferentes filtros (contraste, inversão, histograma), sendo as medidas obtidas comparadas com as trans-operatórias. Os resultados mostraram que as medidas digitais aproximaram-se das medidas intra-cirúrgicas, exibindo uma pequena elevação. As imagens que receberam tratamento digital não exibiram melhores resultados em relação às imagens sem tratamento.

CAMACHO et al. ${ }^{14}$ em 1999, utilizaram o programa Image Tool (University of Texas Health Science Center, San Antonio, Texas, USA), nas mensurações das distâncias lineares de radiografias panorâmicas digitalizadas e tomografias lineares digitalizadas, para compará-las com as medidas obtidas pela análise radiográfica convencional. Esse estudo foi 
realizado para avaliação óssea pré-cirúrgica na colocação de implantes. Para isso, guias esféricas metálicas foram posicionadas para indicar 12 distâncias anatômicas no rebordo alveolar de cinco crânios. Os crânios foram radiografados pelo ortopantomógrafo OP-10 (Siemens) e pelo Tomógrafo Linear Quint Sectograph (Denar). As radiografias obtidas foram digitalizadas pelo escaner Hewllett Packard. Os crânios foram seccionados para a obtenção das medidas reais das distâncias anatômicas. Os resultados mostraram que as medidas digitais (panorâmica e tomografia digitalizadas) foram levemente menores que as medidas obtidas por meio da régua, diretamente sobre as radiografias (diferença de 0,2 $\mathrm{mm}$ ). Comparadas com as medidas reais dos crânios, as medidas que alcançaram melhor resultado foram as obtidas por meio da tomografia digitalizada, seguidas, na ordem decrescente, das medidas da tomografia convencional, da panorâmica digitalizada e da panorâmica convencional.

BAHLIS; VEECK; DI NARDO ${ }^{7}$ em 2000, se propuseram avaliar a confiabilidade da tomografia linear (Vera View Scope S-600, Morita Co.) e de um sistema de digitalização indireta desta imagem tomográfica (DentScan Dent View - APICA Co.). A amostra constituiu em 20 hemimandíbulas humanas secas que foram radiografadas. A área selecionada para estudo foi a região desdentada de forame mentual. As tomografias foram digitalizadas e medidas por meio da escala do programa digital. Com o uso de um paquímetro eletrônico digital foram realizadas medições diretamente sobre as tomografias originais e as hemimandíbulas seccionadas na região proposta para o exame. Os resultados mostraram que as medidas digitais (tomografia digitalizada) foram ligeiramente maiores que as medidas manuais obtidas pelo paquímetro digital (diferença de 0,094 mm), não apresentando, portanto, diferença estatística significante. As comparações entre as medidas digitais, as medidas sobre a tomografia com as medidas reais do crânio, também não demonstraram diferença 
estatística significante. Os autores observaram que as imagens digitalizadas podem auxiliar as medições, mas elas não foram mais precisas que as realizadas diretamente sobre as radiografias. Concluíram também que a tomografia linear tende a superestimar as imagens, quando comparadas com os espécimes (variação de até 1,5 mm em 83\% da amostra e 2,0 mm em 9\%). Por isso, sugerem uma margem de segurança de 2,0 $\mathrm{mm}$ para imagens obtidas com a tomografia linear, diminuindo os riscos de danos às estruturas anatômicas nobres.

EIKENBERG; VANDRE ${ }^{33}$ em 2000, compararam o filme Ekta-speed Plus da Kodak, com o sistema de imagem digital Dexis, na mensuração da distância entre a ponta do instrumento e o forame apical. Após a obtenção das radiografias (digitais e convencionais) das limas no interior de condutos de dentes extraídos, partiu-se para mensuração digital e convencional (régua endodôntica com precisão de 0,25 mm) das imagens das limas. Os resultados revelaram que as medidas das imagens digitais foram menores que as do filme Ekta-speed Plus. Os autores consideraram que essa diferença ocorreu provavelmente pelo fato do método de mensuração digital ser mais preciso que o manual.

SILVA; CLASEN; AUN $^{69}$ em 2000, avaliaram a eficácia do sistema digital RVG na visualização da distância entre a ponta do instrumento endodôntico e o ápice dentário, comparando-o com a radiografia convencional (filme Insight da Kodak). Durante a odontometria utilizaram-se cinco incisivos centrais superiores, onde limas tipo Kerr número 15 foram fixadas a 0,5, 1,0 e 1,5 milímetros aquém do ápice, sendo em seguida radiografados pelos sistemas convencional e digital pela técnica do paralelismo. As imagens obtidas foram avaliadas por cinco examinadores, que estimaram a distância acima mencionada. Os resultados mostraram que as medidas digitais foram ligeramente maiores que as realizadas diretamente sobre o filme, com uma diferença de 0,026 mm, não 
sendo estatisticamente significante. Diante disso, os autores recomendam a radiografia digital direta como um método seguro, prático e confiável de se visualizar detalhes de imagem e de se executar manobras de odontometria.

BRANDÃO; COSTA; RAMALHO ${ }^{12}$ em 2001, avaliaram o comprimento de condutos radiculares por meio do sistema digital Sidexis. Limas endodônticas número 20 introduzidas nos condutos radiculares de dentes extraídos, foram radiografadas pelo método convencional (filme Ultra-speed da Kodak) e pelo sistema digital Sidexis. As mensurações das limas e da radiografia convencional foram obtidas por meio de uma régua milimetrada e um paquímetro digital (precisão de 0,05 mm). Utilizando o programa próprio do sistema Sidexis as mensurações digitais foram realizadas. Os resultados revelaram que as medidas digitais (Sidexis) foram maiores que as medidas realizadas diretamente sobre os filmes com a régua (diferença de 0,24 mm) e com o paquímetro eletrônico (diferença de 0,27 mm). Na comparação das medidas com a régua e com o paquímetro verificou-se que as medidas com a régua foram levemente maiores que as do paquímetro, com diferença de 0,02 mm, sem significância estatística. Após comparação geral entre os três grupos, concluiu-se que não houve diferença estatisticamente significante entre os métodos convencionais e o sistema digital Sidexis na medição de condutos radiculares.

DAVIDOWICZ et al. ${ }^{27}$ em 2001, compararam a mensuração de dentes unirradiculares obtida pelo sistema Schick em relação às medidas efetuadas diretamente sobre filmes periapicais (Agfa). Os resultados revelaram que as medidas digitais (sistema Schick) foram menores que as medidas obtidas com régua milimetrada sobre os filmes.

OLIVEIRA et al. ${ }^{57}$ em 2001, avaliaram comparativamente a eficiência de diferentes sistemas radiográficos nas mensurações endodônticas. Os objetos de estudo foram dentes unirradiculares extraídos e limas endodônticas tamanhos 6 e 10. Os sistemas utilizados foram o 
CDR, o Digora, o DenOptix e o filme periapical Ekta-speed Plus da Kodak. Cinco examinadores realizaram as mensurações das imagens digitais da borda incisal à ponta do instrumento, com as réguas digitais próprias dos sistemas. As medidas do filme foram efetuadas com auxílio de um compasso de ponta seca e uma régua endodôntica. Os resultados mostraram que as medidas digitais dos sistemas CDR e Dent Optix foram maiores em relação às medidas nos filmes (diferença de 0,15 e 0,6 respectivamente). Por outro lado, as medidas obtidas pelo sistema Digora foram menores que as dos filmes (diferença de 0,05). Comparados às medidas reais, os resultados apontaram o Digora como o sistema de melhor desempenho, tendo-se na seqüência, o filme, o CDR e o DenOptix.

HAITER et al. ${ }^{41}$ em 2001, compararam radiografias digitais com radiografias convencionais na mensuração de pequenos desgastes apicais, simulando reabsorções radiculares. Neste estudo foram usados dentes (incisivos central e lateral superiores, um canino superior e prémolar e molar inferiores) de um crânio macerado. Na primeira fase, os dentes foram retirados de seus alvéolos para obtenção da sua medida real, sendo recolocados e radiografados por três sistemas: digital Digora (Soredex), digital DenOptix (Gendex) e filme convencional Ekta-speed Plus da Kodak. Na segunda fase, os dentes foram removidos, desgastados em $2 \mathrm{~mm}$, mensurados e recolocados, para a obtenção de novas radiografias. Em uma terceira etapa os dentes foram novamente desgastados em $2 \mathrm{~mm}$, medidos e radiografados pelos três sistemas. As mensurações radiográficas foram realizadas por seis radiologistas, com auxílio de uma régua, nas radiografias convencionais. As imagens digitais foram medidas com as réguas próprias de cada sistema. Analisando a amostra como um todo, observou-se que as medidas obtidas pelo sistema Digora foram maiores em comparação com as obtidas no filme convencional. Já o sistema DenOptix revelou medidas menores do que o 
filme. A análise estatística demonstrou que as médias das mensurações feitas nos dois sistemas digitais não apresentaram diferença estatisticamente significante com o tamanho real dos dentes analisados, assim como as médias das mensurações no filme, nas duas primeiras fases do experimento. Porém, na terceira fase, as medidas feitas no filme convencional resultaram em valores maiores que os do tamanho real dos dentes. Com base nos resultados do trabalho, os autores concluíram que os sistemas digitais possuem uma alta exatidão na mensuração do comprimento do dente com reabsorções radiculares apicais externas mostrando-se superior ao filme convencional.

WOLF et al. $^{83}$ em 2001, avaliaram a reprodutibilidade e validação de medidas lineares de perda óssea interproximal sobre imagens radiográficas digitalizadas após aplicação de diferentes filtros e magnificação. Imediatamente antes da cirurgia, os pacientes com doença periodontal foram radiografados com filmes Ultra-speed por uma técnica padronizada. Todas radiografias foram digitalizadas por meio de um escaner de superfície plana (resolução 600x1200 dpi e 10 bits). Utilizando o programa Friacom, com e sem tratamento da imagem, as distâncias lineares, da junção amelocementária à extensão do defeito ósseo, e da junção cemento-esmalte à crista alveolar, foram mensuradas e comparadas com as medidas intra-cirúrgicas. Os resultados mostraram que as medidas digitais aproximaram-se das medidas intra-cirúrgicas, exibindo uma pequena elevação. As imagens que receberam tratamento com filtros (difusão e estrutura) e zoom mostraram uma maior reprodutibilidade em comparação às imagens sem tratamento.

KIM; BENN; EICKHOLZ ${ }^{47}$ em 2002, compararam dois sistemas de análise assistida por computador, na mensuração de perda óssea interproximal. Radiografias padronizadas obtidas de pacientes com doença periodontal avançada foram capturadas por meio de um sistema de 
vídeo (WV-BD 400 Panasonic). As mensurações das perdas ósseas foram obtidas por meio de dois programas, o LMSRT e o Friacom, para serem comparadas com as medidas intra-cirúrgicas. As medidas foram realizadas em dois locais: na distância da junção amelocementária à extensão do defeito ósseo; e na distância da junção amelocementária à crista alveolar. Os resultados revelaram que as medidas da distância da junção amelocementária à extensão do defeito ósseo efetuadas pelos dois programas foram maiores que as intra-cirúrgicas (diferença de 0,26 mm para o LMSRT e 0,35 mm para o Friacom), não acusando diferença estatisticamente significante. Porém, as medidas da distância da junção amelocementária à crista alveolar obtidas pelos dois programas foram significantemente maiores que as medidas intra-cirúrgicas (diferença de 1,63 mm para o LMSRT e 2,0 mm para o Friacom). Os autores concluíram que os programas estudados são métodos reproduzíveis para medir distâncias e podem ser recomendados para uso clínico. Constataram, também, que não houve diferença estatística significante entre os dois programas, porém ocorreu uma superestimação das mensurações de perdas ósseas interproximais nos dois programas em relação às medidas intracirúrgicas.

Em pesquisa realizada em 2002, VALE; BRAMANTE ${ }^{71}$ avaliaram a capacidade de visualização de limas endodônticas, dos filmes Ultra-speed DF-58, Ekta-speed Plus, ambos da Kodak, M2 Comfort da Agfa e do sistema de imagem digital Digora (Soredex). As limas foram introduzidas nos condutos radiculares de dentes de mandíbulas secas para serem radiografadas pelos métodos convencional e digital. As mensurações das limas e dos filmes radiográficos foram realizadas com auxílio de um paquímetro digital, enquanto as medidas digitais foram obtidas por meio do recurso de medida do programa "Digora for Windows". Os resultados revelaram que para a lima de número 15 as medidas das imagens digitais 
(Digora) foram maiores que as dos filmes convencionais. Por outro lado, as medidas digitais das limas seis, oito e dez apresentaram-se menores que as obtidas diretamente sobre os filmes. Diante desses resultados os autores concluíram que para visibilidade de limas menos calibrosas (números seis , oito e dez), os filmes radiográficos periapicais foram melhores que as imagens digitais, destacando-se o filme Ultra-speed. As imagens digitais exibiram melhores resultados quanto à visibilidade das limas número 15, em relação aos filmes radiográficos periapicais.

Desta forma, inúmeros trabalhos foram realizados com diferentes programas de imagem para mensurações lineares nas diferentes áreas da Odontologia, porém não observamos na literatura consultada, avaliações em Implantodontia usando diferentes programas e diferentes métodos de captura.

\subsection{2- Programas de imagem para o planejamento pré-cirúrgico de implantes}

De acordo com CHILVARQUER ${ }^{23}$ em 2002, a grande maioria dos protocolos para planejamento de implantes osseointegráveis inclui a "radiografia panorâmica com traçado radiográfico" como técnica préoperatória necessária para uma visualização globalizada do complexo maxilomandibular. Tal técnica visa delinear os principais reparos anatômicos visualizados na radiografia panorâmica e estimar medidas das distâncias anatômicas de interesse.

Freqüentemente, o traçado radiográfico para planejamento de implantes é realizado manualmente, diretamente em papel acetato transparente superposto à radiografia, vista através de um negatoscópio. As 
mensurações das distâncias anatômicas, na grande maioria das vezes, são realizadas com o auxílio de réguas milimetradas.

Os constantes avanços tecnológicos na área da computação, aliados aos avanços científicos na área da Radiologia Odontológica, resultaram no desenvolvimento de programas de imagem, destinados a efetuar os traçados para o planejamento pré-cirúrgico de implantes, a fim de se garantir a qualidade e precisão das medições, aliadas à facilidade e rapidez da operação.

Os programas de imagem possibilitam a realização das medições necessárias e sugestões de tipos e tamanhos de implantes em imagens capturadas por escaneres, câmeras digitais ou obtidas por sensores ou placas ópticas. Eles oferecem várias ferramentas de desenho, efeitos, tratamento de imagem e mensurações. A padronização nos relatórios, emitidos no formato de fichas, pelos diversos programas, possibilita o arquivamento de dados de forma mais organizada e acessível. Além disso, os programas possuem sistemas de calibração da magnificação da imagem a fim de garantir a precisão das medidas.

COSTA et al. ${ }^{26}$ em 2004, consideraram que a aplicação de desenhos anatômicos na avaliação radiográfica do planejamento précirúrgico de implantes, auxilia a observação dos resultados, podendo ser manual ou computadorizado. O desenho manual é o tipo de apresentação mais freqüente, onde por meio de folhas de acetato sobrepostas à radiografia e com o auxílio de negatoscópios, são efetuados os contornos anatômicos da região de interesse, seguidos por mensurações de altura e espessura. O desenho computadorizado pode ser realizado após a digitalização de radiografias por meio de escaner, com tampa para transparências, e a aplicação de programas de computador destinados ao planejamento (Simplant, Imagelab, Implant Preview, Radioimp). Uma vez efetuadas as mensurações e simulações, estes resultados poderão ser 
impressos em folhas de papel fotográfico, folhas de acetato, gravados em CD ou, até mesmo, enviados aos cirurgiões-dentistas por meio de Internet, criando-se interatividade dos exames.

Em 1997, CHILVARQUER ${ }^{24}$ desenvolveu um programa denominado "Método de Localização Para Implantes" (M.L.P.I.). Este programa permite que as imagens sejam ampliadas até quatro vezes sem perda de resolução, alteradas no contraste, brilho, tonalidade e inversão da escala de tons (imagem positiva e negativa). Também é possível fazer mensurações nas áreas de interesse com precisão de até um décimo de milímetro. Desenhos de implantes, com suas medidas, podem ser inseridos nas imagens radiográficas digitalizadas. Outra finalidade deste programa é facilitar a comunicação entre o cirurgião-dentista e o paciente, permitindo a demonstração do caso com bastante clareza, rapidez e com possíveis indicações e contra-indicações dos futuros procedimentos cirúrgicos e protéticos. Com esta metodologia, é possível a comunicação entre o cirurgião-dentista e o radiologista no que se refere a dúvidas de diagnóstico, já que ambos possuem a cópia do exame. Esta comunicação pode ser agilizada quando o exame é entregue via internet. Para fins de documentação, as imagens com os traçados podem ser gravados em CDs ou impressas em papel fotográfico de alta resolução.

O programa americano Implanner - Dolphin, Chatsworth, CA, USA - (DOLPHIN IMPLANER ${ }^{28}$, 2004) foi criado para planejamento de implantes. Por meio de um sistema de calibração referencial o programa calibra automaticamente a magnificação da imagem digitalizada, sendo possível realizar mensurações de estruturas e distâncias anatômicas. Com o auxílio de suas ferramentas, realça as imagens de estruturas anatômicas, das áreas de enxertos ósseos, produzindo traçados coloridos representativos. Com a simulação de colocação de implantes, facilita a 
orientação e comunicação com o paciente e outros profissionais. As informações geradas podem ser arquivadas ou enviadas por $e$-mail.

O programa de imagem Radioimp - Radiomemory, Belo Horizonte, Minas Gerais, Brasil - (RADIOMEMORY ${ }^{58}$, 2004), lançado no mercado em 2000, foi desenvolvido especialmente para planejamento précirúrgico em Implantodontia. Por meio de imagens capturadas por meio de escaner, câmera digital, sensores ou placas ópticas, o programa possibilita a realização das medições necessárias e sugestões de tipos e tamanhos de implantes. Com o programa é possível calcular distâncias, ângulos, fazer indicações e evidenciar particularidades anatômicas com o auxílio de ferramentas de desenho (seta, asterisco, retângulo, elipse, etc.). Além disso, existem recursos de melhoramento da imagem: controle simultâneo de brilho e contraste, pseudocoloração, zoom, filtro médio, negativo/positivo, histograma e textura. Ao usar uma ferramenta, o programa faz o legendamento automático, numerando ou colorindo o objeto e relacionando-o às descrições do laudo. Ele disponibiliza um cadastro com os pinos mais usados pelos implantodontistas, podendo incluir novos pinos. Os laudos podem ser totalmente personalizados: as cores, o tipo de legendas, de letra, a logomarca, cabeçalho e rodapé são totalmente configuráveis. Todos esses recursos permitem a emissão de laudos com alto padrão estético, podendo ser salvos em arquivos digitais, impressos ou enviados via internet. Esse programa também possui um sistema de calibração da magnificação da imagem. A calibração pode ser realizada de duas maneiras: por meio da resolução (dpi) com que foi escaneada a radiografia, ou por meio do sistema referencial, com base em uma medida conhecida. No sistema referencial, basta clicar em dois pontos da imagem de uma medida conhecida. Normalmente utiliza-se como referência a imagem de uma régua que foi escaneada juntamente à radiografia. Para completar o processo de calibração da magnificação da imagem é preciso 
informar o índice de magnificação do aparelho panorâmico ou tomográfico utilizado. Com base nessas informações, o programa realiza a calibração automaticamente.

O programa Planimp - C.D.T. Consultoria, Desenvolvimento e Treinamento em Informática Ltda., Cuiabá, Mato Grosso, Brasil - (CDT ${ }^{17}$, 2004) também foi lançado em 2000, desenvolvido com finalidade de mensuração e planejamento para implante. Com pequenas diferenças, esse programa se assemelha ao Radioimp (Radiomemory), oferecendo várias ferramentas de mensurações, desenho, efeitos, tratamento de imagem, enfim, possibilitando a confecção de traçados radiográficos de alto padrão estético.

Tendo em vista que esses dois últimos programas, de origem nacional, foram recentemente lançados no mercado, pelas amplas possibilidades que oferecem, estão a merecer um estudo e uma avaliação mais acurados, especialmente quanto aos seus sistemas de medição linear e aos seus sistemas de calibração de imagem. Da mesma forma, também é importante a utilização des métodos adequados de captura de imagem, a serem utilizados nesses programas, que garantam a reprodutibilidade das imagens radiográficas que serão neles processados. 
3- PROPOSIÇÃO 


\section{3- PROPOSIÇÃO}

Utilizando radiografias panorâmicas digitalizadas por meio de um escaner e uma câmera fotográfica digital e aplicando os sistemas de calibração dos programas de imagem Radioimp e Planimp utilizados para planejamento em Implantodontia, nos propusemos a:

1- Correlacionar as medidas fornecidas pelos referidos programas, com às obtidas por meio do paquímetro digital nos filmes radiográficos;

2- Correlacionar os sistemas de calibração de imagem por meio das medidas lineares fornecidas pelos programas de imagem

3- Analisar os resultados das imagens obtidas por meio dos dois métodos de digitalização utilizados, escaner e câmera digital. 
4- MATERIAL E MÉTODOS 


\section{4- MATERIAL E MÉTODOS}

\section{1- Radiografias panorâmicas}

A amostra foi constituída de 50 radiografias panorâmicas de pacientes edêntulos, pertencentes ao arquivo da Clínica de Implantodontia da Universidade do Sagrado Coração. As radiografias foram obtidas sob rígidas condições de padronização, incluindo técnica e processamento radiográficos adequados, conforme as instruções do fabricante.

O aparelho panorâmico utilizado foi o Rotograph 230 EUR (Villa Sistemi Medicali, Italy), da Clínica de Radiologia da Universidade do Sagrado Coração. Os filmes utilizados foram T-MAT G/RA da Kodak (Kodak, São José dos Campos, Brasil).

As radiografias foram processadas automaticamente utilizando a processadora Macrotec MX-2 (Macrotec Ind. e equipamentos Ltda., São Paulo, São Paulo, Brasil), com soluções de processamento GBX (Kodak, São José dos Campos, Brasil). 


\section{2- Distâncias anatômicas}

Para delimitar as distâncias anatômicas de maxila e mandíbula a serem mensuradas foram escolhidos pontos de referência. Esses pontos foram marcados em todas as radiografias, utilizando-se uma caneta especial para retroprojetor (marcador para retroprojetor 2.0 VM, Pilot). A escolha das referidas distâncias anatômicas foi realizada com base na literatura (CAMACHO et al. ${ }^{14}$, 1999; CHILVARQUER ${ }^{23}$, 2002; KALIL ${ }^{45}$, 1998).

Assim, foram escolhidos um total de 28 pontos, resultando em sete distâncias anatômicas para maxila e sete para a mandíbula. Com o intuito de aumentar a amostra e melhorar os resultados da análise estatística foram escolhidas 14 distâncias anatômicas em cada radiografia (Figura 1).

As distâncias anatômicas mensuradas foram:

- Distância 1 (MSD), área de Molar Superior Direito: distância que vai desde a crista do Rebordo Alveolar Superior (ponto PRAS 1) até o Soalho do Seio Maxilar (ponto PSM 1);

- Distância 2 (PMSD), área de Pré-Molar Superior Direito: distância que vai desde a crista do Rebordo Alveolar Superior (ponto PRAS 2) até o Soalho do Seio Maxilar (ponto PSM 2);

- Distância 3 (CSD), área de Canino Superior Direito: distância que vai desde a crista do Rebordo Alveolar Superior (ponto PRAS 3) até 2 mm do Y de Ennis para mesial (ponto PY 1); 
- Distância 4 (ICS), área de Incisivo Central Superior: distância que vai desde a crista do Rebordo Alveolar Superior (ponto PRAS 4) até a Espinha Nasal Anterior (ponto PENA);

- Distância 5 (CSE), área de Canino Superior Esquerdo: distância que vai desde a crista do Rebordo Alveolar Superior (ponto PRAS 5) até 2 mm do Y de Ennis para mesial (ponto PY 2);

- Distância 6 (PMSE), área de Pré-Molar Superior Esquerdo: distância que vai desde a crista do Rebordo Alveolar Superior (ponto PRAS 6) até o Soalho do Seio Maxilar (ponto PSM 3);

- Distância 7 (MSE), área de Molar Superior Esquerdo: distância que vai desde a crista do Rebordo Alveolar Superior (ponto PRAS 7) até o Soalho do Seio Maxilar (ponto PSM 4);

- Distância 8 (MID), área de Molar Inferior Direito: distância que vai desde a crista do Rebordo Alveolar Inferior (ponto PRAI 1) até o teto do Canal Mandibular (ponto PCM 1);

- Distância 9 (PMID), área de Pré-Molar Inferior Direito: distância que vai desde a crista do Rebordo Alveolar Inferior (ponto PRAI 2) até a parte superior do Forame Mentual (ponto PFM 1);

- Distância 10 (CID), área de Caninor Inferior Direito: distância que vai desde a crista do Rebordo Alveolar Inferior (ponto PRAI 3) até a linha média entre o Forame Mentual e o Plano Sagital Mediano (ponto PFP 1); 
- Distância 11 (ICI), área de Incisivo Central Inferior: distância que vai desde a crista do Rebordo Alveolar Inferior (ponto PRAI 4) até a Cortical Interna da Mandíbula (ponto PCIM);

- Distância 12 (CIE), área de Canino Inferior Esquerdo: distância que vai desde a crista do Rebordo Alveolar Inferior (ponto PRAI 5) até a linha média entre o Forame Mentual e o Plano Sagital Mediano (ponto PFP 2);

- Distância 13 (PMIE), área de Pré-Molar Inferior Esquerdo: distância que vai desde a crista do Rebordo Alveolar Inferior (ponto PRAI 6) até a porção superior do Forame Mentual (ponto PFM 2);

- Distância 14 (MIE), área de Molar Inferior Esquerdo: distância que vai desde a crista do Rebordo Alveolar Inferior (ponto PRAI 7) até a porção superior do teto do Canal Mandibular (ponto PCM 2). 


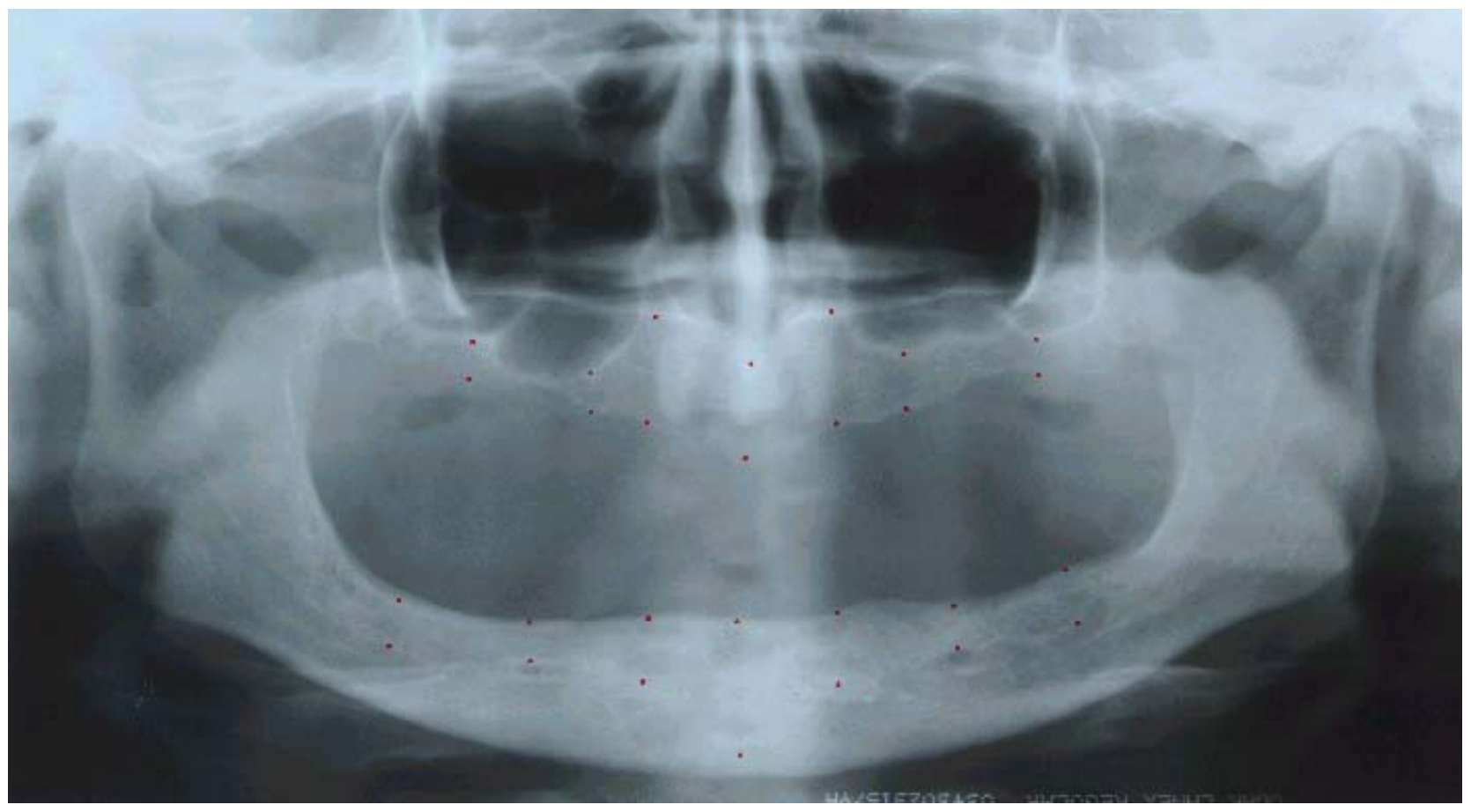

FIGURA 1 - Pontos de referência delimitando as 14 distâncias anatômicas 


\section{3- Digitalização das radiografias panorâmicas}

Foi utilizado um computador Pentium III, 320 MB de RAM, 10 GB de HD, CD ROM 24X, com placa de vídeo de 16 MB e monitor LG, Super-VGA, com resolução de 800x600 pixels e 16 bits, gerenciado pelo programa Windows 98 (Microsoft Corporation, Richmound, VA, USA), para o processamento dos dados obtidos com os programas de imagem Radioimp (Radiomemory, Belo Horizonte, Minas Gerais, Brasil) e Planimp (CDT: Consultoria, Desenvolvimento e Treinamento em Informática Ltda., Cuiabá, Mato Grosso, Brasil).

As radiografias foram digitalizadas por meio de dois métodos de aquisição de imagens indiretos, um escaner de mesa e uma câmera fotográfica digital:

- Um escaner de mesa HP Scanjet 4 C/T (Hewllett Packard, Vancouver, WA, EUA), tendo como acessório um leitor de transparência que permitiu a leitura da imagem e a digitalização dos filmes radiográficos (Figura 2) Máscaras de papel cartão preto emolduraram as radiografias com o objetivo de regular a luminosidade do leitor de transparência. Foi colocada uma régua milimetrada (Menno, São Paulo, Brasil) junto às radiografias no momento da captura das imagens. As radiografias, juntamente com a régua milimetrada, foram digitalizadas de forma padronizada: sempre na mesma posição de escaneamento, sem mudança na configuração do escaner, e sem desligar e ligar o aparelho entre os escaneamentos (CHEN; HOLLENDER ${ }^{20}$, 1995). A imagem da régua foi utilizada como referência de uma medida conhecida, no momento da calibração da magnificação da imagem, realizada pelos programas. As imagens foram escaneadas em 300 dpi (dots per inch: pontos por polegada) e 24 bits e salvas no formato JPEG (Joint Photographic Experts Group), 
com máxima qualidade. Estas imagens foram, então, transmitidas para a memória do computador, onde pudemos realizar a mensuração linear com os programas. Para cópia de segurança dos arquivos de imagens obtidas utilizou-se um gravador de CD da Creative e um compact disc de 650 MB. - Uma câmera fotográfica digital FinePix S602 ZOOM, da Fujifilm, (Fuji Photo Film Co. Ltd., Minato-Ku, Tokyo, Japan) com resolução de 3.1 megapixel, operando com zoom óptico de $2 \mathrm{X}$, foi utilizada para aquisição das imagens. A abertura variou de 3.7 a 4.2 automaticamente. As imagens foram adquiridas com distância lente-filme de $50 \mathrm{~cm}$ (de acordo com teste piloto realizado) e salvas no formato FINE JPEG (2832 x 2128 pixels). Durante a captura das imagens foi utilizado um negatoscópio especialmente projetado, de acordo com instruções do fabricante do programa Planimp $\left(\mathrm{CDT}^{18}, 2000\right)$ contendo no seu interior quatro lâmpadas fluorescentes de 36 W (Osram Dulux F - 36 W/21-840). Máscaras de papel cartão preto emolduraram as radiografias com o objetivo de regular a luminosidade do negatoscópio. A câmera digital permaneceu em posição perpendicular ao negatoscópio, tanto no sentido vertical como no horizontal, com o auxílio de uma estativa(Figura 3). Uma régua foi colocada junto às radiografias durante a captura das imagens para servir de referência no momento da calibração da magnificação da imagem pelos programas. 

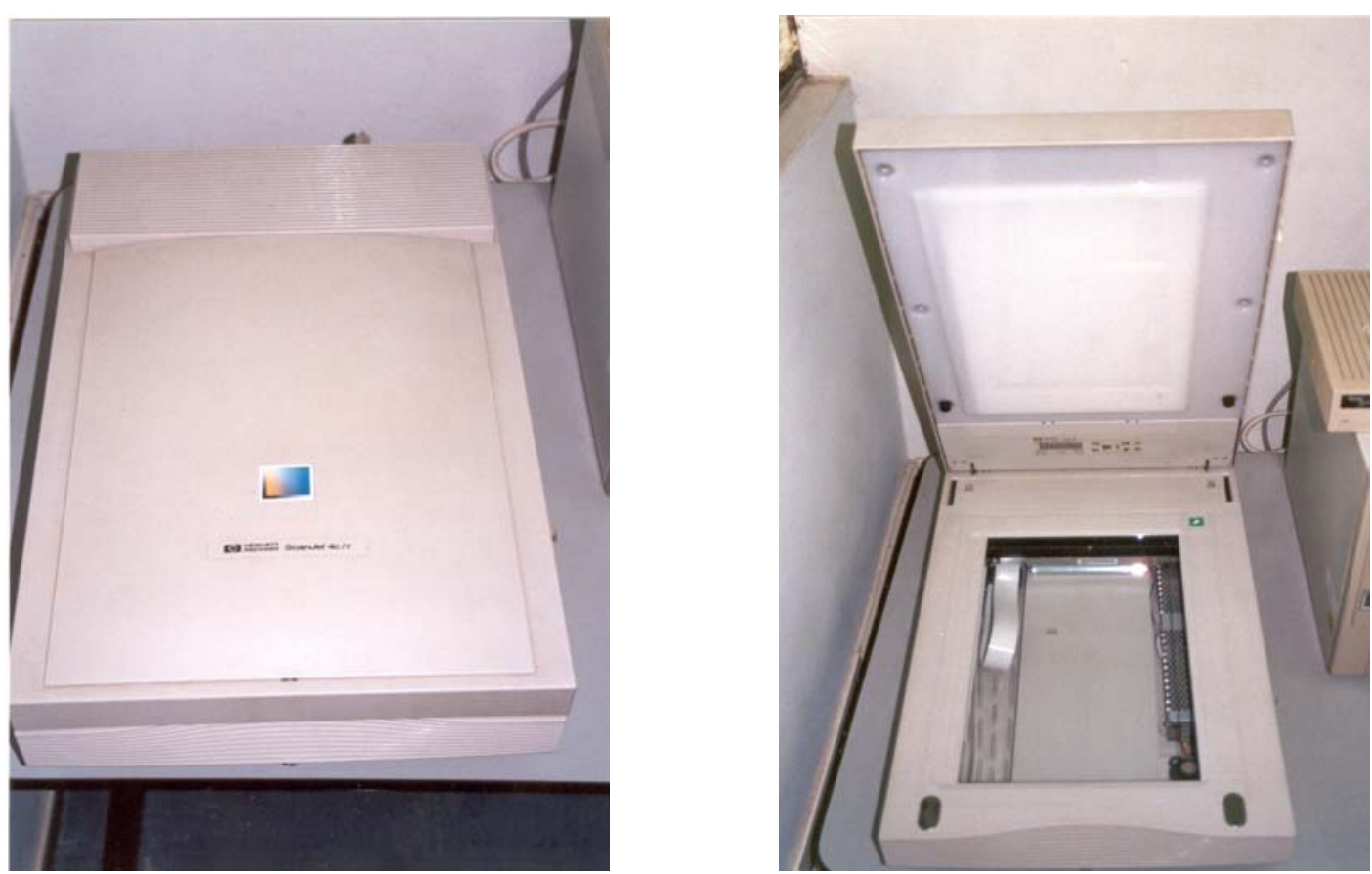

FIGURA 2 - Escaner HP Scanjet 4 C/T com leitor de transparência, utilizado para digitalização das radiografias
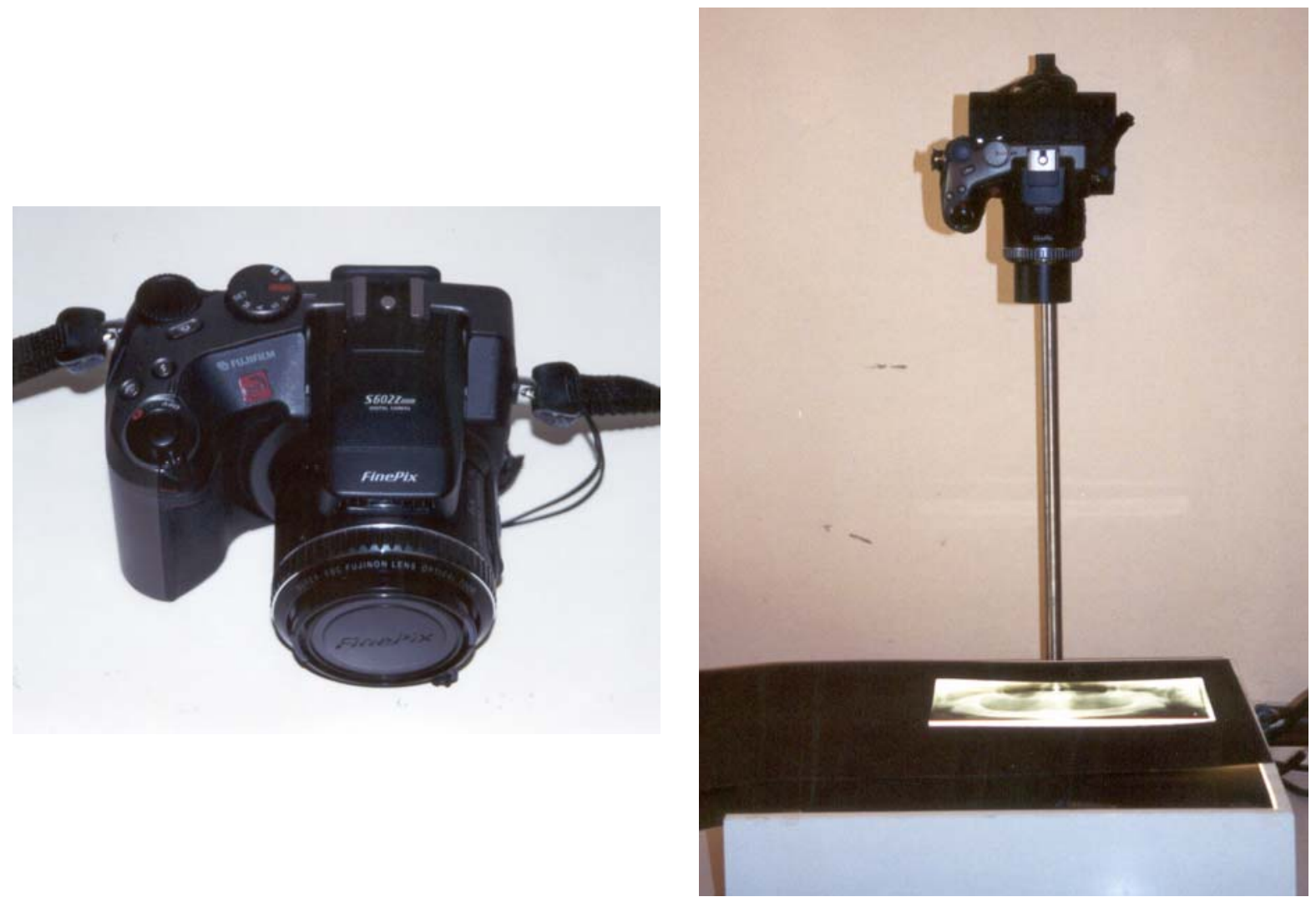

FIGURA 3 - Câmera digital FinePix S602 posicionada na estativa, no momento da digitalização das radiografias 


\section{4- Mensurações lineares das distâncias anatômicas}

Após a digitalização das imagens procedeu-se às mensurações lineares das distâncias anatômicas realizadas por meio de dois métodos: o método manual, onde as mensurações foram obtidas por meio do paquímetro eletrônico digital, e também, pelo método digital, utilizando os programas de imagem para traçado radiográfico e planejamento em Implantodontia, o Radioimp 2000, da Radiomemory - Radiomemory, Belo Horizonte, Minas Gerais, Brasil - (RADIOMEMORY ${ }^{59}$, 2000), e o Planimp 2000, da CDT - Consultoria, Desenvolvimento e Treinamento em Informática Ltda., Cuiabá, Mato Grosso, Brasil - $\left(\mathrm{CDT}^{18}\right.$, 2000) (Figura $4 \mathrm{I}$ e II).

Para esta pesquisa utilizou-se: dois sistemas de digitalização (escaner e câmera digital), dois métodos de mensuração de distâncias lineares (manual - paquímetro, e digital - programas Radioimp e Planimp ), e dois sistemas de calibração da magnificação da imagem contidos nesses programas (sistema por resolução e sistema referencial). A calibração da magnificação da imagem dos programas Radioimp e Planimp pode ser realizada com base na resolução com a qual a radiografia foi escaneada (em dpi: pontos por polegadas) e também pela calibração referencial, onde ela é obtida por meio de uma distância referencial pré-estabelecida (em milímetros).

Face a essas variáveis: sistema de aquisição das imagens, tipo de programa digital e método de mensuração, foram constituídos sete grupos experimentais.

Os grupos obtidos foram: 
GRUPO 1 - Grupo Controle (paquímetro digital):

Constituído pelas medidas obtidas pelo método manual por meio do paquímetro digital.

GRUPO 2 - Radioimp / Calibração por resolução (dpi) / Escaner:

Constituído pelas medidas obtidas no programa Radioimp em imagens digitalizadas por meio escaner e calibradas pelo sistema por resolução.

GRUPO 3 - Radioimp / Calibração referencial (mm) / Escaner:

Constituído pelas medidas obtidas no programa Radioimp em imagens digitalizadas por meio do escaner e calibradas pelo sistema referencial.

GRUPO 4 - Radioimp / Calibração referencial (mm) / Câmera:

Constituído pelas medidas obtidas no programa Radioimp em imagens digitalizadas por meio da câmera digital e calibradas pelo sistema referencial.

GRUPO 5 - Planimp / Calibração por resolução (dpi) / Escaner:

Constituído pelas medidas obtidas no programa Planimp em imagens digitalizadas por meio do escaner e calibradas pelo sistema por resolução.

GRUPO 6 - Planimp / Calibração referencial (mm) / Escaner:

Constituído pelas medidas obtidas no programa Planimp em imagens digitalizadas por meio do escaner e calibradas pelo sistema referencial.

GRUPO 7 - Planimp / Calibração referencial (mm) / Câmera:

Constituído pelas medidas obtidas no programa Planimp em imagens digitalizadas por meio da câmera digital e calibradas pelo sistema referencial. 

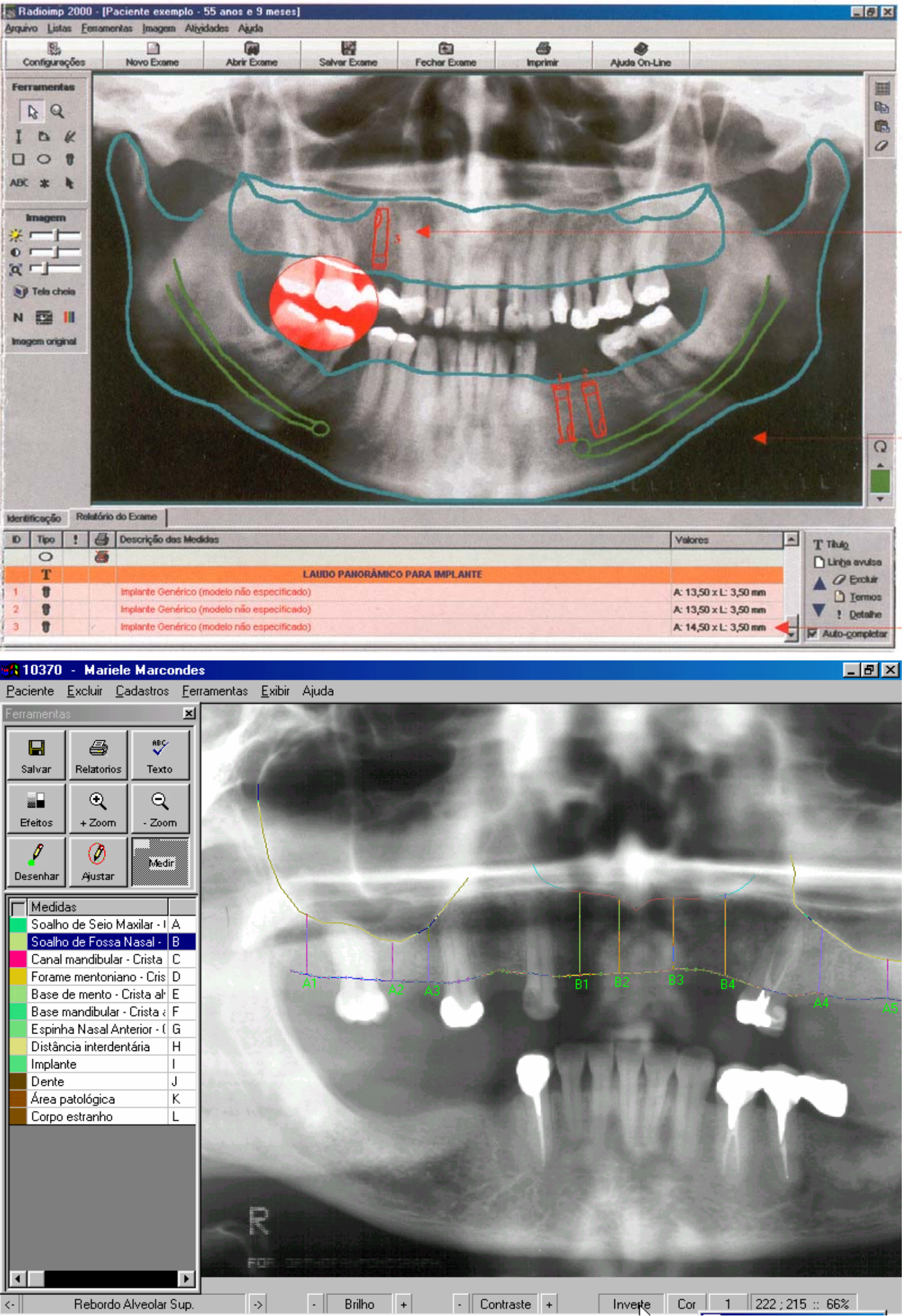

FIGURA 4 - Exemplos de laudos fornecidos por programas de imagem para planejamento de implantes: I Radioimp e II Planimp 


\subsection{1- GRUPO 1}

\section{- Grupo Controle}

O grupo controle foi obtido a partir da mensuração das distâncias anatômicas nas radiografias panorâmicas utilizando-se um paquímetro digital da marca Mitutoyo 150 mm (Mitutoyo Ltd, Andover, UK), com precisão de $0,01 \mathrm{~mm}$.

As distâncias foram mensuradas utilizando-se um negatoscópio (EMB, Brasil) contendo uma lupa acoplada de aumento de 4 vezes, em uma sala em obscurecida (Figura 5). Um conjunto de, no máximo, cinco radiografias foi trabalhada a cada dia, para evitar a fadiga visual do operador, minimizando a possibilidade de erros casuais.

Das medidas realizadas com o paquímetro digital nas radiografias panorâmicas, foi deduzido o índice de magnificação de $20 \%$ do aparelho panorâmico Rotograph, segundo as recomendações do fabricante (ÁVILA ${ }^{6}$, 1996; LANGLAND et al. ${ }^{50}$, 1989; VILLA SISTEMI $\operatorname{MEDICALI}^{76}$, 1992). Os dados foram anotados em fichas próprias e transportados para uma planilha do programa Excel 97 (Microsoft Corporation, Richmound, VA, USA), para posterior tratamento estatístico.

Este grupo foi, então, considerado o grupo controle, isto é, as correlações foram feitas com base nestes resultados. 

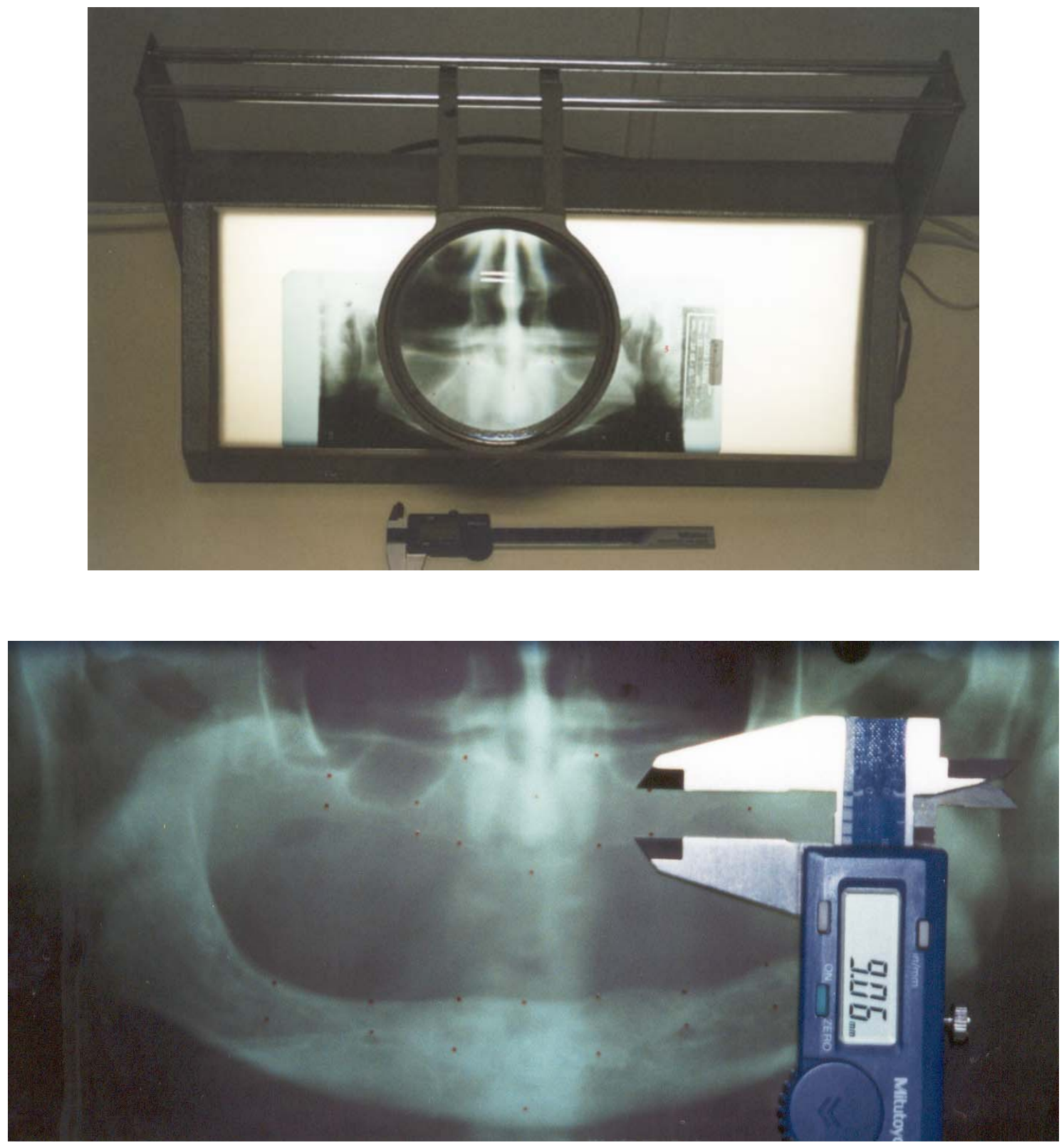

FIGURA 5 - Negatoscópio MB e paquímetro digital Mitutoyo 150 mm, utilizados para mensuração das distâncias anatômicas, nas radiografias (grupo 1) 


\title{
4.4.2- GRUPO 2
}

- Radioimp / Calibração por resolução (dpi) / Escaner:

\begin{abstract}
A calibração da magnificação das imagens capturadas pelo escaner HP, foi obtida por meio da resolução do escaner (300 dpi), denominada "sistema de calibração por resolução", fornecido pelo programa Radioimp. Para a calibração da magnificação da imagem e obtenção das mensurações foram realizados os seguintes passos:
\end{abstract}

\section{a) Abertura do programa}

Para a abertura do programa, clicou-se com o mouse duas vezes no ícone indicativo do programa, aparecendo na tela principal, um menu de opções (Figura 6 I).

\section{b) Busca da imagem}

A busca da imagem se fez clicando no botão novo exame, em seguida na opção abrir imagem do disco (Figura 6 I). Após esse passo, buscou-se a pasta na qual estavam arquivadas as imagens capturadas do escaner HP, selecionando-se a radiografia desejada (Figura 6 II). 

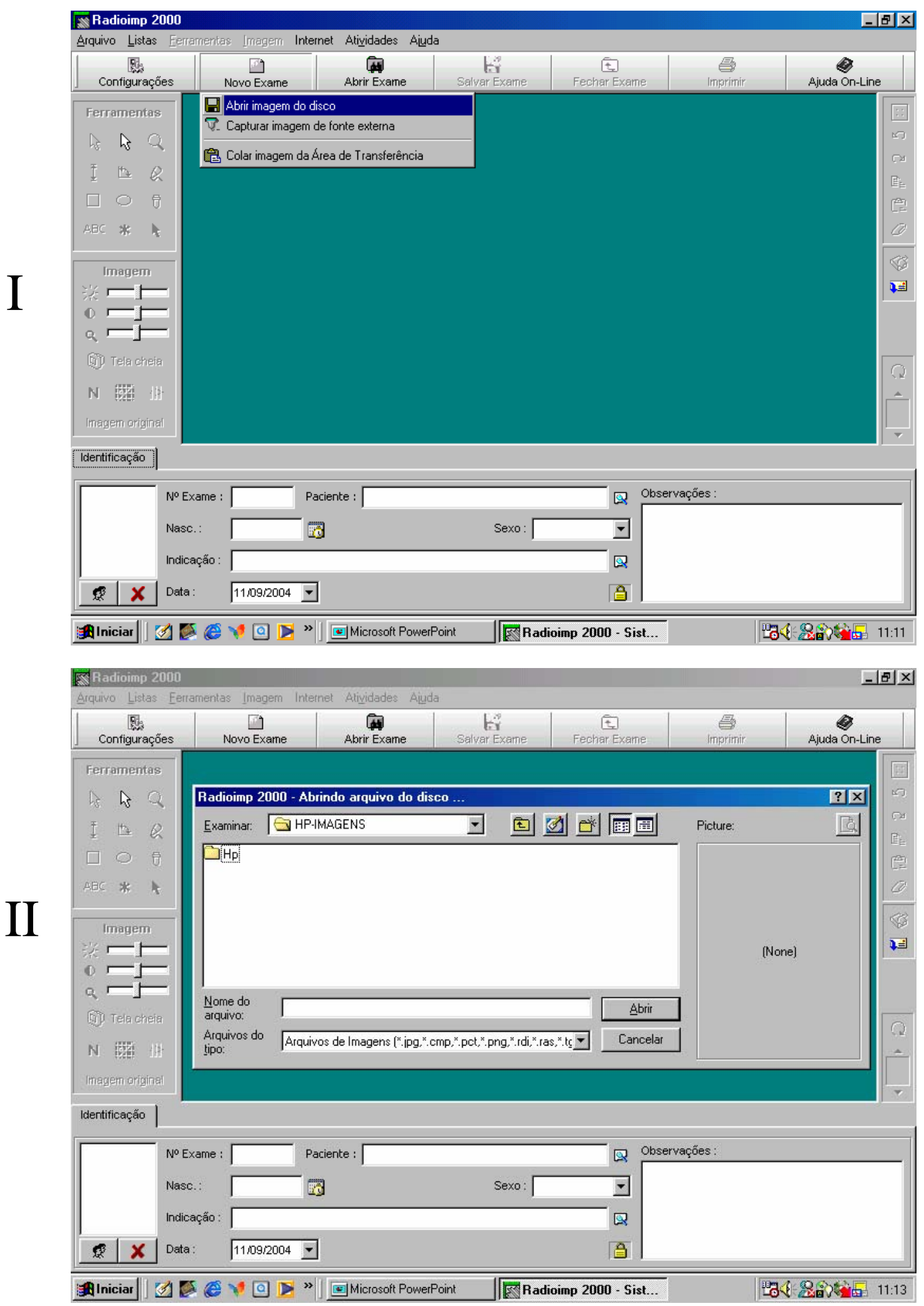

FIGURA 6 - Demonstração na tela do monitor com imagens dos passos seguidos para calibração da imagem e obtenção das medidas do grupo 2 (radioimp/calibração por resolução/escaner): I) abertura do programa, II) busca da imagem radiográfica 


\section{c) Seleção do tipo de calibração}

Neste momento o programa solicitou as configurações da imagem, devendo-se selecionar o tipo escolhido de calibração da magnificação da imagem. Optou-se pela calibração por resolução, através do dpi, com o qual as imagens foram escaneadas. Para isso, clicou-se na opção lista de calibrações, selecionando a opção personalizado (Figura 7 III), dando ok para prosseguir.

\section{d) Calibração da imagem pelo sistema de calibração por resolução (dpi)}

Em seguida, fez-se o preenchimento dos campos resolução da imagem (resolução com a qual as imagens foram escaneadas), e magnificação do aparelho (índice de magnificação do aparelho radiográfico utilizado). O campo resolução da imagem foi preenchido com "300" dpi e o campo magnificação do aparelho preenchido com "20\%" (índice de magnificação do Rotograph) (Figura 7 IV). Após a identificação de todas as configurações de imagens solicitadas, foi dado ok para prosseguir. A partir desse momento as medidas foram calibradas automaticamente. 

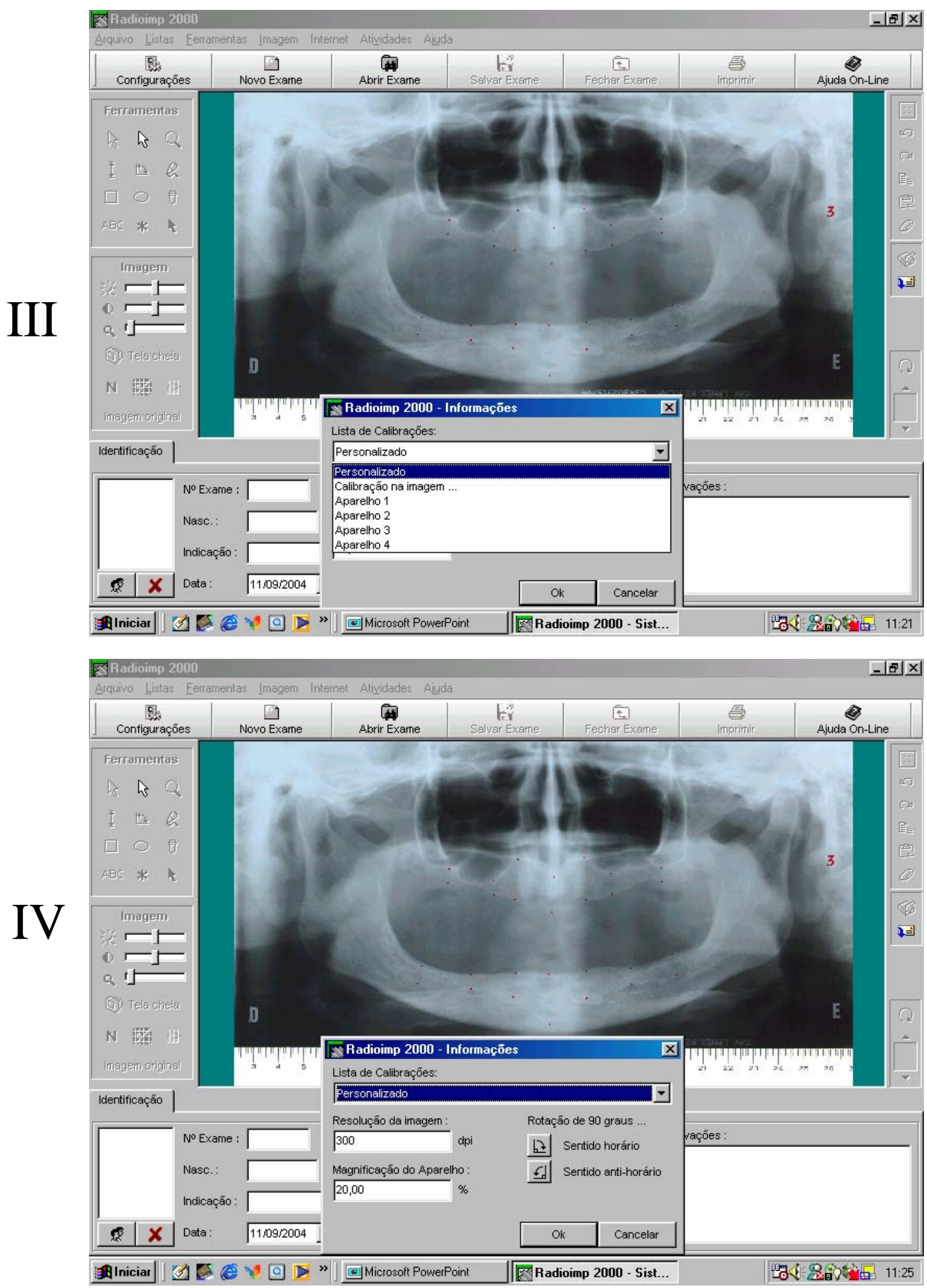

FIGURA 7 - Demonstração na tela do monitor com imagens dos passos seguidos para calibração da imagem e obtenção das medidas do grupo 2 (radioimp/calibração por resolução/escaner). III) seleção do tipo de calibração, IV calibração por resolução 


\section{e) Identificação dos dados do paciente/exame}

Após a calibração, apareceu na tela, a imagem da radiografia digitalizada e abaixo alguns campos que foram preenchidos com informações a respeito do paciente/exame: número do exame, nome do paciente, data de nascimento, sexo e indicação. Terminada essa etapa, clicou-se no botão tela cheia, localizado no menu à esquerda da imagem (Figura $8 \mathrm{~V}$ ), aparecendo uma tela com uma imagem ampliada, disponibilizando um menu de opções com diversas ferramentas para tratamento da imagem, mensurações, desenho e etc (Figura 8 VI).

\section{f) Ampliação da imagem}

Com a ferramenta do zoom selecionada, clicou-se uma vez em cima da imagem, a fim de se trabalhar com uma ampliação de 200\% (Figura 9 VII).

\section{g) Mensurações}

Para realizar as mensurações das distâncias pré-estabelecidas, ativou-se a opção distância, na barra de ferramentas (Figura 9 VII). Com o cursor no início da medida da distância anatômica (parte superior e média do ponto de referência superior), arrastou-se com o botão do mouse pressionado, até o final da medida (parte inferior e média do ponto de referência inferior). Nesse momento apareceu na parte superior da tela, uma legenda mostrando o valor (em mm) da mensuração realizada. Procedeu-se da mesma maneira descrita acima, com as mensurações de todas as distâncias pré-estabelecidas desde a distância 1 à distância 14. Após a obtenção das 14 medidas, clicou-se na opção tela normal e, em seguida, na opção salvar exame (Figura 9 VIII). 


\section{h) Impressão do relatório}

Para imprimir o relatório contendo os valores das mensurações otidas pelo programa Radioimp, selecionou-se a opção imprimir. Assim, apareceu na tela o relatório com as medidas e várias opções de configurações para laudo radiográfico. Com as configurações desejadas, finalmente, clicou-se na opção imprimir.

\section{i) Preenchimento de planilhas para estatística}

Os valores das mensurações foram transcritos para o programa Excel 97 para posterior tratamento estatístico. 
- Radioimp 2000

- 可可

Arquivo Listas Ferramentas Imagem Internet Atividades Aiuda

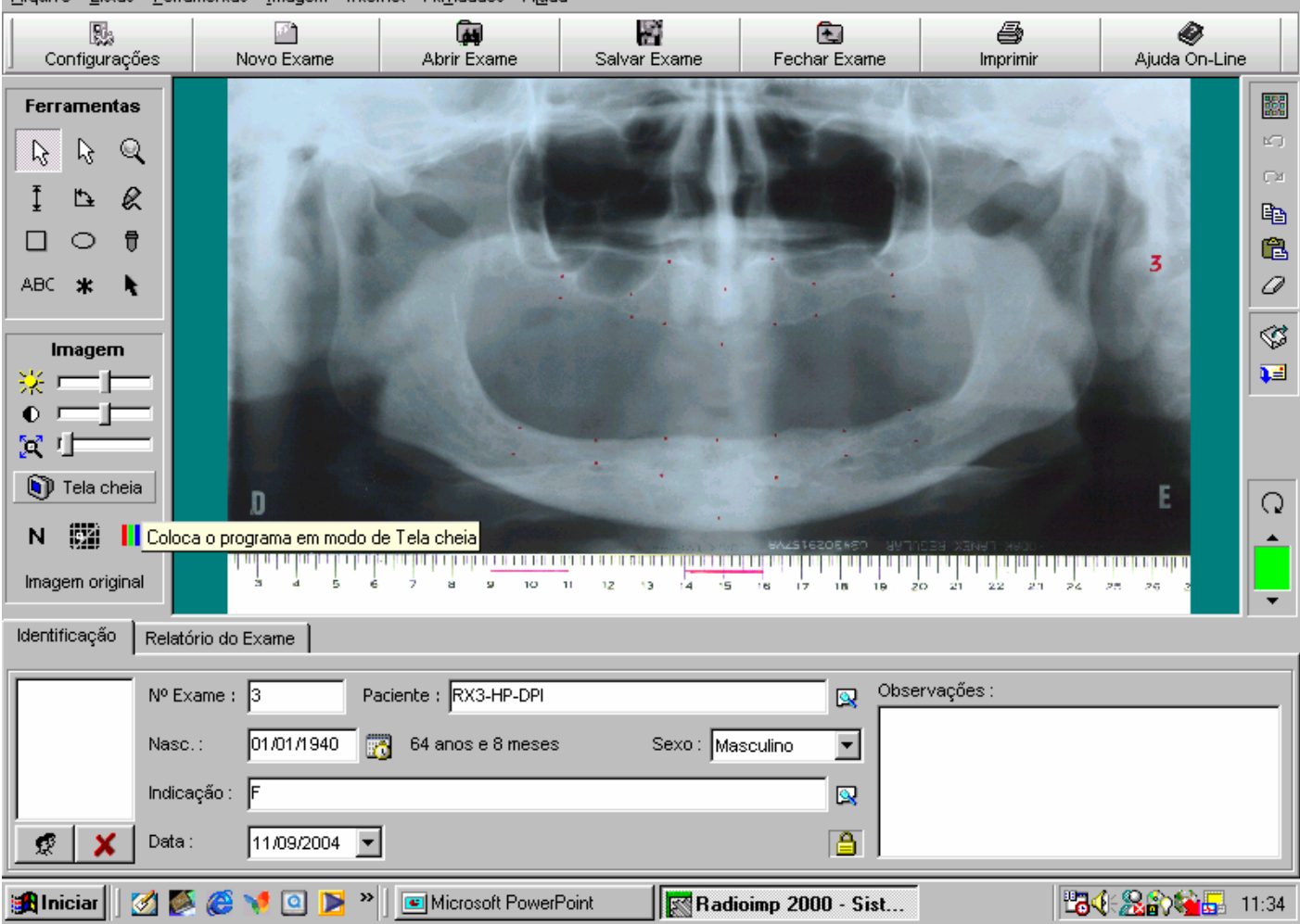

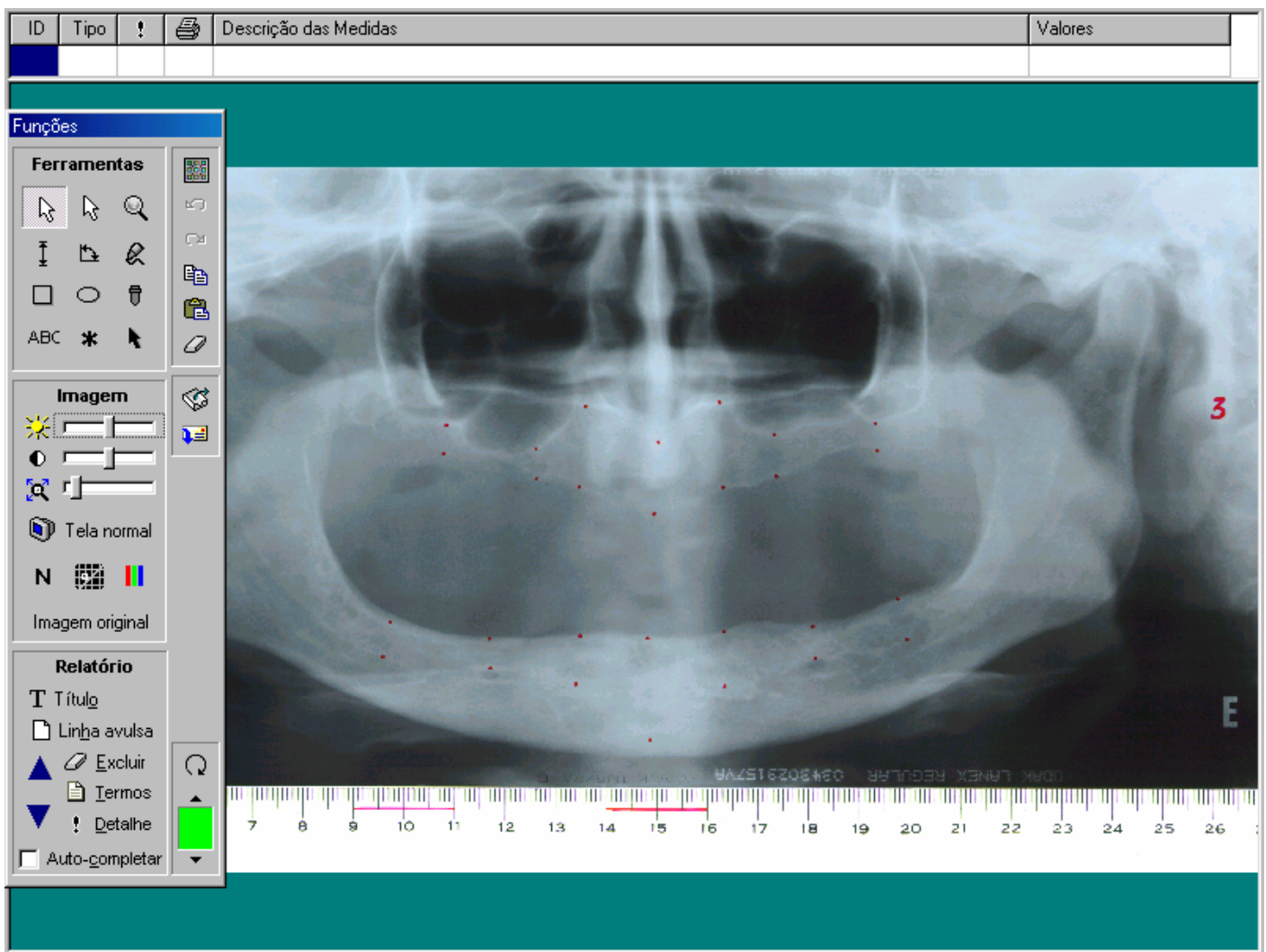

FIGURA 8 - Demonstração na tela do monitor com imagens dos passos seguidos para calibração da imagem e obtenção das medidas do grupo 2 (radioimp/calibração por resolução/escaner): V) identificação dos dados do paciente, VI) ferramentas para tratamento da imagem 

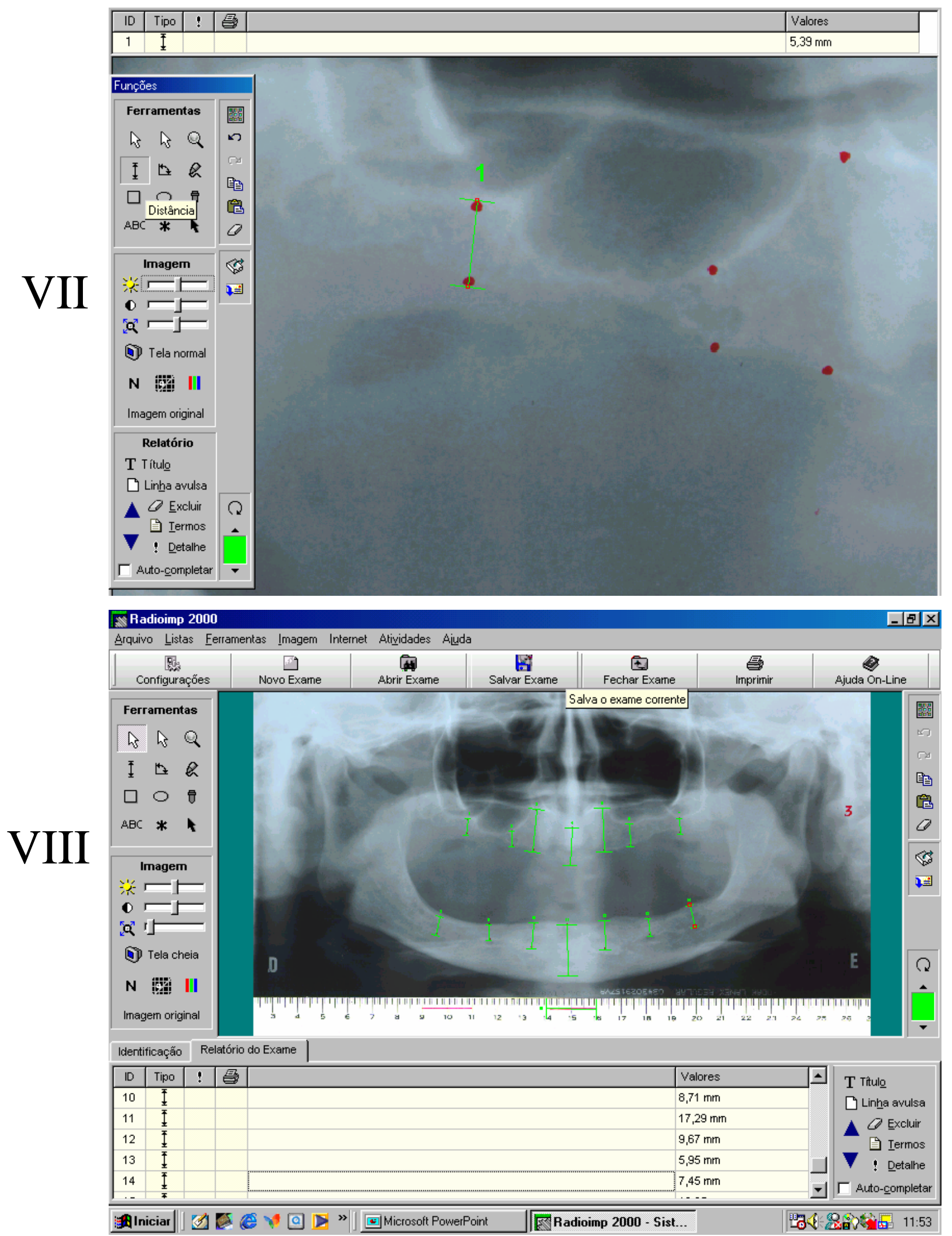

FIGURA 9- Demonstração na tela do monitor com imagens dos passos seguidos para calibração da imagem e obtenção das medidas do grupo 2 (radioimp/calibração por resolução/escaner). VII) medição com a ferramenta distância, VIII) obtenção das 14 medidas 


\subsection{3- GRUPO 3}

\section{- Radioimp / Calibração referencial (mm) / Escaner}

A calibração da magnificação das imagens capturadas pelo escaner HP, foi obtida pelo sistema de calibração referencial, fornecido pelo programa de imagem Radioimp (a calibração da magnificação da imagem é obtida por meio de uma distância referencial pré-estabelecida). Para a obtenção das mensurações foram realizados os seguintes passos:

\section{a) Abertura do programa}

Para a abertura do programa, clicou-se duas vezes no ícone indicativo do programa, aparecendo um menu de opções na tela principal (Figura 6 I).

\section{b) Busca da imagem}

A busca da imagem se fez clicando no botão novo exame $e$ em seguida, na opção abrir imagem do disco. Após esse passo, buscou-se a pasta na qual estavam arquivadas as imagens capturadas do escaner HP, selecionando-se a radiografia desejada (Figura 6 II).

\section{c) Seleção do tipo de calibração}

Neste momento o programa solicitou as configurações da imagem, devendo-se selecionar, no campo lista de calibrações, o tipo de calibração da magnificação da imagem desejada. Optou-se pela calibração da imagem pelo método referencial, clicando-se na opção calibração na imagem, dando ok para prosseguir (Figura 10 I). 


\section{d) Calibração da imagem pelo método referencial}

Apareceram na tela instruções de como proceder para a calibragem. Na imagem da régua foram marcados dois pontos prédeterminados sendo o primeiro no número 14 e o segundo no número 16 (Figura 10 II), resultando uma distância de $20 \mathrm{~mm}$ na imagem da radiografia. Para se obter o valor real dessa mesma distância, deduziu-se o índice de magnificação do aparelho panorâmico (Rotograph: índice de 20\%), apurando-se 16,66 mm, distância esta que foi registrada no campo determinado. Em seguida, procedeu-se a calibração propriamente dita, clicando-se no botão calibrar. A partir desse momento as medidas foram calibradas automaticamente (Figura 10 II).

Os procedimentos relacionados abaixo, foram os mesmos do Grupo 2:
e) Identificação dos dados do paciente/exame
f) Ampliação da imagem
g) Mensurações
h) Impressão do relatório
i) Preenchimento de planilhas para estatística 

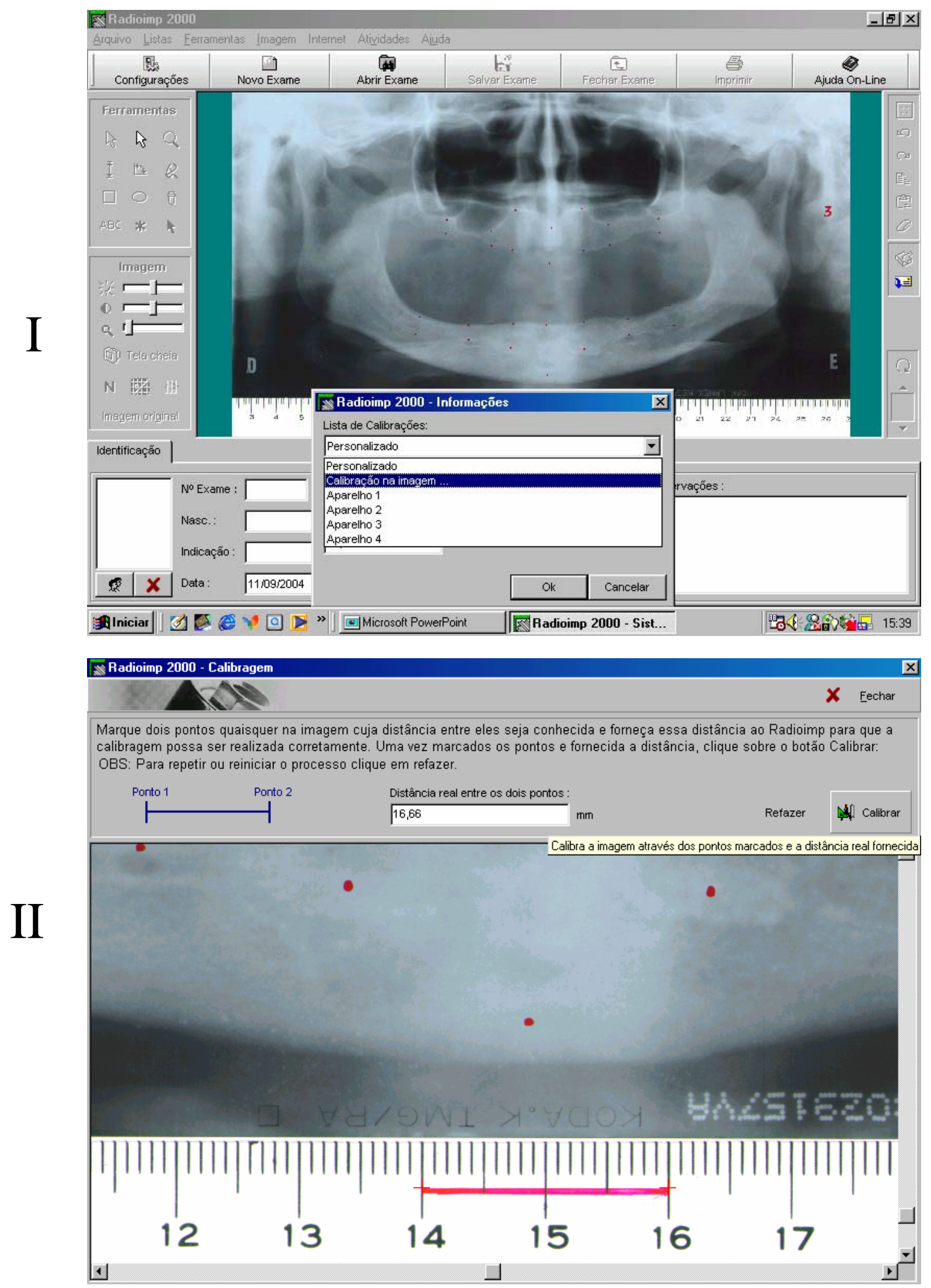

FIGURA 10 - Demonstração na tela do monitor com imagens dos passos seguidos para calibração da imagem e obtenção das medidas do grupo 3 (radioimp/calibração referencial/escaner). I) seleção do tipo de calibração, II) calibração da imagem pelo método referencial 


\subsection{4- GRUPO 4}

- Radioimp / Calibração referencial (mm) / Câmera

A calibração da magnificação das imagens da câmera digital FinePix foi obtida pelo sistema de calibração referencial, fornecida pelo programa de imagem Radioimp. Os passos para a calibração, as mensurações e arquivamento dos dados foram os mesmos descritos para no grupo 3.

\subsection{5- GRUPO 5}

- Planimp / Calibração por resolução (dpi) / Escaner

A calibração da magnificação das imagens capturadas pelo escaner HP, foi obtida por meio da resolução do escaner (300 dpi), denominada sistema de calibração por resolução. Para a calibração da magnificação da imagem e obtenção das mensurações, foram realizados os seguintes passos:

\section{a) Abertura do programa}

Para a abertura do programa clicou-se duas vezes no ícone indicativo, aparecendo a tela de acesso ao Planimp. Foi dado ok e apareceu um menu de opções na tela principal. Clicou-se na opção pacientes para proceder com o cadastro dos dados do paciente (Figura 11 I).

\section{b) Identificação dos dados do paciente/exame}

$\mathrm{Na}$ tela cadastro clicou-se na opção novo para iniciar o cadastro de um novo exame. Para isso, alguns campos relativos a identificação do paciente foram preenchidos com informações como: código (do exame), nome, telefone, atendimento (data), iniciais, 
nascimento, sexo, raça, indicação, previsão de entrega (Figura 11 I). Terminada essa etapa clicou-se no botão salvar e, em seguida, na opção adquirir imagens, para realizar a busca da imagem.

\section{c) Busca da imagem}

Para adquirir as imagens, na tela imagens digitais selecionamos a opção para radiografia panorâmica (representada por um desenho relativo à panorâmica, localizado do lado esquerdo da tela) e clicou-se no botão abrir. Após esse passo, buscou-se a pasta na qual estavam arquivadas as imagens digitalizadas, selecionando-se a radiografia desejada (Figura 11 II).

\section{d) Seleção do tipo de calibração}

Com a imagem da radiografia já aberta na tela, clicou-se no botão calibragem, selecionando a opção calibrar scanner, (Figura 12 III) que corresponde ao sistema de "calibração por resolução".

e) Calibração da imagem pelo sistema de calibração por resolução (dpi)

Na janela calibrar tamanho da imagem, o campo dpi foi preenchido com o valor 300 dpi (relativo à resolução com a qual as imagens foram escaneadas pelo escaner HP) (Figura 12 IV). Em seguida clicou-se no botão salvar. A partir desse momento as medidas foram calibradas automaticamente. Fechando a tela imagens digitais panorâmicas na tela cadastro de pacientes, clicou-se em análise para iniciar as mensurações.

\section{f) Ampliação da imagem}

Com a tela análise aberta, na opção zoom clicou-se em 200\% de ampliação da imagem. 

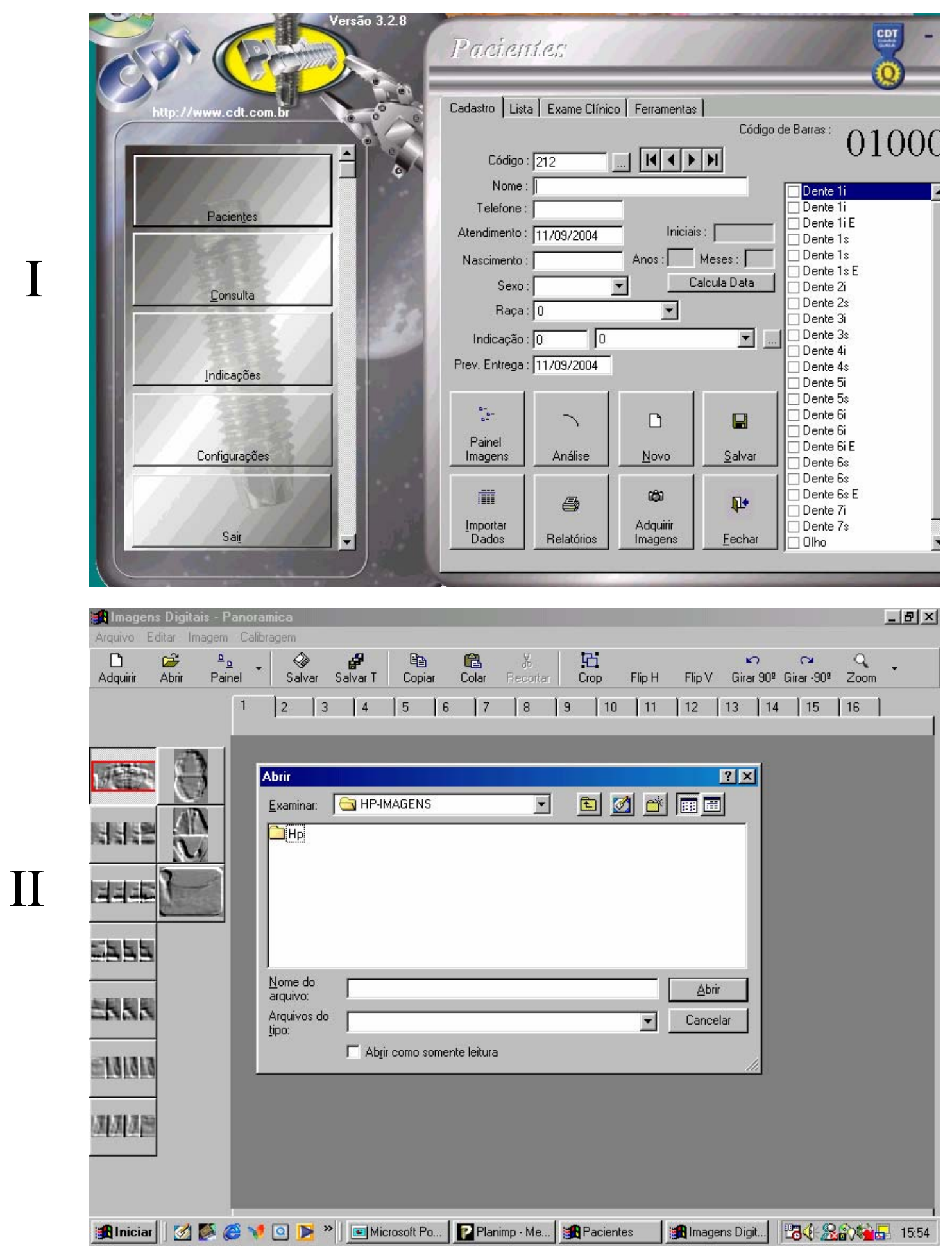

FIGURA 11 - Demonstração na tela do monitor com imagens dos passos seguidos para calibração da imagem e obtenção das medidas do grupo 5 (Planimp/calibração por resolução/escaner). I) abertura do programa e identificação do paciente, II) busca da imagem 

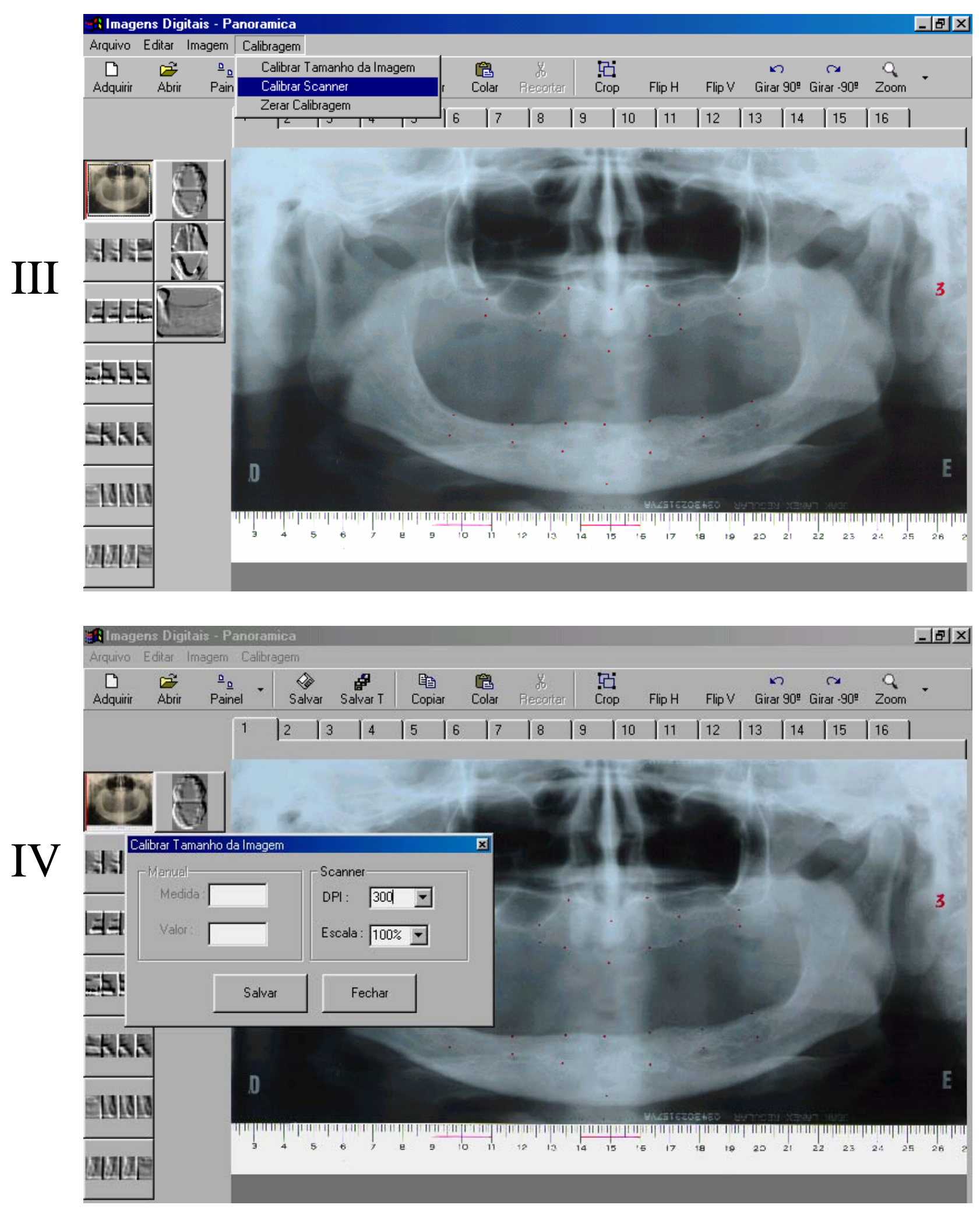

FIGURA 12 - Demonstração na tela do monitor com imagens dos passos seguidos para calibração da imagem e obtenção das medidas do grupo 5 (Planimp/calibração por resolução/escaner). III) seleção do tipo de calibração, IV) calibração por resolução 


\section{g) Mensuração}

$\mathrm{Na}$ janela propriedades (Figura $13 \mathrm{~V}$ ) clicou-se na opção medidas e selecionou-se o aparelho panorâmico que foi utilizado na obtenção das radiografias, a fim de ser deduzido seu índice de magnificação (Rotograph: índice de magnificação de 20\%). Finalmente, partiu-se para a mensuração das distâncias pré-determinadas. Com o cursor no início da medida (parte superior e média do ponto de referência superior), arrastou-se com o botão do mouse pressionado, até o final da medida (parte inferior e média do ponto de referência inferior). O resultado da mensuração (em mm) apareceu no campo identificado como medida (Figura $13 \mathrm{~V}$ ). Prosseguiu-se da mesma maneira descrita acima com as mensurações de todas as distâncias pré-determinadas, desde a distância 1 até a 14. Após a obtenção das 14 medidas clicou-se na opção salvar (Figura $13 \mathrm{VI})$.

\section{h) Impressão do relatório}

Para imprimir o relatório contendo os valores das mensurações obtidas pelo programa Planimp, clicou-se na opção imprimir, ainda na tela análise. Assim, apareceu na tela o relatório com as medidas e várias opções de configurações para laudo radiográfico. Com as configurações desejadas, finalmente, clicou-se no botão identificado com o desenho de uma impressora.

\section{i) Preenchimento de planilhas para estatística}

Os valores das mensurações foram transcritos para o programa Excel 97 para posterior tratamento estatístico. 


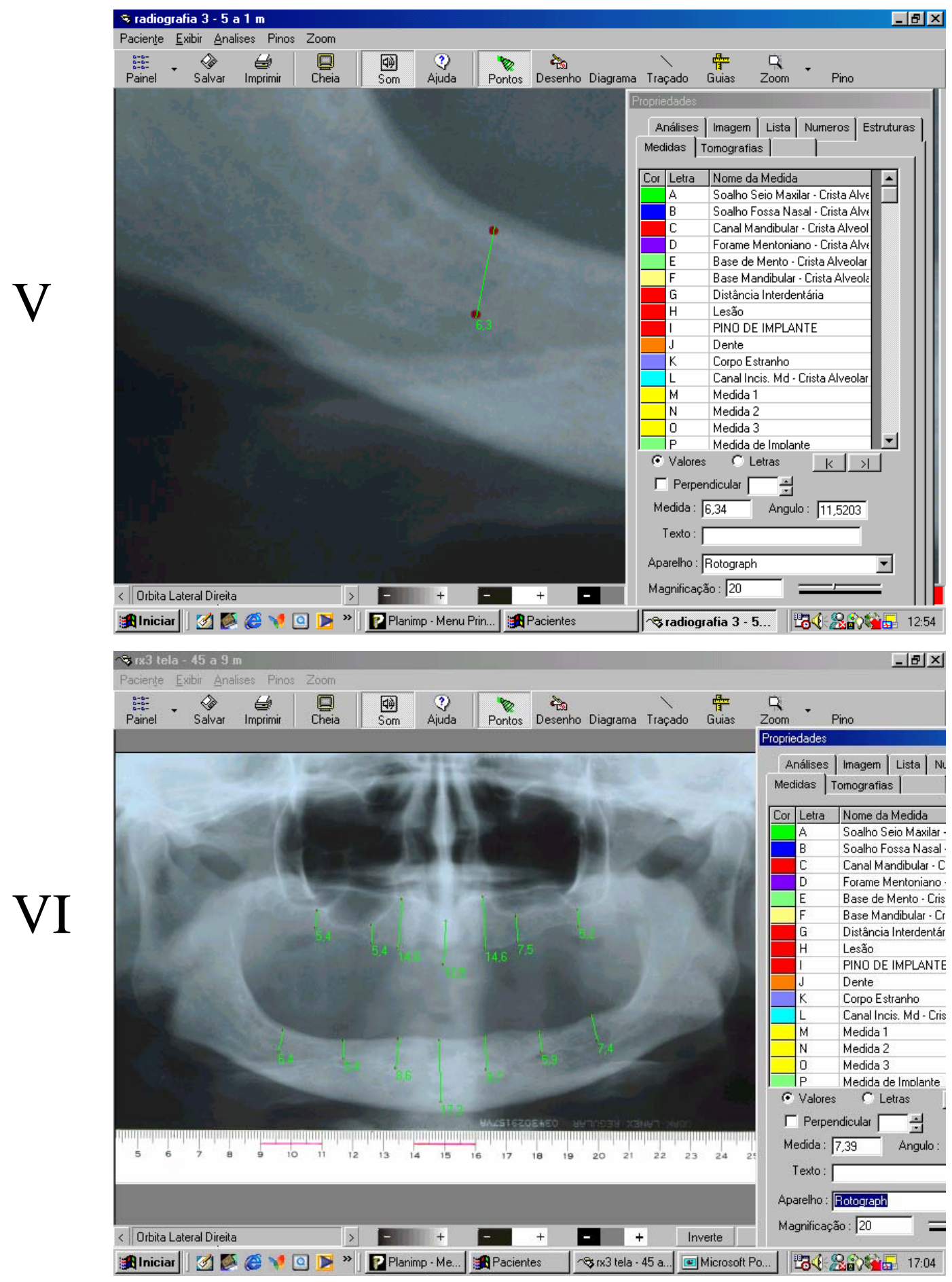

FIGURA 13 - Demonstração na tela do monitor com imagens dos passos seguidos para calibração da imagem e obtenção das medidas do grupo 5 (Planimp/calibração por resolução/escaner). V) medição das distâncias anatômicas, VI) obtenção das 14 medidas 


\title{
4.4.6- GRUPO 6
}

\section{- Planimp / Calibração referencial (mm) / Escaner}

\begin{abstract}
A calibração da magnificação das imagens do escaner HP foi obtida por meio do sistema de calibração referencial fornecida pelo programa de imagem Planimp (a calibração da magnificação da imagem é obtida por meio de uma distância referencial pré-estabelecida). Para a obtenção das mensurações foram realizados os seguintes passos:
\end{abstract}

\section{a) Abertura do programa}

Para a abertura do programa clicou-se duas vezes no respectivo ícone indicativo, aparecendo a tela acesso ao Planimp, e dando $o k$, apareceu um menu de opções na tela principal. Clicou-se na opção pacientes para realizar o cadastro dos dados do paciente (Figura 11 I).

\section{b) Identificação dos dados do paciente/exame}

$\mathrm{Na}$ tela cadastro, clicou-se na opção novo para iniciar o cadastro de um novo exame. Para isso, alguns campos relativos a identificação do paciente foram preenchidos com informações tais como: código (do exame), nome, telefone, atendimento (data), iniciais, nascimento, sexo, raça, indicação, previsão de entrega (Figura 11 I). Terminada essa etapa, clicou-se no botão salvar e, em seguida, na opção adquirir imagens para realizar a busca da imagem.

\section{c) Busca da imagem}

Para adquirir as imagens, na tela imagens digitais selecionouse a opção para radiografia panorâmica (representada por um desenho relativo à panorâmica, localizado do lado esquerdo da tela), clicou-se no botão abrir (Figura 11 II). Após esse passo, buscou-se a pasta na qual 
estavam arquivadas as imagens digitalizadas, selecionando-se a radiografia desejada (Figura 11 II).

\section{d) Seleção do tipo de calibração}

Com a imagem da radiografia já aberta na tela, clicou-se no botão calibragem e selecionou-se a opção calibrar tamanho da imagem, que corresponde ao sistema de calibração referencial (Figura 14 I).

\section{e) Calibração da imagem pelo sistema referencial}

Para calibração da imagem pelo sistema referencial, na imagem da régua, o cursor do mouse foi colocado no primeiro ponto prédeterminado (equivalente ao número 14 da régua) e arrastou-se, com o botão do mouse pressionado até o segundo ponto pré-determinado (equivalente ao número 16 da régua), resultando uma distância de $20 \mathrm{~mm}$ na imagem radiográfica, que foi registrada no campo valor, da tela tamanho da imagem (Figura 14 II). O índice de magnificação do aparelho Rotograph (20\%) já foi deduzido no momento da seleção do aparelho (página 73). Em seguida, procedeu-se a calibração propriamente dita, clicando-se no botão salvar. A partir deste momento as medidas foram calibradas automaticamente. Fechou-se a janela imagens digitais panorâmica e na tela cadastro de pacientes, clicou-se em análise para a ampliação da imagem.

Os procedimentos relacionados abaixo, foram os mesmos descritos para o Grupo 5:
f) Ampliação da imagem
g) Mensuração
h) Impressão do relatório
i) Preenchimento de planilhas para estatística 

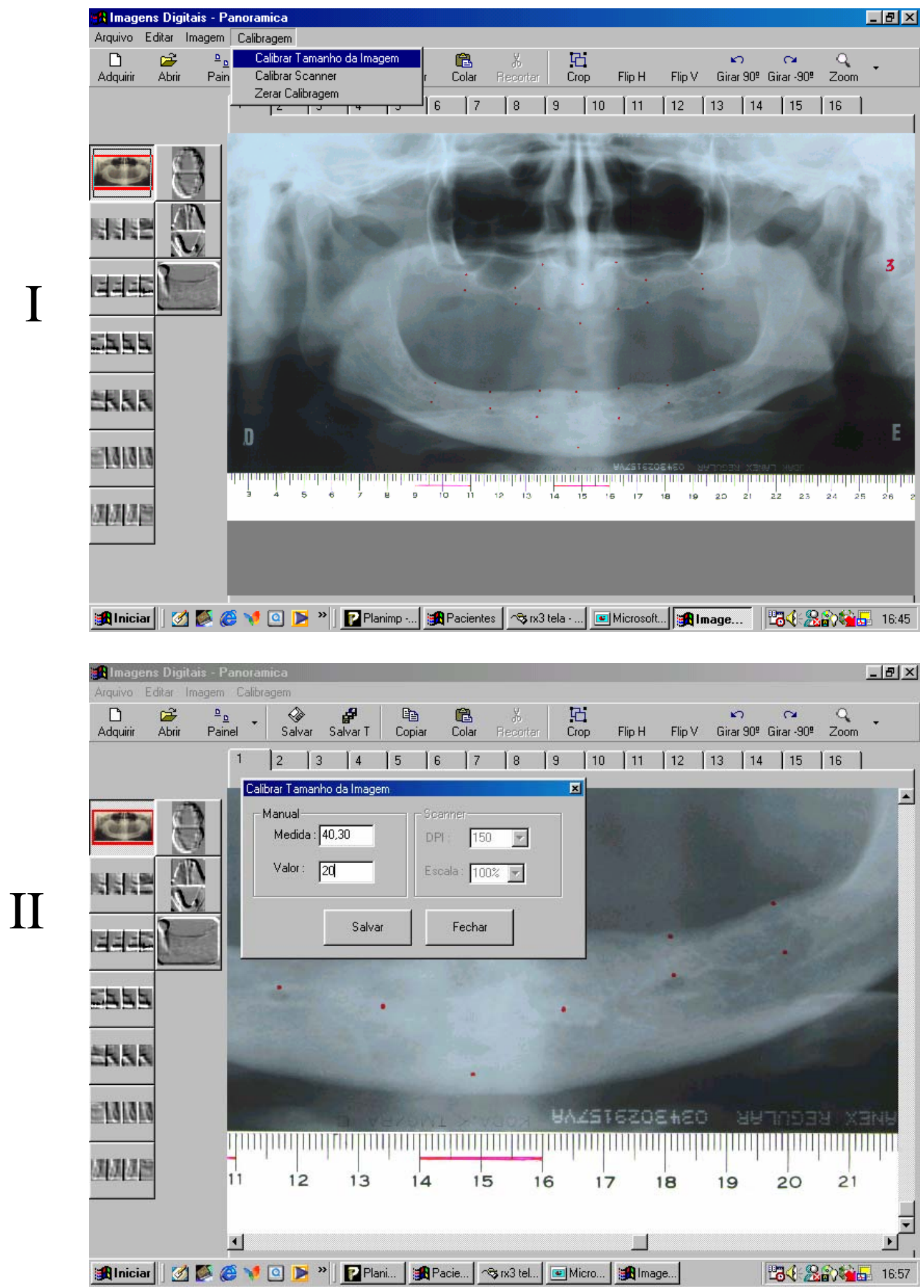

FIGURA 14 - Demonstração na tela do monitor com imagens dos passos seguidos para calibração da imagem e obtenção das medidas do grupo 6 (Planimp/calibração referencial/escaner). I) seleção do tipo de calibração, II) calibração referencial 


\title{
4.4.7- GRUPO 7 \\ - Planimp / Calibração referencial (mm) / Câmera
}

\begin{abstract}
A calibração da magnificação das imagens capturadas pela câmera digital, foi obtida pelo sistema de calibração referencial fornecido pelo programa de imagem Planimp. Os passos para a calibração, as mensurações e arquivamento dos dados foram os mesmos descritos para o grupo 6.
\end{abstract}

\section{5- Análise estatística}

Os dados obtidos dos sete grupos foram analisados estatisticamente por meio do teste "análise de variância a um critério para medidas repetidas", com $\mathrm{p}<0,05$ para a comparação destes. Portanto, a análise estatística foi realizada com base nas medidas das 14 distâncias anatômicas, nas 50 radiografias dos sete grupos, perfazendo um total de 4.900 medidas. A referida análise foi efetuada pela Disciplina de Bioestatística da FOB-USP.

\section{6- Teste piloto}

Este teste piloto foi realizado com o intuito de se estabelecer as distâncias ideais entre a lente da câmera fotográfica digital e as radiografias panorâmicas, de maneira que não houvesse distoções das imagens obtidas e prejuízo nos resultados alcançados com este equipamento. 
Uma régua milimetrada foi submetida à digitalização utilizando-se a câmera fotográfica digital FinePix S602 ZOOM, variando as distâncias lente-filme. A sua largura foi previamente aferida por meio de um paquímetro digital. Utilizou-se o modo automático, que regula a abertura e a velocidade automaticamente, de maneira a obtermos uma padronização para todas as imagens. As distâncias lente-filme testadas foram:

- 20 cm sem zoom óptico;

- 30 cm sem zoom óptico;

- 30 cm com zoom óptico;

- 35 cm sem zoom óptico;

- 35 cm com zoom óptico;

- 40 cm com zoom óptico;

- 45 cm com zoom óptico;

- 50 cm com zoom óptico;

- 55 cm com zoom óptico;

- 60 cm com zoom óptico;

- 70 cm com zoom óptico.

As imagens capturadas foram salvas no formato JPEG (Joint Photographic Experts Group) e inseridas no programa Planimp para avaliação de eventuais distorções. Utilizou-se a seguinte seqüência: na tela análise do referido programa, com o auxílio da ferramenta guias foram plotados pontos de referência para medições da largura da régua em vários locais. Os pontos foram plotados de forma paralela, sendo o primeiro na parte superior da régua e o segundo na parte inferior. Eles foram unidos colocando-se o cursor no ponto superior (início da medida), arrastando, com o botão do mouse pressionado, até o ponto inferior da régua, soltando 
em seguida. Dessa forma obtivemos as medidas da largura da régua em vários locais e comparadas entre si para verificação da presença de eventuais distorções (Figura 15 I e II).

Os resultados mostraram que as distâncias de $20 \mathrm{~cm}$ sem zoom até $45 \mathrm{~cm}$ com zoom, apresentaram variações nos valores da largura da régua. Diante disso, escolhemos a distância de $50 \mathrm{~cm}$ com zoom, para ser utilizada nesta pesquisa (Figura 15 I e II). 

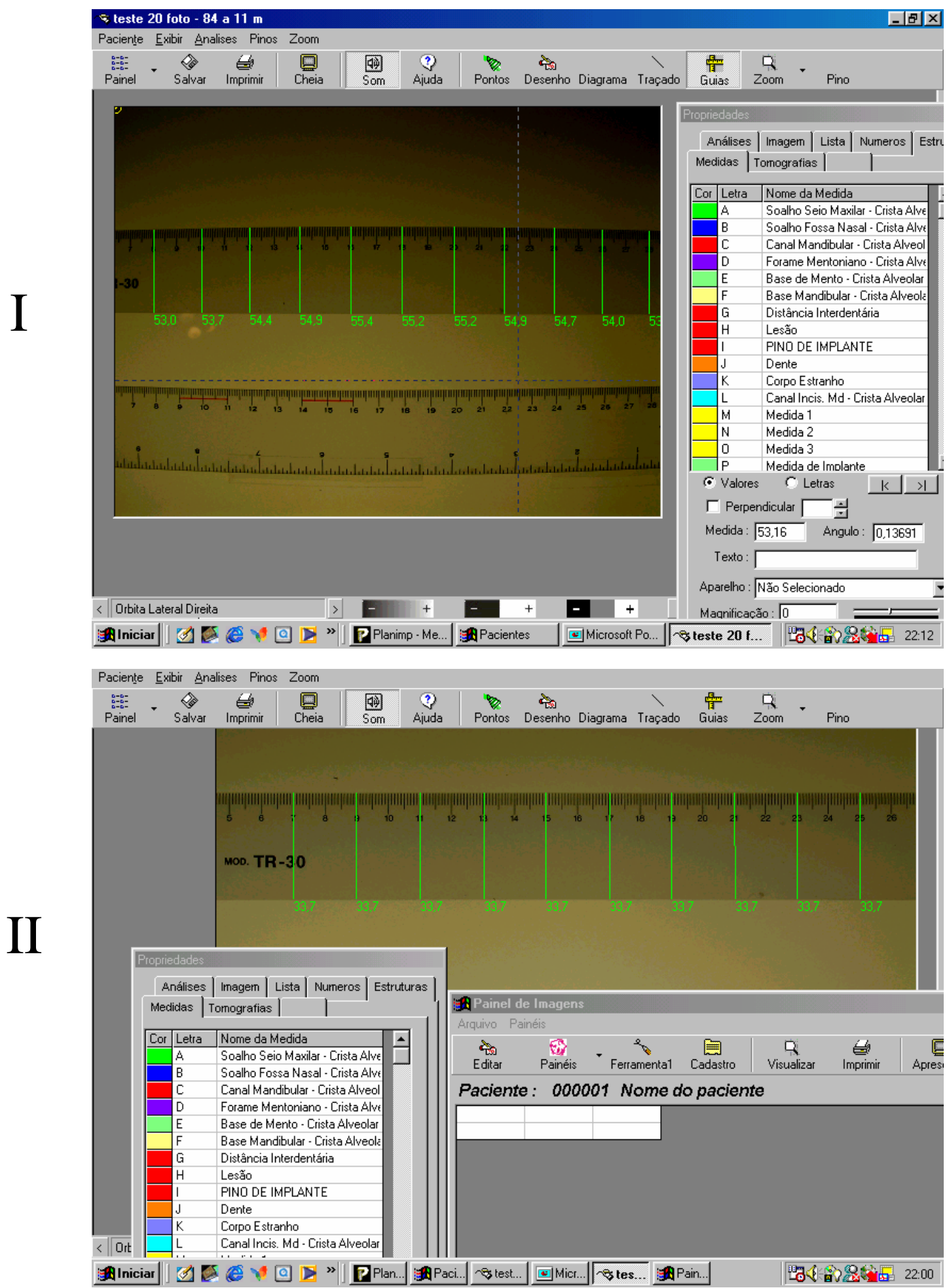

FIGURA 15 - Teste piloto: exemplos de mensuração da espessura da imagem da régua digitalizada. I) distância lente-filme de $20 \mathrm{~cm}$ sem zoom, II) distância lente/filme de $50 \mathrm{~cm}$ com zoom 
5- RESULTADOS 


\section{5- RESULTADOS}

Para facilitar o entendimento, rememoramos as "distâncias anatômicas preconizadas" e os "grupos experimentais".

Distâncias anatômicas preconizadas:

- D1-MSD: Distância 1, área de Molar Superior Direito

- D2-PMSD: Distância 2, área de Pré-Molar Superior Direito

- D3-CSD: Distância 3, área de Canino Superior Direito

- D4-ICS: Distância 4, área de Incisivo Central Superior

- D5-CSE: Distância 5, área de Canino Superior Esquerdo

- D6-PMSE: Distância 6, área de Pré-Molar Superior Esquerdo

- D7-MSE: Distância 7, área de Molar Superior Esquerdo

- D8-MID: Distância 8, área de Molar Inferior Direito

- D9-PMID: Distância 9, área de Pré-Molar Inferior Direito

- D10-CID: Distância 10, área de Caninor Inferior Direito

- D11-ICI: Distância 11, área de Incisivo Central Inferior

- D12-CIE: Distância 12, área de Canino Inferior Esquerdo

- D13-PMIE: Distância 13, área de Pré-Molar Inferior Esquerdo

- D14-MIE: Distância 14, área de Molar Inferior Esquerdo 
Grupos experimentais:

1- Paquímetro - Grupo controle constituído pelas medidas obtidas pelo método manual por meio do paquímetro digital.

2- Radioimp-resolução-escaner - Grupo constituído pelas medidas obtidas pelo programa Radioimp em imagens digitalizadas por meio do escaner e calibradas pelo sistema por resolução.

3- Radioimp-referencial-escaner - Grupo constituído pelas medidas obtidas pelo programa Radioimp em imagens digitalizadas por meio do escaner e calibradas pelo sistema referencial.

4- Radioimp-referencial-câmera - Grupo constituído pelas medidas obtidas pelo programa Radioimp em imagens digitalizadas por meio da câmera digital e calibradas pelo sistema referencial.

5- Planimp-resolução-escaner - Grupo constituído pelas medidas obtidas pelo programa Planimp em imagens digitalizadas poe meio do escaner e calibradas pelo sistema por resolução.

6- Planimp-referencial-escaner - Grupo constituído pelas medidas obtidas pelo programa Planimp em imagens digitalizadas por meio do escaner e calibradas pelo sistema referencial.

7- Planimp-referencial-câmera - Grupo constituído pelas medidas obtidas pelo programa Planimp em imagens digitalizadas por meio da câmera digital e calibradas pelo sistema referencial.

A apresentação dos resultados das médias das medidas das distâncias anatômicas preconizadas, obtidas pelos sete grupos experimentais, encontra-se organizada em tabelas e gráficos a seguir: 
A Tabela 1 exibe os valores das médias, desvios padrão e p referentes ao teste de análise de variância a um critério para medidas repetidas, com nível de significância a 5\%, das medidas obtidas pelos sete grupos (1- Paquímetro, 2- Radioimp-resolução-escaner, 3- Radioimpreferencial-escaner, 4- Radioimp-referencial-câmera, 5- Planimp-resoluçãoescaner, 6-Planimp-referencial-escaner, 7-Planimp-referencial-câmera), para a distância D1-MSD (região de Molar Superior Direito).

O gráfico da Figura 16 mostra um comparativo dos valores das médias das medidas obtidas pelos sete grupos para a distância D1-MSD (região de Molar Superior Direito). 
TABELA 1 - Valores (em mm) das médias, desvios padrão e p referentes ao teste de análise de variância, com nível de significância a 5\%, das medidas obtidas pelos sete grupos, para a distância D1-MSD (Molar Superior Direito)

\begin{tabular}{l|c|c}
\hline \multirow{2}{*}{ Grupos } & \multicolumn{2}{c}{$\begin{array}{c}\text { Distância anatômica } \\
\text { D1 - Molar Superior } \\
\text { Direito }\end{array}$} \\
\cline { 2 - 3 } 1- Paquímetro & Média & DP \\
\hline 2- Radioimp-resolução-escaner & 6,972 & 2,320 \\
\hline 3- Radioimp-referencial-escaner & 6,925 & 2,329 \\
\hline 4- Radioimp-referencial-câmera & 6,922 & 2,328 \\
\hline 5- Planimp-resolução-escaner & 6,926 & 2,325 \\
\hline 6- Planimp-referencial-escaner & 6,925 & 2,327 \\
\hline 7- Planimp-referencial-câmera & 6,934 & 2,329 \\
\hline $\mathbf{p}$ & \multicolumn{2}{|c}{0,698677} \\
\hline
\end{tabular}

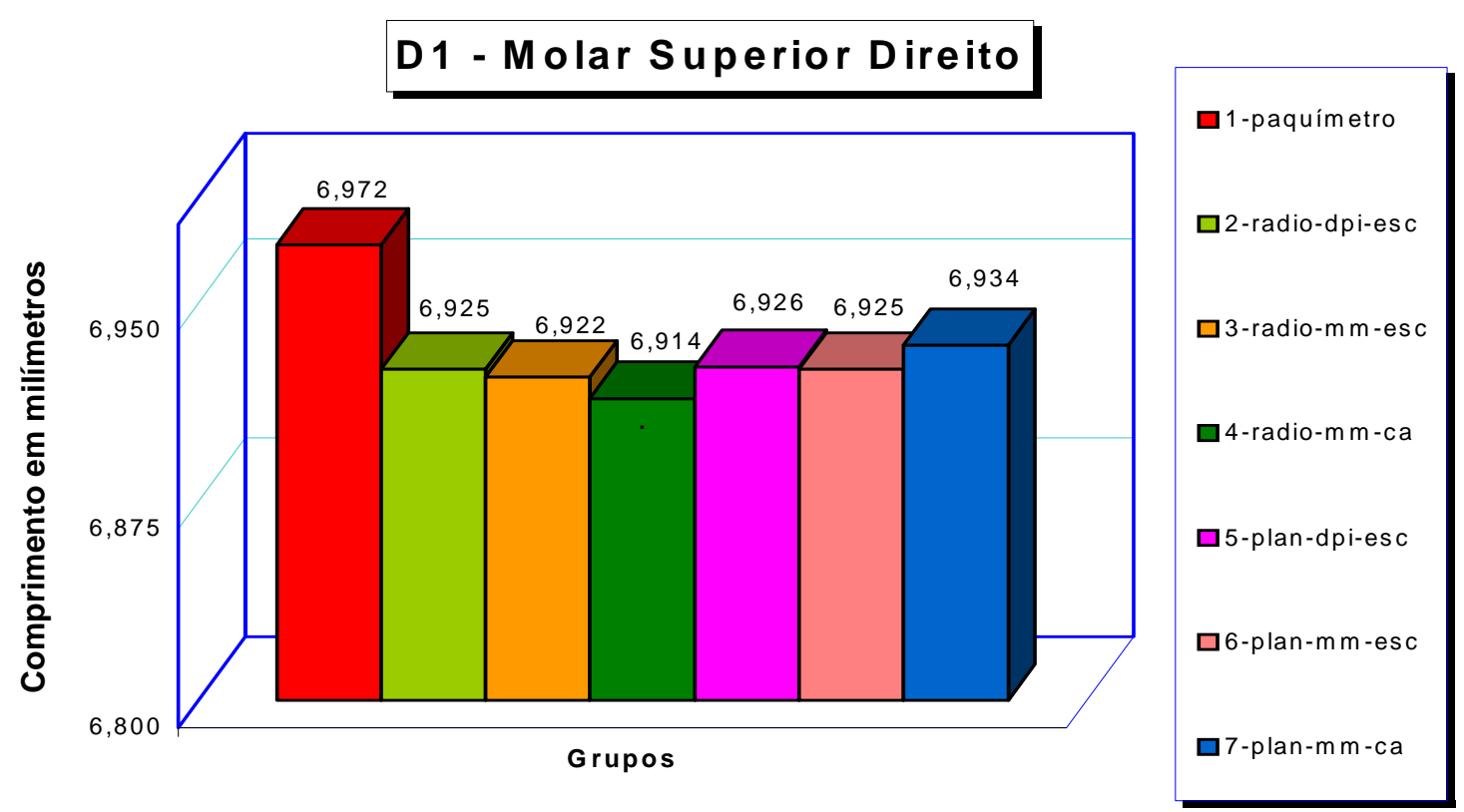

FIGURA 16 - Comparativo dos valores (em mm) das médias das medidas da distância D1-MSD (Molar Superior Direito) obtidas pelos sete grupos. 
A Tabela 2 mostra os valores das médias, desvios padrão e p referentes ao teste de análise de variância a um critério para medidas repetidas, com nível de significância a 5\%, das medidas obtidas pelos sete grupos (1- Paquímetro, 2- Radioimp-resolução-escaner, 3- Radioimpreferencial-escaner, 4- Radioimp-referencial-câmera, 5- Planimp-resoluçãoescaner, 6-Planimp-referencial-escaner, 7-Planimp-referencial-câmera), para a distância D2-PMSD (região de Pré-Molar Superior Direito).

O gráfico da Figura 17 mostra um comparativo dos valores das médias das medidas obtidas pelos sete grupos para a distância D2-PMSD (região de Pré-Molar Superior Direito). 
TABELA 2 - Valores (em mm) das médias, desvios padrão e p referentes ao teste de análise de variância, com nível de significância a 5\%, das medidas obtidas pelos sete grupos, para a distância D2-PMSD (Pré-Molar Superior Direito)

\begin{tabular}{l|c|c}
\hline \multirow{2}{*}{ Grupos } & \multicolumn{2}{c}{$\begin{array}{c}\text { Distância anatômica } \\
\text { D2 - Pré-Molar } \\
\text { Superior Direito }\end{array}$} \\
\cline { 2 - 3 } & Média & DP \\
\hline 1- Paquímetro & 9,577 & 2,493 \\
\hline 2- Radioimp-resolução-escaner & 9,553 & 2,526 \\
\hline 3- Radioimp-referencial-escaner & 9,590 & 2,495 \\
\hline 4- Radioimp-referencial-câmera & 9,580 & 2,494 \\
\hline 5- Planimp-resolução-escaner & 9,553 & 2,526 \\
\hline 6- Planimp-referencial-escaner & 9,591 & 2,495 \\
\hline 7- Planimp-referencial-câmera & 9,580 & 2,495 \\
\hline $\mathbf{p}$ & \multicolumn{2}{|c}{0,681037} \\
\hline
\end{tabular}

D 2 - Pré-M olar Superior Direito

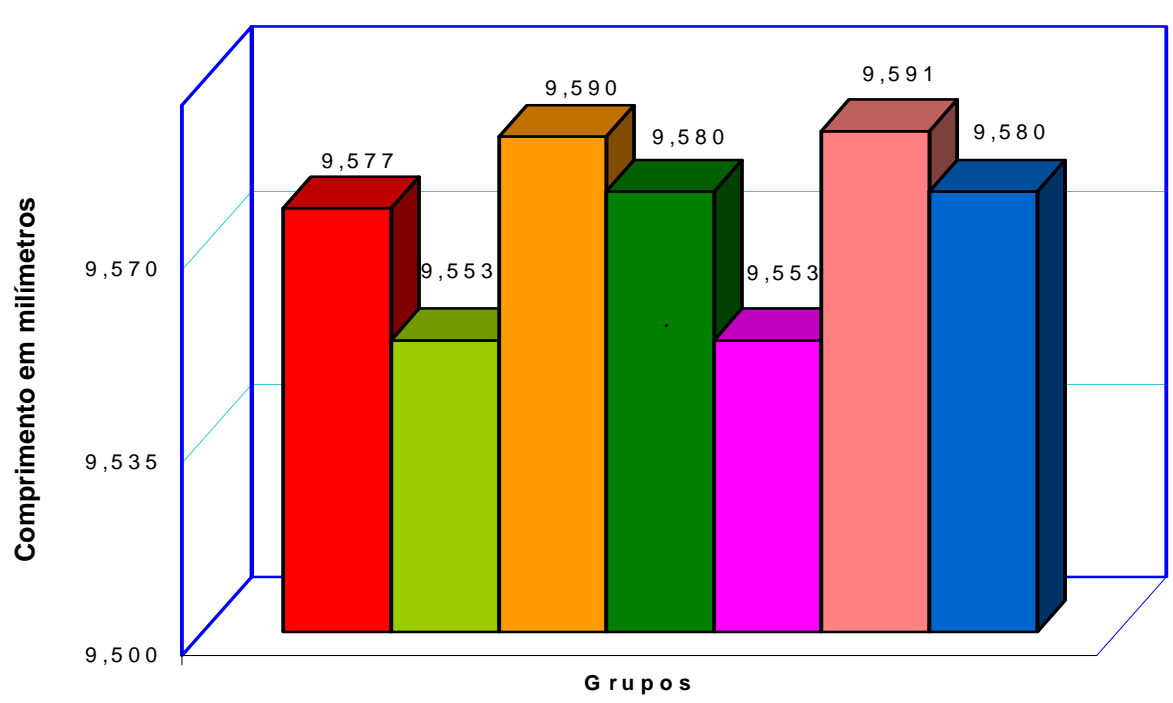

$\square 1$ - paquím etro

$\square 2$-radio-dpi-esc

口3-radio-m m - esc

口4-radio-m m - c a

口 - plan-dpi-esc

口6-plan-m m -e sc

口 7 - plan-m m-ca

FIGURA 17 - Comparativo das médias (em mm) das medidas da distância D2-PMSD (Pré-Molar Superior Direito) obtidas pelos sete grupos 
A Tabela 3 mostra os valores das médias, desvios padrão e p referentes ao teste de análise de variância a um critério para medidas repetidas, com nível de significância a 5\%, das medidas obtidas pelos sete grupos (1- Paquímetro, 2- Radioimp-resolução-escaner, 3- Radioimpreferencial-escaner, 4- Radioimp-referencial-câmera, 5- Planimp-resoluçãoescaner, 6-Planimp-referencial-escaner, 7-Planimp-referencial-câmera), para a distância D3-CSD (região de Canino Superior Direito).

O gráfico da Figura 18 mostra um comparativo dos valores das médias das medidas obtidas pelos sete grupos para a distância D3-CSD (região de Canino Superior Direito). 
TABELA 3 - Valores (em mm) das médias, desvios padrão e p referentes ao teste de análise de variância, com nível de significância a 5\%, das medidas obtidas pelos sete grupos, para a distância D3-CSD (Canino Superior Direito)

\begin{tabular}{l|c|c}
\hline \multirow{2}{*}{ Grupos } & \multicolumn{2}{c}{$\begin{array}{c}\text { Distância anatômica } \\
\text { D3 - Canino Superior } \\
\text { Direito }\end{array}$} \\
\cline { 2 - 3 } & Média & DP \\
\hline 1- Paquímetro & 12,400 & 3,017 \\
\hline 2- Radioimp-resolução-escaner & 12,421 & 3,043 \\
\hline 3- Radioimp-referencial-escaner & 12,400 & 3,017 \\
\hline 4- Radioimp-referencial-câmera & 12,419 & 3,040 \\
\hline 5- Planimp-resolução-escaner & 12,421 & 3,042 \\
\hline 6- Planimp-referencial-escaner & 12,420 & 3,043 \\
\hline 7- Planimp-referencial-câmera & 12,391 & 3,017 \\
\hline $\mathbf{p}$ & \multicolumn{2}{|c}{0,697551} \\
\hline
\end{tabular}

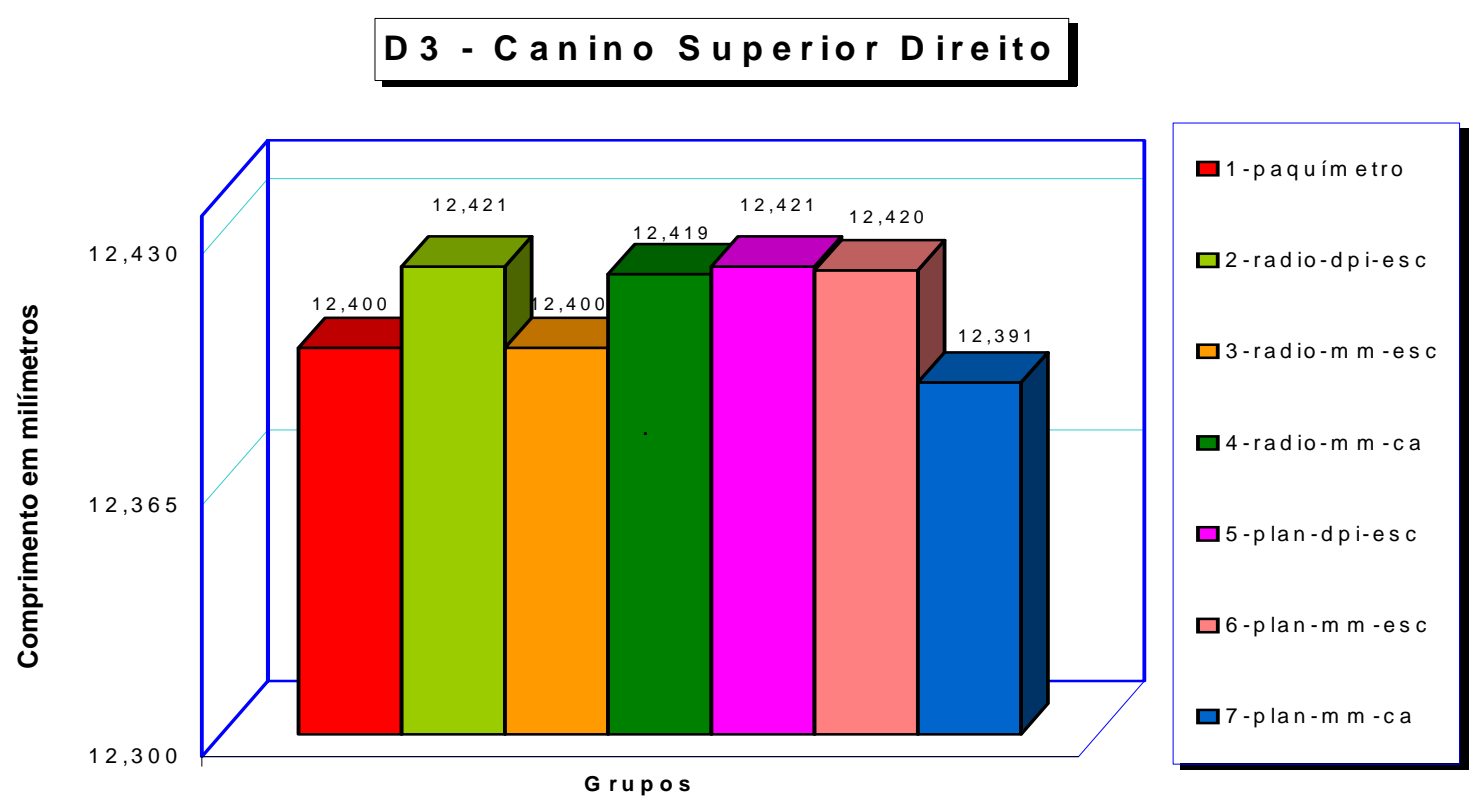

FIGURA 18 - Comparativo das médias (em mm) das medidas da distância D3-CSD (Canino Superior Direito) obtidas pelos sete grupos 
A Tabela 4 mostra os valores das médias, desvios padrão e p referentes ao teste de análise de variância a um critério para medidas repetidas, com nível de significância a 5\%, das medidas obtidas pelos sete grupos (1- Paquímetro, 2- Radioimp-resolução-escaner, 3- Radioimpreferencial-escaner, 4- Radioimp-referencial-câmera, 5- Planimp-resoluçãoescaner, 6-Planimp-referencial-escaner， 7-Planimp-referencial-câmera), para a distância D4-ICS (região de Incisivo Central Superior).

O gráfico da Figura 19 mostra um comparativo dos valores das médias das medidas obtidas pelos sete grupos para a distância D4-ICS (região de Incisivo Central Superior). 
TABELA 4 - Valores (em mm) das médias, desvios padrão e p referentes ao teste de análise de variância, com nível de significância a 5\%, das medidas obtidas pelos sete grupos, para a distância D4-ICS (Incisivo Central Superior)

\begin{tabular}{l|c|c}
\hline \multirow{2}{*}{ Grupos } & \multicolumn{2}{c}{$\begin{array}{c}\text { Distância anatômica } \\
\text { D4 - Incisivo Central } \\
\text { Superior }\end{array}$} \\
\cline { 2 - 3 } & Média & DP \\
\hline 1- Paquímetro & 11,977 & 2,605 \\
\hline 2- Radioimp-resolução-escaner & 11,987 & 2,625 \\
\hline 3- Radioimp-referencial-escaner & 11,984 & 2,623 \\
\hline 4- Radioimp-referencial-câmera & 11,979 & 2,605 \\
\hline 5- Planimp-resolução-escaner & 11,981 & 2,621 \\
\hline 6- Planimp-referencial-escaner & 11,986 & 2,624 \\
\hline 7- Planimp-referencial-câmera & 11,978 & 2,605 \\
\hline $\mathbf{p}$ & \multicolumn{2}{|c}{0,583723} \\
\hline
\end{tabular}

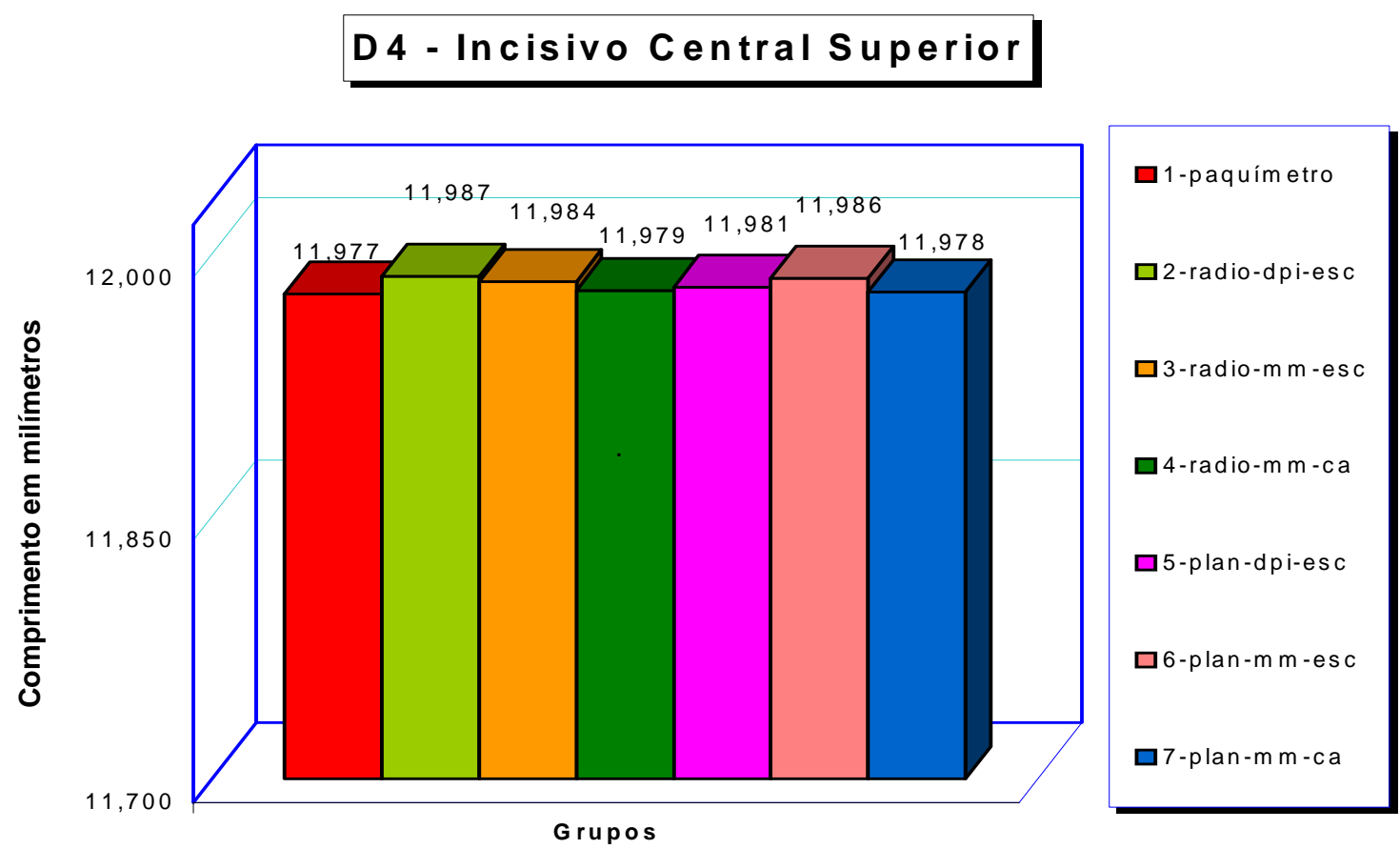

FIGURA 19 - Comparativo das médias (em mm) das medidas da distância D4-ICS (Incisivo Central Superior) obtidas pelos sete grupos 
A Tabela 5 mostra os valores das médias, desvios padrão e p referentes ao teste de análise de variância a um critério para medidas repetidas, com nível de significância a 5\%, das medidas obtidas pelos sete grupos (1- Paquímetro, 2- Radioimp-resolução-escaner, 3- Radioimpreferencial-escaner, 4- Radioimp-referencial-câmera, 5- Planimp-resoluçãoescaner, 6-Planimp-referencial-escaner, 7-Planimp-referencial-câmera), para a distância D5-CSE (região de Canino Superior Esquerdo).

O gráfico da Figura 20 mostra um comparativo dos valores das médias das medidas obtidas pelos sete grupos para a distância D5-CSE (região de Canino Superior Esquerdo). 
TABELA 5 - Valores (em mm) das médias, desvios padrão e p referentes ao teste de análise de variância, com nível de significância a 5\%, das medidas obtidas pelos sete grupos, para a distância D5-CSE (Canino Superior Esquerdo)

\begin{tabular}{l|c|c}
\hline \multirow{2}{*}{ Grupos } & \multicolumn{2}{c}{$\begin{array}{c}\text { Distância anatômica } \\
\text { D5 - Canino Superior } \\
\text { Esquerdo }\end{array}$} \\
\cline { 2 - 3 } & $\begin{array}{c}\text { Média } \\
\text { DP }\end{array}$ \\
\hline 1- Paquímetro & 12,387 & 2,608 \\
\hline 2- Radioimp-resolução-escaner & 12,416 & 2,604 \\
\hline 3- Radioimp-referencial-escaner & 12,473 & 2,068 \\
\hline 4- Radioimp-referencial-câmera & 12,403 & 2,604 \\
\hline 5- Planimp-resolução-escaner & 12,416 & 2,604 \\
\hline 6- Planimp-referencial-escaner & 12,415 & 2,604 \\
\hline 7- Planimp-referencial-câmera & 12,404 & 2,605 \\
\hline $\mathbf{p}$ & \multicolumn{2}{|c}{0,371841} \\
\hline
\end{tabular}

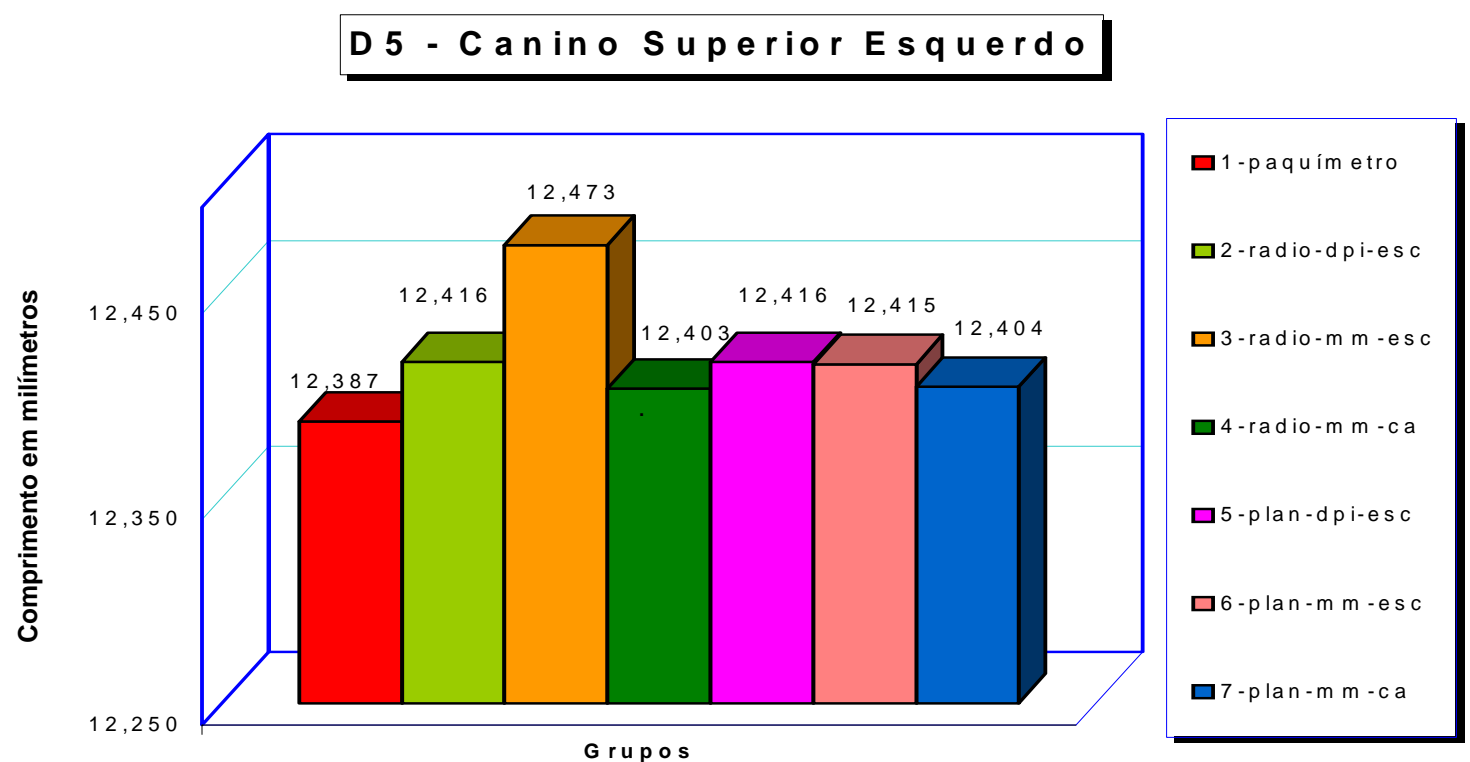

FIGURA 20 - Comparativo das médias (em mm) das medidas da distância D5-CSE (Canino Superior Esquerdo) obtidas pelos sete grupos 
A Tabela 6 mostra os valores das médias, desvios padrão e p referentes ao teste de análise de variância a um critério para medidas repetidas, com nível de significância a 5\%, das medidas obtidas pelos sete grupos (1- Paquímetro, 2- Radioimp-resolução-escaner, 3- Radioimpreferencial-escaner, 4- Radioimp-referencial-câmera, 5- Planimp-resoluçãoescaner, 6-Planimp-referencial-escaner, 7-Planimp-referencial-câmera), para a distância D6-PMSE (região de Pré-Molar Superior Esquerdo).

O gráfico da Figura 21 mostra um comparativo dos valores das médias das medidas obtidas pelos sete grupos para a distância D6-PMSE (região de Pré-Molar Superior Esquerdo). 
TABELA 6 - Valores (em mm) das médias, desvios padrão e p referentes ao teste de análise de variância, com nível de significância a 5\%, das medidas obtidas pelos sete grupos, para a distância D6-PMSE (Pré-Molar Superior Esquerdo)

\begin{tabular}{l|c|c}
\hline \multirow{2}{*}{ Grupos } & \multicolumn{2}{c}{$\begin{array}{c}\text { Distância anatômica } \\
\text { D6 - Pré-Molar } \\
\text { Superior Esquerdo }\end{array}$} \\
\cline { 2 - 3 } & Média & DP \\
\hline 1- Paquímetro & 9,415 & 2,499 \\
\hline 2- Radioimp-resolução-escaner & 9,488 & 2,586 \\
\hline 3- Radioimp-referencial-escaner & 9,486 & 2,584 \\
\hline 4- Radioimp-referencial-câmera & 9,418 & 2,5 \\
\hline 5- Planimp-resolução-escaner & 9,491 & 2,585 \\
\hline 6- Planimp-referencial-escaner & 9,489 & 2,584 \\
\hline 7- Planimp-referencial-câmera & 9,478 & 2,584 \\
\hline \multicolumn{2}{|c}{0,224114} \\
\hline
\end{tabular}

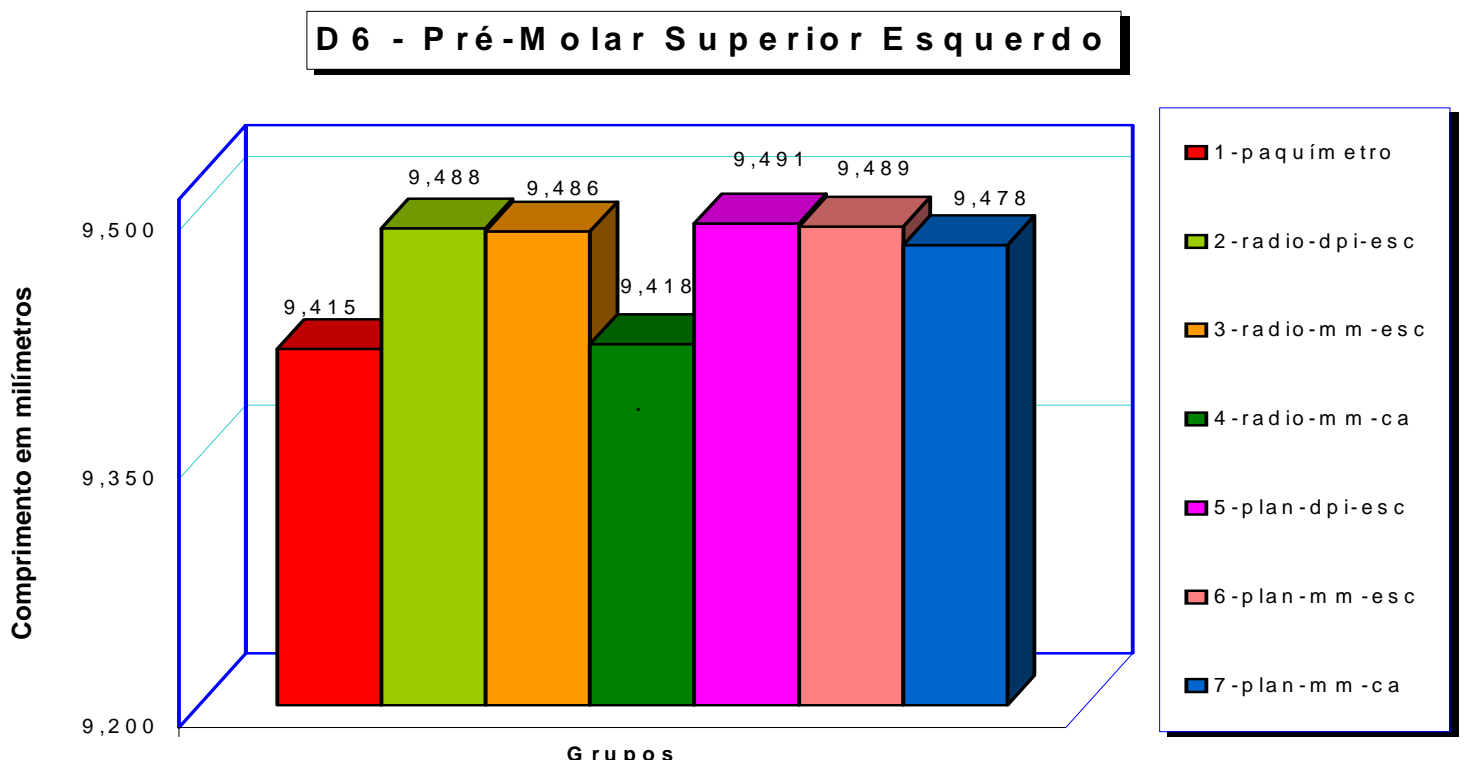

FIGURA 21 - Comparativo das médias (em mm) das medidas da distância D6-PMSE (Pré-Molar Superior Esquerdo) obtidas pelos sete grupos 
A Tabela 7 mostra os valores das médias, desvios padrão e p referentes ao teste de análise de variância a um critério para medidas repetidas, com nível de significância a 5\%, das medidas obtidas pelos sete grupos (1- Paquímetro, 2- Radioimp-resolução-escaner, 3- Radioimpreferencial-escaner, 4- Radioimp-referencial-câmera, 5- Planimp-resoluçãoescaner, 6-Planimp-referencial-escaner, 7-Planimp-referencial-câmera), para a distância D7-MSE (região de Molar Superior Esquerdo).

O gráfico da Figura 22 mostra um comparativo dos valores das médias das medidas obtidas pelos sete grupos para a distância D7-MSE (região de Molar Superior Esquerdo). 
TABELA 7 - Valores (em mm) das médias, desvios padrão e p referentes ao teste de análise de variância, com nível de significância a 5\%, das medidas obtidas pelos sete grupos, para a distância D7-MSE (Molar Superior Esquerdo)

\begin{tabular}{l|c|c}
\hline \multirow{2}{*}{ Grupos } & \multicolumn{2}{|c}{$\begin{array}{c}\text { Distância anatômica } \\
\text { D7 - Molar Superior } \\
\text { Esquerdo }\end{array}$} \\
\cline { 2 - 3 } & $\begin{array}{c}\text { Média } \\
\text { DP }\end{array}$ \\
\hline 1- Paquímetro & 6,279 & 1,736 \\
\hline 2- Radioimp-resolução-escaner & 6,289 & 1,739 \\
\hline 3- Radioimp-referencial-escaner & 6,286 & 1,739 \\
\hline 4- Radioimp-referencial-câmera & 6,28 & 1,737 \\
\hline 5- Planimp-resolução-escaner & 6,333 & 1,752 \\
\hline 6- Planimp-referencial-escaner & 6,33 & 1,747 \\
\hline 7- Planimp-referencial-câmera & 6,319 & 1,747 \\
\hline \multicolumn{2}{|c|}{0,268086} \\
\hline
\end{tabular}

D 7 - Molar S uperior E squerdo

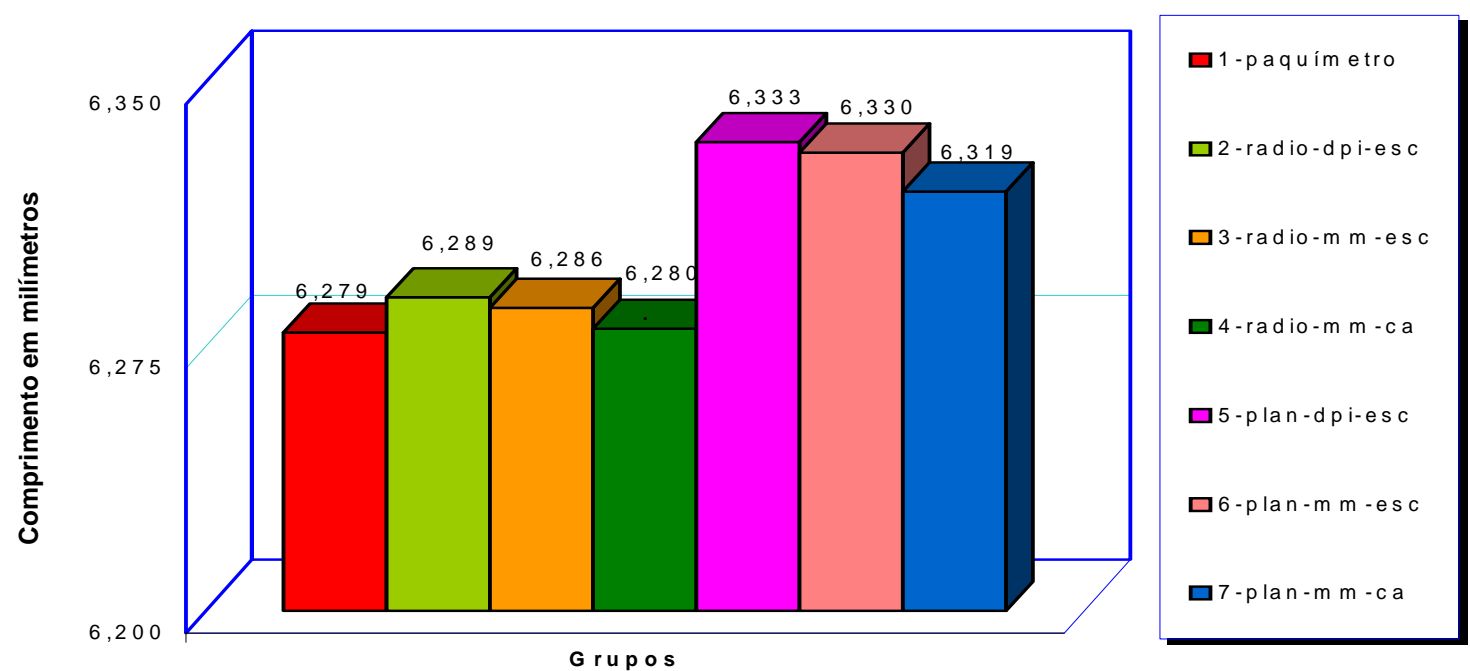

FIGURA 22 - Comparativo das médias (em mm) das medidas da distância D7-MSE (Molar Superior Esquerdo) obtidas pelos sete grupos 
A Tabela 8 mostra os valores das médias, desvios padrão e p referentes ao teste de análise de variância a um critério para medidas repetidas, com nível de significância a 5\%, das medidas obtidas pelos sete grupos (1- Paquímetro, 2- Radioimp-resolução-escaner, 3- Radioimpreferencial-escaner, 4- Radioimp-referencial-câmera, 5- Planimp-resoluçãoescaner, 6-Planimp-referencial-escaner, 7-Planimp-referencial-câmera), para a a distância D8-MID (região de Molar Inferior Direito).

O gráfico da Figura 23 mostra um comparativo dos valores das médias das medidas obtidas pelos sete grupos para a distância D8-MID (região de Molar Inferior Direito). 
TABELA 8 - Valores (em mm) das médias, desvios padrão e p referentes ao teste de análise de variância, com nível de significância a 5\%, das medidas obtidas pelos sete grupos, para a distância D8-MID (Molar Inferior Direito)

\begin{tabular}{l|c|c}
\hline \multirow{2}{*}{ Grupos } & \multicolumn{2}{c}{$\begin{array}{c}\text { Distância anatômica } \\
\text { D8 - Molar Inferior } \\
\text { Direito }\end{array}$} \\
\cline { 2 - 3 } & $\begin{array}{c}\text { Média } \\
\text { DP }\end{array}$ \\
\hline 1- Paquímetro & 7,243 & 2,750 \\
\hline 2- Radioimp-resolução-escaner & 7,252 & 2,753 \\
\hline 3- Radioimp-referencial-escaner & 7,252 & 2,753 \\
\hline 4- Radioimp-referencial-câmera & 7,244 & 2,751 \\
\hline 5- Planimp-resolução-escaner & 7,251 & 2,755 \\
\hline 6- Planimp-referencial-escaner & 7,252 & 2,753 \\
\hline 7- Planimp-referencial-câmera & 7,245 & 2,753 \\
\hline $\mathbf{p}$ & \multicolumn{2}{|c}{0,250771} \\
\hline
\end{tabular}

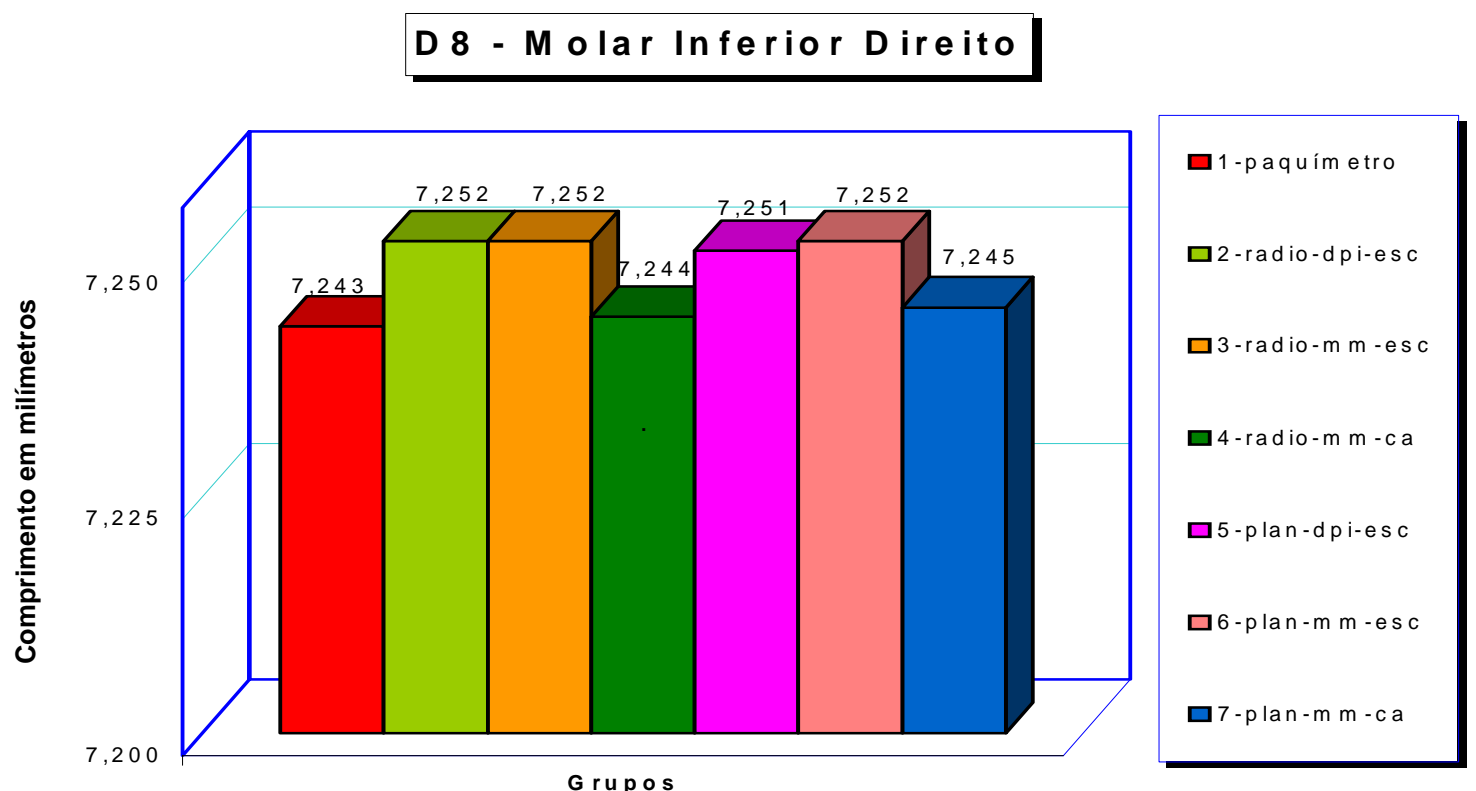

FIGURA 23 - Comparativo das médias (em mm) das medidas da distância D8-MID (Molar Inferior Direito) obtidas pelos sete grupos 
A Tabela 9 mostra os valores das médias, desvios padrão e p referentes ao teste de análise de variância a um critério para medidas repetidas, com nível de significância a 5\%, das medidas obtidas pelos sete grupos (1- Paquímetro, 2- Radioimp-resolução-escaner, 3- Radioimpreferencial-escaner, 4- Radioimp-referencial-câmera, 5- Planimp-resoluçãoescaner, 6-Planimp-referencial-escaner, 7-Planimp-referencial-câmera), para a distância D9-PMID (região de Pré-Molar Inferior Direito).

O gráfico da Figura 24 mostra um comparativo dos valores das médias das medidas obtidas pelos sete grupos para a distância D9-PMID (região de Pré-Molar Inferior Direito). 
TABELA 9 - Valores (em mm) das médias, desvios padrão e p referentes ao teste de análise de variância, com nível de significância a 5\%, das medidas obtidas pelos sete grupos, para a distância D9-PMID Pré-Molar Inferior Direito)

\begin{tabular}{l|c|c}
\hline \multirow{2}{*}{ Grupos } & \multicolumn{2}{c}{$\begin{array}{c}\text { Distância anatômica } \\
\text { D9 - Pré-Molar } \\
\text { Inferior Direito }\end{array}$} \\
\cline { 2 - 3 } & Média & DP \\
\hline 1- Paquímetro & 7,072 & 3,029 \\
\hline 2- Radioimp-resolução-escaner & 7,077 & 3,03 \\
\hline 3- Radioimp-referencial-escaner & 7,069 & 3,029 \\
\hline 4- Radioimp-referencial-câmera & 7,077 & 3,03 \\
\hline 5- Planimp-resolução-escaner & 7,079 & 3,031 \\
\hline 6- Planimp-referencial-escaner & 7,078 & 3,031 \\
\hline 7- Planimp-referencial-câmera & 7,073 & 3,029 \\
\hline \multicolumn{1}{|c}{$\mathbf{p}$} & \multicolumn{2}{|c}{0,431988} \\
\hline
\end{tabular}

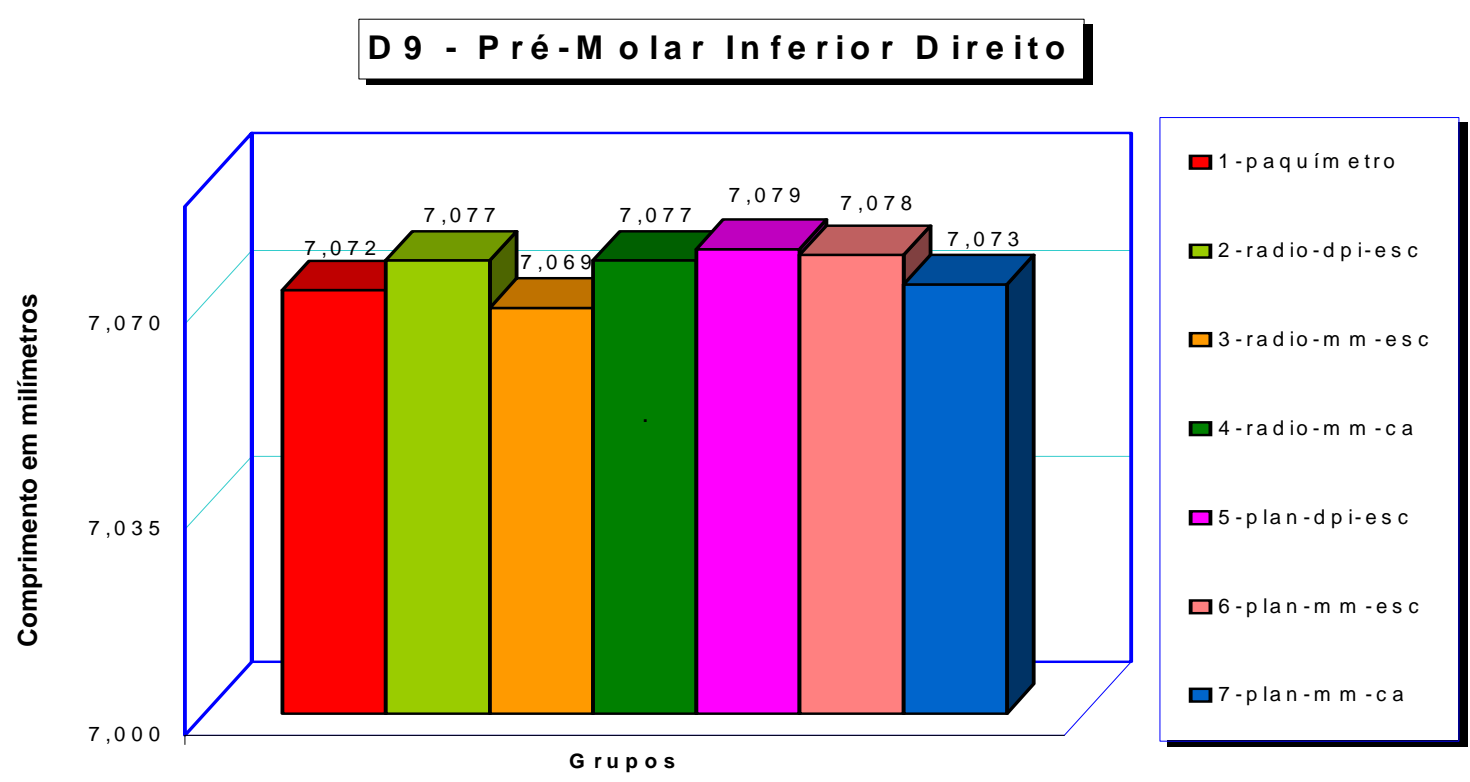

FIGURA 24 - Comparativo das médias (em mm) das medidas da distância D9-PMID (Pré-Molar Inferior Direito), obtidas pelos sete grupos 
A Tabela 10 mostra os valores das médias, desvios padrão e p referentes ao teste de análise de variância a um critério para medidas repetidas, com nível de significância a 5\%, das medidas obtidas pelos sete grupos (1- Paquímetro, 2- Radioimp-resolução-escaner, 3- Radioimpreferencial-escaner, 4- Radioimp-referencial-câmera, 5- Planimp-resoluçãoescaner, 6-Planimp-referencial-escaner, 7-Planimp-referencial-câmera), para a distância D10-CID (região de Caninor Inferior Direito).

O gráfico da Figura 25 mostra um comparativo dos valores das médias das medidas obtidas pelos sete grupos para a distância D10-CID (região de Caninor Inferior Direito). 
TABELA 10 - Valores (em mm) das médias, desvios padrão e p referentes ao teste de análise de variância, com nível de significância a 5\%, das medidas obtidas pelos sete grupos, para a distância D10-CID (Caninor Inferior Direito)

\begin{tabular}{l|c|c}
\hline \multirow{2}{*}{ Grupos } & \multicolumn{2}{c}{$\begin{array}{c}\text { Distância anatômica } \\
\text { D10 - Canino Inferior } \\
\text { Direito }\end{array}$} \\
\cline { 2 - 3 } & $\begin{array}{c}\text { Média } \\
\text { DP }\end{array}$ \\
\hline 1- Paquímetro & 8,629 & 2,781 \\
\hline 2- Radioimp-resolução-escaner & 8,634 & 2,782 \\
\hline 3- Radioimp-referencial-escaner & 8,631 & 2,782 \\
\hline 4- Radioimp-referencial-câmera & 8,635 & 2,783 \\
\hline 5- Planimp-resolução-escaner & 8,635 & 2,784 \\
\hline 6- Planimp-referencial-escaner & 8,635 & 2,783 \\
\hline 7- Planimp-referencial-câmera & 8,629 & 2,781 \\
\hline $\mathbf{p}$ & \multicolumn{2}{|c}{0,3298112} \\
\hline
\end{tabular}

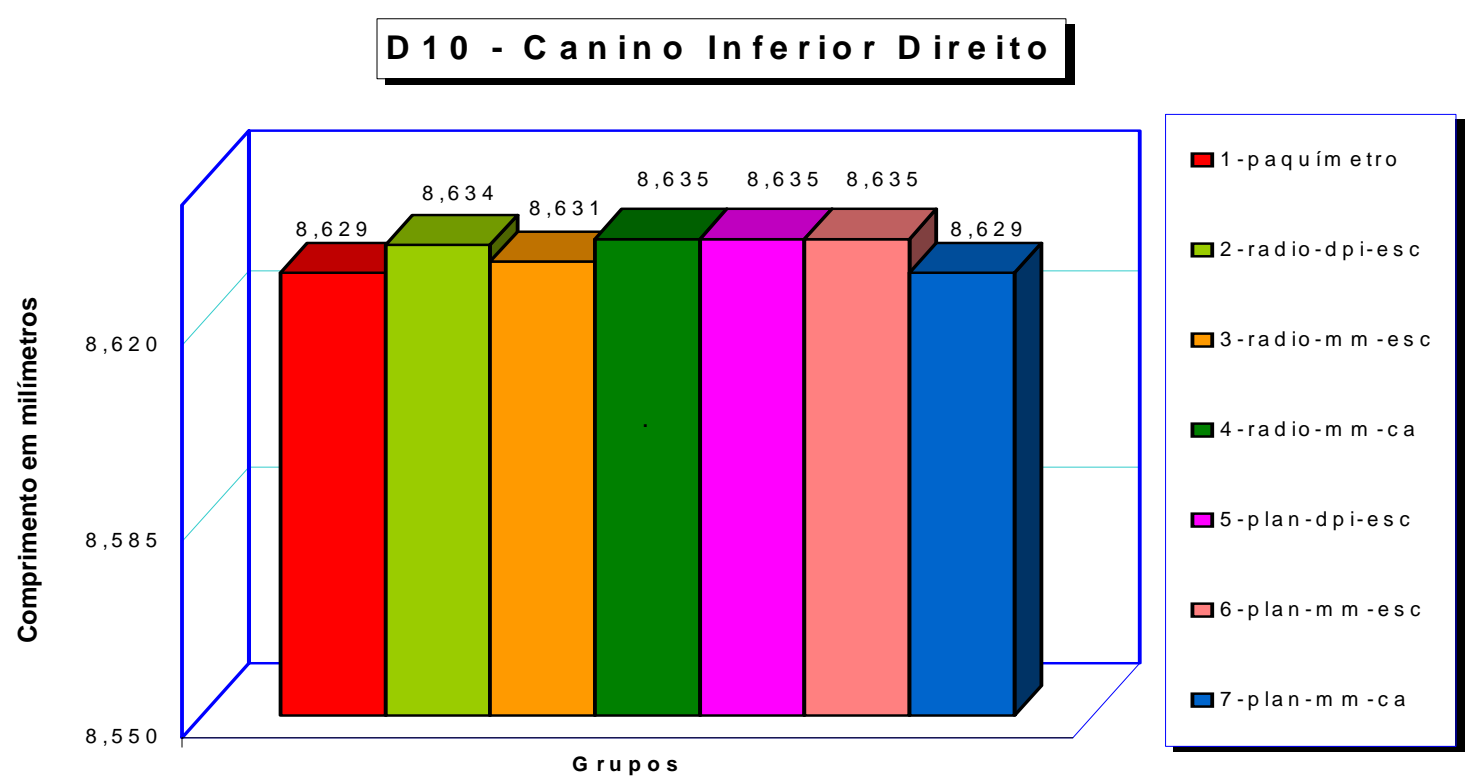

FIGURA 25 - Comparativo das médias (em mm)das medidas da distância D10-CID (Caninor Inferior Direito), obtidas pelos sete grupos 
A Tabela 11 mostra os valores das médias, desvios padrão e p referentes ao teste de análise de variância a um critério para medidas repetidas, com nível de significância a 5\%, das medidas obtidas pelos sete grupos (1- Paquímetro, 2- Radioimp-resolução-escaner, 3- Radioimpreferencial-escaner, 4- Radioimp-referencial-câmera, 5- Planimp-resoluçãoescaner, 6-Planimp-referencial-escaner, 7-Planimp-referencial-câmera), para a distância D11-ICI (região de Incisivo Central Inferior).

O gráfico da Figura 26 mostra um comparativo dos valores das médias das medidas obtidas pelos sete grupos para a distância D11-ICI (região de Incisivo Central Inferior). 
TABELA 11 - Valores (em mm) das médias, desvios padrão e p referentes ao teste de análise de variância, com nível de significância a 5\%, das medidas obtidas pelos sete grupos, para a distância D11-ICI (Incisivo Central Inferior)

\begin{tabular}{l|c|c}
\hline \multirow{2}{*}{ Grupos } & \multicolumn{2}{c}{$\begin{array}{c}\text { Distância anatômica } \\
\text { D11 - Incisivo Central } \\
\text { Inferior }\end{array}$} \\
\cline { 2 - 3 } & Média & DP \\
\hline 1- Paquímetro & 17,896 & 3,763 \\
\hline 2- Radioimp-resolução-escaner & 17,917 & 3,864 \\
\hline 3- Radioimp-referencial-escaner & 17,902 & 3,762 \\
\hline 4- Radioimp-referencial-câmera & 17,902 & 3,862 \\
\hline 5- Planimp-resolução-escaner & 17,916 & 3,958 \\
\hline 6- Planimp-referencial-escaner & 17,916 & 3,602 \\
\hline 7- Planimp-referencial-câmera & 17,903 & 3,866 \\
\hline $\mathbf{p}$ & \multicolumn{2}{|c}{0,500169} \\
\hline
\end{tabular}

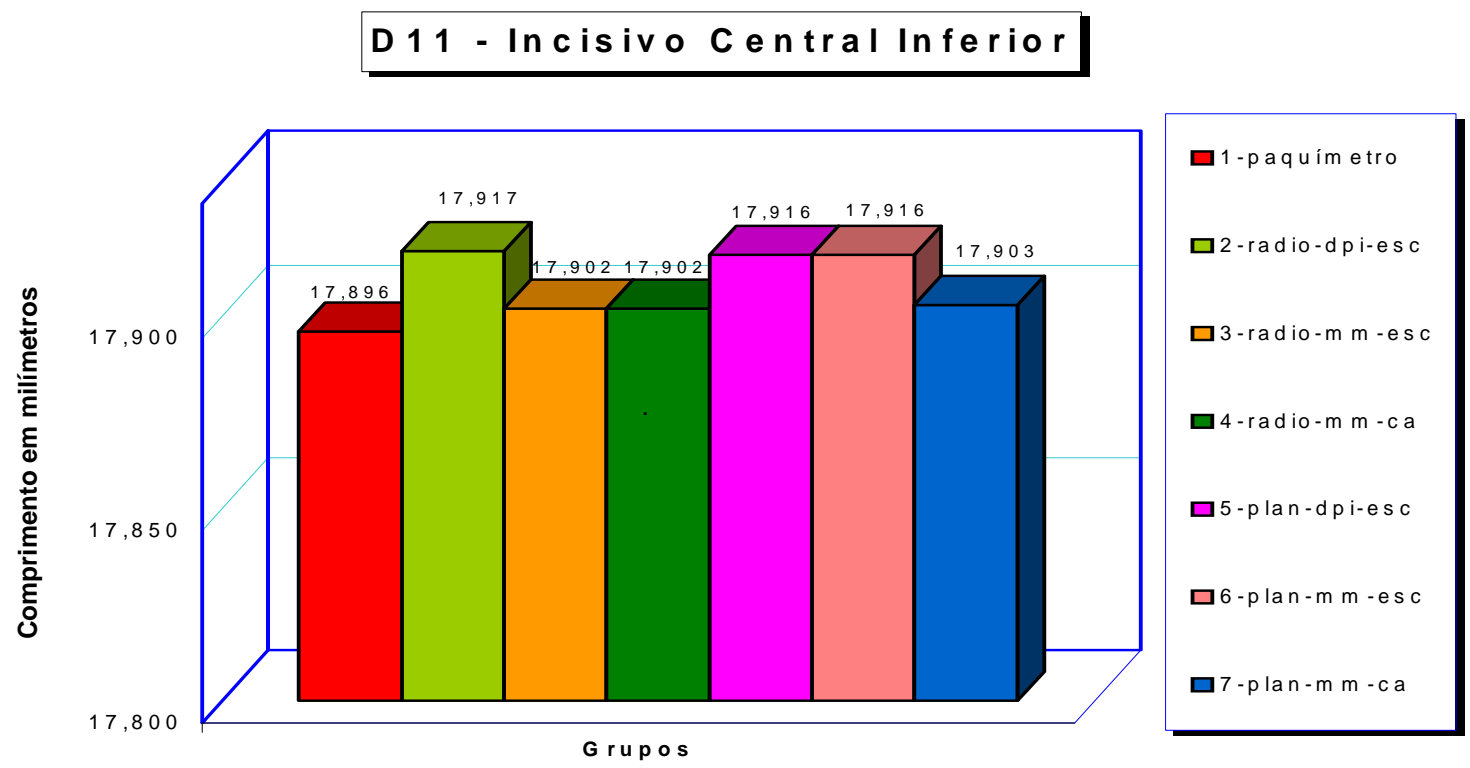

FIGURA 26 - Comparativo das médias (em mm) das medidas da distância D11-ICI (Incisivo Central Inferior) obtidas pelos sete grupos 
A Tabela 12 mostra os valores das médias, desvios padrão e p referentes ao teste de análise de variância a um critério para medidas repetidas, com nível de significância a 5\%, das medidas obtidas pelos sete grupos (1- Paquímetro, 2- Radioimp-resolução-escaner, 3- Radioimpreferencial-escaner, 4- Radioimp-referencial-câmera, 5- Planimp-resoluçãoescaner, 6-Planimp-referencial-escaner, 7-Planimp-referencial-câmera), para a distância D12-CIE (região de Canino Inferior Esquerdo).

O gráfico da Figura 27 mostra um comparativo dos valores das médias das medidas obtidas pelos sete grupos para a distância D12-CIE (região de Canino Inferior Esquerdo). 
TABELA 12 - Valores (em mm) das médias, desvios padrão e p referentes ao teste de análise de variância, com nível de significância a 5\%, das medidas obtidas pelos sete grupos, para a distância D12-CIE (Canino Inferior Esquerdo)

\begin{tabular}{l|c|c}
\hline \multirow{2}{*}{ Grupos } & \multicolumn{2}{c}{$\begin{array}{c}\text { Distância anatômica } \\
\text { D12 - Canino Inferior } \\
\text { Esquerdo }\end{array}$} \\
\cline { 2 - 3 } & $\begin{array}{c}\text { Média } \\
\text { DP }\end{array}$ \\
\hline 1- Paquímetro & 8,72 & 2,673 \\
\hline 2- Radioimp-resolução-escaner & 8,73 & 2,667 \\
\hline 3- Radioimp-referencial-escaner & 8,728 & 2,668 \\
\hline 4- Radioimp-referencial-câmera & 8,721 & 2,673 \\
\hline 5- Planimp-resolução-escaner & 8,733 & 2,667 \\
\hline 6- Planimp-referencial-escaner & 8,732 & 2,67 \\
\hline 7- Planimp-referencial-câmera & 8,722 & 2,667 \\
\hline $\mathbf{p}$ & \multicolumn{2}{|c}{0,236986} \\
\hline
\end{tabular}

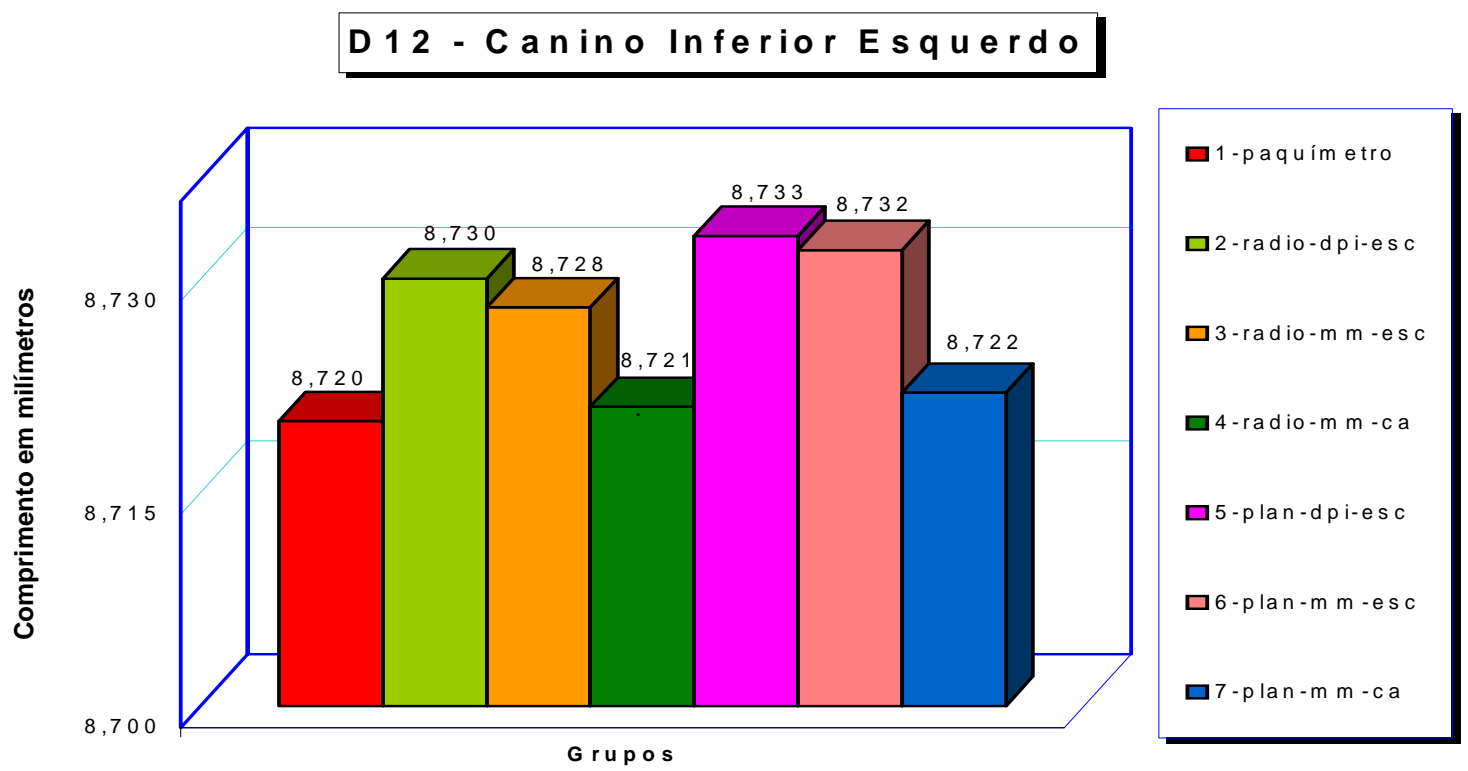

FIGURA 27 - Comparativo das médias (em mm) das medidas da distância D12-CIE (Canino Inferior Esquerdo), obtidas pelos sete grupos 
A Tabela 13 mostra os valores das médias, desvios padrão e $\mathrm{p}$ referentes ao teste de análise de variância a um critério para medidas repetidas, com nível de significância a 5\%, das medidas obtidas pelos sete grupos (1- Paquímetro, 2- Radioimp-resolução-escaner, 3- Radioimpreferencial-escaner, 4- Radioimp-referencial-câmera, 5- Planimp-resoluçãoescaner, 6-Planimp-referencial-escaner， 7-Planimp-referencial-câmera), para a a distância D13-PMIE (região de Pré-Molar Inferior Esquerdo).

O gráfico da Figura 28 mostra um comparativo dos valores das médias das medidas obtidas pelos sete grupos para a distância D13-PMIE (região de Pré-Molar Inferior Esquerdo). 
TABELA 13 - Valores (em mm) das médias, desvios padrão e p referentes ao teste de análise de variância, com nível de significância a 5\%, das medidas obtidas pelos sete grupos, para a distância D13-PMIE (Pré-Molar Inferior Esquerdo)

\begin{tabular}{l|c|c}
\hline \multirow{2}{*}{ Grupos } & \multicolumn{2}{c}{$\begin{array}{c}\text { Distância anatômica } \\
\text { D13 - Pré-Molar } \\
\text { Inferior Esquerdo }\end{array}$} \\
\cline { 2 - 3 } & Média & DP \\
\hline 1- Paquímetro & 7,025 & 2,792 \\
\hline 2- Radioimp-resolução-escaner & 7,033 & 2,795 \\
\hline 3- Radioimp-referencial-escaner & 7,032 & 2,794 \\
\hline 4- Radioimp-referencial-câmera & 7,026 & 2,793 \\
\hline 5- Planimp-resolução-escaner & 7,035 & 2,794 \\
\hline 6- Planimp-referencial-escaner & 7,015 & 2,789 \\
\hline 7- Planimp-referencial-câmera & 7,026 & 2,792 \\
\hline \multicolumn{1}{|c}{$\mathbf{p}$} & \multicolumn{2}{|c}{0,586578} \\
\hline
\end{tabular}

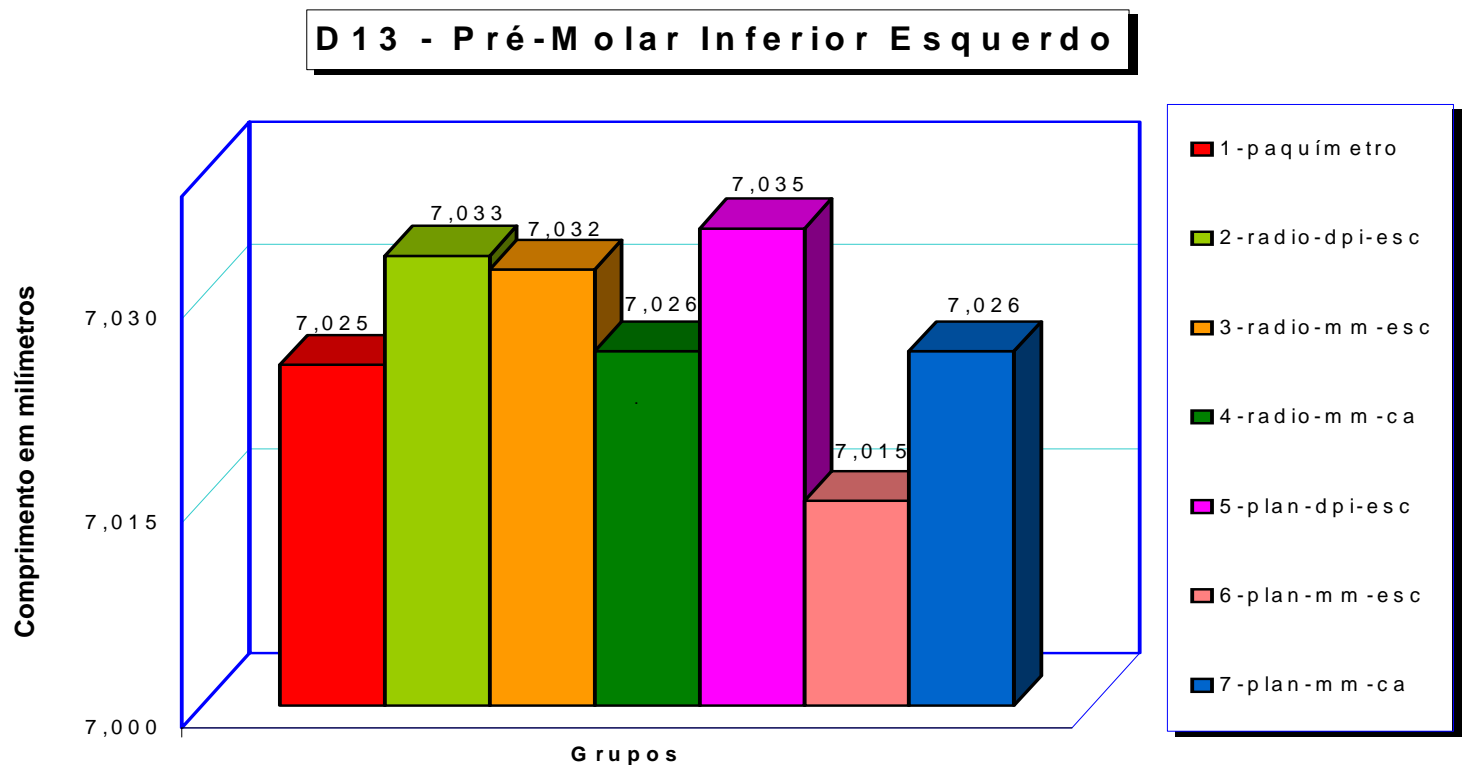

FIGURA 28 - Comparativo das médias (em mm) das medidas da distância D13-PMIE (Pré-Molar Inferior Esquerdo) obtidas pelos sete grupos 
A Tabela 14 mostra os valores das médias, desvios padrão e p referentes ao teste de análise de variância a um critério para medidas repetidas, com nível de significância a 5\%, das medidas obtidas pelos sete grupos (1- Paquímetro, 2- Radioimp-resolução-escaner, 3- Radioimpreferencial-escaner, 4- Radioimp-referencial-câmera, 5- Planimp-resoluçãoescaner, 6-Planimp-referencial-escaner, 7-Planimp-referencial-câmera), para a distância D14-MIE (região de Molar Inferior Esquerdo).

O gráfico da Figura 29 mostra um comparativo dos valores das médias das medidas obtidas pelos sete grupos para a distância D14-MIE (região de Molar Inferior Esquerdo). 
TABELA 14 - Valores (em mm) das médias, desvios padrão e p referentes ao teste de análise de variância, com nível de significância a 5\%, das medidas obtidas pelos sete grupos, para a distância D14-MIE (Molar Inferior Esquerdo)

\begin{tabular}{l|c|c}
\hline \multirow{2}{*}{ Grupos } & \multicolumn{2}{c}{$\begin{array}{c}\text { Distância anatômica } \\
\text { D14 - Molar Inferior } \\
\text { Esquerdo }\end{array}$} \\
\cline { 2 - 3 } & $\begin{array}{c}\text { Média } \\
\text { DP }\end{array}$ \\
\hline 1- Paquímetro & 7,450 & 3,170 \\
\hline 2- Radioimp-resolução-escaner & 7,500 & 2,666 \\
\hline 3- Radioimp-referencial-escaner & 7,499 & 2,666 \\
\hline 4- Radioimp-referencial-câmera & 7,492 & 2,665 \\
\hline 5- Planimp-resolução-escaner & 7,492 & 3,199 \\
\hline 6- Planimp-referencial-escaner & 7,500 & 2,667 \\
\hline 7- Planimp-referencial-câmera & 7,491 & 2,665 \\
\hline $\mathbf{p}$ & \multicolumn{2}{|c}{0,606922} \\
\hline
\end{tabular}

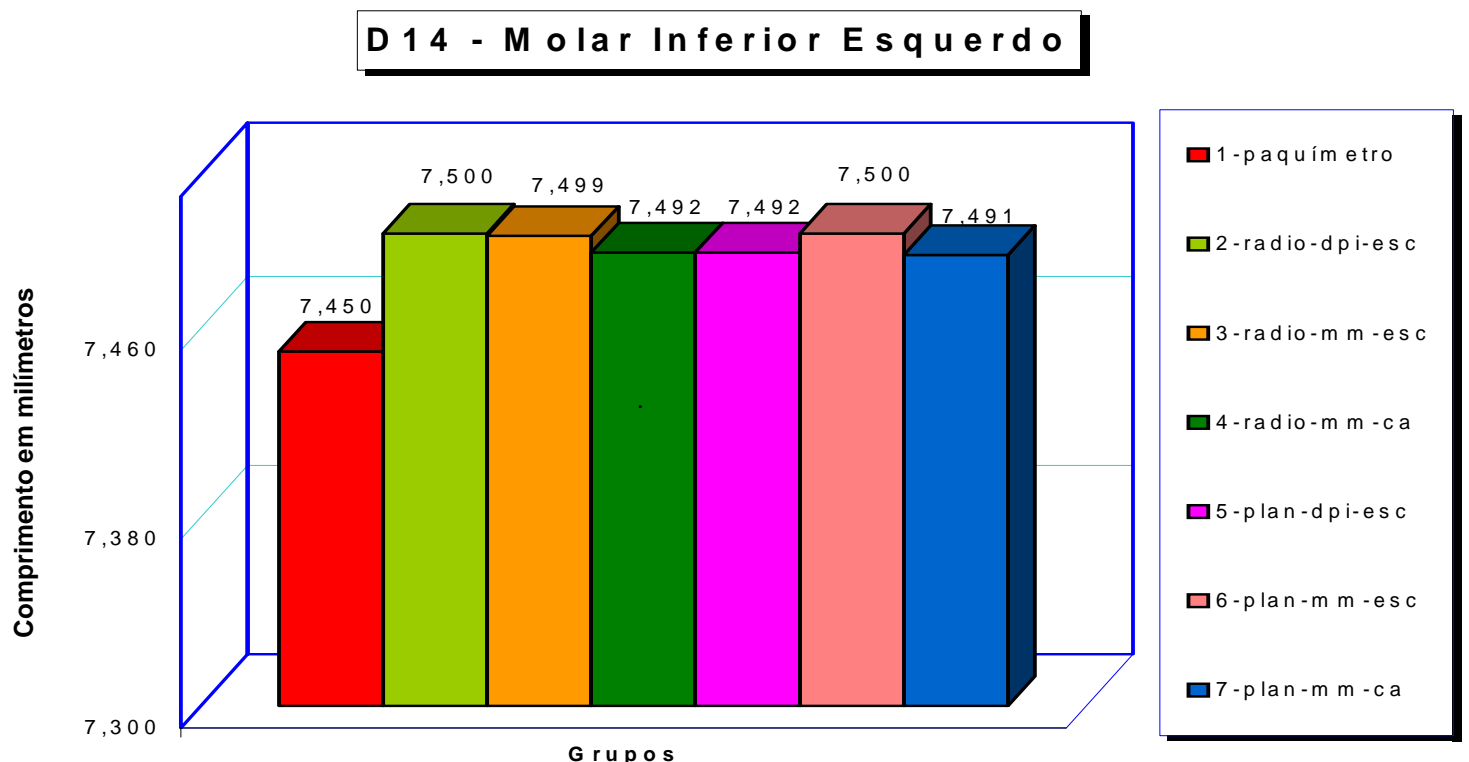

FIGURA 29 - Comparativo das médias (em mm) das medidas da distância D14-MIE (Molar Inferior Esquerdo), obtidas pelos sete grupos 
A Tabela 15 exibe um comparativo geral dos valores das médias das medidas obtidas pelos sete grupos (1- Paquímetro, 2Radioimp-resolução-escaner, 3- Radioimp-referencial-escaner, 4Radioimp-referencial-câmera, 5- Planimp-resolução-escaner, 6-Planimpreferencial-escaner, 7-Planimp-referencial-câmera), para as distâncias de cada área (D1-MSD, D2-PMSD, D3-CSD, D4-ICS, D5-CSE, D6-PMSE, D7-MSE, D8-MID, D9-PMID, D10-CID, D11-ICI, D12-CIE, D13-PMIE, D14-MIE).

O gráfico da Figura 30 mostra um comparativo da média geral das 14 distâncias (D1-MSD, D2-PMSD, D3-CSD, D4-IS, D5-CSE, D6PMSE, D7-MSE, D8-MID, D9-PMID, D10-CID, D11-II, D12-CIE, D13PMIE, D14-MIE), referentes a cada um dos sete grupos (1- Paquímetro, 2Radioimp-resolução-escaner, 3- Radioimp-referencial-escaner, 4Radioimp-referencial-câmera, 5- Planimp-resolução-escaner, 6-Planimpreferencial-escaner, 7-Planimp-referencial-câmera). 
TABELA 15 - Valores (em mm) das médias das medidas obtidas pelos sete grupos, para as 14 distâncias anatômicas

\begin{tabular}{|c|c|c|c|c|c|c|c|c|c|c|c|c|c|c|c|}
\hline \multirow{2}{*}{ Grupos } & \multicolumn{15}{|c|}{ Distâncias anatômicas } \\
\hline & $\begin{array}{c}\text { D1 } \\
\text { MSD } \\
\end{array}$ & $\begin{array}{c}\text { D2 } \\
\text { PMSD }\end{array}$ & $\begin{array}{c}\text { D3 } \\
\text { CSD } \\
\end{array}$ & $\begin{array}{c}\text { D4 } \\
\text { ICS } \\
\end{array}$ & $\begin{array}{c}\text { D5 } \\
\text { CSE } \\
\end{array}$ & $\begin{array}{c}\text { D6 } \\
\text { PMSE } \\
\end{array}$ & $\begin{array}{c}\text { D7 } \\
\text { MSE } \\
\end{array}$ & $\begin{array}{c}\text { D8 } \\
\text { MID } \\
\end{array}$ & $\begin{array}{c}\text { D9 } \\
\text { PMID } \\
\end{array}$ & $\begin{array}{l}\text { D10 } \\
\text { CID } \\
\end{array}$ & $\begin{array}{l}\text { D11 } \\
\text { ICI } \\
\end{array}$ & $\begin{array}{l}\text { D12 } \\
\text { CIE } \\
\end{array}$ & $\begin{array}{c}\text { D13 } \\
\text { PMIE }\end{array}$ & $\begin{array}{l}\text { D14 } \\
\text { MIE }\end{array}$ & $\begin{array}{c}\text { Média } \\
\text { geral }\end{array}$ \\
\hline 1- Paquímetro & 6,972 & 9,577 & 12,400 & 11,977 & 12,387 & 9,415 & 6,279 & 7,243 & 7,072 & 8,629 & 17,896 & 8,720 & 7,025 & 7,450 & 9,503 \\
\hline $\begin{array}{l}\text { 2- Radioimp- } \\
\text { resolução- } \\
\text { escaner } \\
\end{array}$ & 6,925 & 9,553 & 12,421 & 11,987 & 12,416 & 9,488 & 6,289 & 7,252 & 7,077 & 8,634 & 17,917 & 8,730 & 7,033 & 7,500 & 9,516 \\
\hline $\begin{array}{l}\text { 3- Radioimp- } \\
\text { referencial- } \\
\text { escaner } \\
\end{array}$ & 6,922 & 9,590 & 12,400 & 11,984 & 12,473 & 9,486 & 6,286 & 7,252 & 7,069 & 8,631 & 17,902 & 8,728 & 7,032 & 7,499 & 9,518 \\
\hline $\begin{array}{l}\text { 4- Radioimp- } \\
\text { referencial- } \\
\text { câmera }\end{array}$ & 6,914 & 9,580 & 12,419 & 11,979 & 12,403 & 9,418 & 6,280 & 7,244 & 7,077 & 8,635 & 17,902 & 8,721 & 7,026 & 7,492 & 9,506 \\
\hline $\begin{array}{l}\text { 5- Planimp- } \\
\text { resolução- } \\
\text { escaner } \\
\end{array}$ & 6,926 & 9,553 & 12,421 & 11,981 & 12,416 & 9,491 & 6,333 & 7,251 & 7,079 & 8,635 & 17,916 & 8,733 & 7,035 & 7,492 & 9,519 \\
\hline $\begin{array}{l}\text { 6- Planimp- } \\
\text { referencial- } \\
\text { escaner } \\
\end{array}$ & 6,925 & 9,591 & 12,420 & 11,986 & 12,415 & 9,489 & 6,330 & 7,252 & 7,078 & 8,635 & 17,916 & 8,732 & 7,015 & 7,500 & 9,520 \\
\hline $\begin{array}{l}\text { 7- Planimp- } \\
\text { referencial- } \\
\text { câmera }\end{array}$ & 6,934 & 9,580 & 12,391 & 11,978 & 12,404 & 9,478 & 6,319 & 7,245 & 7,073 & 8,629 & 17,903 & 8,722 & 7,026 & 7,491 & 9,512 \\
\hline
\end{tabular}




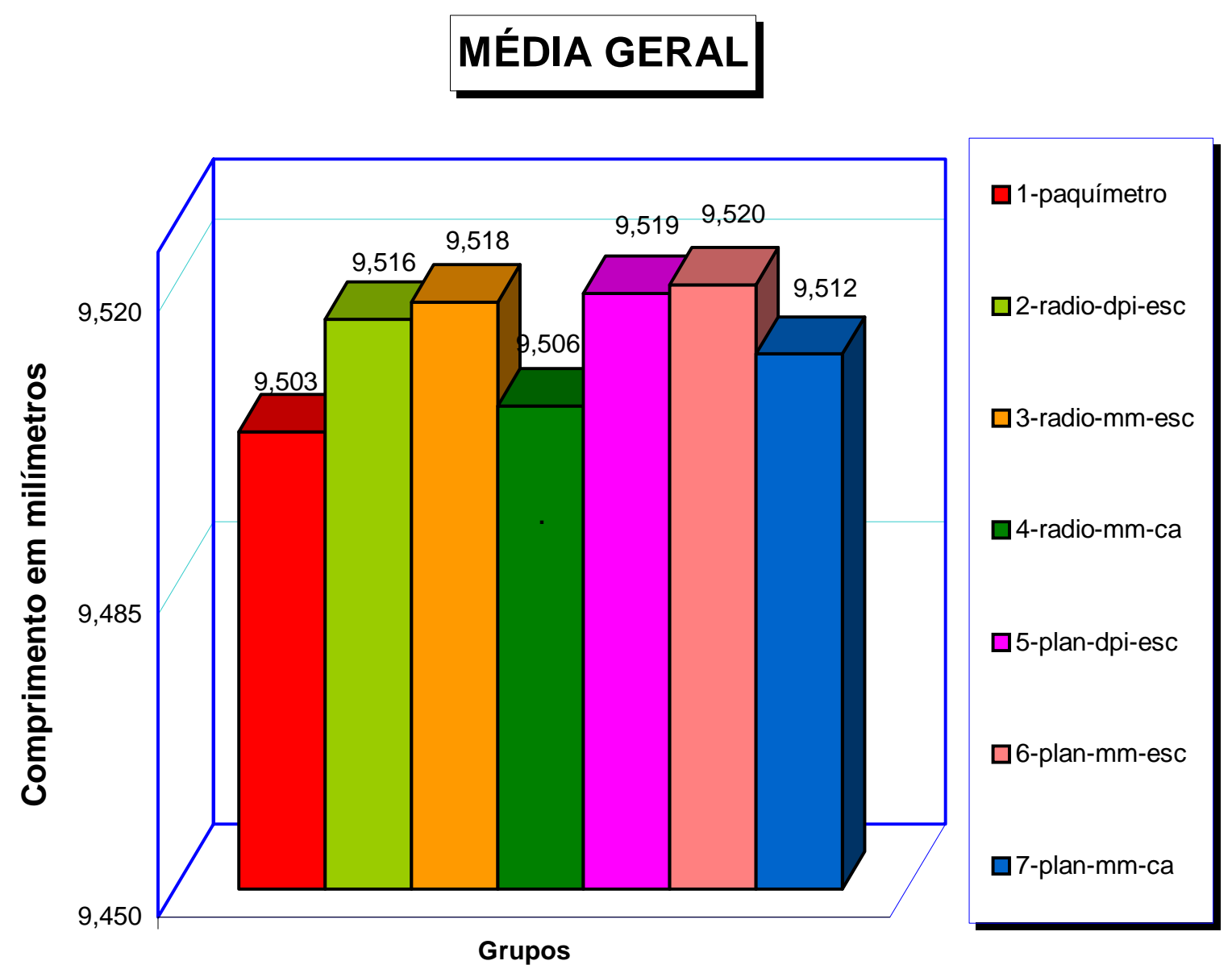

FIGURA 30 - Comparativo entre os valores (em mm) da média geral das 14 distâncias anatômicas referentes a cada um dos sete grupos 
6- DISCUSSÃO 


\section{6- DISCUSSÃO}

\section{1- Amostra utilizada}

A amostra integrante deste trabalho constou de 50 radiografias panorâmicas de pacientes edêntulos, pertencentes ao arquivo da Clínica de Implantodontia da Universidade do Sagrado Coração. Esse critério de radiografias de pacientes totalmente edêntulos foi utilizado com a finalidade de melhor evidenciar os reparos anatômicos. Quanto àquelas dos pacientes parcialmente edêntulos não incluídas nesta amostra, ficaram para um estudo posterior. O número de radiografias incluídas na amostra segundo o estudo estatístico, mostrou-se expressivo e suficiente para a interpretação e análise dos resultados.

Para avaliar as medições lineares fornecidas pelos programas de imagem (Planimp e Radioimp) utilizados em Implantodontia, poderíamos trabalhar com imagens digitalizadas de radiografias panorâmicas ou de tomografias. Optamos pelas imagens da radiografia panorâmica, por se tratar de uma radiografia rotineiramente utilizada no planejamento pré-cirúrgico de implantes, e que fornece uma imagem muito boa das estruturas anatômicas. Elas são de execução e interpretação relativamente fáceis, produzindo uma baixa dose de radiação ao paciente com baixo custo (DULA et al. ${ }^{29}$, 2001; HARRIS et al. ${ }^{42}$, 2002; TYNDALL et al. $\left.{ }^{70}, 2000\right)$.

As radiografias panorâmicas, no relato de vários autores, têm papel fundamental na fase pré-operatória para implantes osseointegráveis, podendo ser utilizadas em associação a outras modalidades radiográficas, incluindo as radiografias periapicais, oclusais e cefalométricas e tomografias (BOUSERHAL ${ }^{11}$, 2002, CHILVARQUER ${ }^{23}$; 2002, DULA et 
al. $^{29}$, 2001; FREDERIKSEN ${ }^{37}$, 1995; HARRIS et al. ${ }^{42}, 2002$; REISKIN ${ }^{60}$, 1998; TYNDALL et al. ${ }^{70}$, 2000).

\section{2- Distâncias anatômicas}

As distâncias anatômicas selecionadas para esta pesquisa englobam as regiões anatômicas relacionadas de acordo com cada paciente, com finalidade de receber o implante, conforme estudos realizados por vários autores (CAMACHO et al. ${ }^{14}$, 1999, CHILVARQUER ${ }^{23}, 2002$, KALIL $^{45}$, 1998).

KALIL $^{45}$ em 1998, salienta que os espaços ou distâncias que devem ser avaliados incluem: as distâncias naso-sinusal, rebordo-nasal, rebordo-sinusal, rebordo-alveolar inferior e rebordo-basal anterior mandibular.

Em seu trabalho, CAMACHO et al. ${ }^{14}$ em 1999, selecionaram 12 distâncias anatômicas de interesse para avaliação óssea pré-cirúrgica na colocação de implantes: áreas de molar, pré-molar e região anterior dos lados direito e esquerdo da maxila e mandíbula.

Muito embora CAMACHO et al. ${ }^{14}$ em 1999, tenham optado por 12 distâncias anatômicas, escolhemos trabalhar com 14 distâncias, visando um maior detalhamento da região anterior de maxila e mandíbula.

Com o objetivo de delimitar e facilitar as mensurações verticais dos possíveis leitos receptores de implantes, CHILVARQUER ${ }^{23}$ em 2002, propõe a confecção de um traçado radiográfico. Essa técnica visa delinear os reparos anatômicos da região mandibular: canal mandibular, emergência do forame mentual e o contorno de todo rebordo remanescente. Para a região maxilar: contorno do assoalho das cavidades sinusais, espinha nasal anterior, palato duro e contorno do rebordo remanescente. 


\section{3- Digitalização das radiografias panorâmicas}

Em nosso trabalho as radiografias foram digitalizadas por dois sistemas indiretos de aquisição de imagens: um escaner e uma câmera fotográfica digital.

O escaner utilizado foi o Hewllett Packard Scanjet $4 \mathrm{C} / \mathrm{T}$, tendo como acessório um leitor de transparência. Nós optamos por trabalhar com um escaner de superfície plana, pois representa o sistema de digitalização de radiografias mais utilizado nas clínicas particulares de Radiologia Odontológica e nas Faculdades de Odontologia.

Em nossa pesquisa, as radiografias, juntamente com a régua milimetrada, foram digitalizadas de forma padronizada: sempre na mesma posição de escaneamento, sem mudança na configuração do escaner, e sem desligar e ligar o aparelho entre os escaneamentos.

Esse procedimento foi empregado com a finalidade de se obter uma reprodutibilidade adequada das imagens radiográficas.

Fundamentamo-nos em trabalho realizado por CHEN; $\operatorname{HOLLENDER}^{20}$ em 1995, que digitalizando uma imagem radiográfica de um penetrômetro por meio de um escaner de superfície plana, observaram que a reprodutibilidade das imagens só foi alcançada quando as radiografias foram escaneadas sempre na mesma posição de escaneamento e sem mudança na configuração do escaner. Nesse estudo, verificou-se que quando a imagem foi escaneada em diferentes locais e quando o aparelho foi desligado entre as leituras, o escaner de superfície plana produziu resultados inconstantes de densidades ópticas.

Muito embora os fabricantes dos programas Planimp (CDT ${ }^{18}$, 2000) e Radioimp (RADIOMEMORY ${ }^{59}$, 2000) recomendem uma resolução mínima de 254 dpi, optamos por escanear as radiografias 
panorâmicas com uma resolução de 300 dpi, tendo em vista a necessidade de uma imagem com resolução suficiente para a observação acurada dos reparos anatômicos, a fim de se otimizar as mensurações. Por outro lado, uma imagem com resolução de 300 dpi, não resulta em um arquivo muito grande facilitando o seu armazenamento.

Da mesma forma, CHEN; CHIANG $^{19}$ em 1997 também utilizaram a resolução de 300 dpi (pixel de tamanho $85 \mu \mathrm{m}$ ) em pesquisa onde se avaliou o desempenho físico de um escaner tipo cilíndrico, em relação ao alcance dinâmico, reprodutibilidade e homogeneidade das imagens de filmes periapicais.

Também ATTAELMANAM; BORG; GRÖNDAHL ${ }^{5}$ em 2000, realizaram um estudo a fim de determinar os parâmetros ideais para digitalização de radiografias. Com esta finalidade, radiografias periapicais foram digitalizadas por um escaner, com três resoluções diferentes (200, 400 e 600 dpi). Após a avaliação subjetiva da qualidade das imagens para identificação de estruturas anatômicas, realizada por sete examinadores, observou-se que as radiografias digitalizadas com 200 e 400 dpi foram as preferidas. As imagens com 600 dpi não acrescentaram melhora substancial na visualização e aumentaram consideravelmente o arquivo.

Assim, utilizando essa resolução de 300 dpi em nosso trabalho, conseguimos um bom resultado, ou seja, imagens com uma elevada definição, permitindo a realização de medições consistentes, com um arquivo adequado.

O segundo meio utilizado para a digitalização das imagens foi a câmera digital. Os fabricantes dos programas Radioimp $\left(\right.$ RADIOMEMORY ${ }^{59}$, 2000) e Planimp $\left(\right.$ CDT $\left.^{18}, 2000\right)$, recomendam a utilização de um equipamento contendo recursos como lentes macro e uma resolução mínima de 640x680 pixels. Utilizamos uma câmera fotográfica 
digital FinePix S602 ZOOM, da Fujifilm, com resolução de 3.1 megapixel, operando com zoom de 2X. A abertura variou de 3.7 a 4.2, automaticamente. Tendo em vista a ausência de trabalhos que pudessem nos fornecer a distância lente-filme adequada para a digitalização de radiografias panorâmicas, realizamos o teste piloto descrito no item 4.6. Diante dos resultados do referido teste, escolhemos a distância lente/filme de $50 \mathrm{~cm}$ para trabalhar com a câmera digital FinePix.

No trabalho de KRUPINSKI et al. $^{48}$ em 2000, para a digitalização de filmes radiográficos médicos, com a finalidade de transmissão via rede de telemedicina, foi utilizada uma câmera fotográfica digital amadora, com resolução de 570.000 pixels. O objetivo principal foi determinar se, em substituição aos sistemas de vídeo e escaneres de alta resolução, a câmera digital e um negatoscópio poderiam ser usados nos pontos de Telemedicina rural, para digitalizar e transmitir imagens radiográficas, a fim de serem avaliadas por especialistas, em Centros de Telemedicina. A câmera utilizada foi uma Canon PowerShot 600, cujas imagens foram capturadas no modo de resolução fino (832x608 pixels), correspondendo a um arquivo de $150 \mathrm{kB}$. Os resultados mostraram que a precisão de diagnóstico foi bem alta para as radiografias de traumas ósseos. Entretanto, os autores admitem que para a observação mais acurada de microcalcificações em mamografias (lesões com $50 \mu \mathrm{m}$ ), o ideal seria a utilização de câmeras digitais com melhores resoluções (1 a 2 megapixels).

Em nossa pesquisa, utilizando a câmera digital FinePix (resolução de 3.1 megapixel), as imagens foram capturadas e salvas no modo FINE JPEG (2832x2128 pixels). Deste modo, obtivemos um arquivo de aproximadamente $1700 \mathrm{kB}$ por imagem. Observamos que a resolução utilizada foi suficiente para se distinguir, com detalhes, os achados anatômicos das radiografias panorâmicas. 


\section{4- Mensuração das distâncias anatômicas}

As distâncias anatômicas foram mensuradas utilizando-se dois métodos: o manual e o digital.

No método manual, as mensurações foram obtidas por meio de um paquímetro digital da marca Mitutoyo $150 \mathrm{~mm}$ (Mitutoyo Ltd, Andover, UK), com precisão de 0,01 mm. Optamos trabalhar com paquímetro digital, pois oferecem dados mais precisos que a régua milimetrada. Na literatura revista, encontramos trabalhos que comentam a respeito da precisão de métodos de mensuração manual (régua milimetrada comum, régua endodôntica e paquímetro eletrônico digital), e o digital (programas de imagem):

VELDERS; SANDERINK; STELT ${ }^{73}$ em 1996, realizaram mensurações do comprimento de limas endodônticas em imagens radiográficas de filmes periapicais, com auxílio de uma régua milimetrada, e comparam com as obtidas por meio do programa digital Emago, em imagens fornecidas pelos aparelhos Sidexis e Digora. Os resultados revelaram que as medidas digitais apresentaram-se maiores (diferença de 0,2 mm) que as medidas manuais realizadas diretamente sobre o filme periapical. Segundo os autores, este fato pode ter sido causado pelo método de mensuração utilizado no filme, já que a régua apresenta uma precisão de $0,5 \mathrm{~mm}$, enquanto que o programa digital de $0,1 \mathrm{~mm}$.

EIKENBERG; VANDRE ${ }^{33}$ em 2000, também compararam medidas digitais (Dexis) com as manuais (régua endodôntica), na determinação da distância entre a ponta do instrumento e o ápice radicular. Os resultados revelaram que as medidas das imagens digitais foram menores que as do filme periapical. Os autores consideraram que essa diferença ocorreu, provavelmente, pelo fato do método de 
mensuração digital ser mais preciso que o manual (régua endodôntica: precisão de $0,25 \mathrm{~mm})$.

VERSTEEG et al. $^{74}$ em 1997, comparando medidas lineares digitais obtidas por meio de programa digital, com medidas manuais realizadas com régua, chamaram a atenção para as diferenças entre os métodos de mensuração utilizados. Segundo os autores, quando a mensuração de uma distância linear é realizada com uma régua comum, o erro máximo permitido é de 0,5 mm, enquanto que nos programas digitais a margem de erro é de $0,1 \mathrm{~mm}$.

SCARFE et al. $^{65}$ em 1999, estudando medidas digitais e manuais de lesões periapicais, também relataram em seu trabalho que as mensurações de imagens digitais realizadas por meio do cursor do mouse tem uma precisão de medida de 0,1 mm, enquanto que a régua milimetrada comum, de $0,5 \mathrm{~mm}$.

BRANDÃO; COSTA; RAMALHO ${ }^{12}$ em 2001, compararam dois métodos de mensuração sobre radiografias convencionais, usando um paquímetro digital (série 727-Starret) e uma régua milimetrada. Comparando os valores das medidas do comprimento das imagens radiográficas de limas endodônticas, os autores observaram que as medidas obtidas com a régua foram minimamente maiores que as do paquímetro digital.

COSTA et al. ${ }^{26}$ em 2004, reportaram que o desenho manual das estruturas anatômicas de uma radiografia, seguido por mensuração manual, é o tipo mais freqüente de apresentação da avaliação radiográfica pré-cirúrgica de implantes. Por outro lado, afirmaram que os programas computadorizados específicos para o planejamento em implantes facilitam a identificação dos pontos de reparos anatômicos, a determinação dos limites das corticais e possibilitam a obtenção de medidas com alto grau de precisão de medida. 
No método digital, utilizou-se nesta pesquisa, os programas de imagem Radioimp e Planimp, recentemente lançados no mercado, destinados a auxiliar na avaliação pré-cirúrgica na colocação de implantes.

Tendo em vista a escassez de trabalhos que mostrem medições por meio de programas de imagem, com métodos padronizados, destinados especificamente à Implantodontia, através da experimentação estabeleceu-se uma metodologia padronizada para esse fim.

Dessa forma, entende-se que a essa pesquisa poderá ser de grande valia para a utilização futura de novos programas que surgirem uma vez que a digitalização de radiografias com o suporte fornecido pela Informática é uma realidade promissora e um caminho aberto a ser percorrido e aperfeiçoado.

\section{5- Discussão dos resultados}

\subsection{1- Análise dos gráficos}

A Figura 16 apresenta um comparativo dos valores (em mm) das médias das medidas obtidas pelos sete grupos para a distância D1-MSD (região de Molar Superior Direito), onde observamos que as medidas obtidas pelo método digital (grupos 2, 3, 4, 5, 6 e 7) foram menores que as obtidas pelo método manual (grupo 1), 6,972. O resultado que mais se aproximou do grupo controle foi obtido pelo grupo 7 (Planimp/calibração referencial/câmera), 6,934.

A Figura 17 mostra um comparativo dos valores (em mm) das médias das medidas obtidas pelos sete grupos para a distância D2-PMSD (região de Pré-Molar Superior Direito), onde observamos que as medidas obtidas pelo método digital dos grupos 3, 4, 6 e 7 foram maiores que as 
obtidas pelo método manual $(9,577)$. Por outro, lado as medidas digitais obtidas pelos grupos 2 (Radioimp/calibração por resolução/escaner), 9,553 e 5 (Planimp/calibração por resolução/escaner), 9,553 foram menores que as do grupo controle. Os resultados que mais se aproximaram do grupo controle foram obtidos pelos grupos 4 (Radioimp/calibração referencial/câmera), 9,580 e 7 (Planimp/ calibração referencial/câmera), 9,580 .

Na análise do gráfico da Figura 17, na distância D2-PMSD (Pré-Molar Superior Direito), notamos um comportamento semelhante entre os programas e seus sistemas de calibração da imagem, onde apresentaram valores muito parecidos: grupo $2(9,553)$ e grupo $5(9,553)$; grupo $3(9,590)$ e grupo $6(9,591)$; grupo $4(9,580)$ e grupo $7(9,580)$.

A Figura 18 exibe um comparativo dos valores (em $\mathrm{mm}$ ) das médias das medidas obtidas pelos sete grupos para a distância D3-CSD (região de Canino Superior Direito), onde observamos que as medidas digitais obtidas pelos grupos 2, 4, 5, e 6 foram maiores que as obtidas pelo grupo controle. $\mathrm{O}$ melhor resultado foi obtido pelo grupo 3 (Radioimp/calibração referencial/escaner), que permaneceu juntamente com o grupo 7 no mesmo patamar do grupo controle.

A Figura 19 expõe um comparativo dos valores (em mm) das médias das medidas obtidas pelos sete grupos para a distância D4-ICS (região de Incisivo Central Superior), onde observamos um comportamento uniforme de todos os grupos. Os valores das medidas digitais obtidas pelos grupos 2, 3, 4, 5, 6 e 7 foram muito próximos do obtido pelo grupo controle, variando de 11,977 (grupo 1) a 11,987 (grupo 2). O resultado mais próximo do grupo controle foi obtido pelo grupo 7 (Planimp/calibração referencial/câmera).

O gráfico da Figura 20 revela um comparativo dos valores (em mm) das médias das medidas obtidas pelos sete grupos para a distância D5- 
CSE (região de Canino Superior Esquerdo), onde observamos que as medidas digitais obtidas pelos grupos 2, 3, 4, 5, 6, e 7 foram maiores que as obtidas pelo grupo controle. Os grupos 2, 4, 5, 6 e 7 permaneceram praticamente no mesmo patamar do grupo controle, tendo o grupo 4 (Planimp/calibração referencial/câmera) alcançado o melhor resultado. O resultado que menos se aproximou da distância D5-CSE foi obtido pelo grupo 3 (Radioimp/calibração referencial/escaner).

A Figura 21 mostra um comparativo dos valores (em mm) das médias das medidas obtidas pelos sete grupos para a distância D6-PMSE (região de Pré-Molar Superior Esquerdo), onde observamos que as medidas digitais obtidas pelos grupos 2, 3, 4, 5, 6, e 7 foram maiores que as obtidas pelo grupo controle. O melhor resultado em relação ao grupo controle foi obtido pelo grupo 4 (Radioimp/calibração referencial/câmera), que permaneceu praticamente no mesmo patamar do grupo controle.

A Figura 22 indica um comparativo dos valores (em $\mathrm{mm}$ ) das médias das medidas obtidas pelos sete grupos para a distância D7-MSE (região de Molar Superior Esquerdo) onde observamos que todas as medidas digitais (grupos 2, 3, 4, 5, 6 e 7) apresentaram-se maiores que as obtidas pelo grupo controle. Analisando este gráfico, notamos um comportamento discrepante entre os programas e seus sistemas de calibração da imagem. As medidas obtidas por meio do programa Radioimp (grupos 2, 3 e 4) alcançaram valores bem próximos aos do grupo controle, enquanto que os valores das medidas obtidas no programa Planimp (grupos 5, 6 e 7) foram uniformes entre si, porém discrepantes em relação aos demais grupos. O melhor resultado foi alcançado pelo grupo 4 (Radioimp/calibração referencial/câmera).

O gráfico da Figura 23 mostra um comparativo dos valores (em mm) das médias das medidas obtidas pelos sete grupos para a distância D8-MID (região de Molar Inferior Direito), onde observamos que todas as 
medidas digitais obtidas pelos grupos 2, 3, 4, 5, 6 e 7, foram maiores que as obtidas pelo grupo controle. $\mathrm{Na}$ análise deste gráfico, notamos um comportamento semelhante entre os programas e seus sistemas de calibração da imagem, onde apresentaram valores muito parecidos: grupo 2 $(7,252)$ e grupo $5(7,251)$; grupo $3(7,252)$ e grupo $6(7,252)$; grupo 4 $(7,244)$ e grupo $7(7,245)$. As medidas obtidas pelos grupos 4 e 7 permaneceram no mesmo patamar das obtidas pelo grupo controle, sendo que o grupo 4 (Radioimp/calibração referencial/câmera) apresentou o melhor resultado.

O gráfico da Figura 24 delineia um comparativo dos valores (em mm) das médias das medidas obtidas pelos sete grupos para a distância D9-PMID (região de Pré-Molar Inferior Direito), onde notamos que apenas as medidas obtidas pelo grupo 3 (Radioimp/calibração referencial/escaner), foram menores que as obtidas pelo grupo controle, porém bem próximas. As medidas obtidas pelos demais grupos (2, 4, 5, 6 e 7) foram maiores que as obtidas pelo grupo controle. Observamos que para a área de Pré-Molar Inferior Direito, ocorreu uma certa uniformidade entre os grupos, que mostram apenas pequenas diferenças. O resultado mais próximo do grupo $\begin{array}{llllll}\text { controle foi alcançado pelo grupo } 7 & \text { (Planimp/calibração }\end{array}$ referencial/câmera).

A Figura 25 demonstra um comparativo dos valores (em mm) das médias das medidas obtidas pelos sete grupos para a distância D10-CID (região de Canino Inferior Direito), onde observamos grande uniformidade entre os grupos. O grupo 7 (Planimp/calibração referencial/câmera) alcançou valores iguais aos obtidos pelo grupo controle, tendo portanto o melhor desempenho. Os demais grupos (2, 3, 4, 5 e 6) obtiveram valores imperceptivelmente maiores que os obtidos pelo grupo controle.

O gráfico da Figura 26 mostra um comparativo dos valores (em mm) das médias das medidas obtidas pelos sete grupos para a distância 
D11-ICI (região de Incisivo Central Inferior), observamos que as medidas digitais obtidas pelos grupos 2, 3, 4, 5, 6 e 7, foram maiores que as obtidas pelo grupo controle. Os grupos 3, 4 e 7 tiveram grande uniformidade em relação ao grupo controle, sendo que o melhor resultado foi obtido pelos $\begin{array}{llllll}\text { grupos } & 3 & \text { (Radioimp/calibração } & \text { referencial/escaner) } & \text { e }\end{array}$ (Radioimp/calibração referencial/câmera).

A Figura 27 mostra um comparativo dos valores (em mm) das médias das medidas obtidas pelos sete grupos para a distância D12-CIE (região de Canino Inferior Esquerdo), onde observamos que todas as medidas digitais obtidas pelos grupos 2, 3, 4, 5, 6 e 7, foram maiores que as obtidas pelo grupo controle. Analisando visualmente esse gráfico, notamos um comportamento semelhante entre os programas de imagem e seus sistemas de calibração da imagem, onde apresentaram valores muito parecidos: grupo $2(8,730)$ e grupo $5(8,733)$; grupo $3(8,728)$ e grupo 6 (8,732); grupo $4(8,721)$ e grupo $7(8,722)$. As medidas obtidas pelos grupos 4 e 7 permaneceram no mesmo patamar das obtidas pelo grupo controle, sendo que o grupo 4 (Radioimp/calibração referencial/câmera) alcançou o melhor resultado. Salientamos que esses resultados foram equivalentes aos apresentados nas medições da distância D8-MID (Molar Inferior Direito), exibidas no gráfico da Figura 23.

O gráfico da Figura 28 exibe um comparativo dos valores (em $\mathrm{mm}$ ) das médias das medidas obtidas pelos sete grupos para a distância D13-PMIE (região de Pré-Molar Inferior Esquerdo), onde observamos que as medidas digitais obtidas pelo grupo 6 (Planimp/calibração referencial/escaner) foram menores que as obtidas pelo grupo controle. Por outro lado, as medidas digitais dos demais grupos $(2,3,4,5$, e 7$)$ exibiram valores maiores que os do grupo controle. Os melhores resultados foram obtidos pelos grupos 4 (Radioimp/calibração referencial/câmera) e 7 
(Planimp/calibração referencial/câmera), que permaneceram no mesmo patamar do grupo controle.

A Figura 29 projeta um comparativo dos valores (em $\mathrm{mm}$ ) das médias das medidas obtidas pelos sete grupos para a distância D14-MIE (região de Molar Inferior Esquerdo), onde observamos que as medidas digitais (grupos 2, 3, 4, 5, 6 e 7) foram maiores que às medidas manuais (grupo controle). Ocorreu uma certa uniformidade entre os grupos constituídos pelas medidas obtidas pelos programas de imagem, porém foram discrepantes em relação às medidas do grupo controle. O resultado mais próximo do obtido pelo grupo controle foi obtido pelo grupo 7 (Planimp/calibração referencial/câmera).

Analisando-se individualmente os gráficos representativos das 14 distâncias anatômicas, constatamos que não houve discrepância significativa entre elas, e que a média geral registrada no gráfico da Figura 30 é representativo. Assim, optou-se por trabalhar com essa média geral.

\subsection{2- Comparação entre medidas digitais e as medidas manuais}

O gráfico da Figura 30 ilustra um comparativo da média geral das 14 distâncias (D1-MSD, D2-PMSD, D3-CSD, D4-ICS, D5-CSE, D6PMSE, D7-MSE, D8-MID, D9-PMID, D10-CID, D11-ICI, D12-CIE, D13PMIE, D14-MIE), referentes a cada um dos sete grupos (1- Paquímetro, 2Radio-dpi-esc, 3- Radio-mm-esc, 4- Radio-mm-ca, 5- Plan-dpi-esc, 6-Planmm-esc, 7-Plan-mm-ca). Analisando o referido gráfico observamos que, de um modo geral, as medidas digitais obtidas pelos grupos 2, 3, 4, 5, 6 e 7 foram maiores que as obtidas pelo método manual (grupo controle). Mas essa diferença foi muito pequena, não sendo suficiente para ser estatisticamente significante. 
Resultado semelhante ao esse estudo foi encontrado por CONOVER; HILDEBOLT; YOKOYAMA-CROTHERS ${ }^{25}$, em 1996. Eles compararam medidas lineares tomadas diretamente sobre radiografias convencionais, radiografias indiretamente digitalizadas e imagens digitais obtidas por meio de placas de armazenamento de fósforo. Foram radiografadas hemimandíbulas secas contendo pontos radiopacos, que serviram de referência para as mensurações. O método indireto de digitalização utilizado foi um escaner de superfície plana, regulado para uma resolução espacial de $50 \mu \mathrm{m}$. A mensuração das distâncias lineares das imagens digitais foram obtidas por meio do programa DIPStation 1.0.6, enquanto que as medições manuais, realizadas com auxílio de um paquímetro, diretamente sobre as radiografias. Após a comparação, os resultados mostraram que as medidas das imagens dos filmes escaneados foram maiores que as obtidas manualmente sobre as radiografias, com uma diferença média de $1 \mathrm{~mm}$. Contudo, essas diferenças não foram estatisticamente significantes.

BAHLIS; VEECK; DI NARDO ${ }^{7}$ em 2000, utilizando imagens de tomografia linear, compararam mensurações realizadas diretamente sobre as tomografias convencionais com as obtidas por meio de programa digital, a partir da digitalização das mesmas. A amostra foi constituída de 20 hemimandíbulas humanas secas, que foram radiografadas. A área selecionada para estudo foi a região desdentada de forame mentual. As tomografias foram digitalizadas e medidas por meio da escala do programa digital (DentScan Dent View - APICA Co.). Com o uso de um paquímetro eletrônico digital foram realizadas medições diretamente sobre as tomografias originais. Os resultados mostraram que as medidas digitais (tomografia digitalizada) foram insignificantemente maiores que as medidas manuais obtidas pelo paquímetro digital (diferença aproximada de 0,094 mm), não apresentando, contudo, diferença estatística significante. 
Esses resultados foram semelhantes aos dessa pesquisa, com diferenças mínimas na metodologia, que se valeu do sistema de digitalização indireta e programa de imagem da APICA em imagens tomográficas.

Por outro lado, CAMACHO et al. ${ }^{14}$ em 1999, apesar de terem trabalhado com o mesmo tipo de radiografia (panorâmica) e o mesmo método de digitalização (escaner) utilizados nessa pesquisa, apresentaram resultados diferentes. O referido estudo foi realizado para avaliação óssea pré-cirúrgica. Para isso, guias esféricas metálicas foram posicionadas para indicar 12 distâncias anatômicas, no rebordo alveolar de cinco crânios. As radiografias panorâmicas dos crânios foram digitalizadas pelo escaner Hewlett Packard, e as medições digitais, obtidas por meio do programa Image Tool, enquanto que as mensurações manuais sobre as panorâmicas, foram realizadas com auxílio de uma régua. Os resultados mostraram que as medidas digitais foram menores que as medidas obtidas por meio da régua, aplicada diretamente sobre as radiografias (diferença aproximada de 0,2 mm). Provavelmente essa diferença pode ter sido ocasionada em virtude de termos usado um paquímetro digital, com precisão de 0,01 mm, enquanto que os autores fizeram uso de uma régua, que pode apresentar um erro máximo de $0,5 \mathrm{~mm}$.

Vários autores, entre eles BRANDÃO; COSTA; RAMALHO $^{12}$, 2001, CEDERBERG et al. ${ }^{16}, 1998$, OLIVEIRA et al. ${ }^{57}$, 2001, SILVA; CLASEN; AUN ${ }^{69}$, 2000, VELDERS; SANDERINK; STELT $^{73}, 1996$ e VERSTEEG et al. ${ }^{74}, 1997$, utilizando a radiografia digital direta em diferentes aparelhos, comparando medidas lineares do comprimento de limas endodônticas, em filmes convencionais, com as medidas digitais, observaram que as digitais foram levemente maiores que aquelas realizadas com régua diretamente sobre os filmes periapicais. Os resultados encontrados foram semelhantes aos obtidos neste estudo, apesar de terem utilizado um método direto de radiografias digitais (sistemas 
Sidexis, Digora, Vixa, RVG, CDR, DenOptix). Entretanto, ARAÚJO FILHO et al. ${ }^{4}$, 1999, DAVIDOWICZ et al. ${ }^{27}$, 2001, EIKENBERG; VANDRE $^{33}$, 2000, SCARFE; NORTON; FARMAN ${ }^{66}$, 1995, VERSTEEG et al. $^{74}, 1997$, encontraram medidas digitais obtidas por meio de sistemas digitais diretos (Vixa, Schick, Sens-A-Ray, Dexis Vixa, RVG-S, Flash Dent), menores que as realizadas manualmente sobre as radiografias convencionais.

Para mensurações de lesões periapicais, SCARFE et al. ${ }^{65}$ em 1999, utilizaram o programa VixWin em radiografias digitais obtidas por meio do sistema Visualix-2, e uma régua milimetrada em radiografias periapicais. Após a comparação, os autores observaram que as medidas digitais foram maiores que as obtidas manualmente.

HAITER et al. $^{41}$ em 2001, utilizando o sistema Digora, também encontraram valores de medidas digitais maiores que as manuais, na mensuração de reabsorções radiculares.

Analisando os trabalhos de vários autores, observamos que há uma tendência das medidas digitais serem maiores que as medidas manuais, porém sem significância estatística. Essa observação é importante para que os profissionais, especialmente das áreas de Endodontia e Implantodontia, atentem para o resguardo da margem de segurança.

Apesar da observação acima, muitos autores sugerem que o uso dos programas de imagem para medições são alternativas plenamente viáveis para esse fim.

Assim, SCARFE; NORTON; FARMAN ${ }^{66}$ 1995, sugeriram que as medidas digitais são no mínimo tão precisas ou até mais que aquelas obtidas com réguas milimetradas, para obtenção de medidas dimensionais. CONOVER; HILDEBOLT; YOKOYAMA-CROTHERS ${ }^{25}$ em 1996, concluíram que as imagens radiográficas digitalizadas, quando analisadas por meio de programas de imagem, são alternativas viáveis na realização 
de mensurações de distâncias lineares. VERSTEEG et al. ${ }^{74}$ em 1997, concluíram que estimar distâncias sobre imagens digitalizadas é comparável às medidas sobre radiografias convencionais, ou mais precisas.

Desse modo, conforme observou-se, os programas de imagem utilizados em diferentes áreas da Odontologia, apresentaram resultados altamente satisfatórios, sendo os mesmos recomendados para medições lineares.

Neste trabalho, avaliando os programas Planimp e Radioimp para mensuração linear em Implantodontia, constatamos que as medições fornecidas pelos mesmos foram compatíveis com aquelas efetudadas com auxílio do paquímetro digital, pelo método manual. Além disso observamos, durante o experimento, que a mensuração computadorizada oferece algumas vantagens em relação ao método manual, pela facilidade de visualização dos pontos de referência, rapidez no momento da mensuração, sendo inclusive menos trabalhosa e cansativa.

Diante desses resultados podemos afirmar que esses programas podem ser utilizados como um auxílio valioso no planejamento précirúrgico de implantes.

\subsection{3- Comparação entre os sistemas de calibração dos programas}

Os programas de imagem Radioimp e Planimp oferecem a possibilidade de se realizar a calibração por meio de dois sistemas: o referencial e por resolução. 
Dessa forma, neste trabalho essa calibração por meio desses dois métodos foi realizada, objetivando verificar o comportamento dos mesmos.

Observando o gráfico da Figura 30 constatou-se que os dois sistemas de calibração da imagem, tanto o referencial quanto o sistema por resolução, apresentaram comportamento semelhante. A média dos grupos 3, 4, 6 e 7 - referencial foi de 9,514; enquanto que a média dos grupos 2 e 5 - por resolução foi de 9,517. Essa diferença não foi estatisticamente significante.

\subsection{4- Comparação entre os programas Radioimp e Planimp}

Para realizar esse trabalho, procedeu-se a uma comparação dos resultados alcançados pelos dois programas, com aqueles fornecidos pelo grupo controle.

\subsubsection{1- Em relação aos seus sistemas de calibração}

Analisando o gráfico da Figura 30, observou-se que os valores do grupo 2 - sistema de calibração por resolução do Radioimp - foi de 9,516; enquanto que os valores do grupo 5 - sistema de calibração por resolução do Planimp - foi de 9,519. Por outro lado, os valores da média dos grupos 3 e 4 - sistema de calibração referencial do Radioimp -, foi de 9,512, enquanto que a média dos grupos 6 e 7 - sistema referencial do Planimp -, foi de 9,516. Correlacionando esses valores com aqueles do grupo controle, observamos que a diferença não foi estatisticamente significante. Dessa forma pode-se dizer que o comportamento dos dois programas de imagem em relação aos seus sistemas de calibração, foi equivalente. 


\subsubsection{Em relação aos seus sistemas de medição}

Dessa forma, a média dos grupos 2, 3 e 4 - Radioimp - foi de 9,513, enquanto a média dos grupos 5, 6 e 7 - Planimp - foi de 9,517. A diferença de milésimos de milímetro, que é pouco significante, motivo pelo qual pode-se dizer que os dois programas se equivalem em relação aos seus sistemas de medição linear.

\subsection{5- Comparação entre os métodos de aquisição de imagem: escaner e câmera digital}

Observando o gráfico exibido na Figura 30, que demonstra a comparação da média geral das 14 distâncias, referentes aos sete grupos, nota-se que as medidas obtidas nas radiografias digitalizadas pela câmera digital, dos grupos $4(9,506)$ e $7(9,512)$ estiveram mais próximas das do grupo controle $(9,503)$ em comparação com aquelas obtidas por meio do escaner nos grupos 2 (9,516), 3 (9,518), 5 (9,519), 6 (9,520). Contudo, essa diferença é pouco significativa, situando-se na casa de milésimos de milímetro.

Para realizar as medições pelo método digital, utilizou-se de um escaner de superfície plana, com leitor de transparência, visto que é o tipo de digitalizador mais utilizado no Brasil.

Segundo a observação de CHEN; HOLLENDER ${ }^{20}$ em 1995, os sistemas de vídeo, e escaneres a tambor e a laser também podem ser utilizados para a digitalização de radiografias. O sistema de escaner é considerado mais prático e menos susceptível a erros em relação ao sistema de câmeras de vídeo, pois não requer ajustes de zoom e de posicionamento da câmera para a obtenção da reprodução de imagens digitais. 
Escaneres a tambor e a laser têm sido usados com sucesso para digitalização de filmes radiográficos, acarretando, entretanto custo elevado. Dessa forma, uma opção mais acessível é o escaner de superfície plana com leitor de transparência (CHEN; CHIANG ${ }^{19}$, 1997; CHEN; HOLLENDER $^{20}$, 1995; OHKI; OKANO; NAKAMURA $\left.{ }^{56}, 1994\right)$.

CHEN; CHIANG ${ }^{19}$ em 1997, apresentaram, em termos de custos, uma opção intermediária - o escaner tipo cilíndrico. Ele não é tão caro quanto os escaneres a laser e a tambor, nem tão barato quanto o escaner de superfície plana. Porém, na realidade brasileira, ainda podemos considerá-lo de custo elevado. Esse escaner tipo cilíndrico foi inicialmente desenvolvido para digitalização de filmes médicos. Após avaliação feita pelos autores, observou-se que esse escaner obteve um ótimo alcance dinâmico, semelhante ao da radiografia original, sendo, portanto, também adequado para digitalização de radiografias odontológicas.

Sabe-se que a câmera fotográfica digital tem sido recentemente utilizada por alguns profissionais, para a digitalização indireta de radiografias.

Contudo, não é do nosso conhecimento a existência de um protocolo específico disciplinando o seu uso para digitalização de filmes radiográficos em Odontologia.

Face a essa ausência, nessa pesquisa, para a sua utilização, tivemos que elaborar um projeto piloto, no sentido de selecionar uma distância lente/filme adequada para a digitalização de radiografias panorâmicas, com a máquina escolhida.

Constatamos que, após os cuidados iniciais de instalação para o seu uso, o qual implica em muitos detalhes, tais como: o posicionamento correto da câmera na estativa, distância adequada e ajuste do foco e do zoom, o procedimento específico da digitalização ocorre com rapidez. 
Observamos ainda que a utilização do escaner, por ser mais simples, embora mais lenta, não oferece tantos riscos de uma falha do operador.

A digitalização efetuada por meio da câmera fotográfica digital foi feita com a finalidade específica de realizar mensurações lineares.

Entretanto, notamos que ela oferece imensas outras possibilidades na área da Implantodontia: o ajuste do zoom da lente para focalização de uma área clínica de interesse, oportuniza também a repetição das tomadas fotográficas no ato. Também como auxiliar valioso no planejamento de implantes, documentando os procedimentos clínicos, na fase pré-cirúrgica, dos procedimentos cirúrgicos e protéticos, e na fase pósimplante. Facilita, sobremaneira, a comunicação com o paciente, que poderá visualizar todas as fases do tratamento. Ainda, em uma fase de planejamento cirúrgico, o paciente, em frente ao monitor de TV, recebendo explicações do profissional sobre a situação atual, sobre os procedimentos que serão feitos, e uma prospecção futura, se sentirá mais confiante no trabalho do profissional e no resultado final.

Existem trabalhos que se reportam ao uso da câmera digital para aquisição de imagens radiográficas na área de Telemedicina e Telerradiologia, com resultados altamente satisfatórios para fim de diagnóstico, conforme estudo realizado por KRUPINSKI ${ }^{48}$, em 2000.

Diante dos resultados obtidos em nossa pesquisa, com a sua utilização, podemos concluir que a câmera fotográfica digital é um instrumento perfeitamente utilizável para a digitalização de radiografias, observados os cuidados necessários em sua manipulação.

Entretanto, ressaltamos que a sua utilização foi feita em caráter essencialmente experimental e, ainda, por se tratar de um meio, relativamente novo na digitalização de radiografias, face a escassa literatura 
a respeito, o seu uso nesse sentido merece futuros estudos, inclusive para o estabelecimento de procedimentos e parâmetros para o seu emprego na Odontologia.

\subsection{6- Considerações finais}

À vista do que foi observado, os resultados podem ser visualizados nas Tabelas de 1 a 14, onde estão expostos os valores das médias, desvios padrão e p calculados pela análise de variância a um critério para medidas repetidas, com nível de significância a 5\%, a partir das medidas obtidas pelos sete grupos (1- Paquímetro, 2- Radioimpresolução-escaner, 3- Radioimp-referencial-escaner, 4- Radioimpreferencial-câmera, 5- Planimp-resolução-escaner, 6- Planimp-referencialescaner, 7- Planimp-referencial-câmera) para as distâncias de cada área (D1-MSD, D2-PMSD, D3-CSD, D4-ICS, D5-CSE, D6-PMSE, D7-MSE, D8-MID, D9-PMID, D10-CID, D11-ICI, D12-CIE, D13-PMIE, D14-MIE).

Em uma observação detalhada desses valores, percebe-se que as médias e os desvios padrão dos sete grupos atingiram valores muito próximos, refletindo valores de p não significantes para todas as medidas. A partir desses resultados não foi necessária a realização do teste de Tukey, previsto para a localização exata das diferenças significantes entre os pares de grupos.

Em função destes dados podemos afirmar que os programas utilizados nas mensurações (Radioimp e Planimp), os seus sistemas de calibração da imagem (sistema por resolução e referencial), bem como os métodos de aquisição de imagem (escaner e câmera digital), são comparáveis e passíveis de serem utilizados no planejamento pré-cirúrgico de implantes osseintegrados. 
Confirmando as nossas observações, COSTA et al. ${ }^{26}$ em 2004, também concluíram que o desenvolvimento de novos programas de computador que possibilitem a observação das medidas e simulação da colocação de implantes, seriam extremamente úteis em Radiologia voltada para a Implantodontia.

Esse estudo vem de encontro às expectativas desses autores, haja vista que os recentes programas Radioimp e Planimp oferecem essas e outras possibilidades e alternativas. 
7- CONCLUSÕES 


\section{7- CONCLUSÕES}

À luz dos resultados obtidos e da metodologia aplicada neste estudo, podemos concluir que:

1- Os programas de imagem Radioimp e Planimp, quanto aos seus sistemas de medição linear, demonstraram desempenho compatível com o grupo controle - paquímetro digital - pois não apresentaram diferença estatisticamente significante;

2- Os programas Radioimp e Planimp , em relação aos seus sistemas de calibração - sistema referencial e sistema por resolução - apresentaram desempenho adequado para a calibração da magnificação da imagem radiográfica; podendo ser utilizados no planejamento pré-cirúrgico de implantes odontológicos

3- Em relação aos métodos de digitalização - escaner e câmera fotográfica digital - constatamos que não houve diferenças estatisticamente significantes entre eles, sendo adequados para o uso com os programas estudados. 
REFERÊNCIAS BIBLIOGRÁFICAS 


\section{REFERÊNCIAS BIBLIOGRÁFICAS*}

1 - ABRAHAMS, J.J. The role of diagnostic imaging in dental radiology. Radiol Clin North Am., v.31, n.1, p.163-80, Jan. 1993.

2 - ALVARES, L.C.; FREITAS, J.A.S.; CAPELOZZA, A.L.A. "R" In:__ Glossário de termos técnicos de radiologia odontológica e radiobiologia. 2. ed. Bauru, EDUSC, 2000. 131p.

3 - ALVARES, L.C.; TAVANO, O. Curso de radiologia em odontologia. 4. ed, São Paulo, Editora Santos, 2002.

4 - ARAÚJO FILHO et al. Radiografia digital direta X radiografia convencional na obtenção da odontometria: uma comparação "in vivo". Rev Bras Odontol., v. 56, n.6, p.323-6, nov./dez. 1999.

\footnotetext{
* Normas recomendadas para uso no âmbito da Universidade de São Paulo, com base no documento "Referências Bibliográficas: exemplos", emanado do conselho Supervisor do Sistema Integrado de Biblioteca da USP, em reunião de 20 de setembro de 1990.
} 
5 - ATTAELMANAN, A.; BORG, E.; GRÖNDAHL, H.G. Digitization and display of intra-oral films. Dentomaxillofac Radiol, v.29, n.2, p.97-102, Mar. 2000.

6 - ÁVILA, M.A.G. Análise da imagem radiográfica em diferentes aparelhos panorâmicos. Bauru, 1996, 124p. Dissertação (Mestrado) - Faculdade de Odontologia de Bauru, Universidade de São Paulo.

7 - BAHLIS, A.; VEECK, E.B.; DI NARDO, M.I. Avaliação, em mandíbulas secas, da confiabilidade das medidas nas tomografias lineares. Rev Odonto Ciênc, v.15, n.31, p.125-41, dez. 2000.

8 - BENGEL, W. Digital photography in the dental practice - an overview. Int J Comput Dent, v.3, n.2, p.121-32, May 2000.

9 - BORG, E.; GRÖNDAHL, H.G. On the dynamic range of different X ray photon detectors in intra-oral radiography. A comparison of image quality in film, charge-couple device and storage phosphor systems. Dentomaxillofac Radiol, v.25, n.2, p.82-8, Apr. 1996.

10 - BÓSCOLO, F.N. et al. Estudo clínico comparativo da qualidade de imagem de três sistemas radiográficos digitais, filme E-speed e filme digitalizado. Pesqui Odontol Bras, v. 15, n.4, p.327-33, out./dez. 2001. 
11 - BOUSERHAL, C. et al. Imaging tecnique selection for the preoperative planning of oral implants: a review of the literature. Clin Implant Dent Relat Res, v.4, n.3, p.156-72, 2002.

12 - BRANDÃO, E.G.; COSTA, N.P.; RAMALHO, L.M.P. Avaliação do comprimento de condutos radiculares utilizando um sistema de radiografia digitalizada. Rev Odonto Ciênc, v.16, n.33, p.111-9, maio/ago., 2001.

13 - BROOKS, S.L.; MILES, D.A. Advances in diagnostic imaging in dentistry. Dent Clin North Am., v.37, n.1, p.91-111, Jan. 1993.

14 - CAMACHO, H.M. et al. Conventional radiographic and digital computerized analysis in osseous assessment for implants. Univ Odontol, v.19, n.39, p.9-13, Aug. 1999.

15 - CAPELOZZA, A.L.A. Estudo comparativo de algumas lesões do periápice através da imagem radiográfica convencional e imagem digital indireta utilizando o programa Adobe Photoshop 5.0. Bauru, 2001. 116p. Tese (Livre Docência) Faculdade de Odontologia de Bauru, Universidade de São Paulo.

16 - CEDERBERG, R.A. et al. Endodontic working length assessment. Oral Surg Oral Med Oral Pathol Oral Radiol Endod, v.85, n.3, p.325-8, Mar. 1998. 
17 - CDT CONSULTORIA DESENVOLVIMENTO E TREINAMENTO EM INFORMÁTICA. Disponível na Internet http://www. cdt.com.br. 20 maio 2004.

18 - CDT. Manual do programa Planimp 3.2.8. Cuiabá, M.T., Brasil. 2000.

19 - CHEN, S.K.; CHIANG, T.C. Digitizing of radiographs with a rollertype CCD scanner. Oral Surg Oral Med Oral Pathol Oral Radiol Endod, v.83, n.6, p.719-24, June 1997.

20 - CHEN, S.K.; HOLLENDER, L. Digitizing of radiographs with a flatbed scanner. J Dent, v. 23, n.4, p.205-8, July 1995.

21 - CHILVARQUER, I. A Radiologia e seus avanços contemporâneos. Rev Assoc Paul Cirurg Dent, v. 47, n.2, p.1001-4, mar./abr. 1993.

22 - CHILVARQUER, I. Novos métodos de exames radiológicos: radiologia na implantodontia osseointegrada. In: Freitas, A.; Rosa, J.E.; Souza, I. F. Radiologia odontológica. 4. ed. São Paulo, Artes Médicas, 1998. p.644.

23 - CHILVARQUER, I. Imageologia da osseointegração moderna. In:_ GOMES, L. A. Implantes osseointegrados: técnica e arte. São Paulo: Editora Santos, 2002. p.211-9. 
24 - CHILVARQUER, I.; CHILVARQUER, L.W. Método de localização para implantes. Disponível na Internet. http//www.indor.com.br/htm/serviços/implantes/linear.php

25 - CONOVER, G.L.; HILDEBOLT, C.F.; YOKOHAMA-CROTHERS, N. Comparison of linear measurements made from storage phospor and dental radiographs. Dentomaxillofac Radiol, v.25, n.5, p.268-73, Nov. 1996.

26 - COSTA, C. et al. Fundamentos radiográficos para implantes odontológicos. Rev ABRO, v.5, n.2, p.63-6, jul./dez. 2004.

27 - DAVIDOWICZ, H. et al. A radiografia digital na Endodontia. Rev. ABO, v.9, n.5, p. 310-4, out./nov. 2001.

28- DOLPHIN IMPLANER. Disponível na Internet http://www. dolphinimaging.com. 20 maio 2004.

29 - DULA, K. et al. The radiographic assessment of implant patients: decision-marking criteria. Int J Oral Maxillofac Implants, v. 16, n.1, p.80-9, Nov. 2001.

30 - DUNN, J.; BECKLER, G. Digital photography technology offers unique capabilities, advantages, and challenges to dental practices. J Calif Dent Assoc, v.29, n.10, p.744-50, Oct. 2001. 
31 - DUNN, M.S.; KANTOR, M.L. Digital radiology: facts and fictions. J Am Dent Assoc., v. 124, n.2, p.39-47, Dec. 1993.

32 - EICKHOLZ, P. et al. Digital radiography of interproximal bone loss; validity of different filters. J Clin Periodontol, v.26, p. 294-300 Aug. 1999.

33 - EIKENBERG, L.S.; VANDRE, C.R. Comparision of digital x-ray systems with self-development film and manual processing for endodontic file length determination. J Endod., v.26, n.2, p.65-7, Feb. 2000.

34 - FARMAN, A.G. et al. In vivo comparision of Visualix-2 and Ektaspeed Plus in the assessment of periadicular lesion dimensions. Oral Surg Oral Med Oral Pathol Oral Radiol Endod, v.85, n.2, p.203-9, Feb. 1998.

35 - FERREIRA, R.A. Odontologia em imagens. Rev Assoc Paul Cirurg Dent, v.50, n.3, p.218-28, maio/jun. 1996.

36 - FOTOGRAFIA DIGITAL. Disponível na Internet http://www.cdt.com.br/site-br/sla-informacao/sla-materiascientificas. 20 maio 2004.

37 - FREDERIKSEN, N.L. Diagnostic imaging in dental implantology. Oral Surg Oral Med Oral Pathol Oral Radiol Endod, v. 80, n.5, p.540-54, Nov. 1995. 
38 - FUJITA, M. et al. Digital image processing of periapical radiographs. Oral Surg Oral Med Oral Pathol Oral Radiol Endod, v.65, n.4, p.490-4, Apr. 1988.

39 - GRÖNDAHL, H.G. Digital Radiology in dental diagnosis: a critical view. Dentomaxillofac Radiol, v.21, n.4, p.198-202, Nov 1992.

40- GROSSI, A.T.R.; TAVANO O. A radiografia digital na Odontologia. Bauru. 1997. 78p. Monografia (Especialização) Faculdade de Odontologia de Bauru, Universidade de São Paulo.

41 - HAITER, C. et al. Avaliação de simulações de reabsorções radiculares por meio de imagens digitais e convencionais. Ortodontia, v.34, n.2, p.37-43, maio/ago. 2001.

42 - HARRIS. D. et al. E.A.O. Guidelines for the use of diagnostic imaging in Implant Dentistry. Clin Oral Implants Res, v.13, p. 566-70, 2002.

43 - HILDEBOLT, C.F. et al. Quantitative evaluation of digital dental radiograph imaging systems. Oral Surg Oral Med Oral Pathol Oral Radiol Endod, v.70, n.5, p.661-8, Nov. 1990.

44 - IMAGENS DIGITAIS. Disponível na Internet http://www.radiomemory.com.br/cursos/imagensdigitais/cap2.html. 20 maio 2004. 
45 - KALIL, M.V. Traçado radiográfico em radiografia panorâmica como recurso no planejamento dos implantes osseoinegrados. Rev Bras Implant, p.8-10, maio/jun. 1998.

46 - KASSEBAUM, D.K. et al. Spatial resolution requirements for digitizing dental radiographs. Oral Surg Oral Med Oral Pathol Oral Radiol Endod, v.67, n.6, p.760-9, June 1989.

47 - KIM, T.; BENN, D.K.; EICKHOLZ, P. Accuracy of computer-assisted radiographic measurement of interproximal bone loss in vertical bone defects. Oral Surg Oral Med Oral Pathol Oral Radiol Endod, v.44, n.3, p.379-87, Sept. 2002.

48 - KRUPINSK, E. et al. Evaluation of a digital camera for acquiring radiographic images for telemedicine applications. Telemed $\mathbf{J} \mathbf{E}$ Health, v.6, n.3, p.297-302, June 2000.

49 - KURITA, L.M. et al. Análise comparativa de radiografias panorâmicas convencionais e digitais no controle de alterações ósseas periimplantares. BCI, v. 8, n.31, p.202-6, jul./set. 2001.

50 - LANGLAND, O.E. et al. Panoramic radiology. 2. ed. Philadelphia, Lea \& Febiger, 1989. 
51 - LAURIS, J.R.P. SPIRO - Sistema para processamento de imagem radiográfica odontológica. Campinas, 1997, 72p. Dissertação (Mestrado) - Faculdade de Engenharia Elétrica e de Computação, Universidade Estadual de Campinas.

52 - MC DONNELL, D. Digital dental imaging systems: a review. J Canad Dent Assoc., v.61, n.11, p.962-4, Nov. 1995.

53 - MILES, D.A.; VAN DIS, M.L. Implant radiology. Dent Clin North Am, v.37, n.4, p.645-668, Oct. 1993.

54 - MONTEBELO FILHO, A. Avaliação da fidelidade das imagens obtidas de crânios secos, por meio de exames radiográficos convencionais (intra e extra bucais) e tomográficos (panorâmico convencionais e computadorizado) em comparação com anatomia óssea topográfica. Piracicaba, 2000, 183p. Tese (Livre Docência) - Faculdade de Odontologia de Piracicaba, Universidade Estadual de Campinas.

55 - MOYSTAD, A. et al. Detection of approximal caries with a storage phosphor system. A comparison of enhaced digital images with dental X-ray film. Dentomaxillofac Radiol, v.25, n.4, p.202-6, Sept. 1996. 
56 - OHKI, M.; OKANO, T.; NAKAMURA, T. Factors determining the diagnostic accuracy of digitized conventional intra-oral radiographs. Dentomaxillofac Radiol, v.23, n.2, p.77-82, May 1994.

57 - OLIVEIRA, A.E.F. et al. Estudo da eficiência de diferentes sistemas radiográficos nas mensurações endodônticas. RPG rev. Pós-grad, v. 8, n.1, p.29-34, jan./mar. 2001.

58- RADIOMEMORY. Disponível na Internet http://www. radiomemoy.com.br. 20 maio 2004.

59 - RADIOMEMORY. Manual do programa Radioimp. Belo Horizonte, M.G., 2000.

60 - REISKIN, A.B. Implant imaging. Dent Clin North Am, v.42, n.1, p.47-56, Jan. 1998.

61 - SANDERINK, G.C.H. Imaging: new versus traditional technological. Int Dent J, v.43, n.4, p.335-42, Aug. 1993.

62 - SARMENTO, V.A. et al. Imagem digitalizada em Odontologia evolução até os dias atuais. Rev Fac Odontol Univ Fed Bahia, v.20, p.38-42, jan./jun. 2000. 
63- SARMENTO, V.A.; PINHO, C.B.; RIVAS, C.C. Influência do tempo de exposição à radiação $\mathrm{X}$ e do tamanho de captura da radiografia na amplitude dinâmica de imagens digitalizadas. Rev Odontol UNESP, v.31, n.1, p.61-70, jan./jun. 2002.

64 - SARMENTO, V.A.; PRETTO, S.M.; COSTA, N.P. Entendendo a imagem digitalizada. Rev Odonto Ciênc, v. 14, n.27, p.171-8, jun. 1999.

65 - SCARFE, W.C. et al. In vivo accuracy and reliability of color-coded image enhancements for the assessment of periradicular lesion dimensions. Oral Surg Oral Med Oral Pathol Oral Radiol Endod, v.88, n.5, p.603-11, Nov. 1999.

66 - SCARFE, W.C.; NORTON, S.; FARMAN, A. G. Measurement accuracy: a comparison of two intra-oral digital radiographic systems, RadioVisoGraphy-S and FlashDent, with analog film. Dentomaxillofac Radiol, v.24, n.4, p.215-20, Nov 1995.

67 - SEWELL, C.M.D.; FENYO PEREIRA, M.; VAROLI, O. J. Princípios de produção da imagem digitalizada. RPG rev. pos-grad, v.4, n.1, p.55-8, jan./mar. 1997.

68 - SHROUT, M.K. et al. 35mm film scanner as na intraoral dental radiograph digitizer I: A quantitative evaluation. Oral Surg Oral Med Oral Pathol Oral Radiol Endod, v.76, n.4, p.502-9, Oct. 1993. 
69 - SILVA, A.H.F.; CLASEN, N.F.; AUN, C.E. Comparação entre radiografia digital direta e convencional na determinação da distância entre a ponta do instrumento endodôntico e o ápice dentário durante a odontometria. Rev Odontol UNICID, v.12, n.2, p.129-137, jul./dez. 2000.

70 - TYNDALL, D.A. et al. Selection criteria for dental implant site imaging: a position paper of the American Academy of Oral and Maxillofacial Radiology. Oral Surg Oral Med Oral Pathol Oral Radiol Endod,v. 89, n.5, p.630-7, May 2000.

71 - VALE, I.S.; BRAMANTE, C.M. Visibilidade de algumas limas endodônticas por meio do sistema de imagem digital Digora e de três filmes radiográficos periapicais. Rev Fac Odontol Bauru, v. 10, n.1, p.29-33, jan./mar. 2002.

72 - VAN DER STELT, P.F. Principles of digital imaging. Dent Clin North Am, v.44, n.2, p.237-48, Apr. 2000.

73 - VELDERS, X.L.; SANDERINK, G.C.; VAN DER STELT, P.F. Dose reduction of two digital sensor systems measuring file lengths. Oral Surg Oral Med Oral Pathol Oral Radiol Endod,v.81, n.5, p.607-12, May 1996.

74 - VERSTEEG, C.H. et al. Estimating distances on direct digital images and conventional radiographs. J Am Dent Assoc, v. 128, n.4, p.439-43, Apr. 1997. 
75 - VERSTEEG, C.H.; SANDERINK, G.C.H.; VAN DER STELT, P.F. Efficacy of digital intra-oral radiograpy in clinical dentistry. $\mathbf{J}$ Dent, v.25, n.3/4, p.215-24, May/July 1997

76 - VILLA SISTEMI MEDICALI. Manual do aparelho panorâmico Rotograph 230. Buccinasco, Italy. 1992.

77 - VISSER, H.; AYABAKAN, V. H. Imaging properties of high resolution film scanners. Dentomaxillofac Radiol, v.24, n. 2, p. 84-5, Oct. 1995.

78 - ZENÓBIO, E.G.; FERREIRA, B.A. Estudo das perdas ósseas periodontais através da imagem radiográfica digitalizada. Rev Gauch Odontol, v. 45, n.1, p.12-4, jan./fev. 1997.

79 - WATANABE, P.C.A. et al. Estado atual da arte da imagem digital em Odontologia. Rev Assoc Paul Cirurg Dent, v.53, n.4, p.320-5, jul./ago. 1999.

80 - WENZEL, A. Effect of image enhancement for detectability of bone lesions in digitized in intraoral radiographs. Scand J Dent Res, v.96, p.149-60, 1988.

81 - WENZEL, A. Effect of varying gray-scale resolution for detectability of bone lesions in intraoral radiographs digitized for teletransmission. Scand J Dent Res, v.95, p.483-92, 1987. 
82 - WENZEL, A.; GRÖNDAHL, H.G. Direct digital radiograph in the dental office. Int Dent J, v.45, n.1, p.27-34, Feb. 1995.

83 - WOLF, B. et al. Reability of assessing interproximal bone loss by digital radiography: intrabony defects. J Clin Periodontol, v.28, n.9, p.869-78, Sept. 2001. 


\section{ABSTRACT}

The present study evaluated the linear measurements on panoramic radiographs obtained in image softwares for presurgical implant planning (Radioimp and Planimp) compared to the manual technique using a digital caliper. And evaluated the systems for image digitization employed: scanner and digital camera. The sample comprised 50 panoramic radiographs of edentulous patients, on which reference points were traced for delineation of 14 anatomical dimensions on each radiograph. The radiographs were digitized with a HP Scanjet 4C/T scanner (Hewllett Packard) and a digital camera FinePix S602 (Fujifilm). Linear measurements of the anatomical dimensions were achieved by the manual method (digital pachymeter) and digital method (Radioimp and Planimp softwares). The data achieved were submitted to statistical analysis of variance, at a significance level of $5 \%$. This statistical analysis has not demonstrate any significant difference between the manual and digital measurements. The results allowed the conclusion that the Radioimp and Planimp softwares displayed proper performances for calibration of the radiographic image and for measurement of linear dimensions. The systems for image digitization employed (scanner and digital camera) has not present significant differences, being adequate for utilization with such softwares. 


\section{ANEXOS}

Anexo 1- Tabela com as medidas das 14 distâncias anatômicas obtidas pelos sete grupos experimentais para a radiografia 1

\begin{tabular}{|c|c|c|c|c|c|c|c|c|c|c|c|c|c|c|}
\hline \multirow{2}{*}{ RX 1} & \multicolumn{14}{|c|}{ Distâncias anatômicas } \\
\hline & $\begin{array}{l}\text { D1 } \\
\text { MSD }\end{array}$ & $\begin{array}{l}\text { D2 } \\
\text { PMSD }\end{array}$ & $\begin{array}{l}\text { D3 } \\
\text { CSD }\end{array}$ & $\begin{array}{l}\text { D4 } \\
\text { ICS }\end{array}$ & $\begin{array}{l}\text { D5 } \\
\text { CSE }\end{array}$ & $\begin{array}{l}\text { D6 } \\
\text { PMSE }\end{array}$ & $\begin{array}{l}\text { D7 } \\
\text { MSE }\end{array}$ & $\begin{array}{l}\text { D8 } \\
\text { MID }\end{array}$ & $\begin{array}{l}\text { D9 } \\
\text { PMID }\end{array}$ & $\begin{array}{l}\text { D10 } \\
\text { CID }\end{array}$ & $\begin{array}{l}\text { D11 } \\
\text { ICI }\end{array}$ & $\begin{array}{l}\text { D12 } \\
\text { CIE }\end{array}$ & \begin{tabular}{|l} 
D13 \\
PMIE
\end{tabular} & $\begin{array}{l}\text { D14 } \\
\text { MIE }\end{array}$ \\
\hline 1- Paquímetro & 5,27 & 8,25 & 16,08 & 14,98 & 14,90 & 8,44 & 4,16 & 10,16 & 8,10 & 9,99 & 21,38 & 8,68 & 6,44 & 7,90 \\
\hline $\begin{array}{l}\text { 2- Radioimp-resolução- } \\
\text { escaner }\end{array}$ & 5,28 & 8,29 & 17,00 & 15,02 & 14,93 & 8,44 & 4,16 & 10,18 & 8,12 & 10,01 & 21,42 & 8,68 & 6,44 & 7,90 \\
\hline $\begin{array}{l}\text { 3- Radioimp-referencial- } \\
\text { escaner }\end{array}$ & 5,28 & 8,28 & 16,09 & 15,02 & 14,93 & 8,44 & 4,16 & 10,18 & 8,12 & 10,01 & 21,41 & 8,68 & 6,44 & 7,90 \\
\hline $\begin{array}{l}\text { 4- Radioimp-referencial- } \\
\text { câmera }\end{array}$ & 5,27 & 8,26 & 16,07 & 15,00 & 14,91 & 8,44 & 4,17 & 10,16 & 8,11 & 10,00 & 21,40 & 8,68 & 6,43 & 7,90 \\
\hline $\begin{array}{l}\text { 5- Planimp-resolução- } \\
\text { escaner }\end{array}$ & 5,28 & 8,29 & 17,01 & 15,02 & 14,93 & 8,45 & 4,17 & 10,18 & 8,13 & 10,02 & 21,42 & 8,69 & 6,45 & 7,92 \\
\hline $\begin{array}{l}\text { 6- Planimp-referencial- } \\
\text { escaner }\end{array}$ & 5,27 & 8,29 & 17,00 & 15,02 & 14,93 & 8,45 & 4,17 & 10,19 & 8,13 & 10,02 & 21,40 & 8,69 & 6,45 & 7,91 \\
\hline $\begin{array}{l}\text { 7- Planimp-referencial- } \\
\text { câmera }\end{array}$ & 5,27 & 8,25 & 16,09 & 15,00 & 14,91 & 8,44 & 5,78 & 10,17 & 8,10 & 9,99 & 21,40 & 8,68 & 6,43 & 7,90 \\
\hline
\end{tabular}

Anexo 2- Tabela com as medidas das 14 distâncias anatômicas obtidas pelos sete grupos experimentais para a radiografia 2

\begin{tabular}{l|l|l|l|l|l|l|l|l|l|l|l|l|l|l}
\hline \multirow{2}{*}{ RX 2 } & \multicolumn{7}{l}{ Distâncias anatômicas } \\
\cline { 2 - 13 } & $\begin{array}{l}\text { D1 } \\
\text { MSD }\end{array}$ & $\begin{array}{l}\text { D2 } \\
\text { PMSD }\end{array}$ & $\begin{array}{l}\text { D3 } \\
\text { CSD }\end{array}$ & $\begin{array}{l}\text { D4 } \\
\text { ICS }\end{array}$ & $\begin{array}{l}\text { D5 } \\
\text { CSE }\end{array}$ & $\begin{array}{l}\text { D6 } \\
\text { PMS } \\
\text { E }\end{array}$ & $\begin{array}{l}\text { D7 } \\
\text { MSE }\end{array}$ & $\begin{array}{l}\text { D8 } \\
\text { MID }\end{array}$ & $\begin{array}{l}\text { D9 } \\
\text { PMID }\end{array}$ & $\begin{array}{l}\text { D10 } \\
\text { CID }\end{array}$ & $\begin{array}{l}\text { D11 } \\
\text { ICI }\end{array}$ & $\begin{array}{l}\text { D12 } \\
\text { CIE }\end{array}$ & $\begin{array}{l}\text { D13 } \\
\text { PMIE }\end{array}$ & $\begin{array}{l}\text { D14 } \\
\text { MIE }\end{array}$ \\
\hline \hline -Paquímetro & 4,75 & 5,76 & 11,14 & 10,83 & 13,13 & 3,53 & 3,16 & 11,93 & 8,55 & 12,40 & 22,48 & 11,94 & 10,44 & 11,00 \\
\hline $\begin{array}{l}\text {-Radioimp-resolução- } \\
\text { scaner }\end{array}$ & 4,77 & 5,77 & 11,16 & 10,85 & 13,15 & 3,53 & 3,16 & 11,95 & 8,56 & 12,42 & 22,51 & 11,93 & 10,45 & 11,02 \\
\hline $\begin{array}{l}\text {-Radioimp-referencial- } \\
\text { scaner }\end{array}$ & 4,77 & 5,77 & 11,16 & 10,85 & 13,13 & 3,53 & 3,16 & 11,95 & 8,55 & 12,43 & 22,50 & 11,95 & 10,45 & 11,03 \\
\hline $\begin{array}{l}\text {-Radioimp-referencial- } \\
\text { âmera }\end{array}$ & 4,76 & 5,76 & 11,14 & 10,84 & 13,12 & 3,53 & 3,15 & 11,94 & 8,55 & 12,40 & 22,49 & 11,93 & 10,45 & 11,01 \\
\hline $\begin{array}{l}\text {-Planimp-resolução- } \\
\text { scaner }\end{array}$ & 4,77 & 5,77 & 11,15 & 10,85 & 13,14 & 3,53 & 3,16 & 11,96 & 8,57 & 12,42 & 22,52 & 11,95 & 10,46 & 11,03 \\
\hline $\begin{array}{l}\text {-Planimp-referencial- } \\
\text { scaner }\end{array}$ & 4,76 & 5,77 & 11,15 & 10,84 & 13,13 & 3,53 & 3,16 & 11,96 & 8,57 & 12,42 & 22,51 & 11,95 & 10,46 & 11,02 \\
\hline $\begin{array}{l}\text {-Planimp-referencial- } \\
\text { âmera }\end{array}$ & 4,75 & 5,76 & 11,15 & 10,83 & 13,12 & 3,53 & 5,78 & 11,95 & 8,54 & 12,41 & 22,50 & 11,94 & 10,44 & 11,01 \\
\hline
\end{tabular}


Anexo 3- Tabela com as medidas das 14 distâncias anatômicas obtidas pelos sete grupos experimentais para a radiografia 3

\begin{tabular}{|c|c|c|c|c|c|c|c|c|c|c|c|c|c|c|}
\hline \multirow{2}{*}{$\mathrm{RX} 3$} & \multicolumn{14}{|c|}{ Distâncias anatômicas } \\
\hline & $\begin{array}{l}\text { D1 } \\
\text { MSD }\end{array}$ & $\begin{array}{l}\text { D2 } \\
\text { PMSD }\end{array}$ & $\begin{array}{l}\text { D3 } \\
\text { CSD }\end{array}$ & $\begin{array}{l}\text { D4 } \\
\text { ICS }\end{array}$ & $\begin{array}{l}\text { D5 } \\
\text { CSE }\end{array}$ & $\begin{array}{l}\text { D6 } \\
\text { PMSE }\end{array}$ & $\begin{array}{l}\text { D7 } \\
\text { MSE }\end{array}$ & $\begin{array}{l}\text { D8 } \\
\text { MID }\end{array}$ & $\begin{array}{l}\text { D9 } \\
\text { PMID }\end{array}$ & $\begin{array}{l}\text { D10 } \\
\text { CID }\end{array}$ & $\begin{array}{l}\text { D11 } \\
\text { ICI }\end{array}$ & $\begin{array}{l}\text { D12 } \\
\text { CIE }\end{array}$ & $\begin{array}{l}\text { D13 } \\
\text { PMIE }\end{array}$ & $\begin{array}{l}\text { D14 } \\
\text { MIE }\end{array}$ \\
\hline 1- Paquímetro & 5,31 & 5,37 & 13,91 & 12,40 & 14,55 & 7,48 & 5,05 & 6,31 & 5,35 & 8,63 & 17,18 & 9,51 & 5,78 & 7,31 \\
\hline $\begin{array}{l}\text { 2- Radioimp-resolução- } \\
\text { escaner }\end{array}$ & 5,34 & 5,38 & 13,95 & 12,44 & 14,58 & 7,49 & 5,06 & 6,34 & 5,37 & 8,63 & 17,23 & 9,53 & 5,78 & 7,33 \\
\hline $\begin{array}{l}\text { 3- Radioimp-referencial- } \\
\text { escaner }\end{array}$ & 5,32 & 5,37 & 13,90 & 12,44 & 14,57 & 7,49 & 5,05 & 6,34 & 5,35 & 8,64 & 17,21 & 9,52 & 5,80 & 7,33 \\
\hline $\begin{array}{l}\text { 4- Radioimp-referencial- } \\
\text { câmera }\end{array}$ & 5,32 & 5,36 & 13,95 & 12,42 & 14,55 & 7,49 & 5,07 & 6,33 & 5,36 & 8,63 & 17,20 & 9,52 & 5,79 & 7,31 \\
\hline $\begin{array}{l}\text { 5- Planimp-resolução- } \\
\text { escaner }\end{array}$ & 5,33 & 5,38 & 13,95 & 12,44 & 14,58 & 7,50 & 5,07 & 6,34 & 5,37 & 8,63 & 17,24 & 9,53 & 5,80 & 7,32 \\
\hline $\begin{array}{l}\text { 6- Planimp-referencial- } \\
\text { escaner }\end{array}$ & 5,33 & 5,38 & 13,97 & 12,43 & 14,58 & 7,49 & 5,06 & 6,34 & 5,37 & 8,64 & 17,24 & 9,53 & 5,80 & 7,32 \\
\hline $\begin{array}{l}\text { 7- Planimp-referencial- } \\
\text { câmera }\end{array}$ & 5,32 & 5,37 & 13,94 & 12,41 & 14,56 & 7,49 & 5,78 & 6,32 & 5,36 & 8,63 & 17,21 & 9,53 & 5,80 & 7,31 \\
\hline
\end{tabular}

Anexo 4- Tabela com as medidas das 14 distâncias anatômicas obtidas pelos sete grupos experimentais para a radiografia 4

\begin{tabular}{|c|c|c|c|c|c|c|c|c|c|c|c|c|c|c|}
\hline \multirow{2}{*}{ RX 4} & \multicolumn{14}{|c|}{ Distâncias anatômicas } \\
\hline & \begin{tabular}{|l} 
D1 \\
MSD
\end{tabular} & \begin{tabular}{|l|} 
D2 \\
PMSD
\end{tabular} & $\begin{array}{l}\text { D3 } \\
\text { CSD }\end{array}$ & \begin{tabular}{|l} 
D4 \\
ICS
\end{tabular} & $\begin{array}{l}\text { D5 } \\
\text { CSE }\end{array}$ & \begin{tabular}{|l} 
D6 \\
PMSE
\end{tabular} & $\begin{array}{l}\text { D7 } \\
\text { MSE }\end{array}$ & $\begin{array}{l}\text { D8 } \\
\text { MID }\end{array}$ & $\begin{array}{l}\text { D9 } \\
\text { PMID }\end{array}$ & $\begin{array}{l}\text { D10 } \\
\text { CID }\end{array}$ & $\begin{array}{l}\text { D11 } \\
\text { ICI }\end{array}$ & $\begin{array}{l}\text { D12 } \\
\text { CIE }\end{array}$ & $\begin{array}{l}\text { D13 } \\
\text { PMIE }\end{array}$ & $\begin{array}{l}\text { D14 } \\
\text { MIE }\end{array}$ \\
\hline 1- Paquímetro & 8,35 & 5,80 & 11,75 & 14,92 & 10,46 & 7,43 & 4,62 & 9,01 & 7,31 & 10,20 & 22,51 & 11,57 & 7,59 & 8,44 \\
\hline $\begin{array}{l}\text { 2- Radioimp-resolução- } \\
\text { escaner }\end{array}$ & 8,36 & 5,82 & 11,76 & 14,94 & 10,47 & 7,44 & 4,62 & 9,02 & 7,33 & 10,30 & 22,55 & 11,56 & 7,61 & 8,46 \\
\hline $\begin{array}{l}\text { 3- Radioimp-referencial- } \\
\text { escaner }\end{array}$ & 8,37 & 5,82 & 11,76 & 14,93 & 10,47 & 7,43 & 4,62 & 9,02 & 7,34 & 10,30 & 22,56 & 11,56 & 7,60 & 8,45 \\
\hline $\begin{array}{l}\text { 4- Radioimp-referencial- } \\
\text { câmera }\end{array}$ & 8,36 & 5,80 & 11,74 & 14,91 & 10,46 & 7,42 & 4,62 & 9,02 & 7,31 & 10,20 & 22,55 & 11,57 & 7,59 & 8,45 \\
\hline $\begin{array}{l}\text { 5- Planimp-resolução- } \\
\text { escaner }\end{array}$ & 8,36 & 5,83 & 11,77 & 14,93 & 10,48 & 7,44 & 4,62 & 9,03 & 7,33 & 10,40 & 22,56 & 11,58 & 7,60 & 8,47 \\
\hline $\begin{array}{l}\text { 6- Planimp-referencial- } \\
\text { escaner }\end{array}$ & 8,36 & 5,81 & 11,76 & 14,94 & 10,48 & 7,43 & 4,62 & 9,03 & 7,33 & 10,40 & 22,57 & 11,57 & 7,61 & 8,47 \\
\hline $\begin{array}{l}\text { 7- Planimp-referencial- } \\
\text { câmera }\end{array}$ & 8,35 & 5,82 & 11,75 & 14,91 & 10,47 & 7,43 & 5,78 & 9,01 & 7,32 & 10,20 & 22,54 & 11,57 & 7,59 & 8,44 \\
\hline
\end{tabular}


Anexo 5- Tabela com as medidas das 14 distâncias anatômicas obtidas pelos sete grupos experimentais para a radiografia 5

\begin{tabular}{|c|c|c|c|c|c|c|c|c|c|c|c|c|c|c|}
\hline \multirow{2}{*}{ RX 5} & \multicolumn{14}{|c|}{ Distâncias anatômicas } \\
\hline & $\begin{array}{l}\text { D1 } \\
\text { MSD }\end{array}$ & \begin{tabular}{|l|} 
D2 \\
PMSD
\end{tabular} & $\begin{array}{l}\text { D3 } \\
\text { CSD }\end{array}$ & $\begin{array}{l}\text { D4 } \\
\text { ICS }\end{array}$ & $\begin{array}{l}\text { D5 } \\
\text { CSE }\end{array}$ & \begin{tabular}{|l|} 
D6 \\
PMSE
\end{tabular} & $\begin{array}{l}\text { D7 } \\
\text { MSE }\end{array}$ & $\begin{array}{l}\text { D8 } \\
\text { MID }\end{array}$ & $\begin{array}{l}\text { D9 } \\
\text { PMID }\end{array}$ & $\begin{array}{l}\text { D10 } \\
\text { CID }\end{array}$ & $\begin{array}{l}\text { D11 } \\
\text { ICI }\end{array}$ & $\begin{array}{l}\text { D12 } \\
\text { CIE }\end{array}$ & $\begin{array}{l}\text { D13 } \\
\text { PMIE }\end{array}$ & $\begin{array}{l}\text { D14 } \\
\text { MIE }\end{array}$ \\
\hline 1- Paquímetro & 4,66 & 8,08 & 13,21 & 11,74 & 11,43 & 8,22 & 5,71 & 10,07 & 12,10 & 12,65 & 21,15 & 13,02 & 12,00 & 8,85 \\
\hline $\begin{array}{l}\text { 2- Radioimp-resolução- } \\
\text { escaner }\end{array}$ & 4,67 & 8,11 & 13,22 & 11,78 & 11,45 & 8,22 & 5,72 & 10,10 & 12,12 & 12,67 & 21,17 & 13,02 & 12,00 & 8,87 \\
\hline $\begin{array}{l}\text { 3- Radioimp-referencial- } \\
\text { escaner }\end{array}$ & 4,67 & 8,10 & 13,23 & 11,78 & 11,45 & 8,22 & 5,72 & 10,09 & 12,11 & 12,68 & 21,17 & 13,03 & 12,00 & 8,87 \\
\hline $\begin{array}{l}\text { 4- Radioimp-referencial- } \\
\text { câmera }\end{array}$ & 4,66 & 8,09 & 13,21 & 11,75 & 11,43 & 8,21 & 5,71 & 10,07 & 12,10 & 12,66 & 21,16 & 13,02 & 12,01 & 8,86 \\
\hline $\begin{array}{l}\text { 5- Planimp-resolução- } \\
\text { escaner }\end{array}$ & 4,67 & 8,09 & 13,22 & 11,78 & 11,44 & 8,23 & 5,71 & 10,10 & 12,11 & 12,67 & 21,19 & 13,02 & 12,01 & 8,86 \\
\hline $\begin{array}{l}\text { 6- Planimp-referencial- } \\
\text { escaner }\end{array}$ & 4,66 & 8,09 & 13,22 & 11,77 & 11,44 & 8,23 & 5,71 & 10,09 & 12,12 & 12,67 & 21,19 & 13,02 & 12,02 & 8,87 \\
\hline $\begin{array}{l}\text { 7- Planimp-referencial- } \\
\text { câmera }\end{array}$ & 4,67 & 8,08 & 13,21 & 11,75 & 11,43 & 8,22 & 5,78 & 10,08 & 12,10 & 12,66 & 21,17 & 13,02 & 12,01 & 8,85 \\
\hline
\end{tabular}

Anexo 6- Tabela com as medidas das 14 distâncias anatômicas obtidas pelos sete grupos experimentais para a radiografia 6

\begin{tabular}{l|l|l|l|l|l|l|l|l|l|l|l|l|l|l}
\hline \multirow{2}{*}{ RX 6 } & \multicolumn{2}{l}{ Distâncias anatômicas } \\
\cline { 2 - 13 } & $\begin{array}{l}\text { D1 } \\
\text { MSD }\end{array}$ & $\begin{array}{l}\text { D2 } \\
\text { PMS } \\
\text { D }\end{array}$ & $\begin{array}{l}\text { D3 } \\
\text { CSD }\end{array}$ & $\begin{array}{l}\text { D4 } \\
\text { ICS }\end{array}$ & $\begin{array}{l}\text { D5 } \\
\text { CSE }\end{array}$ & $\begin{array}{l}\text { D6 } \\
\text { PMSE }\end{array}$ & $\begin{array}{l}\text { D7 } \\
\text { MSE }\end{array}$ & $\begin{array}{l}\text { D8 } \\
\text { MID }\end{array}$ & $\begin{array}{l}\text { D9 } \\
\text { PMID }\end{array}$ & $\begin{array}{l}\text { D10 } \\
\text { CID }\end{array}$ & $\begin{array}{l}\text { D11 } \\
\text { ICI }\end{array}$ & $\begin{array}{l}\text { D12 } \\
\text { CIE }\end{array}$ & $\begin{array}{l}\text { D13 } \\
\text { PMIE }\end{array}$ & $\begin{array}{l}\text { D14 } \\
\text { MIE }\end{array}$ \\
\hline \hline 1- Paquímetro & 5,22 & 7,45 & 11,25 & 10,66 & 11,21 & 7,76 & 4,51 & 3,50 & 4,00 & 4,02 & 13,49 & 4,64 & 2,96 & 4,07 \\
\hline $\begin{array}{l}\text { 2- Radioimp-resolução- } \\
\text { escaner }\end{array}$ & 5,23 & 7,47 & 11,25 & 10,67 & 11,23 & 7,77 & 4,51 & 3,51 & 4,02 & 4,03 & 13,52 & 4,64 & 2,95 & 4,09 \\
\hline $\begin{array}{l}\text { 3- Radioimp-referencial- } \\
\text { escaner }\end{array}$ & 5,23 & 7,47 & 11,26 & 10,68 & 11,22 & 7,77 & 4,53 & 3,51 & 4,01 & 4,02 & 13,52 & 4,64 & 2,95 & 4,09 \\
\hline $\begin{array}{l}\text { 4- Radioimp-referencial- } \\
\text { câmera }\end{array}$ & 5,22 & 7,45 & 11,26 & 10,66 & 11,22 & 7,77 & 4,52 & 3,50 & 4,00 & 4,02 & 13,50 & 4,63 & 2,96 & 4,08 \\
\hline $\begin{array}{l}\text { 5- Planimp-resolução- } \\
\text { escaner }\end{array}$ & 5,23 & 7,47 & 11,25 & 10,68 & 11,24 & 7,76 & 4,51 & 3,50 & 4,02 & 4,02 & 13,52 & 4,64 & 2,96 & 4,08 \\
\hline $\begin{array}{l}\text { 6- Planimp-referencial- } \\
\text { escaner }\end{array}$ & 5,22 & 7,46 & 11,26 & 10,68 & 11,23 & 7,77 & 4,51 & 3,50 & 4,02 & 4,02 & 13,51 & 4,63 & 2,96 & 4,08 \\
\hline $\begin{array}{l}\text { 7- Planimp-referencial- } \\
\text { câmera }\end{array}$ & 5,22 & 7,46 & 11,25 & 10,66 & 11,22 & 7,76 & 5,78 & 3,50 & 4,00 & 4,01 & 13,51 & 4,64 & 2,96 & 4,07 \\
\hline
\end{tabular}


Anexo 7- Tabela com as medidas das 14 distâncias anatômicas obtidas pelos sete grupos experimentais para a radiografia 7

\begin{tabular}{|c|c|c|c|c|c|c|c|c|c|c|c|c|c|c|}
\hline \multirow{2}{*}{$\mathrm{RX} 7$} & \multicolumn{14}{|c|}{ Distâncias anatômicas } \\
\hline & $\begin{array}{c}\text { D1 } \\
\text { MSD }\end{array}$ & $\begin{array}{c}\text { D2 } \\
\text { PMSD }\end{array}$ & $\begin{array}{c}\text { D3 } \\
\text { CSD }\end{array}$ & $\begin{array}{l}\text { D4 } \\
\text { ICS }\end{array}$ & $\begin{array}{c}\text { D5 } \\
\text { CSE }\end{array}$ & $\begin{array}{c}\text { D6 } \\
\text { PMSE }\end{array}$ & $\begin{array}{l}\text { D7 } \\
\text { MSE }\end{array}$ & $\begin{array}{l}\text { D8 } \\
\text { MID }\end{array}$ & $\begin{array}{c}\text { D9 } \\
\text { PMID }\end{array}$ & $\begin{array}{l}\text { D10 } \\
\text { CID }\end{array}$ & $\begin{array}{l}\text { D11 } \\
\text { ICI }\end{array}$ & \begin{tabular}{|l} 
D12 \\
CIE
\end{tabular} & \begin{tabular}{|c|} 
D13 \\
PMIE
\end{tabular} & $\begin{array}{l}\text { D14 } \\
\text { MIE }\end{array}$ \\
\hline 1- Paquímetro & 7,93 & 8,91 & 10,65 & 9,49 & 11,65 & 8,20 & 5,78 & 7,34 & 6,32 & 7,40 & 9,80 & 5,20 & 3,10 & 7,58 \\
\hline $\begin{array}{l}\text { 2- Radioimp-resolução- } \\
\text { escaner }\end{array}$ & 7,96 & 8,94 & 10,67 & 9,51 & 11,67 & 8,23 & 5,79 & 7,35 & 6,32 & 7,43 & 9,83 & 5,20 & 3,11 & 7,59 \\
\hline $\begin{array}{l}\text { 3- Radioimp-referencial- } \\
\text { escaner }\end{array}$ & 7,95 & 8,93 & 10,67 & 9,52 & 11,66 & 8,23 & 5,79 & 7,34 & 6,32 & 7,42 & 9,82 & 5,20 & 3,11 & 7,59 \\
\hline $\begin{array}{l}\text { 4- Radioimp-referencial- } \\
\text { câmera }\end{array}$ & 7,93 & 8,91 & 10,66 & 9,50 & 11,64 & 8,21 & 5,78 & 7,32 & 6,31 & 7,40 & 9,81 & 5,20 & 3,10 & 7,58 \\
\hline $\begin{array}{l}\text { 5- Planimp-resolução- } \\
\text { escaner }\end{array}$ & 7,95 & 8,94 & 10,68 & 9,52 & 11,68 & 8,23 & 5,80 & 7,35 & 6,33 & 7,43 & 9,83 & 5,21 & 3,11 & 7,59 \\
\hline $\begin{array}{l}\text { 6- Planimp-referencial- } \\
\text { escaner }\end{array}$ & 7,94 & 8,94 & 10,68 & 9,51 & 11,67 & 8,22 & 5,79 & 7,35 & 6,33 & 7,43 & 9,82 & 5,20 & 3,11 & 7,60 \\
\hline $\begin{array}{l}\text { 7- Planimp-referencial- } \\
\text { câmera }\end{array}$ & 7,94 & 8,91 & 10,66 & 9,51 & 11,65 & 8,22 & 5,78 & 7,33 & 6,31 & 7,41 & 9,80 & 5,20 & 3,10 & 7,58 \\
\hline
\end{tabular}

Anexo 8- Tabela com as medidas das 14 distâncias anatômicas obtidas pelos sete grupos experimentais para a radiografia 8

\begin{tabular}{l|c|c|c|c|c|c|c|c|c|c|c|c|c|c}
\hline \multirow{2}{*}{ RX 8 } & \multicolumn{10}{|l}{ Distâncias anatômicas } \\
\cline { 2 - 13 } & $\begin{array}{c}\text { D1 } \\
\text { MSD }\end{array}$ & $\begin{array}{c}\text { D2 } \\
\text { PMSD }\end{array}$ & $\begin{array}{c}\text { D3 } \\
\text { CSD }\end{array}$ & $\begin{array}{c}\text { D4 } \\
\text { ICS }\end{array}$ & $\begin{array}{c}\text { D5 } \\
\text { CSE }\end{array}$ & $\begin{array}{c}\text { D6 } \\
\text { PMSE }\end{array}$ & $\begin{array}{c}\text { D7 } \\
\text { MSE }\end{array}$ & $\begin{array}{c}\text { D8 } \\
\text { MID }\end{array}$ & $\begin{array}{c}\text { D9 } \\
\text { PMID }\end{array}$ & $\begin{array}{c}\text { D10 } \\
\text { CID }\end{array}$ & $\begin{array}{c}\text { D11 } \\
\text { ICI }\end{array}$ & $\begin{array}{c}\text { D12 } \\
\text { CIE }\end{array}$ & $\begin{array}{c}\text { D13 } \\
\text { PMIE }\end{array}$ & $\begin{array}{c}\text { D14 } \\
\text { MIE }\end{array}$ \\
\hline \hline \begin{tabular}{l} 
1- Paquímetro \\
\hline $\begin{array}{l}\text { 2- Radioimp-resolução- } \\
\text { escaner }\end{array}$
\end{tabular} & 4,63 & 5,42 & 8,34 & 7,96 & 6,90 & 4,42 & 6,62 & 3,65 & 1,96 & 5,89 & 12,92 & 6,30 & 4,04 & 4,16 \\
\hline $\begin{array}{l}\text { 3- Radioimp-referencial- } \\
\text { escaner }\end{array}$ & 4,63 & 5,42 & 8,36 & 7,97 & 6,92 & 4,42 & 6,63 & 3,65 & 1,97 & 5,90 & 12,95 & 6,31 & 4,04 & 4,17 \\
\hline $\begin{array}{l}\text { 4- Radioimp-referencial- } \\
\text { câmera }\end{array}$ & 4,62 & 5,42 & 8,35 & 7,96 & 6,91 & 4,42 & 6,61 & 3,65 & 1,96 & 5,89 & 12,93 & 6,30 & 4,03 & 4,16 \\
\hline $\begin{array}{l}\text { 5- Planimp-resolução- } \\
\text { escaner }\end{array}$ & 4,63 & 5,43 & 8,37 & 7,48 & 6,92 & 4,43 & 6,63 & 3,65 & 1,97 & 5,89 & 12,94 & 6,31 & 4,04 & 4,17 \\
\hline $\begin{array}{l}\text { 6- Planimp-referencial- } \\
\text { escaner }\end{array}$ & 4,63 & 5,43 & 8,37 & 7,98 & 6,91 & 4,43 & 6,62 & 3,65 & 1,96 & 5,90 & 12,95 & 6,31 & 4,04 & 4,17 \\
\hline $\begin{array}{l}\text { 7- Planimp-referencial- } \\
\text { câmera }\end{array}$ & 4,62 & 5,42 & 8,35 & 7,96 & 6,90 & 4,42 & 6,61 & 3,65 & 1,96 & 5,89 & 12,93 & 6,30 & 4,04 & 4,16 \\
\hline
\end{tabular}


Anexo 9- Tabela com as medidas das 14 distâncias anatômicas obtidas pelos sete grupos experimentais para a radiografia 9

\begin{tabular}{|c|c|c|c|c|c|c|c|c|c|c|c|c|c|c|}
\hline RX 9 & $\begin{array}{l}\text { D1 } \\
\text { MSD }\end{array}$ & \begin{tabular}{|l|} 
D2 \\
PMS \\
D \\
\end{tabular} & $\begin{array}{l}\text { D3 } \\
\text { CSD }\end{array}$ & \begin{tabular}{|l} 
D4 \\
ICS
\end{tabular} & $\begin{array}{l}\text { D5 } \\
\text { CSE }\end{array}$ & $\left|\begin{array}{|l}\text { D6 } \\
\text { PMSE }\end{array}\right|$ & MS & \begin{tabular}{|l} 
D8 \\
MID
\end{tabular} & $\begin{array}{l}\text { D9 } \\
\text { PMID }\end{array}$ & $\begin{array}{l}\text { D10 } \\
\text { CID }\end{array}$ & $\begin{array}{l}\text { D11 } \\
\text { ICI }\end{array}$ & $\begin{array}{l}\text { D12 } \\
\text { CIE }\end{array}$ & $\begin{array}{l}\text { D13 } \\
\text { PMIE }\end{array}$ & $\begin{array}{l}\text { D14 } \\
\text { MIE }\end{array}$ \\
\hline 1- Paquímetro & 5,79 & 9,75 & 12,75 & 11,92 & 10,39 & 5,95 & 5,46 & 7,00 & 6,97 & 9,71 & 17,44 & 7,87 & 4,29 & 6,21 \\
\hline $\begin{array}{l}\text { 2- Radioimp-resolução- } \\
\text { escaner }\end{array}$ & 5,79 & 9,78 & 12,77 & 11,93 & 10,41 & 5,95 & 5,46 & 7,03 & 6,98 & 9,73 & 17,48 & 7,89 & 4,29 & 6,22 \\
\hline $\begin{array}{l}\text { 3- Radioimp-referencial- } \\
\text { escaner }\end{array}$ & 5,79 & 9,77 & 12,76 & 11,93 & 10,41 & 5,95 & 5,46 & 7,02 & 6,97 & 9,73 & 17,47 & 7,88 & 4,30 & 6,22 \\
\hline $\begin{array}{l}\text { 4- Radioimp-referencial- } \\
\text { câmera }\end{array}$ & 5,79 & 9,76 & 12,74 & 11,92 & 10,40 & 5,95 & 5,45 & 7,01 & 6,97 & 9,72 & 17,45 & 7,88 & 4,29 & 6,22 \\
\hline $\begin{array}{l}\text { 5- Planimp-resolução- } \\
\text { escaner }\end{array}$ & 5,80 & 9,78 & 12,76 & 11,94 & 10,39 & 5,96 & 5,46 & 7,03 & 6,97 & 9,73 & 17,48 & 7,90 & 4,30 & 6,23 \\
\hline $\begin{array}{l}\text { 6- Planimp-referencial- } \\
\text { escaner }\end{array}$ & 5,80 & 9,77 & 12,75 & 11,94 & 10,41 & 5,96 & 5,46 & 7,03 & 6,98 & 9,72 & 17,48 & 7,90 & 4,30 & 6,23 \\
\hline $\begin{array}{l}\text { 7- Planimp-referencial- } \\
\text { câmera }\end{array}$ & 5,79 & 9,75 & 12,74 & 11,92 & 10,39 & 5,95 & 5,46 & 7,02 & 6,97 & 9,72 & 17,45 & 7,88 & 4,29 & 6,21 \\
\hline
\end{tabular}

Anexo 10- Tabela com as medidas das 14 distâncias anatômicas obtidas pelos sete grupos experimentais para a radiografia 10

\begin{tabular}{l|l|l|l|l|l|l|l|l|l|l|l|l|l|l}
\hline \multirow{2}{*}{ RX 10 } & \multicolumn{10}{l}{ Distâncias anatômicas } \\
\cline { 2 - 13 } & $\begin{array}{l}\text { D1 } \\
\text { MSD }\end{array}$ & $\begin{array}{l}\text { D2 } \\
\text { PMS } \\
\text { D }\end{array}$ & $\begin{array}{l}\text { D3 } \\
\text { CSD }\end{array}$ & $\begin{array}{l}\text { D4 } \\
\text { ICS }\end{array}$ & $\begin{array}{l}\text { D5 } \\
\text { CSE }\end{array}$ & $\begin{array}{l}\text { D6 } \\
\text { PMSE }\end{array}$ & $\begin{array}{l}\text { D7 } \\
\text { MSE }\end{array}$ & $\begin{array}{l}\text { D8 } \\
\text { MID }\end{array}$ & $\begin{array}{l}\text { D9 } \\
\text { PMID }\end{array}$ & $\begin{array}{l}\text { D10 } \\
\text { CID }\end{array}$ & $\begin{array}{l}\text { D11 } \\
\text { ICI }\end{array}$ & $\begin{array}{l}\text { D12 } \\
\text { CIE }\end{array}$ & $\begin{array}{l}\text { D13 } \\
\text { PMIE }\end{array}$ & $\begin{array}{l}\text { D14 } \\
\text { MIE }\end{array}$ \\
\hline \hline 1- Paquímetro & 4,72 & 9,37 & 4,44 & 9,29 & 13,72 & 10,65 & 4,40 & 9,01 & 7,76 & 8,09 & 18,27 & 9,72 & 8,43 & 10,01 \\
\hline $\begin{array}{l}\text { 2- Radioimp-resolução- } \\
\text { escaner }\end{array}$ & 4,73 & 9,39 & 4,44 & 9,29 & 13,75 & 10,65 & 4,41 & 9,04 & 7,77 & 8,11 & 18,29 & 9,75 & 8,45 & 10,02 \\
\hline $\begin{array}{l}\text { 3- Radioimp-referencial- } \\
\text { escaner }\end{array}$ & 4,72 & 9,38 & 4,44 & 9,30 & 13,75 & 10,66 & 4,40 & 9,03 & 7,77 & 8,10 & 18,30 & 9,75 & 8,45 & 10,02 \\
\hline $\begin{array}{l}\text { 4- Radioimp-referencial- } \\
\text { câmera }\end{array}$ & 4,72 & 9,38 & 4,44 & 9,30 & 13,73 & 10,65 & 4,40 & 9,02 & 7,77 & 8,09 & 18,28 & 9,73 & 8,43 & 10,00 \\
\hline $\begin{array}{l}\text { 5- Planimp-resolução- } \\
\text { escaner }\end{array}$ & 4,72 & 9,39 & 4,45 & 9,30 & 13,76 & 10,67 & 4,40 & 9,04 & 7,78 & 8,11 & 18,29 & 9,74 & 8,45 & 10,01 \\
\hline $\begin{array}{l}\text { 6- Planimp-referencial- } \\
\text { escaner }\end{array}$ & 4,73 & 9,39 & 4,45 & 9,30 & 13,75 & 10,66 & 4,40 & 9,04 & 7,78 & 8,11 & 18,29 & 9,74 & 7,44 & 10,02 \\
\hline $\begin{array}{l}\text { 7- Planimp-referencial- } \\
\text { câmera }\end{array}$ & 4,72 & 9,38 & 4,44 & 9,29 & 13,73 & 10,65 & 4,40 & 9,03 & 7,77 & 8,10 & 18,28 & 9,72 & 8,43 & 10,01 \\
\hline
\end{tabular}


Anexo 11- Tabela com as medidas das 14 distâncias anatômicas obtidas pelos sete grupos experimentais para a radiografia 11

\begin{tabular}{|c|c|c|c|c|c|c|c|c|c|c|c|c|c|c|}
\hline \multirow[b]{2}{*}{ RX 11} & \multicolumn{14}{|c|}{ Distâncias anatômicas } \\
\hline & D1 & \begin{tabular}{|l|} 
D2 \\
PMS \\
D
\end{tabular} & $\begin{array}{l}\text { D3 } \\
\text { CSD }\end{array}$ & $\begin{array}{l}\text { D4 } \\
\text { ICS }\end{array}$ & $\begin{array}{l}\text { D5 } \\
\text { CSE }\end{array}$ & $\begin{array}{l}\text { D6 } \\
\text { PMSE }\end{array}$ & $\begin{array}{l}\text { D7 } \\
\text { MSE }\end{array}$ & $\begin{array}{l}\text { D8 } \\
\text { MID }\end{array}$ & $\begin{array}{l}\text { D9 } \\
\text { PMID }\end{array}$ & $\begin{array}{l}\text { D10 } \\
\text { CID }\end{array}$ & $\begin{array}{l}\text { D11 } \\
\text { ICI }\end{array}$ & $\begin{array}{l}\text { D12 } \\
\text { CIE }\end{array}$ & $\begin{array}{l}\text { D13 } \\
\text { PMIE }\end{array}$ & $\begin{array}{l}\text { D14 } \\
\text { MIE }\end{array}$ \\
\hline 1- Paquímetro & 8,53 & 5,95 & 10,72 & 10,41 & 11,27 & 8,78 & 6,26 & 5,24 & 5,75 & 7,60 & 13,61 & 8,55 & 7,15 & 5,90 \\
\hline $\begin{array}{l}\text { 2- Radioimp-resolução- } \\
\text { escaner }\end{array}$ & 8,55 & 5,95 & 10,75 & 10,43 & 11,31 & 8,80 & 6,27 & 5,24 & 5,76 & 7,62 & 13,63 & 8,57 & 7,17 & 5,91 \\
\hline $\begin{array}{l}\text { 3- Radioimp-referencial- } \\
\text { escaner }\end{array}$ & 8,55 & 5,95 & 10,75 & 10,43 & 11,30 & 8,79 & 6,26 & 5,24 & 5,76 & 7,61 & 13,64 & 8,56 & 7,16 & 5,90 \\
\hline $\begin{array}{l}\text { 4- Radioimp-referencial- } \\
\text { câmera }\end{array}$ & 8,54 & 5,95 & 10,73 & 10,41 & 11,28 & 8,78 & 6,26 & 5,24 & 5,75 & 7,61 & 13,62 & 8,55 & 7,15 & 5,90 \\
\hline $\begin{array}{l}\text { 5- Planimp-resolução- } \\
\text { escaner }\end{array}$ & 8,56 & 5,95 & 10,75 & 10,43 & 11,31 & 8,80 & 6,27 & 5,25 & 5,76 & 7,61 & 13,63 & 8,57 & 7,17 & 5,91 \\
\hline $\begin{array}{l}\text { 6- Planimp-referencial- } \\
\text { escaner }\end{array}$ & 8,55 & 5,95 & 10,74 & 10,42 & 11,31 & 8,79 & 6,26 & 5,25 & 5,75 & 7,62 & 13,63 & 8,56 & 7,17 & 5,91 \\
\hline $\begin{array}{l}\text { 7- Planimp-referencial- } \\
\text { câmera }\end{array}$ & 8,54 & 5,94 & 10,73 & 10,40 & 11,29 & 8,78 & 6,26 & 5,24 & 5,75 & 7,60 & 13,62 & 8,56 & 7,15 & 5,90 \\
\hline
\end{tabular}

Anexo 12- Tabela com as medidas das 14 distâncias anatômicas obtidas pelos sete grupos experimentais para a radiografia 12

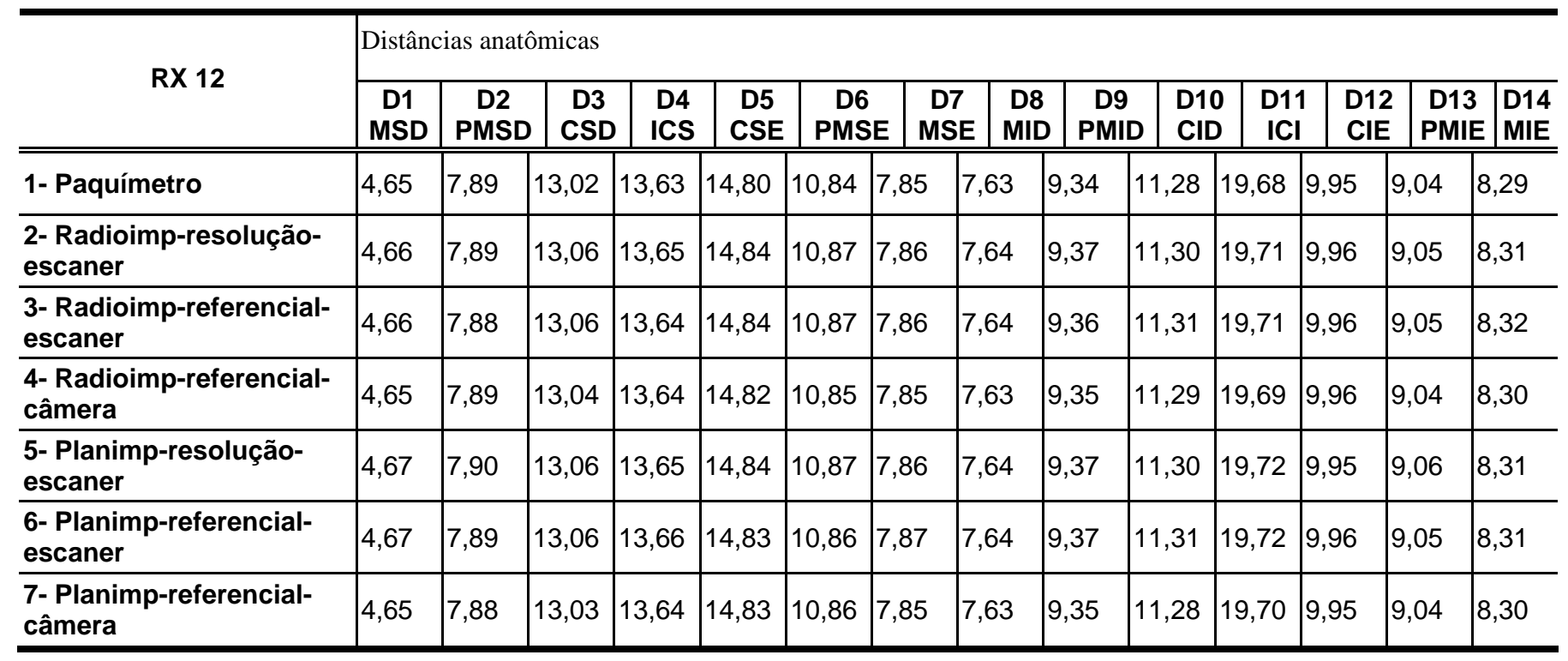


Anexo 13- Tabela com as medidas das 14 distâncias anatômicas obtidas pelos sete grupos experimentais para a radiografia 13

\begin{tabular}{|c|c|c|c|c|c|c|c|c|c|c|c|c|c|c|}
\hline \multirow{2}{*}{ RX 13} & \multicolumn{14}{|c|}{ Distâncias anatômicas } \\
\hline & $\begin{array}{l}\text { D1 } \\
\text { MSD }\end{array}$ & \begin{tabular}{|l|} 
D2 \\
PMSD \\
\end{tabular} & \begin{tabular}{|l|} 
D3 \\
CSD
\end{tabular} & \begin{tabular}{|l|} 
D4 \\
ICS \\
\end{tabular} & \begin{tabular}{|l|} 
D5 \\
CSE
\end{tabular} & \begin{tabular}{|l|} 
D6 \\
PMSE \\
\end{tabular} & \begin{tabular}{|l|} 
D7 \\
MSE
\end{tabular} & \begin{tabular}{|l|} 
D8 \\
MID \\
\end{tabular} & \begin{tabular}{|l|} 
D9 \\
PMID \\
\end{tabular} & $\begin{array}{l}\text { D10 } \\
\text { CID }\end{array}$ & \begin{tabular}{|l|} 
D11 \\
ICI \\
\end{tabular} & \begin{tabular}{|l} 
D12 \\
CIE
\end{tabular} & \begin{tabular}{|l|} 
D13 \\
PMIE \\
\end{tabular} & \begin{tabular}{|l|} 
D14 \\
MIE
\end{tabular} \\
\hline 1- Paquímetro & 4,84 & 8,41 & 5,35 & 13,92 & 13,2 & 8,31 & 4,7 & 4,7 & 4,52 & 6,25 & 15,09 & 6,7 & 3,8 & 4,19 \\
\hline $\begin{array}{l}\text { 2- Radioimp-resolução- } \\
\text { escaner }\end{array}$ & 4,84 & 8,44 & 5,35 & 13,94 & 13,22 & 8,33 & 4,72 & 4,71 & 4,52 & 6,26 & 11,12 & 6,72 & 3,81 & 4,2 \\
\hline $\begin{array}{l}\text { 3- Radioimp-referencial- } \\
\text { escaner }\end{array}$ & 4,84 & 8,43 & 5,35 & 13,94 & 13,21 & 8,31 & 4,71 & 4,71 & 4,52 & 6,26 & 15,1 & 6,72 & 3,81 & 4,2 \\
\hline $\begin{array}{l}\text { 4- Radioimp-referencial- } \\
\text { câmera }\end{array}$ & 4,84 & 8,42 & 5,35 & 13,92 & 13,21 & 8,32 & 4,7 & 4,7 & 4,52 & 6,25 & 15,09 & 6,71 & 3,81 & 4,19 \\
\hline $\begin{array}{l}\text { 5- Planimp-resolução- } \\
\text { escaner }\end{array}$ & 4,84 & 8,43 & 5,36 & 13,95 & 13,21 & 8,33 & 4,72 & 4,71 & 4,52 & 6,26 & 11,11 & 6,72 & 3,81 & 4,2 \\
\hline $\begin{array}{l}\text { 6- Planimp-referencial- } \\
\text { escaner }\end{array}$ & 4,84 & 8,43 & 5,35 & 13,95 & 13,21 & 8,32 & 4,72 & 4,72 & 4,53 & 6,26 & 11,12 & 6,72 & 3,81 & 4,19 \\
\hline $\begin{array}{l}\text { 7- Planimp-referencial- } \\
\text { câmera }\end{array}$ & 4,83 & 8,41 & 5,35 & 13,92 & 13,2 & 8,31 & 4,7 & 4,71 & 4,52 & 6,25 & 11,1 & 6,7 & 3,81 & 4,19 \\
\hline
\end{tabular}

Anexo 14- Tabela com as medidas das 14 distâncias anatômicas obtidas pelos sete grupos experimentais para a radiografia 14

\begin{tabular}{|c|c|c|c|c|c|c|c|c|c|c|c|c|c|c|}
\hline \multirow{2}{*}{ RX 14} & \multicolumn{14}{|c|}{ Distâncias anatômicas } \\
\hline & $\begin{array}{c}\text { D1 } \\
\text { MSD }\end{array}$ & $\begin{array}{c}\text { D2 } \\
\text { PMSD }\end{array}$ & $\begin{array}{l}\text { D3 } \\
\text { CSD }\end{array}$ & $\begin{array}{l}\text { D4 } \\
\text { ICS }\end{array}$ & $\begin{array}{l}\text { D5 } \\
\text { CSE }\end{array}$ & $\begin{array}{c}\text { D6 } \\
\text { PMSE }\end{array}$ & $\begin{array}{c}\text { D7 } \\
\text { MSE }\end{array}$ & $\begin{array}{l}\text { D8 } \\
\text { MID }\end{array}$ & $\begin{array}{l}\text { D9 } \\
\text { PMID }\end{array}$ & $\begin{array}{l}\text { D10 } \\
\text { CID }\end{array}$ & $\begin{array}{l}\text { D11 } \\
\text { ICI }\end{array}$ & $\begin{array}{l}\text { D12 } \\
\text { CIE }\end{array}$ & $\begin{array}{l}\text { D13 } \\
\text { PMIE }\end{array}$ & $\begin{array}{l}\text { D14 } \\
\text { MIE }\end{array}$ \\
\hline 1- Paquímetro & 8,95 & 8,70 & 8,50 & 8,03 & 7,20 & 7,30 & 8,18 & 8,97 & 7,77 & 7,62 & 15,47 & 7,84 & 5,31 & 8,38 \\
\hline $\begin{array}{l}\text { 2- Radioimp-resolução- } \\
\text { escaner }\end{array}$ & 8,96 & 8,71 & 8,51 & 8,05 & 7,23 & 7,32 & 8,19 & 8,99 & 7,77 & 7,62 & 15,50 & 7,85 & 5,31 & 8,39 \\
\hline $\begin{array}{l}\text { 3- Radioimp-referencial- } \\
\text { escaner }\end{array}$ & 8,97 & 8,72 & 8,51 & 8,04 & 7,22 & 7,32 & 8,19 & 8,99 & 7,77 & 7,63 & 15,49 & 7,85 & 5,32 & 8,40 \\
\hline $\begin{array}{l}\text { 4- Radioimp-referencial- } \\
\text { câmera }\end{array}$ & 8,95 & 8,71 & 8,50 & 8,04 & 7,21 & 7,31 & 8,18 & 8,97 & 7,77 & 7,61 & 15,47 & 7,84 & 5,31 & 8,39 \\
\hline $\begin{array}{l}\text { 5- Planimp-resolução- } \\
\text { escaner }\end{array}$ & 8,96 & 8,72 & 8,52 & 8,05 & 7,22 & 7,32 & 8,19 & 8,98 & 7,78 & 7,62 & 15,48 & 7,85 & 5,31 & 8,39 \\
\hline $\begin{array}{l}\text { 6- Planimp-referencial- } \\
\text { escaner }\end{array}$ & 8,97 & 8,72 & 8,52 & 8,04 & 7,23 & 7,33 & 8,19 & 8,99 & 7,78 & 7,63 & 15,50 & 7,86 & 5,31 & 8,38 \\
\hline $\begin{array}{l}\text { 7- Planimp-referencial- } \\
\text { câmera }\end{array}$ & 8,96 & 8,71 & 8,50 & 8,04 & 7,21 & 7,30 & 8,18 & 8,97 & 7,77 & 7,62 & 15,47 & 7,84 & 5,31 & 8,38 \\
\hline
\end{tabular}


Anexo 15- Tabela com as medidas das 14 distâncias anatômicas obtidas pelos sete grupos experimentais para a radiografia 15

\begin{tabular}{|c|c|c|c|c|c|c|c|c|c|c|c|c|c|c|}
\hline \multirow{2}{*}{ RX 15} & \multicolumn{14}{|c|}{ Distâncias anatômicas } \\
\hline & $\begin{array}{l}\text { D1 } \\
\text { MSD }\end{array}$ & $\begin{array}{l}\text { D2 } \\
\text { PMSD }\end{array}$ & $\begin{array}{l}\text { D3 } \\
\text { CSD }\end{array}$ & $\begin{array}{l}\text { D4 } \\
\text { ICS }\end{array}$ & $\begin{array}{l}\text { D5 } \\
\text { CSE }\end{array}$ & $\begin{array}{l}\text { D6 } \\
\text { PMSE }\end{array}$ & $\begin{array}{l}\text { D7 } \\
\text { MSE }\end{array}$ & $\begin{array}{l}\text { D8 } \\
\text { MID }\end{array}$ & $\begin{array}{l}\text { D9 } \\
\text { PMID }\end{array}$ & $\begin{array}{l}\text { D10 } \\
\text { CID }\end{array}$ & $\begin{array}{l}\text { D11 } \\
\text { ICI }\end{array}$ & $\begin{array}{l}\text { D12 } \\
\text { CIE }\end{array}$ & $\begin{array}{l}\text { D13 } \\
\text { PMIE }\end{array}$ & $\begin{array}{l}\text { D14 } \\
\text { MIE }\end{array}$ \\
\hline 1- Paquímetro & 8,83 & 8,14 & 6,90 & 10,16 & 9,50 & 11,23 & 9,21 & 3,33 & 5,60 & 5,77 & 16,63 & 5,40 & 4,27 & 4,75 \\
\hline $\begin{array}{l}\text { 2- Radioimp-resolução- } \\
\text { escaner }\end{array}$ & 8,84 & 8,16 & 6,92 & 10,18 & 9,51 & 11,25 & 9,23 & 3,33 & 5,61 & 5,79 & 16,67 & 5,42 & 4,27 & 4,75 \\
\hline $\begin{array}{l}\text { 3- Radioimp-referencial- } \\
\text { escaner }\end{array}$ & 8,83 & 8,15 & 6,90 & 10,18 & 9,51 & 11,24 & 9,22 & 3,34 & 5,61 & 5,78 & 16,66 & 5,41 & 4,28 & 4,75 \\
\hline $\begin{array}{l}\text { 4- Radioimp-referencial- } \\
\text { câmera }\end{array}$ & 8,83 & 8,14 & 6,91 & 10,17 & 9,50 & 11,23 & 9,22 & 3,33 & 5,60 & 5,78 & 16,64 & 5,41 & 4,27 & 4,75 \\
\hline $\begin{array}{l}\text { 5- Planimp-resolução- } \\
\text { escaner }\end{array}$ & 8,83 & 8,16 & 6,92 & 10,18 & 9,52 & 11,25 & 9,23 & 3,34 & 5,61 & 5,79 & 16,66 & 5,41 & 4,28 & 4,75 \\
\hline $\begin{array}{l}\text { 6- Planimp-referencial- } \\
\text { escaner }\end{array}$ & 8,84 & 8,15 & 6,92 & 10,17 & 9,52 & 11,24 & 9,23 & 3,34 & 5,62 & 5,79 & 16,67 & 5,42 & 4,28 & 4,76 \\
\hline $\begin{array}{l}\text { 7- Planimp-referencial- } \\
\text { câmera }\end{array}$ & 8,83 & 8,14 & 6,90 & 10,18 & 9,51 & 11,23 & 9,22 & 3,33 & 5,60 & 5,78 & 16,65 & 5,41 & 4,28 & 4,75 \\
\hline
\end{tabular}

Anexo 16- Tabela com as medidas das 14 distâncias anatômicas obtidas pelos sete grupos experimentais para a radiografia 16

\begin{tabular}{|c|c|c|c|c|c|c|c|c|c|c|c|c|c|c|}
\hline \multirow{2}{*}{ RX 16} & \multicolumn{14}{|c|}{ Distâncias anatômicas } \\
\hline & $\begin{array}{c}\text { D1 } \\
\text { MSD }\end{array}$ & $\begin{array}{c}\text { D2 } \\
\text { PMSD }\end{array}$ & $\begin{array}{l}\text { D3 } \\
\text { CSD }\end{array}$ & $\begin{array}{l}\text { D4 } \\
\text { ICS }\end{array}$ & $\begin{array}{l}\text { D5 } \\
\text { CSE }\end{array}$ & $\begin{array}{c}\text { D6 } \\
\text { PMSE }\end{array}$ & $\begin{array}{c}\text { D7 } \\
\text { MSE }\end{array}$ & $\begin{array}{l}\text { D8 } \\
\text { MID }\end{array}$ & $\begin{array}{c}\text { D9 } \\
\text { PMID }\end{array}$ & $\begin{array}{l}\text { D10 } \\
\text { CID }\end{array}$ & $\begin{array}{l}\text { D11 } \\
\text { ICI }\end{array}$ & $\begin{array}{l}\text { D12 } \\
\text { CIE }\end{array}$ & $\begin{array}{c}\text { D13 } \\
\text { PMIE }\end{array}$ & $\begin{array}{l}\text { D14 } \\
\text { MIE }\end{array}$ \\
\hline 1- Paquímetro & 6,36 & 9,41 & 15,04 & 11,52 & 15,43 & 11,24 & 5,30 & 8,68 & 9,54 & 9,93 & 17,75 & 8,35 & 6,59 & 6,71 \\
\hline $\begin{array}{l}\text { 2- Radioimp-resolução- } \\
\text { escaner }\end{array}$ & 6,37 & 9,43 & 15,06 & 11,54 & 15,45 & 11,26 & 5,32 & 8,70 & 9,56 & 9,95 & 17,78 & 8,37 & 6,60 & 6,72 \\
\hline $\begin{array}{l}\text { 3- Radioimp-referencial- } \\
\text { escaner }\end{array}$ & 6,36 & 9,43 & 15,07 & 11,55 & 15,46 & 11,24 & 5,31 & 8,70 & 9,55 & 9,95 & 17,78 & 8,37 & 6,60 & 6,72 \\
\hline $\begin{array}{l}\text { 4- Radioimp-referencial- } \\
\text { câmera }\end{array}$ & 6,36 & 9,42 & 15,02 & 11,53 & 15,44 & 11,25 & 5,30 & 8,69 & 9,55 & 9,94 & 17,76 & 8,35 & 6,59 & 6,72 \\
\hline $\begin{array}{l}\text { 5- Planimp-resolução- } \\
\text { escaner }\end{array}$ & 6,38 & 9,44 & 15,06 & 11,54 & 15,46 & 11,25 & 5,32 & 8,71 & 9,57 & 9,96 & 11,79 & 8,38 & 6,62 & 6,74 \\
\hline $\begin{array}{l}\text { 6- Planimp-referencial- } \\
\text { escaner }\end{array}$ & 6,37 & 9,43 & 15,07 & 11,53 & 15,45 & 11,26 & 5,31 & 8,71 & 9,56 & 9,95 & 17,78 & 8,38 & 6,61 & 6,73 \\
\hline $\begin{array}{l}\text { 7- Planimp-referencial- } \\
\text { câmera }\end{array}$ & 6,36 & 9,42 & 15,04 & 11,52 & 15,44 & 11,25 & 5,30 & 8,69 & 9,55 & 9,94 & 17,76 & 8,36 & 6,59 & 6,72 \\
\hline
\end{tabular}


Anexo 17- Tabela com as medidas das 14 distâncias anatômicas obtidas pelos sete grupos experimentais para a radiografia 17

\begin{tabular}{|c|c|c|c|c|c|c|c|c|c|c|c|c|c|c|}
\hline \multirow{2}{*}{ RX 17} & \multicolumn{14}{|c|}{ Distâncias anatômicas } \\
\hline & $\begin{array}{l}\text { D1 } \\
\text { MSD }\end{array}$ & $\begin{array}{c}\text { D2 } \\
\text { PMSD }\end{array}$ & $\begin{array}{l}\text { D3 } \\
\text { CSD }\end{array}$ & $\begin{array}{l}\text { D4 } \\
\text { ICS }\end{array}$ & $\begin{array}{l}\text { D5 } \\
\text { CSE }\end{array}$ & \begin{tabular}{|c|} 
D6 \\
PMSE
\end{tabular} & $\begin{array}{l}\text { D7 } \\
\text { MSE }\end{array}$ & $\begin{array}{l}\text { D8 } \\
\text { MID }\end{array}$ & $\begin{array}{c}\text { D9 } \\
\text { PMID }\end{array}$ & $\begin{array}{l}\text { D10 } \\
\text { CID }\end{array}$ & $\begin{array}{l}\text { D11 } \\
\text { ICI }\end{array}$ & $\begin{array}{l}\text { D12 } \\
\text { CIE }\end{array}$ & $\begin{array}{l}\text { D13 } \\
\text { PMIE }\end{array}$ & $\begin{array}{l}\text { D14 } \\
\text { MIE }\end{array}$ \\
\hline 1- Paquímetro & 9,52 & 11,66 & 12,91 & 13,91 & 12,50 & 11,25 & 9,08 & 7,70 & 7,65 & 10,30 & 21,66 & 12,04 & 9,37 & 10,20 \\
\hline $\begin{array}{l}\text { 2- Radioimp-resolução- } \\
\text { escaner }\end{array}$ & 9,56 & 11,67 & 12,93 & 13,95 & 12,53 & 11,27 & 9,10 & 7,73 & 7,66 & 10,34 & 21,70 & 12,05 & 9,39 & 10,23 \\
\hline $\begin{array}{l}\text { 3- Radioimp-referencial- } \\
\text { escaner }\end{array}$ & 9,55 & 11,66 & 12,92 & 13,93 & 12,53 & 11,27 & 9,10 & 7,73 & 7,65 & 10,33 & 21,69 & 12,05 & 9,39 & 10,23 \\
\hline $\begin{array}{l}\text { 4- Radioimp-referencial- } \\
\text { câmera }\end{array}$ & 9,53 & 11,65 & 12,91 & 13,92 & 12,51 & 11,25 & 9,09 & 7,71 & 7,65 & 10,32 & 21,67 & 12,04 & 9,38 & 10,21 \\
\hline $\begin{array}{l}\text { 5- Planimp-resolução- } \\
\text { escaner }\end{array}$ & 9,56 & 11,68 & 12,92 & 13,94 & 12,52 & 11,26 & 9,11 & 7,73 & 7,67 & 10,33 & 21,70 & 12,05 & 9,39 & 10,22 \\
\hline $\begin{array}{l}\text { 6- Planimp-referencial- } \\
\text { escaner }\end{array}$ & 9,56 & 11,68 & 12,92 & 13,93 & 12,52 & 11,26 & 9,11 & 7,73 & 7,67 & 10,34 & 21,70 & 12,05 & 9,39 & 10,22 \\
\hline $\begin{array}{l}\text { 7- Planimp-referencial- } \\
\text { câmera }\end{array}$ & 9,53 & 11,66 & 12,91 & 13,93 & 12,50 & 11,25 & 9,09 & 7,72 & 7,65 & 10,31 & 21,68 & 12,05 & 9,38 & 10,21 \\
\hline
\end{tabular}

Anexo 18- Tabela com as medidas das 14 distâncias anatômicas obtidas pelos sete grupos experimentais para a radiografia 18

\begin{tabular}{l|l|l|l|l|l|l|l|l|l|l|l|l|l|l}
\hline \multirow{2}{*}{ RX 18 } & \multicolumn{10}{l|}{ Distâncias anatômicas } \\
\cline { 2 - 14 } & $\begin{array}{l}\text { D1 } \\
\text { MSD }\end{array}$ & $\begin{array}{l}\text { D2 } \\
\text { PMSD }\end{array}$ & $\begin{array}{l}\text { D3 } \\
\text { CSD }\end{array}$ & $\begin{array}{l}\text { D4 } \\
\text { ICS }\end{array}$ & $\begin{array}{l}\text { D5 } \\
\text { CSE }\end{array}$ & $\begin{array}{l}\text { D6 } \\
\text { PMSE }\end{array}$ & $\begin{array}{l}\text { D7 } \\
\text { MSE }\end{array}$ & $\begin{array}{l}\text { D8 } \\
\text { MID }\end{array}$ & $\begin{array}{l}\text { D9 } \\
\text { PMID }\end{array}$ & $\begin{array}{l}\text { D10 } \\
\text { CID }\end{array}$ & $\begin{array}{l}\text { D11 } \\
\text { ICI }\end{array}$ & $\begin{array}{l}\text { D12 } \\
\text { CIE }\end{array}$ & $\begin{array}{l}\text { D13 } \\
\text { PMIE }\end{array}$ & $\begin{array}{l}\text { D14 } \\
\text { MIE }\end{array}$ \\
\hline \hline 1- Paquímetro & 4,07 & 6,59 & 15,85 & 15,44 & 13,40 & 5,69 & 5,47 & 5,14 & 5,65 & 7,70 & 17,63 & 7,96 & 7,18 & 7,08 \\
\hline $\begin{array}{l}\text { 2- Radioimp-resolução- } \\
\text { escaner }\end{array}$ & 4,09 & 6,60 & 15,87 & 15,44 & 13,42 & 5,69 & 5,49 & 5,15 & 5,67 & 7,70 & 17,66 & 7,98 & 7,19 & 7,09 \\
\hline $\begin{array}{l}\text { 3- Radioimp-referencial- } \\
\text { escaner }\end{array}$ & 4,09 & 6,60 & 15,86 & 15,45 & 13,41 & 5,70 & 5,49 & 5,15 & 5,66 & 7,71 & 17,65 & 7,97 & 7,19 & 7,09 \\
\hline $\begin{array}{l}\text { 4- Radioimp-referencial- } \\
\text { câmera }\end{array}$ & 4,08 & 6,59 & 15,86 & 15,44 & 13,40 & 5,69 & 5,48 & 5,14 & 5,66 & 7,69 & 13,64 & 7,96 & 7,19 & 7,08 \\
\hline $\begin{array}{l}\text { 5- Planimp-resolução- } \\
\text { escaner }\end{array}$ & 4,09 & 6,60 & 15,86 & 15,44 & 13,40 & 5,70 & 5,48 & 5,15 & 5,65 & 7,70 & 17,66 & 7,98 & 7,20 & 7,10 \\
\hline $\begin{array}{l}\text { 6- Planimp-referencial- } \\
\text { escaner }\end{array}$ & 4,08 & 6,61 & 15,86 & 15,45 & 13,41 & 5,70 & 5,48 & 5,15 & 5,65 & 7,69 & 17,65 & 7,97 & 7,20 & 7,10 \\
\hline $\begin{array}{l}\text { 7- Planimp-referencial- } \\
\text { câmera }\end{array}$ & 4,08 & 6,59 & 15,85 & 15,45 & 13,41 & 5,69 & 5,47 & 5,14 & 5,66 & 7,69 & 17,64 & 7,96 & 7,20 & 7,08 \\
\hline
\end{tabular}


Anexo 19- Tabela com as medidas das 14 distâncias anatômicas obtidas pelos sete grupos experimentais para a radiografia 19

\begin{tabular}{|c|c|c|c|c|c|c|c|c|c|c|c|c|c|c|}
\hline \multirow{2}{*}{ RX 19} & \multicolumn{14}{|c|}{ Distâncias anatômicas } \\
\hline & $\begin{array}{l}\text { D1 } \\
\text { MSD }\end{array}$ & $\begin{array}{c}\text { D2 } \\
\text { PMSD }\end{array}$ & $\begin{array}{l}\text { D3 } \\
\text { CSD }\end{array}$ & $\begin{array}{l}\text { D4 } \\
\text { ICS }\end{array}$ & $\begin{array}{l}\text { D5 } \\
\text { CSE }\end{array}$ & $\begin{array}{l}\text { D6 } \\
\text { PMSE }\end{array}$ & $\begin{array}{l}\text { D7 } \\
\text { MSE }\end{array}$ & $\begin{array}{l}\text { D8 } \\
\text { MID }\end{array}$ & $\begin{array}{c}\text { D9 } \\
\text { PMID }\end{array}$ & $\begin{array}{l}\text { D10 } \\
\text { CID }\end{array}$ & $\begin{array}{l}\text { D11 } \\
\text { ICI }\end{array}$ & $\begin{array}{l}\text { D12 } \\
\text { CIE }\end{array}$ & $\begin{array}{l}\text { D13 } \\
\text { PMIE }\end{array}$ & $\begin{array}{l}\text { D14 } \\
\text { MIE }\end{array}$ \\
\hline 1- Paquímetro & 7,51 & 8,60 & 11,16 & 14,70 & 12,65 & 9,62 & 6,35 & 8,69 & 7,25 & 8,56 & 18,58 & 9,18 & 7,05 & 7,87 \\
\hline $\begin{array}{l}\text { 2- Radioimp-resolução- } \\
\text { escaner }\end{array}$ & 7,51 & 6,62 & 11,19 & 14,72 & 12,64 & 9,63 & 6,37 & 8,70 & 7,25 & 8,58 & 18,62 & 9,19 & 7,05 & 9,87 \\
\hline $\begin{array}{l}\text { 3- Radioimp-referencial- } \\
\text { escaner }\end{array}$ & 7,52 & 8,63 & 11,18 & 14,72 & 12,63 & 9,63 & 6,37 & 8,70 & 7,26 & 8,58 & 18,61 & 9,19 & 7,05 & 9,88 \\
\hline $\begin{array}{l}\text { 4- Radioimp-referencial- } \\
\text { câmera }\end{array}$ & 7,51 & 8,60 & 11,17 & 14,71 & 12,66 & 9,62 & 6,35 & 8,69 & 7,25 & 8,56 & 18,59 & 9,18 & 7,06 & 9,87 \\
\hline $\begin{array}{l}\text { 5- Planimp-resolução- } \\
\text { escaner }\end{array}$ & 7,53 & 6,61 & 11,18 & 14,71 & 12,65 & 9,63 & 6,35 & 8,71 & 7,25 & 8,57 & 18,62 & 9,20 & 7,06 & 9,89 \\
\hline $\begin{array}{l}\text { 6- Planimp-referencial- } \\
\text { escaner }\end{array}$ & 7,53 & 8,61 & 11,19 & 14,71 & 12,65 & 9,63 & 6,36 & 8,71 & 7,26 & 8,58 & 18,61 & 9,20 & 7,06 & 9,88 \\
\hline $\begin{array}{l}\text { 7- Planimp-referencial- } \\
\text { câmera }\end{array}$ & 7,51 & 8,60 & 11,17 & 14,70 & 12,66 & 9,62 & 6,36 & 8,69 & 7,25 & 8,57 & 18,58 & 9,19 & 7,06 & 9,87 \\
\hline
\end{tabular}

Anexo 20- Tabela com as medidas das 14 distâncias anatômicas obtidas pelos sete grupos experimentais para a radiografia 20

\begin{tabular}{|c|c|c|c|c|c|c|c|c|c|c|c|c|c|c|c|c|c|c|c|}
\hline \multirow{2}{*}{$\mathrm{RX} 20$} & \multicolumn{19}{|c|}{ Distâncias anatômicas } \\
\hline & $\begin{array}{r}\text { D1 } \\
\text { MSD }\end{array}$ & $\begin{array}{c}\text { D2 } \\
\text { PMSD }\end{array}$ & $\begin{array}{r}\text { D3 } \\
\text { CSD }\end{array}$ & $\begin{array}{l}\text { D4 } \\
\text { ICS }\end{array}$ & $\begin{array}{l}\text { D5 } \\
\text { CSE }\end{array}$ & \multicolumn{2}{|c|}{$\begin{array}{c}\text { D6 } \\
\text { PMSE }\end{array}$} & \multicolumn{2}{|c|}{$\begin{array}{r}\text { D7 } \\
\text { MSE }\end{array}$} & $\begin{array}{l}\text { D8 } \\
\text { MID }\end{array}$ & \multicolumn{2}{|c|}{$\begin{array}{r}\text { D9 } \\
\text { PMID }\end{array}$} & \multicolumn{2}{|c|}{$\begin{array}{l}\text { D10 } \\
\text { CID }\end{array}$} & \multicolumn{2}{|c|}{$\begin{array}{l}\text { D11 } \\
\text { ICI }\end{array}$} & $\begin{array}{l}\text { D12 } \\
\text { CIE }\end{array}$ & $\begin{array}{l}\text { D13 } \\
\text { PMIE }\end{array}$ & \begin{tabular}{l|l}
3 & D14 \\
& MIE
\end{tabular} \\
\hline 1- Paquímetro & 4,50 & 7,17 & 10,93 & 8,76 & 10,25 & 5,37 & 4,5 & & 6,97 & & 13 & 9,2 & 26 & 18,7 & & 8,95 & & 6,21 & 8,90 \\
\hline $\begin{array}{l}\text { 2- Radioimp-resolução- } \\
\text { scaner }\end{array}$ & 4,51 & 7,18 & 10,96 & 8,78 & 10,27 & 5,38 & 4,5 & & 6,98 & & 14 & 9,2 & 28 & 18,8 & & 8,97 & & 6,23 & 8,92 \\
\hline $\begin{array}{l}\text { 3- Radioimp-referencial- } \\
\text { scaner }\end{array}$ & 4,50 & 7,18 & 10,96 & 8,77 & 10,27 & 5,37 & 4,5 & & 6,99 & & 14 & 9,2 & 28 & 18,8 & & 8,96 & & 6,22 & 8,92 \\
\hline $\begin{array}{l}\text { 4- Radioimp-referencial- } \\
\text { âmera }\end{array}$ & 4,51 & 7,17 & 10,94 & 8,76 & 10,26 & 5,37 & 4,5 & & 6,98 & & 13 & 9,2 & 27 & 18,8 & & 8,95 & & 6,21 & 8,91 \\
\hline $\begin{array}{l}\text { 5- Planimp-resolução- } \\
\text { scaner }\end{array}$ & 4,51 & 7,18 & 10,96 & 8,78 & 10,26 & 5,37 & 4,5 & & 6,99 & & 14 & 9,2 & 29 & 18,8 & & 8,97 & & 6,21 & 8,92 \\
\hline $\begin{array}{l}\text { 6- Planimp-referencial- } \\
\text { scaner }\end{array}$ & 4,51 & 7,17 & 10,95 & 8,77 & 10,26 & 5,37 & 4,5 & & 6,98 & & 13 & 9,2 & 28 & 18,8 & & 8,97 & & 6,22 & 8,91 \\
\hline $\begin{array}{l}\text { 7- Planimp-referencial- } \\
\text { âmera }\end{array}$ & 4,50 & 7,16 & 10,95 & 8,76 & 10,25 & 5,36 & 4,5 & & 6,97 & & 13 & 9,2 & 27 & 18,7 & & 8,96 & & 6,21 & 8,91 \\
\hline
\end{tabular}


Anexo 21- Tabela com as medidas das 14 distâncias anatômicas obtidas pelos sete grupos experimentais para a radiografia 21

\begin{tabular}{|c|c|c|c|c|c|c|c|c|c|c|c|c|c|c|}
\hline \multirow{2}{*}{ RX 21} & \multicolumn{14}{|c|}{ Distâncias anatômicas } \\
\hline & $\begin{array}{l}\text { D1 } \\
\text { MSD }\end{array}$ & $\begin{array}{c}\text { D2 } \\
\text { PMSD }\end{array}$ & $\begin{array}{l}\text { D3 } \\
\text { CSD }\end{array}$ & $\begin{array}{l}\text { D4 } \\
\text { ICS }\end{array}$ & $\begin{array}{l}\text { D5 } \\
\text { CSE }\end{array}$ & $\begin{array}{c}\text { D6 } \\
\text { PMSE }\end{array}$ & $\begin{array}{l}\text { D7 } \\
\text { MSE }\end{array}$ & $\begin{array}{l}\text { D8 } \\
\text { MID }\end{array}$ & $\begin{array}{l}\text { D9 } \\
\text { PMID }\end{array}$ & $\begin{array}{l}\text { D10 } \\
\text { CID }\end{array}$ & $\begin{array}{l}\text { D11 } \\
\text { ICI }\end{array}$ & $\begin{array}{l}\text { D12 } \\
\text { CIE }\end{array}$ & $\begin{array}{l}\text { D13 } \\
\text { PMIE }\end{array}$ & $\begin{array}{l}\text { D14 } \\
\text { MIE }\end{array}$ \\
\hline 1- Paquímetro & 9,25 & 11,11 & 10,65 & 7,85 & 10,57 & 7,86 & 5,93 & 7,81 & 9,98 & 9,26 & 17,95 & 8,85 & 7,84 & 8,34 \\
\hline $\begin{array}{l}\text { 2- Radioimp-resolução- } \\
\text { escaner }\end{array}$ & 9,26 & 11,13 & 10,67 & 7,86 & 10,58 & 7,88 & 5,94 & 7,81 & 9,99 & 9,27 & 17,98 & 8,85 & 7,85 & 8,36 \\
\hline $\begin{array}{l}\text { 3- Radioimp-referencial- } \\
\text { escaner }\end{array}$ & 9,26 & 11,13 & 10,66 & 7,86 & 10,58 & 7,87 & 5,94 & 7,81 & 9,98 & 9,27 & 17,98 & 8,86 & 7,84 & 8,36 \\
\hline $\begin{array}{l}\text { 4- Radioimp-referencial- } \\
\text { câmera }\end{array}$ & 9,25 & 11,11 & 10,65 & 7,85 & 10,57 & 7,86 & 5,93 & 7,80 & 9,97 & 9,26 & 17,96 & 8,85 & 7,83 & 8,34 \\
\hline $\begin{array}{l}\text { 5- Planimp-resolução- } \\
\text { escaner }\end{array}$ & 9,25 & 11,12 & 10,66 & 7,86 & 10,59 & 7,88 & 5,94 & 7,82 & 9,99 & 9,28 & 17,96 & 8,86 & 7,85 & 8,36 \\
\hline $\begin{array}{l}\text { 6- Planimp-referencial- } \\
\text { escaner }\end{array}$ & 9,26 & 11,12 & 10,65 & 7,87 & 10,58 & 7,88 & 5,94 & 7,82 & 9,98 & 9,28 & 17,96 & 8,86 & 7,85 & 8,35 \\
\hline $\begin{array}{l}\text { 7- Planimp-referencial- } \\
\text { câmera }\end{array}$ & 9,25 & 11,11 & 10,66 & 7,86 & 10,57 & 7,86 & 5,93 & 7,80 & 9,97 & 9,26 & 17,97 & 8,85 & 7,83 & 8,34 \\
\hline
\end{tabular}

Anexo 22- Tabela com as medidas das 14 distâncias anatômicas obtidas pelos sete grupos experimentais para a radiografia 22

\begin{tabular}{|c|c|c|c|c|c|c|c|c|c|c|c|c|c|c|}
\hline RX 22 & $\begin{array}{l}\text { D1 } \\
\text { MSD }\end{array}$ & $\begin{array}{c}\text { D2 } \\
\text { PMSD }\end{array}$ & $\begin{array}{l}\text { D3 } \\
\text { CSD }\end{array}$ & $\begin{array}{l}\text { D4 } \\
\text { ICS }\end{array}$ & $\begin{array}{l}\text { D5 } \\
\text { CSE }\end{array}$ & $\begin{array}{c}\text { D6 } \\
\text { PMSE }\end{array}$ & $\begin{array}{l}\text { D7 } \\
\text { MSE }\end{array}$ & $\begin{array}{l}\text { D8 } \\
\text { MID }\end{array}$ & $\begin{array}{c}\text { D9 } \\
\text { PMID }\end{array}$ & $\begin{array}{l}\text { D10 } \\
\text { CID }\end{array}$ & $\begin{array}{l}\text { D11 } \\
\text { ICI }\end{array}$ & $\begin{array}{l}\text { D12 } \\
\text { CIE }\end{array}$ & $\begin{array}{l}\text { D13 } \\
\text { PMIE }\end{array}$ & $\begin{array}{l}\text { D14 } \\
\text { MIE }\end{array}$ \\
\hline 1- Paquímetro & 8,97 & 12,33 & 12,02 & 12,46 & 13,44 & 11,71 & 7,55 & 8,75 & 5,35 & 6,08 & 12,29 & 5,05 & 4,35 & 4,93 \\
\hline $\begin{array}{l}\text { 2- Radioimp-resolução- } \\
\text { escaner }\end{array}$ & 8,99 & 12,35 & 12,02 & 12,49 & 13,45 & 11,74 & 7,56 & 8,74 & 5,36 & 6,09 & 12,32 & 5,05 & 4,35 & 4,93 \\
\hline $\begin{array}{l}\text { 3- Radioimp-referencial- } \\
\text { escaner }\end{array}$ & 8,99 & 12,36 & 12,03 & 12,48 & 13,45 & 11,74 & 7,56 & 8,75 & 5,36 & 6,09 & 12,31 & 5,05 & 4,35 & 4,94 \\
\hline $\begin{array}{l}\text { 4- Radioimp-referencial- } \\
\text { câmera }\end{array}$ & 8,98 & 12,34 & 12,02 & 12,47 & 13,44 & 11,72 & 7,55 & 8,74 & 5,35 & 6,08 & 12,30 & 5,05 & 4,35 & 4,94 \\
\hline $\begin{array}{l}\text { 5- Planimp-resolução- } \\
\text { escaner }\end{array}$ & 8,98 & 12,35 & 12,04 & 12,48 & 13,46 & 11,74 & 7,57 & 8,76 & 5,36 & 6,09 & 12,29 & 5,06 & 4,36 & 4,93 \\
\hline $\begin{array}{l}\text { 6- Planimp-referencial- } \\
\text { escaner }\end{array}$ & 8,97 & 12,36 & 12,04 & 12,48 & 13,46 & 11,73 & 7,57 & 8,76 & 5,35 & 6,08 & 12,29 & 5,06 & 4,36 & 4,94 \\
\hline $\begin{array}{l}\text { 7- Planimp-referencial- } \\
\text { câmera }\end{array}$ & 8,97 & 12,34 & 12,03 & 12,46 & 13,45 & 11,72 & 7,55 & 8,75 & 5,35 & 6,08 & 12,30 & 5,05 & 4,35 & 4,93 \\
\hline
\end{tabular}


Anexo 23- Tabela com as medidas das 14 distâncias anatômicas obtidas pelos sete grupos experimentais para a radiografia 23

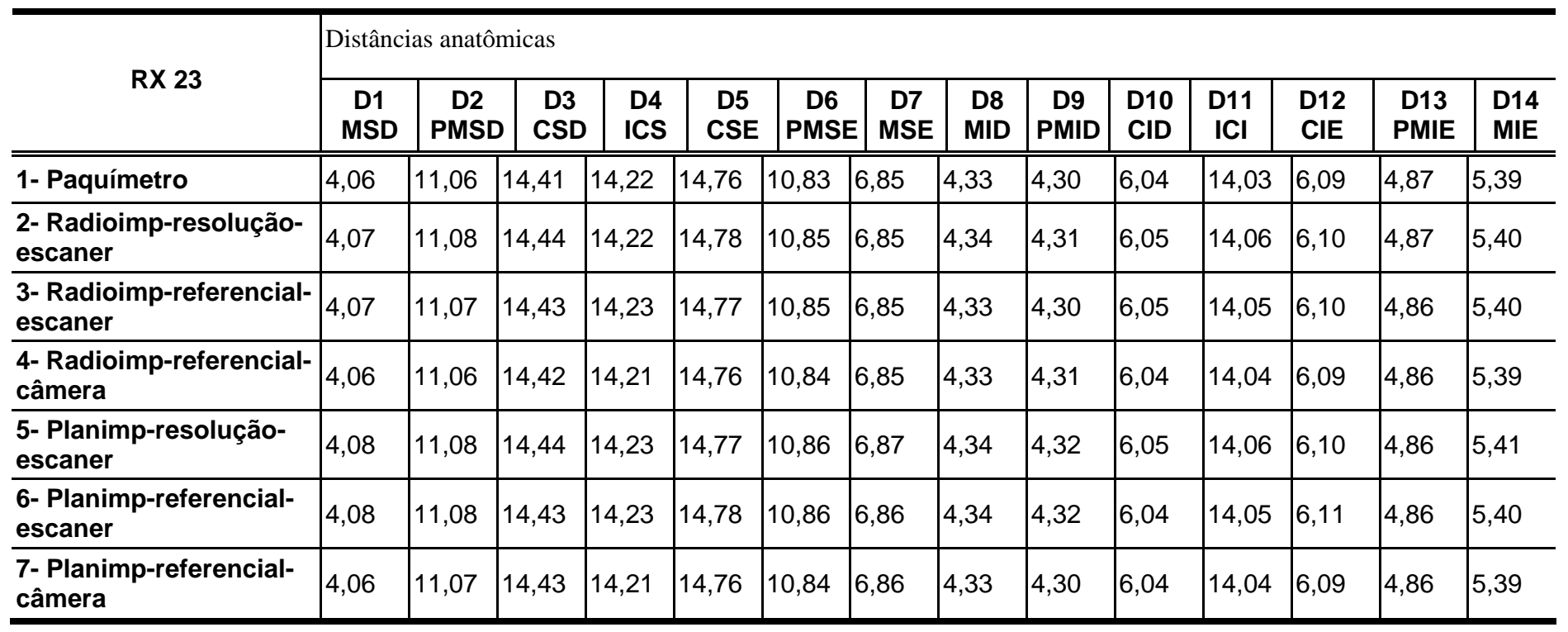

Anexo 24- Tabela com as medidas das 14 distâncias anatômicas obtidas pelos sete grupos experimentais para a radiografia 24

\begin{tabular}{|c|c|c|c|c|c|c|c|c|c|c|c|c|c|c|}
\hline 1- Paquímetro & 8,83 & 10,54 & 13,21 & 12,15 & 11,68 & 10,12 & 7,74 & 4,66 & 5,10 & 7,18 & 16,47 & 8,39 & 6,78 & 4,95 \\
\hline $\begin{array}{l}\text { 2- Radioimp-resolução- } \\
\text { escaner }\end{array}$ & 8,85 & 10,55 & 13,24 & 12,17 & 11,70 & 10,13 & 7,75 & 4,67 & 5,13 & 7,20 & 16,49 & 8,41 & 6,78 & 4,96 \\
\hline $\begin{array}{l}\text { 4- Radioimp-referencial- } \\
\text { câmera }\end{array}$ & 8,83 & 10,54 & 13,22 & 12,16 & 11,68 & 10,11 & 7,74 & 4,66 & 5,12 & 7,18 & 16,48 & 8,39 & 6,78 & 4,95 \\
\hline $\begin{array}{l}\text { 5- Planimp-resolução- } \\
\text { escaner }\end{array}$ & 8,84 & 10,56 & 13,24 & 12,17 & 11,69 & 10,13 & 7,76 & 4,67 & 5,12 & 7,20 & 16,49 & 8,41 & 6,79 & 4,97 \\
\hline $\begin{array}{l}\text { 6- Planimp-referencial- } \\
\text { escaner }\end{array}$ & 8,83 & 10,56 & 13,23 & 12,16 & 11,69 & 10,13 & 7,76 & 4,66 & 5,13 & 7,19 & 16,50 & 8,41 & 6,79 & 4,96 \\
\hline
\end{tabular}


Anexo 25- Tabela com as medidas das 14 distâncias anatômicas obtidas pelos sete grupos experimentais para a radiografia 25

\begin{tabular}{|c|c|c|c|c|c|c|c|c|c|c|c|c|c|c|}
\hline \multirow{2}{*}{ RX 25} & \multicolumn{14}{|c|}{ Distâncias anatômicas } \\
\hline & $\begin{array}{l}\text { D1 } \\
\text { MSD }\end{array}$ & $\begin{array}{l}\text { D2 } \\
\text { PMSD }\end{array}$ & $\begin{array}{l}\text { D3 } \\
\text { CSD }\end{array}$ & $\begin{array}{l}\text { D4 } \\
\text { ICS }\end{array}$ & $\begin{array}{l}\text { D5 } \\
\text { CSE }\end{array}$ & $\begin{array}{c}\text { D6 } \\
\text { PMSE }\end{array}$ & $\begin{array}{l}\text { D7 } \\
\text { MSE }\end{array}$ & $\begin{array}{l}\text { D8 } \\
\text { MID }\end{array}$ & $\begin{array}{l}\text { D9 } \\
\text { PMID }\end{array}$ & $\begin{array}{l}\text { D10 } \\
\text { CID }\end{array}$ & $\begin{array}{l}\text { D11 } \\
\text { ICI }\end{array}$ & $\begin{array}{l}\text { D12 } \\
\text { CIE }\end{array}$ & \begin{tabular}{|c|} 
D13 \\
PMIE
\end{tabular} & $\begin{array}{l}\text { D14 } \\
\text { MIE }\end{array}$ \\
\hline 1- Paquímetro & 10,39 & 11,36 & 10,10 & 12,15 & 14,44 & 10,85 & 7,18 & 5,40 & 5,80 & 10,83 & 18,40 & 9,55 & 6,70 & 7,05 \\
\hline $\begin{array}{l}\text { 2- Radioimp-resolução- } \\
\text { escaner }\end{array}$ & 10,41 & 11,37 & 10,11 & 12,17 & 14,46 & 10,87 & 7,20 & 5,42 & 5,81 & 10,85 & 18,43 & 9,56 & 6,72 & 7,06 \\
\hline $\begin{array}{l}\text { 3- Radioimp-referencial- } \\
\text { escaner }\end{array}$ & 10,40 & 11,38 & 10,11 & 12,17 & 14,46 & 10,87 & 7,19 & 5,41 & 5,81 & 10,84 & 18,43 & 9,56 & 6,71 & 7,06 \\
\hline $\begin{array}{l}\text { 4- Radioimp-referencial- } \\
\text { câmera }\end{array}$ & 10,39 & 11,37 & 10,10 & 12,16 & 14,45 & 10,85 & 7,18 & 5,40 & 5,80 & 10,83 & 18,41 & 9,55 & 6,70 & 7,05 \\
\hline $\begin{array}{l}\text { 5- Planimp-resolução- } \\
\text { escaner }\end{array}$ & 10,42 & 11,37 & 10,12 & 12,18 & 14,45 & 10,86 & 7,19 & 5,41 & 5,82 & 10,86 & 18,43 & 9,57 & 6,72 & 7,07 \\
\hline $\begin{array}{l}\text { 6- Planimp-referencial- } \\
\text { escaner }\end{array}$ & 10,43 & 11,37 & 10,12 & 12,18 & 14,46 & 10,86 & 7,19 & 5,41 & 5,81 & 10,86 & 18,43 & 9,57 & 6,71 & 7,07 \\
\hline $\begin{array}{l}\text { 7- Planimp-referencial- } \\
\text { câmera }\end{array}$ & 10,40 & 11,36 & 10,10 & 12,16 & 14,45 & 10,85 & 7,18 & 5,40 & 5,80 & 10,84 & 18,42 & 9,55 & 6,70 & 7,05 \\
\hline
\end{tabular}

Anexo 26- Tabela com as medidas das 14 distâncias anatômicas obtidas pelos sete grupos experimentais para a radiografia 26

\begin{tabular}{|c|c|c|c|c|c|c|c|c|c|c|c|c|c|c|}
\hline \multirow{2}{*}{$R \times 26$} & \multicolumn{14}{|c|}{ Distâncias anatômicas } \\
\hline & $\begin{array}{l}\text { D1 } \\
\text { MSD }\end{array}$ & $\begin{array}{c}\text { D2 } \\
\text { PMSD }\end{array}$ & $\begin{array}{l}\text { D3 } \\
\text { CSD }\end{array}$ & $\begin{array}{l}\text { D4 } \\
\text { IS }\end{array}$ & $\begin{array}{l}\text { D5 } \\
\text { CSE }\end{array}$ & $\begin{array}{c}\text { D6 } \\
\text { PMSE }\end{array}$ & $\begin{array}{l}\text { D7 } \\
\text { MSE }\end{array}$ & $\begin{array}{l}\text { D8 } \\
\text { MID }\end{array}$ & $\begin{array}{l}\text { D9 } \\
\text { PMID }\end{array}$ & $\begin{array}{l}\text { D10 } \\
\text { CID }\end{array}$ & $\begin{array}{c}\text { D11 } \\
\text { II }\end{array}$ & $\begin{array}{l}\text { D12 } \\
\text { CIE }\end{array}$ & \begin{tabular}{|l} 
D13 \\
PMIE
\end{tabular} & $\begin{array}{l}\text { D14 } \\
\text { MIE }\end{array}$ \\
\hline 1- Paquímetro & 9,48 & 11,72 & 19,10 & 17,11 & 18,75 & 13,57 & 7,94 & 12,34 & 15,44 & 15,28 & 26,55 & 15,20 & 14,13 & 16,28 \\
\hline $\begin{array}{l}\text { 2- Radioimp-resolução- } \\
\text { escaner }\end{array}$ & 9,51 & 11,74 & 19,12 & 17,14 & 18,75 & 13,59 & 7,97 & 12,36 & 15,44 & 15,31 & 26,57 & 15,22 & 14,14 & 16,30 \\
\hline $\begin{array}{l}\text { 3- Radioimp-referencial- } \\
\text { escaner }\end{array}$ & 9,50 & 11,73 & 19,12 & 17,14 & 18,77 & 13,58 & 7,95 & 12,36 & 15,43 & 15,30 & 26,56 & 15,22 & 14,14 & 16,30 \\
\hline $\begin{array}{l}\text { 4- Radioimp-referencial- } \\
\text { câmera }\end{array}$ & 9,49 & 11,72 & 19,10 & 17,12 & 18,76 & 13,57 & 7,95 & 12,34 & 15,44 & 15,29 & 26,55 & 15,21 & 14,13 & 16,29 \\
\hline $\begin{array}{l}\text { 5- Planimp-resolução- } \\
\text { escaner }\end{array}$ & 9,51 & 11,74 & 19,11 & 17,13 & 18,77 & 13,58 & 7,96 & 12,35 & 15,45 & 15,32 & 26,57 & 15,23 & 14,14 & 16,31 \\
\hline $\begin{array}{l}\text { 6- Planimp-referencial- } \\
\text { escaner }\end{array}$ & 9,52 & 11,74 & 19,10 & 17,13 & 18,75 & 13,58 & 7,96 & 12,35 & 15,44 & 15,31 & 26,56 & 15,23 & 14,14 & 16,31 \\
\hline $\begin{array}{l}\text { 7- Planimp-referencial- } \\
\text { câmera }\end{array}$ & 9,48 & 11,72 & 19,10 & 17,12 & 18,76 & 13,57 & 7,95 & 12,34 & 15,43 & 15,29 & 26,55 & 15,21 & 14,13 & 16,29 \\
\hline
\end{tabular}


Anexo 27- Tabela com as medidas das 14 distâncias anatômicas obtidas pelos sete grupos experimentais para a radiografia 27

\begin{tabular}{|c|c|c|c|c|c|c|c|c|c|c|c|c|c|c|}
\hline \multirow{2}{*}{$\mathrm{RX} 27$} & \multicolumn{14}{|c|}{ Distâncias anatômicas } \\
\hline & $\begin{array}{l}\text { D1 } \\
\text { MSD }\end{array}$ & $\begin{array}{c}\text { D2 } \\
\text { PMSD }\end{array}$ & $\begin{array}{l}\text { D3 } \\
\text { CSD }\end{array}$ & $\begin{array}{l}\text { D4 } \\
\text { ICS }\end{array}$ & $\begin{array}{l}\text { D5 } \\
\text { CSE }\end{array}$ & $\begin{array}{c}\text { D6 } \\
\text { PMSE }\end{array}$ & $\begin{array}{l}\text { D7 } \\
\text { MSE }\end{array}$ & $\begin{array}{l}\text { D8 } \\
\text { MID }\end{array}$ & $\begin{array}{l}\text { D9 } \\
\text { PMID }\end{array}$ & $\begin{array}{l}\text { D10 } \\
\text { CID }\end{array}$ & $\begin{array}{l}\text { D11 } \\
\text { ICI }\end{array}$ & $\begin{array}{l}\text { D12 } \\
\text { CIE }\end{array}$ & $\begin{array}{l}\text { D13 } \\
\text { PMIE }\end{array}$ & $\begin{array}{l}\text { D14 } \\
\text { MIE }\end{array}$ \\
\hline 1- Paquímetro & 5,04 & 11,23 & 10,95 & 8,60 & 9,84 & 8,74 & 5,91 & 6,08 & 7,27 & 8,56 & 20,20 & 9,07 & 9,09 & 20,07 \\
\hline $\begin{array}{l}\text { 2- Radioimp-resolução- } \\
\text { escaner }\end{array}$ & 5,04 & 11,24 & 10,97 & 8,62 & 9,86 & 8,75 & 5,93 & 6,10 & 7,29 & 8,58 & 20,23 & 9,08 & 9,10 & 10,08 \\
\hline $\begin{array}{l}\text { 3- Radioimp-referencial- } \\
\text { escaner }\end{array}$ & 5,04 & 11,24 & 10,97 & 8,62 & 9,86 & 8,75 & 5,92 & 6,09 & 7,29 & 8,58 & 20,23 & 9,08 & 9,10 & 10,07 \\
\hline $\begin{array}{l}\text { 4- Radioimp-referencial- } \\
\text { câmera }\end{array}$ & 5,04 & 11,23 & 10,95 & 8,60 & 9,85 & 8,74 & 5,91 & 6,08 & 7,27 & 8,57 & 20,21 & 9,07 & 9,09 & 10,07 \\
\hline $\begin{array}{l}\text { 5- Planimp-resolução- } \\
\text { escaner }\end{array}$ & 5,05 & 11,26 & 10,98 & 8,62 & 9,87 & 8,75 & 5,92 & 6,09 & 7,30 & 8,59 & 20,24 & 9,09 & 9,11 & 20,08 \\
\hline $\begin{array}{l}\text { 6- Planimp-referencial- } \\
\text { escaner }\end{array}$ & 5,05 & 11,25 & 10,97 & 8,61 & 9,87 & 8,75 & 5,93 & 6,09 & 7,30 & 8,59 & 20,23 & 9,09 & 9,10 & 10,08 \\
\hline $\begin{array}{l}\text { 7- Planimp-referencial- } \\
\text { câmera }\end{array}$ & 5,04 & 11,24 & 10,96 & 8,60 & 9,85 & 8,74 & 5,91 & 6,08 & 7,28 & 8,57 & 20,22 & 9,07 & 9,10 & 10,07 \\
\hline
\end{tabular}

Anexo 28- Tabela com as medidas das 14 distâncias anatômicas obtidas pelos sete grupos experimentais para a radiografia 28

\begin{tabular}{|c|c|c|c|c|c|c|c|c|c|c|c|c|c|c|}
\hline \multirow{2}{*}{$\mathrm{RX} 28$} & \multicolumn{14}{|c|}{ Distâncias anatômicas } \\
\hline & $\begin{array}{c}\text { D1 } \\
\text { MSD }\end{array}$ & \begin{tabular}{|c|} 
D2 \\
PMSD
\end{tabular} & $\begin{array}{c}\text { D3 } \\
\text { CSD }\end{array}$ & $\begin{array}{l}\text { D4 } \\
\text { ICS }\end{array}$ & \begin{tabular}{|c|} 
D5 \\
CSE
\end{tabular} & \begin{tabular}{|c|} 
D6 \\
PMSE
\end{tabular} & $\begin{array}{c}\text { D7 } \\
\text { MSE }\end{array}$ & $\begin{array}{l}\text { D8 } \\
\text { MID }\end{array}$ & \begin{tabular}{|c|} 
D9 \\
PMID \\
\end{tabular} & $\begin{array}{l}\text { D10 } \\
\text { CID }\end{array}$ & $\begin{array}{l}\text { D11 } \\
\text { ICI }\end{array}$ & $\begin{array}{l}\text { D12 } \\
\text { CIE }\end{array}$ & $\begin{array}{c}\text { D13 } \\
\text { PMIE }\end{array}$ & $\begin{array}{l}\text { D14 } \\
\text { MIE }\end{array}$ \\
\hline 1- Paquímetro & 5,65 & 7,70 & 9,07 & 8,40 & 8,85 & 5,21 & 6,00 & 9,55 & 8,18 & 9,17 & 18,47 & 10,80 & 10,41 & 10,23 \\
\hline $\begin{array}{l}\text { 2- Radioimp-resolução- } \\
\text { escaner }\end{array}$ & 5,65 & 7,72 & 9,09 & 8,41 & 8,87 & 5,22 & 6,03 & 9,57 & 8,19 & 9,18 & 18,50 & 10,83 & 10,42 & 10,24 \\
\hline $\begin{array}{l}\text { 3- Radioimp-referencial- } \\
\text { escaner }\end{array}$ & 5,65 & 7,72 & 9,08 & 8,41 & 8,87 & 5,22 & 6,02 & 9,57 & 8,19 & 9,17 & 18,49 & 10,83 & 10,42 & 10,24 \\
\hline $\begin{array}{l}\text { 4- Radioimp-referencial- } \\
\text { câmera }\end{array}$ & 5,65 & 7,70 & 9,07 & 8,40 & 8,86 & 5,21 & 6,01 & 9,55 & 8,18 & 9,16 & 18,48 & 10,81 & 10,41 & 10,23 \\
\hline $\begin{array}{l}\text { 5- Planimp-resolução- } \\
\text { escaner }\end{array}$ & 5,66 & 7,71 & 9,09 & 8,42 & 8,88 & 5,22 & 6,03 & 9,56 & 8,18 & 9,17 & 18,49 & 10,82 & 10,43 & 10,25 \\
\hline $\begin{array}{l}\text { 6- Planimp-referencial- } \\
\text { escaner }\end{array}$ & 5,66 & 7,72 & 9,08 & 8,42 & 8,87 & 5,22 & 6,03 & 9,57 & 8,18 & 9,17 & 18,49 & 10,82 & 10,43 & 10,25 \\
\hline $\begin{array}{l}\text { 7- Planimp-referencial- } \\
\text { câmera }\end{array}$ & 5,65 & 7,71 & 9,07 & 8,40 & 8,86 & 5,21 & 6,01 & 9,56 & 8,17 & 9,16 & 18,47 & 10,81 & 10,41 & 10,23 \\
\hline
\end{tabular}


Anexo 29- Tabela com as medidas das 14 distâncias anatômicas obtidas pelos sete grupos experimentais para a radiografia 29

\begin{tabular}{|c|c|c|c|c|c|c|c|c|c|c|c|c|c|c|}
\hline \multirow{2}{*}{ RX 29} & \multicolumn{14}{|c|}{ Distâncias anatômicas } \\
\hline & $\begin{array}{c}\text { D1 } \\
\text { MSD }\end{array}$ & $\begin{array}{c}\text { D2 } \\
\text { PMSD }\end{array}$ & $\begin{array}{l}\text { D3 } \\
\text { CSD }\end{array}$ & $\begin{array}{l}\text { D4 } \\
\text { ICS }\end{array}$ & $\begin{array}{l}\text { D5 } \\
\text { CSE }\end{array}$ & $\begin{array}{c}\text { D6 } \\
\text { PMSE }\end{array}$ & $\begin{array}{c}\text { D7 } \\
\text { MSE }\end{array}$ & $\begin{array}{l}\text { D8 } \\
\text { MID }\end{array}$ & $\begin{array}{c}\text { D9 } \\
\text { PMID }\end{array}$ & $\begin{array}{l}\text { D10 } \\
\text { CID }\end{array}$ & $\begin{array}{l}\text { D11 } \\
\text { ICI }\end{array}$ & $\begin{array}{l}\text { D12 } \\
\text { CIE }\end{array}$ & $\begin{array}{l}\text { D13 } \\
\text { PMIE }\end{array}$ & $\begin{array}{l}\text { D14 } \\
\text { MIE }\end{array}$ \\
\hline 1- Paquímetro & 11,63 & 14,50 & 15,20 & 10,88 & 14,02 & 13,27 & 8,25 & 8,20 & 7,12 & 8,45 & 18,70 & 10,27 & 8,44 & 8,15 \\
\hline $\begin{array}{l}\text { 2- Radioimp-resolução- } \\
\text { escaner }\end{array}$ & 11,65 & 14,53 & 15,21 & 10,89 & 14,03 & 13,30 & 8,27 & 8,22 & 7,14 & 8,46 & 18,73 & 10,28 & 8,46 & 8,16 \\
\hline $\begin{array}{l}\text { 3- Radioimp-referencial- } \\
\text { escaner }\end{array}$ & 11,66 & 14,53 & 15,21 & 10,90 & 14,03 & 13,29 & 8,26 & 8,21 & 7,14 & 8,45 & 18,73 & 10,29 & 8,45 & 8,16 \\
\hline $\begin{array}{l}\text { 4- Radioimp-referencial- } \\
\text { câmera }\end{array}$ & 11,64 & 14,50 & 15,20 & 10,89 & 14,02 & 13,28 & 8,25 & 8,20 & 7,13 & 8,45 & 18,71 & 10,28 & 8,44 & 8,15 \\
\hline $\begin{array}{l}\text { 5- Planimp-resolução- } \\
\text { escaner }\end{array}$ & 11,65 & 14,52 & 15,23 & 10,90 & 14,04 & 13,29 & 8,26 & 8,23 & 7,15 & 8,46 & 18,74 & 10,28 & 8,46 & 8,17 \\
\hline $\begin{array}{l}\text { 6- Planimp-referencial- } \\
\text { escaner }\end{array}$ & 11,66 & 14,52 & 15,22 & 10,90 & 14,03 & 13,29 & 8,25 & 8,23 & 7,15 & 8,46 & 18,72 & 10,29 & 8,46 & 8,17 \\
\hline $\begin{array}{l}\text { 7- Planimp-referencial- } \\
\text { câmera }\end{array}$ & 11,64 & 14,51 & 15,21 & 10,89 & 14,02 & 13,28 & 8,25 & 8,20 & 7,13 & 8,45 & 18,71 & 10,28 & 8,44 & 8,15 \\
\hline
\end{tabular}

Anexo 30- Tabela com as medidas das 14 distâncias anatômicas obtidas pelos sete grupos experimentais para a radiografia 30

\begin{tabular}{|c|c|c|c|c|c|c|c|c|c|c|c|c|c|c|}
\hline \multirow{2}{*}{ RX 30} & \multicolumn{14}{|c|}{ Distâncias anatômicas } \\
\hline & $\begin{array}{l}\text { D1 } \\
\text { MSD }\end{array}$ & $\begin{array}{c}\text { D2 } \\
\text { PMSD } \\
\end{array}$ & $\begin{array}{c}\text { D3 } \\
\text { CSD }\end{array}$ & $\begin{array}{l}\text { D4 } \\
\text { ICS }\end{array}$ & $\begin{array}{c}\text { D5 } \\
\text { CSE }\end{array}$ & $\begin{array}{c}\text { D6 } \\
\text { PMSE }\end{array}$ & $\begin{array}{c}\text { D7 } \\
\text { MSE }\end{array}$ & $\begin{array}{l}\text { D8 } \\
\text { MID }\end{array}$ & $\begin{array}{c}\text { D9 } \\
\text { PMID }\end{array}$ & $\begin{array}{l}\text { D10 } \\
\text { CID }\end{array}$ & $\begin{array}{l}\text { D11 } \\
\text { ICI }\end{array}$ & $\begin{array}{l}\text { D12 } \\
\text { CIE }\end{array}$ & $\begin{array}{l}\text { D13 } \\
\text { PMIE }\end{array}$ & $\begin{array}{l}\text { D14 } \\
\text { MIE }\end{array}$ \\
\hline 1- Paquímetro & 4,31 & 8,57 & 13,21 & 12,49 & 13,16 & 10,81 & 4,70 & 8,14 & 8,58 & 9,18 & 16,51 & 10,19 & 10,14 & 8,66 \\
\hline $\begin{array}{l}\text { 2- Radioimp-resolução- } \\
\text { escaner }\end{array}$ & 4,32 & 8,60 & 13,22 & 12,52 & 13,18 & 10,83 & 4,70 & 8,16 & 8,59 & 9,19 & 16,53 & 10,22 & 10,15 & 8,67 \\
\hline $\begin{array}{l}\text { 3- Radioimp- } \\
\text { referencial-escaner }\end{array}$ & 4,31 & 8,59 & 13,21 & 12,50 & 13,17 & 10,83 & 4,70 & 8,15 & 8,60 & 9,18 & 16,52 & 10,20 & 10,15 & 8,66 \\
\hline $\begin{array}{l}\text { 4- Radioimp- } \\
\text { referencial-câmera }\end{array}$ & 4,30 & 8,58 & 13,20 & 12,49 & 13,17 & 10,81 & 4,70 & 8,14 & 8,59 & 9,18 & 16,50 & 10,19 & 10,14 & 8,66 \\
\hline $\begin{array}{l}\text { 5- Planimp-resolução- } \\
\text { escaner }\end{array}$ & 4,32 & 8,59 & 13,22 & 12,51 & 13,18 & 10,82 & 4,70 & 8,16 & 8,60 & 9,19 & 16,53 & 10,21 & 10,14 & 8,67 \\
\hline $\begin{array}{l}\text { 6- Planimp-referencial- } \\
\text { escaner }\end{array}$ & 4,32 & 8,59 & 13,22 & 12,51 & 13,18 & 10,82 & 4,70 & 8,16 & 8,60 & 9,19 & 16,53 & 10,21 & 10,14 & 8,66 \\
\hline $\begin{array}{l}\text { 7- Planimp-referencial- } \\
\text { câmera }\end{array}$ & 4,31 & 8,58 & 13,20 & 12,50 & 13,17 & 10,81 & 4,70 & 8,14 & 8,58 & 9,18 & 16,51 & 10,20 & 10,14 & 8,65 \\
\hline
\end{tabular}


Anexo 31- Tabela com as medidas das 14 distâncias anatômicas obtidas pelos sete grupos experimentais para a radiografia 31

\begin{tabular}{|c|c|c|c|c|c|c|c|c|c|c|c|c|c|c|}
\hline \multirow{2}{*}{$\mathrm{RX} 31$} & \multicolumn{14}{|c|}{ Distâncias anatômicas } \\
\hline & $\begin{array}{c}\text { D1 } \\
\text { MSD }\end{array}$ & $\begin{array}{c}\text { D2 } \\
\text { PMSD }\end{array}$ & $\begin{array}{c}\text { D3 } \\
\text { CSD }\end{array}$ & $\begin{array}{l}\text { D4 } \\
\text { ICS }\end{array}$ & $\begin{array}{c}\text { D5 } \\
\text { CSE }\end{array}$ & $\begin{array}{c}\text { D6 } \\
\text { PMSE }\end{array}$ & $\begin{array}{c}\text { D7 } \\
\text { MSE }\end{array}$ & $\begin{array}{c}\text { D8 } \\
\text { MID }\end{array}$ & $\begin{array}{c}\text { D9 } \\
\text { PMID }\end{array}$ & $\begin{array}{l}\text { D10 } \\
\text { CID }\end{array}$ & $\begin{array}{l}\text { D11 } \\
\text { ICI }\end{array}$ & $\begin{array}{l}\text { D12 } \\
\text { CIE }\end{array}$ & \begin{tabular}{|l|} 
D13 \\
PMIE
\end{tabular} & \begin{tabular}{|l|} 
D14 \\
MIE
\end{tabular} \\
\hline 1- Paquímetro & 5,25 & 11,69 & 10,38 & 11,79 & 10,56 & 9,32 & 6,01 & 3,50 & 3,85 & 6,34 & 11,52 & 4,66 & 3,12 & 2,95 \\
\hline $\begin{array}{l}\text { 2- Radioimp-resolução- } \\
\text { escaner }\end{array}$ & 5,25 & 11,71 & 10,39 & 11,82 & 10,58 & 9,33 & 6,03 & 3,51 & 3,85 & 6,36 & 11,54 & 4,66 & 3,12 & 2,95 \\
\hline $\begin{array}{l}\text { 3- Radioimp-referencial- } \\
\text { escaner }\end{array}$ & 5,25 & 11,70 & 10,39 & 11,82 & 10,57 & 9,33 & 6,02 & 3,51 & 3,85 & 6,35 & 11,53 & 4,66 & 3,12 & 2,95 \\
\hline $\begin{array}{l}\text { 4- Radioimp-referencial- } \\
\text { câmera }\end{array}$ & 5,24 & 11,69 & 10,38 & 11,80 & 10,56 & 9,32 & 6,01 & 3,50 & 3,85 & 6,34 & 11,53 & 4,66 & 3,12 & 2,94 \\
\hline $\begin{array}{l}\text { 5- Planimp-resolução- } \\
\text { escaner }\end{array}$ & 5,26 & 11,71 & 10,40 & 11,81 & 10,57 & 9,33 & 6,02 & 3,51 & 3,86 & 6,36 & 11,55 & 4,67 & 3,13 & 2,95 \\
\hline $\begin{array}{l}\text { 6- Planimp-referencial- } \\
\text { escaner }\end{array}$ & 5,26 & 11,71 & 10,40 & 11,81 & 10,56 & 9,33 & 6,02 & 3,50 & 3,86 & 6,36 & 11,55 & 4,67 & 3,12 & 2,95 \\
\hline $\begin{array}{l}\text { 7- Planimp-referencial- } \\
\text { câmera }\end{array}$ & 5,24 & 11,69 & 10,38 & 11,81 & 10,55 & 9,32 & 6,01 & 3,50 & 3,86 & 6,34 & 11,53 & 4,66 & 3,12 & 2,95 \\
\hline
\end{tabular}

Anexo 32- Tabela com as medidas das 14 distâncias anatômicas obtidas pelos sete grupos experimentais para a radiografia 32

\begin{tabular}{l|c|c|c|c|c|c|c|c|c|c|c|c|c|c}
\hline \multirow{2}{*}{ RX 32 } & \multicolumn{10}{|c}{ Distâncias anatômicas } \\
\cline { 2 - 14 } & $\begin{array}{c}\text { D1 } \\
\text { MSD }\end{array}$ & $\begin{array}{c}\text { DM2 } \\
\text { PMSD }\end{array}$ & $\begin{array}{c}\text { D3 } \\
\text { CSD }\end{array}$ & $\begin{array}{c}\text { D4 } \\
\text { ICS }\end{array}$ & $\begin{array}{c}\text { D5 } \\
\text { CSE }\end{array}$ & $\begin{array}{c}\text { D6 } \\
\text { PMSE }\end{array}$ & $\begin{array}{c}\text { D7 } \\
\text { MSE }\end{array}$ & $\begin{array}{c}\text { D8 } \\
\text { MID }\end{array}$ & $\begin{array}{c}\text { D9 } \\
\text { PMID }\end{array}$ & $\begin{array}{c}\text { D10 } \\
\text { CID }\end{array}$ & $\begin{array}{c}\text { D11 } \\
\text { ICI }\end{array}$ & $\begin{array}{c}\text { D12 } \\
\text { CIE }\end{array}$ & $\begin{array}{c}\text { D13 } \\
\text { PMIE }\end{array}$ & $\begin{array}{c}\text { D14 } \\
\text { MIE }\end{array}$ \\
\hline \hline 1- Paquímetro & 11,35 & 13,28 & 15,11 & 17,10 & 16,36 & 14,46 & 9,58 & 3,29 & 3,51 & 4,37 & 12,30 & 4,87 & 2,91 & 4,10 \\
\hline $\begin{array}{l}\text { 2- Radioimp-resolução- } \\
\text { escaner }\end{array}$ & 11,37 & 13,28 & 15,11 & 17,12 & 16,38 & 14,48 & 9,58 & 3,29 & 3,52 & 4,37 & 12,31 & 4,88 & 2,91 & 4,11 \\
\hline $\begin{array}{l}\text { 3- Radioimp-referencial- } \\
\text { escaner }\end{array}$ & 11,36 & 13,28 & 15,11 & 17,13 & 16,37 & 14,47 & 9,59 & 3,29 & 3,52 & 4,38 & 12,30 & 4,88 & 2,91 & 4,11 \\
\hline $\begin{array}{l}\text { 4- Radioimp-referencial- } \\
\text { câmera }\end{array}$ & 11,35 & 13,27 & 15,11 & 17,11 & 16,36 & 14,47 & 9,58 & 3,29 & 3,51 & 4,37 & 12,31 & 4,87 & 2,91 & 4,10 \\
\hline $\begin{array}{l}\text { 5- Planimp-resolução- } \\
\text { escaner }\end{array}$ & 11,37 & 13,29 & 15,12 & 17,12 & 16,37 & 14,49 & 9,59 & 3,29 & 3,52 & 4,38 & 12,32 & 4,88 & 2,91 & 4,11 \\
\hline $\begin{array}{l}\text { 6- Planimp-referencial- } \\
\text { escaner }\end{array}$ & 11,37 & 13,29 & 15,12 & 17,14 & 16,37 & 14,49 & 9,59 & 3,29 & 3,51 & 4,38 & 12,31 & 4,87 & 2,91 & 4,11 \\
\hline $\begin{array}{l}\text { 7- Planimp-referencial- } \\
\text { câmera }\end{array}$ & 11,35 & 13,28 & 15,10 & 17,11 & 16,36 & 14,47 & 9,58 & 3,29 & 3,51 & 4,37 & 12,30 & 4,87 & 2,91 & 4,10 \\
\hline
\end{tabular}


Anexo 33- Tabela com as medidas das 14 distâncias anatômicas obtidas pelos sete grupos experimentais para a radiografia 33

\begin{tabular}{|c|c|c|c|c|c|c|c|c|c|c|c|c|c|c|}
\hline \multirow[b]{2}{*}{ RX 33} & \multicolumn{14}{|c|}{ Distâncias anatômicas } \\
\hline & $\begin{array}{c}\text { D1 } \\
\text { MSD }\end{array}$ & \begin{tabular}{|c|} 
D2 \\
PMS \\
D \\
\end{tabular} & $\begin{array}{l}\text { D3 } \\
\text { CSD }\end{array}$ & $\begin{array}{l}\text { D4 } \\
\text { ICS }\end{array}$ & $\begin{array}{l}\text { D5 } \\
\text { CSE }\end{array}$ & \begin{tabular}{|c|} 
D6 \\
PMS \\
E \\
\end{tabular} & $\begin{array}{l}\text { D7 } \\
\text { MSE }\end{array}$ & $\begin{array}{l}\text { D8 } \\
\text { MID }\end{array}$ & $\begin{array}{l}\text { D9 } \\
\text { PMID }\end{array}$ & $\begin{array}{l}\text { D10 } \\
\text { CID }\end{array}$ & $\begin{array}{l}\text { D11 } \\
\text { ICI }\end{array}$ & $\begin{array}{l}\text { D12 } \\
\text { CIE }\end{array}$ & $\begin{array}{l}\text { D13 } \\
\text { PMIE }\end{array}$ & $\begin{array}{l}\text { D14 } \\
\text { MIE }\end{array}$ \\
\hline 1- Paquímetro & 9,08 & 10,85 & 14,60 & 14,68 & 13,04 & 11,85 & 10,63 & 11,63 & 13,43 & 14,22 & 22,58 & 11,76 & 10,54 & 10,05 \\
\hline $\begin{array}{l}\text { 2- Radioimp-resolução- } \\
\text { escaner }\end{array}$ & 9,10 & 10,87 & 14,61 & 14,69 & 13,06 & 11,87 & 10,65 & 11,64 & 13,45 & 14,24 & 22,59 & 11,77 & 10,55 & 10,06 \\
\hline $\begin{array}{l}\text { 3- Radioimp-referencial- } \\
\text { escaner }\end{array}$ & 9,09 & 10,87 & 14,61 & 14,70 & 13,05 & 11,86 & 10,64 & 11,64 & 13,45 & 14,23 & 22,58 & 11,76 & 10,55 & 10,05 \\
\hline $\begin{array}{l}\text { 4- Radioimp-referencial- } \\
\text { câmera }\end{array}$ & 9,08 & 10,86 & 14,60 & 14,69 & 13,04 & 11,86 & 10,63 & 11,63 & 13,44 & 14,22 & 22,58 & 11,75 & 10,54 & 10,04 \\
\hline $\begin{array}{l}\text { 5- Planimp-resolução- } \\
\text { escaner }\end{array}$ & 9,10 & 10,88 & 14,62 & 14,72 & 13,05 & 11,87 & 10,64 & 11,64 & 13,44 & 14,24 & 22,59 & 11,77 & 10,55 & 10,06 \\
\hline $\begin{array}{l}\text { 6- Planimp-referencial- } \\
\text { escaner }\end{array}$ & 9,10 & 10,88 & 14,62 & 14,71 & 13,06 & 11,86 & 10,63 & 11,64 & 13,45 & 14,23 & 22,58 & 11,77 & 10,55 & 10,05 \\
\hline $\begin{array}{l}\text { 7- Planimp-referencial- } \\
\text { câmera }\end{array}$ & 9,08 & 10,86 & 14,60 & 14,69 & 13,04 & 11,86 & 10,63 & 11,63 & 13,44 & 14,22 & 22,58 & 11,76 & 10,54 & 10,04 \\
\hline
\end{tabular}

Anexo 34- Tabela com as medidas das 14 distâncias anatômicas obtidas pelos sete grupos experimentais para a radiografia 34

\begin{tabular}{l|l|l|l|l|l|l|l|l|l|l|l|l|l|l}
\hline \multirow{2}{*}{ RX 34 } & \multicolumn{10}{c}{ Distâncias anatômicas } \\
\cline { 2 - 14 } & $\begin{array}{l}\text { D1 } \\
\text { MSD }\end{array}$ & $\begin{array}{l}\text { D2 } \\
\text { PMSD }\end{array}$ & $\begin{array}{l}\text { D3 } \\
\text { CSD }\end{array}$ & $\begin{array}{l}\text { D4 } \\
\text { ICS }\end{array}$ & $\begin{array}{l}\text { D5 } \\
\text { CSE }\end{array}$ & $\begin{array}{l}\text { D6 } \\
\text { PMSE }\end{array}$ & $\begin{array}{l}\text { D7 } \\
\text { MSE }\end{array}$ & $\begin{array}{l}\text { D8 } \\
\text { MID }\end{array}$ & $\begin{array}{l}\text { D9 } \\
\text { PMID }\end{array}$ & $\begin{array}{l}\text { D10 } \\
\text { CID }\end{array}$ & $\begin{array}{l}\text { D11 } \\
\text { ICI }\end{array}$ & $\begin{array}{l}\text { D12 } \\
\text { CIE }\end{array}$ & $\begin{array}{l}\text { D13 } \\
\text { PMIE }\end{array}$ & $\begin{array}{l}\text { D14 } \\
\text { MIE }\end{array}$ \\
\hline \hline $\begin{array}{l}\text { 1- Paquímetro } \\
\text { 2- Radioimp-resolução- } \\
\text { escaner }\end{array}$ & 6,15 & 15,40 & 17,37 & 14,37 & 14,93 & 11,93 & 8,28 & 3,91 & 3,43 & 5,23 & 16,00 & 5,00 & 3,49 & 4,47 \\
\hline $\begin{array}{l}\text { 3- Radioimp-referencial- } \\
\text { escaner }\end{array}$ & 6,15 & 15,43 & 17,39 & 14,38 & 14,95 & 11,94 & 8,29 & 3,92 & 3,43 & 5,24 & 16,03 & 5,00 & 3,50 & 4,47 \\
\hline $\begin{array}{l}\text { 4- Radioimp-referencial- } \\
\text { câmera }\end{array}$ & 6,15 & 15,41 & 17,37 & 14,37 & 14,95 & 11,94 & 8,29 & 3,91 & 3,43 & 5,24 & 16,03 & 5,00 & 3,50 & 4,47 \\
\hline $\begin{array}{l}\text { 5- Planimp-resolução- } \\
\text { escaner }\end{array}$ & 6,17 & 15,42 & 17,39 & 14,38 & 14,94 & 11,95 & 8,30 & 3,92 & 3,43 & 5,24 & 16,03 & 5,01 & 3,50 & 4,48 \\
\hline $\begin{array}{l}\text { 6- Planimp-referencial- } \\
\text { escaner }\end{array}$ & 6,16 & 15,42 & 17,39 & 14,38 & 14,94 & 11,95 & 8,23 & 3,92 & 3,43 & 5,23 & 16,03 & 5,01 & 3,49 & 4,47 \\
\hline $\begin{array}{l}\text { 7- Planimp-referencial- } \\
\text { câmera }\end{array}$ & 6,15 & 15,41 & 17,37 & 14,38 & 14,93 & 11,93 & 8,28 & 3,91 & 3,42 & 5,23 & 16,02 & 5,00 & 3,49 & 4,47 \\
\hline
\end{tabular}


Anexo 35- Tabela com as medidas das 14 distâncias anatômicas obtidas pelos sete grupos experimentais para a radiografia 35

\begin{tabular}{|c|c|c|c|c|c|c|c|c|c|c|c|c|c|c|}
\hline \multirow{2}{*}{$\mathrm{RX} 35$} & \multicolumn{14}{|c|}{ Distâncias anatômicas } \\
\hline & $\begin{array}{c}\text { D1 } \\
\text { MSD }\end{array}$ & $\begin{array}{c}\text { D2 } \\
\text { PMSD }\end{array}$ & $\begin{array}{c}\text { D3 } \\
\text { CSD }\end{array}$ & $\begin{array}{r}\text { D4 } \\
\text { ICS }\end{array}$ & $\begin{array}{l}\text { D5 } \\
\text { CSE }\end{array}$ & $\begin{array}{c}\text { D6 } \\
\text { PMSE }\end{array}$ & $\begin{array}{c}\text { D7 } \\
\text { MSE }\end{array}$ & $\begin{array}{l}\text { D8 } \\
\text { MID }\end{array}$ & $\begin{array}{c}\text { D9 } \\
\text { PMID }\end{array}$ & $\begin{array}{l}\text { D10 } \\
\text { CID }\end{array}$ & $\begin{array}{l}\text { D11 } \\
\text { ICI }\end{array}$ & $\begin{array}{l}\text { D12 } \\
\text { CIE }\end{array}$ & $\begin{array}{l}\text { D13 } \\
\text { PMIE }\end{array}$ & $\begin{array}{l}\text { D14 } \\
\text { MIE }\end{array}$ \\
\hline 1- Paquímetro & 4,65 & 10,49 & 14,47 & 14,78 & 11,25 & 7,83 & 4,00 & 9,45 & 5,85 & 8,85 & 21,75 & 8,87 & 5,31 & 8,22 \\
\hline $\begin{array}{l}\text { 2- Radioimp-resolução- } \\
\text { escaner }\end{array}$ & 4,66 & 10,50 & 14,50 & 14,79 & 11,86 & 7,84 & 4,00 & 9,47 & 5,86 & 8,86 & 21,78 & 8,88 & 5,32 & 8,23 \\
\hline $\begin{array}{l}\text { 3- Radioimp-referencial- } \\
\text { escaner }\end{array}$ & 4,66 & 10,50 & 14,49 & 14,80 & 11,86 & 7,85 & 4,00 & 9,46 & 5,85 & 8,86 & 21,78 & 8,88 & 5,32 & 8,22 \\
\hline $\begin{array}{l}\text { 4- Radioimp-referencial- } \\
\text { câmera }\end{array}$ & 4,65 & 10,49 & 14,48 & 14,79 & 11,85 & 7,83 & 4,00 & 9,45 & 5,85 & 8,85 & 21,77 & 8,87 & 5,31 & 8,21 \\
\hline $\begin{array}{l}\text { 5- Planimp-resolução- } \\
\text { escaner }\end{array}$ & 4,66 & 10,51 & 14,49 & 14,79 & 11,86 & 7,85 & 4,00 & 9,47 & 5,86 & 8,86 & 21,76 & 8,89 & 5,31 & 8,22 \\
\hline $\begin{array}{l}\text { 6- Planimp-referencial- } \\
\text { escaner }\end{array}$ & 4,66 & 10,51 & 14,50 & 14,79 & 11,86 & 7,84 & 4,10 & 9,46 & 5,85 & 8,86 & 21,78 & 8,88 & 5,31 & 8,23 \\
\hline $\begin{array}{l}\text { 7- Planimp-referencial- } \\
\text { câmera }\end{array}$ & 4,65 & 10,49 & 14,48 & 14,79 & 11,85 & 7,83 & 4,00 & 9,45 & 5,85 & 8,85 & 21,77 & 8,87 & 5,31 & 8,21 \\
\hline
\end{tabular}

Anexo 36- Tabela com as medidas das 14 distâncias anatômicas obtidas pelos sete grupos experimentais para a radiografia 36

\begin{tabular}{|c|c|c|c|c|c|c|c|c|c|c|c|c|c|c|}
\hline \multirow{2}{*}{ RX 36} & \multicolumn{14}{|c|}{ Distâncias anatômicas } \\
\hline & $\begin{array}{c}\text { D1 } \\
\text { MSD }\end{array}$ & $\begin{array}{c}\text { D2 } \\
\text { PMSD }\end{array}$ & $\begin{array}{l}\text { D3 } \\
\text { CSD }\end{array}$ & $\begin{array}{l}\text { D4 } \\
\text { IS }\end{array}$ & $\begin{array}{l}\text { D5 } \\
\text { CSE }\end{array}$ & $\begin{array}{c}\text { D6 } \\
\text { PMSE }\end{array}$ & $\begin{array}{c}\text { D7 } \\
\text { MSE }\end{array}$ & $\begin{array}{l}\text { D8 } \\
\text { MID }\end{array}$ & $\begin{array}{c}\text { D9 } \\
\text { PMID }\end{array}$ & $\begin{array}{l}\text { D10 } \\
\text { CID }\end{array}$ & $\begin{array}{c}\text { D11 } \\
\text { II }\end{array}$ & $\begin{array}{l}\text { D12 } \\
\text { CIE }\end{array}$ & $\begin{array}{c}\text { D13 } \\
\text { PMIE }\end{array}$ & $\begin{array}{l}\text { D14 } \\
\text { MIE }\end{array}$ \\
\hline 1- Paquímetro & 12,62 & 14,90 & 14,10 & 11,34 & 12,35 & 12,45 & 9,10 & 8,14 & 6,59 & 9,09 & 19,65 & 10,58 & 8,35 & 9,04 \\
\hline $\begin{array}{l}\text { 2- Radioimp-resolução- } \\
\text { escaner }\end{array}$ & 12,64 & 14,92 & 14,12 & 11,34 & 12,36 & 12,45 & 9,11 & 8,14 & 6,59 & 9,10 & 19,66 & 10,59 & 8,37 & 9,04 \\
\hline $\begin{array}{l}\text { 3- Radioimp-referencial- } \\
\text { escaner }\end{array}$ & 12,63 & 14,92 & 14,11 & 11,34 & 12,36 & 12,46 & 9,11 & 8,15 & 6,59 & 9,10 & 19,65 & 10,59 & 8,36 & 9,04 \\
\hline $\begin{array}{l}\text { 4- Radioimp-referencial- } \\
\text { câmera }\end{array}$ & 12,61 & 14,91 & 14,10 & 11,34 & 12,35 & 12,45 & 9,10 & 8,15 & 6,58 & 9,09 & 19,65 & 10,58 & 8,36 & 9,04 \\
\hline $\begin{array}{l}\text { 5- Planimp-resolução- } \\
\text { escaner }\end{array}$ & 12,63 & 14,91 & 14,12 & 11,35 & 12,36 & 12,46 & 9,12 & 8,15 & 6,59 & 9,10 & 19,65 & 10,59 & 8,32 & 9,05 \\
\hline $\begin{array}{l}\text { 6- Planimp-referencial- } \\
\text { escaner }\end{array}$ & 12,63 & 14,92 & 14,12 & 11,35 & 12,36 & 12,46 & 9,12 & 8,15 & 6,58 & 9,11 & 19,66 & 10,59 & 8,37 & 9,05 \\
\hline $\begin{array}{l}\text { 7- Planimp-referencial- } \\
\text { câmera }\end{array}$ & 12,62 & 14,91 & 14,10 & 11,34 & 12,35 & 12,45 & 9,10 & 8,14 & 6,58 & 9,09 & 19,65 & 10,58 & 8,35 & 9,04 \\
\hline
\end{tabular}


Anexo 37- Tabela com as medidas das 14 distâncias anatômicas obtidas pelos sete grupos experimentais para a radiografia 37

\begin{tabular}{|c|c|c|c|c|c|c|c|c|c|c|c|c|c|c|}
\hline \multirow{2}{*}{$\mathrm{RX} 37$} & \multicolumn{14}{|c|}{ Distâncias anatômicas } \\
\hline & $\begin{array}{c}\text { D1 } \\
\text { MSD }\end{array}$ & \begin{tabular}{|c|} 
D2 \\
PMSD
\end{tabular} & $\begin{array}{c}\text { D3 } \\
\text { CSD }\end{array}$ & $\begin{array}{l}\text { D4 } \\
\text { ICS }\end{array}$ & $\begin{array}{c}\text { D5 } \\
\text { CSE }\end{array}$ & \begin{tabular}{|c|} 
D6 \\
PMSE
\end{tabular} & \begin{tabular}{|c|} 
D7 \\
MSE \\
\end{tabular} & $\begin{array}{c}\text { D8 } \\
\text { MID }\end{array}$ & \begin{tabular}{|c|} 
D9 \\
PMID
\end{tabular} & $\begin{array}{l}\text { D10 } \\
\text { CID }\end{array}$ & $\begin{array}{l}\text { D11 } \\
\text { ICI }\end{array}$ & $\begin{array}{l}\text { D12 } \\
\text { CIE }\end{array}$ & $\begin{array}{l}\text { D13 } \\
\text { PMIE }\end{array}$ & $\begin{array}{l}\text { D14 } \\
\text { MIE }\end{array}$ \\
\hline 1- Paquímetro & 6,85 & 7,66 & 12,12 & 13,55 & 14,86 & 10,54 & 4,31 & 4,74 & 3,80 & 6,21 & 15,40 & 6,16 & 3,94 & 3,46 \\
\hline $\begin{array}{l}\text { 2- Radioimp-resolução- } \\
\text { escaner }\end{array}$ & 6,86 & 7,67 & 12,14 & 13,56 & 14,86 & 10,55 & 4,32 & 4,74 & 3,80 & 6,23 & 15,42 & 6,17 & 3,94 & 3,47 \\
\hline $\begin{array}{l}\text { 3- Radioimp-referencial- } \\
\text { escaner }\end{array}$ & 6,86 & 7,67 & 12,13 & 13,56 & 14,86 & 10,55 & 4,31 & 4,74 & 3,80 & 6,22 & 15,42 & 6,16 & 3,94 & 3,46 \\
\hline $\begin{array}{l}\text { 4- Radioimp-referencial- } \\
\text { câmera }\end{array}$ & 6,85 & 7,66 & 12,13 & 13,55 & 14,87 & 10,54 & 4,31 & 4,73 & 3,80 & 6,21 & 15,41 & 6,16 & 3,94 & 3,46 \\
\hline $\begin{array}{l}\text { 5- Planimp-resolução- } \\
\text { escaner }\end{array}$ & 6,87 & 7,67 & 12,14 & 13,56 & 14,88 & \begin{tabular}{l|l}
10,55 \\
\end{tabular} & 4,31 & 4,73 & 3,81 & 6,22 & 15,43 & 6,17 & 3,95 & 3,47 \\
\hline $\begin{array}{l}\text { 6- Planimp-referencial- } \\
\text { escaner }\end{array}$ & 6,87 & 7,67 & 12,13 & 13,56 & 14,88 & 10,55 & 4,31 & 4,74 & 3,80 & 6,23 & 15,42 & 6,17 & 3,94 & 3,46 \\
\hline $\begin{array}{l}\text { 7- Planimp-referencial- } \\
\text { câmera }\end{array}$ & 6,85 & 7,66 & 12,13 & 13,55 & 14,87 & 10,54 & 4,31 & 4,73 & 3,80 & 6,21 & 15,41 & 6,16 & 3,94 & 3,46 \\
\hline
\end{tabular}

Anexo 38- Tabela com as medidas das 14 distâncias anatômicas obtidas pelos sete grupos experimentais para a radiografia 38

\begin{tabular}{l|c|c|c|c|c|c|c|c|c|c|c|c|c|c}
\hline \multirow{2}{*}{ RX 38 } & \multicolumn{10}{|c}{ Distâncias anatômicas } \\
\cline { 2 - 13 } & $\begin{array}{c}\text { D1 } \\
\text { MSD }\end{array}$ & $\begin{array}{c}\text { D2 } \\
\text { PMSD }\end{array}$ & $\begin{array}{c}\text { D3 } \\
\text { CSD }\end{array}$ & $\begin{array}{c}\text { D4 } \\
\text { ICS }\end{array}$ & $\begin{array}{c}\text { D5 } \\
\text { CSE }\end{array}$ & $\begin{array}{c}\text { D6 } \\
\text { PMSE }\end{array}$ & $\begin{array}{c}\text { D7 } \\
\text { MSE }\end{array}$ & $\begin{array}{c}\text { D8 } \\
\text { MID }\end{array}$ & $\begin{array}{c}\text { D9 } \\
\text { PMID }\end{array}$ & $\begin{array}{c}\text { D10 } \\
\text { CID }\end{array}$ & $\begin{array}{c}\text { D11 } \\
\text { ICI }\end{array}$ & $\begin{array}{c}\text { D12 } \\
\text { CIE }\end{array}$ & $\begin{array}{c}\text { D13 } \\
\text { PMIE }\end{array}$ & $\begin{array}{c}\text { D14 } \\
\text { MIE }\end{array}$ \\
\hline \hline \begin{tabular}{l} 
1- Paquímetro \\
\hline $\begin{array}{l}\text { 2- Radioimp-resolução- } \\
\text { escaner }\end{array}$
\end{tabular} & 5,83 & 8,95 & 16,65 & 16,95 & 14,53 & 8,54 & 5,72 & 10,28 & 8,80 & 9,54 & 20,20 & 10,89 & 11,60 & 9,36 \\
\hline $\begin{array}{l}\text { 3- Radioimp-referencial- } \\
\text { escaner }\end{array}$ & 5,84 & 8,96 & 16,65 & 16,98 & 14,53 & 8,55 & 5,73 & 10,30 & 8,80 & 9,55 & 20,21 & 10,91 & 11,61 & 9,38 \\
\hline $\begin{array}{l}\text { 4- Radioimp-referencial- } \\
\text { câmera }\end{array}$ & 5,83 & 8,95 & 16,66 & 16,96 & 14,52 & 8,54 & 5,72 & 10,29 & 8,80 & 9,54 & 20,20 & 10,89 & 11,60 & 9,37 \\
\hline $\begin{array}{l}\text { 5- Planimp-resolução- } \\
\text { escaner }\end{array}$ & 5,84 & 8,97 & 16,66 & 16,97 & 14,53 & 8,56 & 7,73 & 10,29 & 8,82 & 9,56 & 20,21 & 10,91 & 11,62 & 9,38 \\
\hline $\begin{array}{l}\text { 6- Planimp-referencial- } \\
\text { escaner }\end{array}$ & 5,84 & 8,97 & 16,66 & 16,97 & 14,54 & 8,56 & 7,73 & 10,29 & 8,82 & 9,56 & 20,21 & 10,90 & 11,62 & 9,38 \\
\hline $\begin{array}{l}\text { 7- Planimp-referencial- } \\
\text { câmera }\end{array}$ & 5,84 & 8,96 & 16,66 & 16,96 & 14,53 & 8,54 & 7,72 & 10,29 & 8,81 & 9,54 & 20,20 & 10,89 & 11,60 & 9,37 \\
\hline
\end{tabular}


Anexo 39- Tabela com as medidas das 14 distâncias anatômicas obtidas pelos sete grupos experimentais para a radiografia 39

\begin{tabular}{|c|c|c|c|c|c|c|c|c|c|c|c|c|c|c|}
\hline \multirow{2}{*}{ RX 39} & \multicolumn{14}{|c|}{ Distâncias anatômicas } \\
\hline & $\begin{array}{c}\text { D1 } \\
\text { MSD }\end{array}$ & $\begin{array}{c}\text { D2 } \\
\text { PMSD }\end{array}$ & $\begin{array}{l}\text { D3 } \\
\text { CSD }\end{array}$ & $\begin{array}{l}\text { D4 } \\
\text { ICS }\end{array}$ & $\begin{array}{l}\text { D5 } \\
\text { CSE }\end{array}$ & $\begin{array}{c}\text { D6 } \\
\text { PMSE }\end{array}$ & $\begin{array}{l}\text { D7 } \\
\text { MSE }\end{array}$ & $\begin{array}{l}\text { D8 } \\
\text { MID }\end{array}$ & $\begin{array}{c}\text { D9 } \\
\text { PMID }\end{array}$ & $\begin{array}{l}\text { D10 } \\
\text { CID }\end{array}$ & $\begin{array}{l}\text { D11 } \\
\text { ICI }\end{array}$ & $\begin{array}{l}\text { D12 } \\
\text { CIE }\end{array}$ & $\begin{array}{l}\text { D13 } \\
\text { PMIE }\end{array}$ & $\begin{array}{l}\text { D14 } \\
\text { MIE }\end{array}$ \\
\hline 1- Paquímetro & 9,50 & 9,97 & 11,65 & 9,62 & 10,80 & 10,96 & 7,00 & 10,16 & 13,57 & 14,40 & 21,34 & 14,61 & 12,37 & 11,48 \\
\hline $\begin{array}{l}\text { 2- Radioimp-resolução- } \\
\text { escaner }\end{array}$ & 9,52 & 9,98 & 11,66 & 9,62 & 10,81 & 10,99 & 7,00 & 10,30 & 13,58 & 14,42 & 21,35 & 14,63 & 12,37 & 11,48 \\
\hline $\begin{array}{l}\text { 3- Radioimp-referencial- } \\
\text { escaner }\end{array}$ & 9,51 & 9,98 & 11,66 & 9,62 & 10,81 & 10,98 & 7,00 & 10,29 & 13,58 & 14,41 & 21,34 & 14,63 & 12,38 & 11,49 \\
\hline $\begin{array}{l}\text { 4- Radioimp-referencial- } \\
\text { câmera }\end{array}$ & 9,50 & 9,97 & 11,65 & 9,62 & 10,80 & 10,97 & 7,00 & 10,29 & 13,57 & 14,40 & 21,34 & 14,62 & 12,37 & 11,48 \\
\hline $\begin{array}{l}\text { 5- Planimp-resolução- } \\
\text { escaner }\end{array}$ & 9,51 & 9,97 & 11,67 & 9,63 & 10,82 & 10,98 & 7,20 & 10,29 & 13,58 & 14,42 & 21,35 & 14,62 & 12,37 & 11,48 \\
\hline $\begin{array}{l}\text { 6- Planimp-referencial- } \\
\text { escaner }\end{array}$ & 9,51 & 9,98 & 11,66 & 9,63 & 10,81 & 10,98 & 7,10 & 10,30 & 13,58 & 14,42 & 21,35 & 14,67 & 12,38 & 11,49 \\
\hline $\begin{array}{l}\text { 7- Planimp-referencial- } \\
\text { câmera }\end{array}$ & 9,50 & 9,97 & 11,65 & 9,62 & 10,80 & 10,96 & 7,00 & 10,29 & 13,57 & 14,41 & 21,34 & 14,61 & 12,37 & 11,48 \\
\hline
\end{tabular}

Anexo 40- Tabela com as medidas das 14 distâncias anatômicas obtidas pelos sete grupos experimentais para a radiografia 40

\begin{tabular}{|c|c|c|c|c|c|c|c|c|c|c|c|c|c|c|}
\hline \multirow{2}{*}{$\mathrm{RX} 40$} & \multicolumn{14}{|c|}{ Distâncias anatômicas } \\
\hline & $\begin{array}{l}\text { D1 } \\
\text { MSD }\end{array}$ & $\begin{array}{c}\text { D2 } \\
\text { PMSD }\end{array}$ & $\begin{array}{l}\text { D3 } \\
\text { CSD }\end{array}$ & $\begin{array}{l}\text { D4 } \\
\text { ICS }\end{array}$ & $\begin{array}{l}\text { D5 } \\
\text { CSE }\end{array}$ & $\begin{array}{c}\text { D6 } \\
\text { PMSE }\end{array}$ & $\begin{array}{l}\text { D7 } \\
\text { MSE }\end{array}$ & $\begin{array}{l}\text { D8 } \\
\text { MID }\end{array}$ & $\begin{array}{c}\text { D9 } \\
\text { PMID }\end{array}$ & $\begin{array}{l}\text { D10 } \\
\text { CID }\end{array}$ & $\begin{array}{l}\text { D11 } \\
\text { ICI }\end{array}$ & $\begin{array}{l}\text { D12 } \\
\text { CIE }\end{array}$ & $\begin{array}{c}\text { D13 } \\
\text { PMIE }\end{array}$ & $\begin{array}{l}\text { D14 } \\
\text { MIE }\end{array}$ \\
\hline 1- Paquímetro & 8,35 & 12,35 & 13,79 & 9,60 & 11,86 & 11,10 & 8,37 & 3,91 & 3,32 & 5,70 & 17,95 & 7,03 & 4,61 & 4,39 \\
\hline $\begin{array}{l}\text { 2- Radioimp-resolução- } \\
\text { escaner }\end{array}$ & 8,35 & 12,37 & 13,80 & 9,61 & 11,87 & 11,12 & 8,39 & 3,91 & 3,32 & 5,71 & 17,95 & 7,05 & 4,62 & 4,40 \\
\hline $\begin{array}{l}\text { 3- Radioimp-referencial- } \\
\text { escaner }\end{array}$ & 8,36 & 12,37 & 13,80 & 9,62 & 11,87 & 11,11 & 8,39 & 3,91 & 3,32 & 5,71 & 17,95 & 7,05 & 4,62 & 4,39 \\
\hline $\begin{array}{l}\text { 4- Radioimp-referencial- } \\
\text { câmera }\end{array}$ & 8,35 & 12,36 & 13,79 & 9,61 & 11,87 & 11,10 & 8,38 & 3,91 & 3,32 & 5,70 & 17,95 & 7,04 & 4,61 & 4,39 \\
\hline $\begin{array}{l}\text { 5- Planimp-resolução- } \\
\text { escaner }\end{array}$ & 8,36 & 12,36 & 13,80 & 9,63 & 11,88 & 11,11 & 8,38 & 3,91 & 3,32 & 5,70 & 17,96 & 7,06 & 4,63 & 4,39 \\
\hline $\begin{array}{l}\text { 6- Planimp-referencial- } \\
\text { escaner }\end{array}$ & 8,36 & 12,35 & 13,80 & 9,62 & 11,88 & 11,12 & 8,39 & 3,92 & 3,32 & 5,71 & 17,96 & 7,06 & 4,62 & 4,39 \\
\hline $\begin{array}{l}\text { 7- Planimp-referencial- } \\
\text { câmera }\end{array}$ & 8,35 & 12,36 & 13,79 & 9,61 & 11,87 & 11,10 & 8,38 & 3,91 & 3,32 & 5,70 & 17,95 & 7,04 & 4,61 & 4,39 \\
\hline
\end{tabular}


Anexo 41- Tabela com as medidas das 14 distâncias anatômicas obtidas pelos sete grupos experimentais para a radiografia 41

\begin{tabular}{|c|c|c|c|c|c|c|c|c|c|c|c|c|c|c|}
\hline \multirow[b]{2}{*}{ RX 41} & \multicolumn{14}{|c|}{ Distâncias anatômicas } \\
\hline & \begin{tabular}{|l} 
D1 \\
MSD
\end{tabular} & \begin{tabular}{|l} 
D2 \\
PMSD
\end{tabular} & \begin{tabular}{|l|} 
D3 \\
CSD
\end{tabular} & \begin{tabular}{|l} 
D4 \\
ICS
\end{tabular} & \begin{tabular}{|l} 
D5 \\
CSE
\end{tabular} & \begin{tabular}{|l} 
D6 \\
PMSE
\end{tabular} & \begin{tabular}{|l} 
D7 \\
MSE
\end{tabular} & \begin{tabular}{|l} 
D8 \\
MID
\end{tabular} & \begin{tabular}{|l} 
D9 \\
PMID
\end{tabular} & $\begin{array}{l}\text { D10 } \\
\text { CID }\end{array}$ & \begin{tabular}{|l} 
D11 \\
ICI
\end{tabular} & $\begin{array}{l}\text { D12 } \\
\text { CIE }\end{array}$ & \begin{tabular}{|l} 
D13 \\
PMI \\
E \\
\end{tabular} & \begin{tabular}{|l} 
D14 \\
MIE
\end{tabular} \\
\hline 1- Paquímetro & 7,30 & 8,21 & 8,31 & 6,40 & 7,94 & 7,12 & 5,58 & 3,11 & 3,08 & 5,40 & 14,37 & 6,95 & 5,32 & 5,55 \\
\hline $\begin{array}{l}\text { 2- Radioimp-resolução- } \\
\text { escaner }\end{array}$ & 7,31 & 8,22 & 8,32 & 6,42 & 7,95 & 7,13 & 5,59 & 3,12 & 3,08 & 5,40 & 14,39 & 9,96 & 5,33 & 5,55 \\
\hline $\begin{array}{l}\text { 3- Radioimp-referencial- } \\
\text { escaner }\end{array}$ & 7,31 & 8,21 & 8,32 & 6,41 & 7,95 & 7,13 & 5,59 & 3,12 & 3,08 & 5,41 & 14,38 & 9,96 & 5,33 & 5,55 \\
\hline $\begin{array}{l}\text { 4- Radioimp-referencial- } \\
\text { câmera }\end{array}$ & 7,30 & 8,21 & 8,30 & 6,41 & 7,94 & 7,12 & 5,58 & 3,11 & 3,07 & 5,40 & 14,37 & 6,96 & 5,32 & 5,54 \\
\hline $\begin{array}{l}\text { 5- Planimp-resolução- } \\
\text { escaner }\end{array}$ & 7,32 & 8,23 & 8,31 & 6,41 & 7,95 & 7,14 & 5,59 & 3,11 & 3,08 & 5,41 & 14,39 & 9,97 & 5,33 & 5,55 \\
\hline $\begin{array}{l}\text { 6- Planimp-referencial- } \\
\text { escaner }\end{array}$ & 7,32 & 8,22 & 8,31 & 6,41 & 7,94 & 7,14 & 5,59 & 3,11 & 3,08 & 5,41 & 14,38 & 9,97 & 5,33 & 5,55 \\
\hline $\begin{array}{l}\text { 7- Planimp-referencial- } \\
\text { câmera }\end{array}$ & 7,31 & 8,21 & 8,30 & 6,40 & 7,94 & 7,12 & 5,58 & 3,11 & 3,07 & 5,40 & 14,37 & 9,97 & 5,32 & 5,55 \\
\hline
\end{tabular}

Anexo 42- Tabela com as medidas das 14 distâncias anatômicas obtidas pelos sete grupos experimentais para a radiografia 42

\begin{tabular}{|c|c|c|c|c|c|c|c|c|c|c|c|c|c|c|}
\hline \multirow{2}{*}{ RX 42} & \multicolumn{14}{|c|}{ Distâncias anatômicas } \\
\hline & $\begin{array}{c}\text { D1 } \\
\text { MSD }\end{array}$ & $\begin{array}{c}\text { D2 } \\
\text { PMSD }\end{array}$ & $\begin{array}{l}\text { D3 } \\
\text { CSD }\end{array}$ & $\begin{array}{l}\text { D4 } \\
\text { ICS }\end{array}$ & $\begin{array}{l}\text { D5 } \\
\text { CSE }\end{array}$ & $\begin{array}{c}\text { D6 } \\
\text { PMSE }\end{array}$ & $\begin{array}{l}\text { D7 } \\
\text { MSE }\end{array}$ & $\begin{array}{l}\text { D8 } \\
\text { MID }\end{array}$ & $\begin{array}{c}\text { D9 } \\
\text { PMID }\end{array}$ & $\begin{array}{l}\text { D10 } \\
\text { CID }\end{array}$ & $\begin{array}{l}\text { D11 } \\
\text { ICI }\end{array}$ & $\begin{array}{l}\text { D12 } \\
\text { CIE }\end{array}$ & $\begin{array}{l}\text { D13 } \\
\text { PMIE }\end{array}$ & $\begin{array}{l}\text { D14 } \\
\text { MIE }\end{array}$ \\
\hline 1- Paquímetro & 5,68 & 9,05 & 17,55 & 14,27 & 12,92 & 11,58 & 4,95 & 14,82 & 14,05 & 15,21 & 28,18 & 14,16 & 12,17 & 13,68 \\
\hline $\begin{array}{l}\text { 2- Radioimp-resolução- } \\
\text { escaner }\end{array}$ & 5,69 & 9,07 & 17,56 & 14,29 & 12,94 & 11,59 & 4,96 & 14,84 & 14,06 & 15,23 & 28,19 & 14,17 & 12,19 & 13,69 \\
\hline $\begin{array}{l}\text { 3- Radioimp-referencial- } \\
\text { escaner }\end{array}$ & 5,69 & 9,06 & 17,55 & 14,28 & 12,93 & 11,59 & 4,96 & 14,84 & 14,06 & 15,23 & 28,18 & 14,17 & 12,18 & 13,69 \\
\hline $\begin{array}{l}\text { 4- Radioimp-referencial- } \\
\text { câmera }\end{array}$ & 5,68 & 9,06 & 17,55 & 14,27 & 12,92 & 11,59 & 4,95 & 14,83 & 14,05 & 15,22 & 28,17 & 14,16 & 12,17 & 13,69 \\
\hline $\begin{array}{l}\text { 5- Planimp-resolução- } \\
\text { escaner }\end{array}$ & 5,69 & 9,06 & 17,55 & 14,29 & 12,94 & 11,60 & 4,95 & 14,85 & 14,07 & 15,22 & 28,18 & 14,16 & 12,19 & 13,69 \\
\hline $\begin{array}{l}\text { 6- Planimp-referencial- } \\
\text { escaner }\end{array}$ & 5,68 & 9,07 & 17,56 & 14,28 & 12,94 & 11,60 & 4,95 & 14,85 & 14,07 & 15,22 & 21,28 & 14,17 & 12,18 & 13,69 \\
\hline $\begin{array}{l}\text { 7- Planimp-referencial- } \\
\text { câmera }\end{array}$ & 5,68 & 9,05 & 17,55 & 14,27 & 12,92 & 11,59 & 4,95 & 14,84 & 14,05 & 15,21 & 28,18 & 14,16 & 12,17 & 13,68 \\
\hline
\end{tabular}


Anexo 43- Tabela com as medidas das 14 distâncias anatômicas obtidas pelos sete grupos experimentais para a radiografia 43

\begin{tabular}{|c|c|c|c|c|c|c|c|c|c|c|c|c|c|c|}
\hline \multirow{2}{*}{ RX 43} & \multicolumn{14}{|c|}{ Distâncias anatômicas } \\
\hline & $\begin{array}{c}\text { D1 } \\
\text { MSD }\end{array}$ & $\begin{array}{c}\text { D2 } \\
\text { PMSD }\end{array}$ & $\begin{array}{l}\text { D3 } \\
\text { CSD }\end{array}$ & $\begin{array}{l}\text { D4 } \\
\text { ICS }\end{array}$ & $\begin{array}{l}\text { D5 } \\
\text { CSE }\end{array}$ & $\begin{array}{c}\text { D6 } \\
\text { PMSE }\end{array}$ & $\begin{array}{l}\text { D7 } \\
\text { MSE }\end{array}$ & $\begin{array}{l}\text { D8 } \\
\text { MID }\end{array}$ & $\begin{array}{l}\text { D9 } \\
\text { PMID }\end{array}$ & $\begin{array}{l}\text { D10 } \\
\text { CID }\end{array}$ & $\begin{array}{l}\text { D11 } \\
\text { ICI }\end{array}$ & $\begin{array}{l}\text { D12 } \\
\text { CIE }\end{array}$ & $\begin{array}{l}\text { D13 } \\
\text { PMIE }\end{array}$ & $\begin{array}{l}\text { D14 } \\
\text { MIE }\end{array}$ \\
\hline 1- Paquímetro & 4,47 & 9,68 & 14,52 & 13,57 & 14,90 & 10,45 & 5,27 & 9,84 & 11,75 & 12,50 & 20,55 & 11,66 & 8,40 & 8,13 \\
\hline $\begin{array}{l}\text { 2- Radioimp-resolução- } \\
\text { escaner }\end{array}$ & 4,48 & 9,68 & 14,55 & 13,58 & 14,93 & 10,45 & 5,27 & 9,85 & 11,77 & 12,52 & 20,56 & 11,67 & 8,40 & 8,13 \\
\hline $\begin{array}{l}\text { 3- Radioimp-referencial- } \\
\text { escaner }\end{array}$ & 4,47 & 9,69 & 14,54 & 13,58 & 14,93 & 10,45 & 5,27 & 9,85 & 11,76 & 12,51 & 20,56 & 11,66 & 8,40 & 8,14 \\
\hline $\begin{array}{l}\text { 4- Radioimp-referencial- } \\
\text { câmera }\end{array}$ & 4,47 & 9,69 & 14,53 & 13,57 & 14,91 & 10,45 & 5,27 & 9,84 & 11,75 & 12,51 & 20,55 & 11,65 & 8,40 & 8,13 \\
\hline $\begin{array}{l}\text { 5- Planimp-resolução- } \\
\text { escaner }\end{array}$ & 4,47 & 9,69 & 14,53 & 13,58 & 14,92 & 10,47 & 5,28 & 9,84 & 11,77 & 12,52 & 20,56 & 11,67 & 8,41 & 8,14 \\
\hline $\begin{array}{l}\text { 6- Planimp-referencial- } \\
\text { escaner }\end{array}$ & 4,48 & 9,68 & 14,53 & 13,58 & 14,92 & 10,46 & 5,28 & 9,84 & 11,76 & 12,51 & 20,55 & 11,67 & 8,41 & 8,14 \\
\hline $\begin{array}{l}\text { 7- Planimp-referencial- } \\
\text { câmera }\end{array}$ & 4,47 & 9,68 & 14,53 & 13,57 & 14,91 & 10,45 & 5,27 & 9,83 & 11,75 & 12,50 & 20,55 & 11,65 & 8,40 & 8,13 \\
\hline
\end{tabular}

Anexo 44- Tabela com as medidas das 14 distâncias anatômicas obtidas pelos sete grupos experimentais para a radiografia 44

\begin{tabular}{l|l|l|l|l|l|l|l|l|l|l|l|l|l|l}
\hline \multirow{2}{*}{ RX 44 } & \multicolumn{6}{l|}{ Distâncias anatômicas } \\
\cline { 2 - 23 } & $\begin{array}{l}\text { D1 } \\
\text { MSD }\end{array}$ & $\begin{array}{l}\text { D2 } \\
\text { PMSD }\end{array}$ & $\begin{array}{l}\text { D3 } \\
\text { CSD }\end{array}$ & $\begin{array}{l}\text { D4 } \\
\text { ICS }\end{array}$ & $\begin{array}{l}\text { D5 } \\
\text { CSE }\end{array}$ & $\begin{array}{l}\text { D6 } \\
\text { PMSE }\end{array}$ & $\begin{array}{l}\text { D7 } \\
\text { MSE }\end{array}$ & $\begin{array}{l}\text { D8 } \\
\text { MID }\end{array}$ & $\begin{array}{l}\text { D9 } \\
\text { PMID }\end{array}$ & $\begin{array}{l}\text { D10 } \\
\text { CID }\end{array}$ & $\begin{array}{l}\text { D11 } \\
\text { ICI }\end{array}$ & $\begin{array}{l}\text { D12 } \\
\text { CIE }\end{array}$ & $\begin{array}{l}\text { D13 } \\
\text { PMIE }\end{array}$ & $\begin{array}{l}\text { D14 } \\
\text { MIE }\end{array}$ \\
\hline \hline 1- Paquímetro & 4,74 & 9,85 & 11,36 & 11,26 & 9,20 & 9,77 & 4,38 & 3,84 & 4,00 & 5,20 & 14,48 & 4,97 & 4,65 & 4,72 \\
\hline $\begin{array}{l}\text { 2- Radioimp-resolução- } \\
\text { escaner }\end{array}$ & 4,75 & 9,87 & 11,38 & 11,28 & 9,20 & 9,78 & 4,38 & 3,84 & 4,01 & 5,21 & 14,51 & 4,98 & 4,65 & 4,73 \\
\hline $\begin{array}{l}\text { 3- Radioimp-referencial- } \\
\text { escaner }\end{array}$ & 4,74 & 9,86 & 11,38 & 11,28 & 9,20 & 9,78 & 4,38 & 3,84 & 4,00 & 5,20 & 14,50 & 4,98 & 4,65 & 4,73 \\
\hline $\begin{array}{l}\text { 4- Radioimp-referencial- } \\
\text { câmera }\end{array}$ & 4,74 & 9,85 & 11,37 & 11,26 & 9,20 & 9,77 & 4,38 & 3,83 & 4,01 & 5,20 & 14,49 & 4,97 & 4,65 & 4,72 \\
\hline $\begin{array}{l}\text { 5- Planimp-resolução- } \\
\text { escaner }\end{array}$ & 4,74 & 9,87 & 11,38 & 11,27 & 9,21 & 9,78 & 4,38 & 3,85 & 4,01 & 5,21 & 14,51 & 4,98 & 4,65 & 4,22 \\
\hline $\begin{array}{l}\text { 6- Planimp-referencial- } \\
\text { escaner }\end{array}$ & 4,75 & 9,86 & 11,38 & 11,27 & 9,21 & 9,78 & 4,39 & 3,84 & 4,01 & 5,21 & 14,50 & 4,98 & 4,65 & 4,73 \\
\hline $\begin{array}{l}\text { 7- Planimp-referencial- } \\
\text { câmera }\end{array}$ & 4,74 & 9,85 & 11,37 & 11,26 & 9,20 & 9,77 & 4,38 & 3,83 & 4,01 & 5,20 & 14,49 & 4,97 & 4,65 & 4,72 \\
\hline
\end{tabular}


Anexo 45- Tabela com as medidas das 14 distâncias anatômicas obtidas pelos sete grupos experimentais para a radiografia 45

\begin{tabular}{|c|c|c|c|c|c|c|c|c|c|c|c|c|c|c|}
\hline \multirow{2}{*}{ RX 45} & \multicolumn{14}{|c|}{ Distâncias anatômicas } \\
\hline & $\begin{array}{l}\text { D1 } \\
\text { MSD }\end{array}$ & $\begin{array}{c}\text { D2 } \\
\text { PMSD }\end{array}$ & $\begin{array}{l}\text { D3 } \\
\text { CSD }\end{array}$ & $\begin{array}{l}\text { D4 } \\
\text { ICS }\end{array}$ & $\begin{array}{l}\text { D5 } \\
\text { CSE }\end{array}$ & $\begin{array}{c}\text { D6 } \\
\text { PMSE }\end{array}$ & $\begin{array}{l}\text { D7 } \\
\text { MSE }\end{array}$ & $\begin{array}{l}\text { D8 } \\
\text { MID }\end{array}$ & $\begin{array}{l}\text { D9 } \\
\text { PMID }\end{array}$ & $\begin{array}{l}\text { D10 } \\
\text { CID }\end{array}$ & $\begin{array}{l}\text { D11 } \\
\text { ICI }\end{array}$ & $\begin{array}{l}\text { D12 } \\
\text { CIE }\end{array}$ & $\begin{array}{l}\text { D13 } \\
\text { PMIE }\end{array}$ & $\begin{array}{l}\text { D14 } \\
\text { MIE }\end{array}$ \\
\hline 1- Paquímetro & 5,35 & 7,60 & 12,72 & 9,85 & 13,66 & 14,40 & 7,60 & 6,22 & 5,65 & 6,85 & 18,34 & 7,68 & 6,93 & 6,85 \\
\hline $\begin{array}{l}\text { 2- Radioimp-resolução- } \\
\text { escaner }\end{array}$ & 5,36 & 7,62 & 12,74 & 9,85 & 13,68 & 14,40 & 7,62 & 6,22 & 5,65 & 6,85 & 18,36 & 7,69 & 6,95 & 6,85 \\
\hline $\begin{array}{l}\text { 3- Radioimp-referencial- } \\
\text { escaner }\end{array}$ & 5,36 & 7,62 & 12,74 & 9,85 & 13,67 & 14,40 & 7,61 & 6,23 & 5,65 & 6,85 & 18,35 & 7,69 & 6,93 & 6,85 \\
\hline $\begin{array}{l}\text { 4- Radioimp-referencial- } \\
\text { câmera }\end{array}$ & 5,35 & 7,61 & 12,73 & 9,85 & 13,66 & 14,40 & 7,60 & 6,22 & 5,64 & 6,85 & 18,34 & 7,68 & 6,94 & 6,85 \\
\hline $\begin{array}{l}\text { 5- Planimp-resolução- } \\
\text { escaner }\end{array}$ & 5,37 & 7,61 & 12,74 & 9,86 & 13,67 & 14,42 & 7,62 & 6,23 & 5,65 & 6,85 & 18,37 & 7,69 & 6,94 & 6,86 \\
\hline $\begin{array}{l}\text { 6- Planimp-referencial- } \\
\text { escaner }\end{array}$ & 5,36 & 7,61 & 12,73 & 9,86 & 13,68 & 14,41 & 7,62 & 6,23 & 5,65 & 6,86 & 18,36 & 7,69 & 6,94 & 6,86 \\
\hline $\begin{array}{l}\text { 7- Planimp-referencial- } \\
\text { câmera }\end{array}$ & 6,35 & 7,60 & 12,73 & 9,85 & 13,66 & 14,40 & 7,60 & 6,22 & 5,64 & 6,85 & 18,35 & 7,68 & 6,93 & 6,85 \\
\hline
\end{tabular}

Anexo 46- Tabela com as medidas das 14 distâncias anatômicas obtidas pelos sete grupos experimentais para a radiografia 46

\begin{tabular}{|c|c|c|c|c|c|c|c|c|c|c|c|c|c|c|}
\hline \multirow{2}{*}{$\mathrm{RX} 46$} & \multicolumn{14}{|c|}{ Distâncias anatômicas } \\
\hline & $\begin{array}{c}\text { D1 } \\
\text { MSD }\end{array}$ & $\begin{array}{c}\text { D2 } \\
\text { PMSD }\end{array}$ & $\begin{array}{l}\text { D3 } \\
\text { CSD }\end{array}$ & $\begin{array}{l}\text { D4 } \\
\text { ICS }\end{array}$ & $\begin{array}{l}\text { D5 } \\
\text { CSE }\end{array}$ & $\begin{array}{c}\text { D6 } \\
\text { PMSE }\end{array}$ & $\begin{array}{c}\text { D7 } \\
\text { MSE }\end{array}$ & $\begin{array}{l}\text { D8 } \\
\text { MID }\end{array}$ & $\begin{array}{c}\text { D9 } \\
\text { PMID }\end{array}$ & $\begin{array}{l}\text { D10 } \\
\text { CID }\end{array}$ & $\begin{array}{l}\text { D11 } \\
\text { ICI }\end{array}$ & $\begin{array}{l}\text { D12 } \\
\text { CIE }\end{array}$ & $\begin{array}{l}\text { D13 } \\
\text { PMIE }\end{array}$ & $\begin{array}{l}\text { D14 } \\
\text { MIE }\end{array}$ \\
\hline 1- Paquímetro & 7,05 & 10,80 & 9,67 & 11,87 & 9,58 & 7,05 & 3,72 & 6,10 & 6,00 & 5,55 & 14,60 & 6,64 & 6,07 & 6,25 \\
\hline $\begin{array}{l}\text { 2- Radioimp-resolução- } \\
\text { escaner }\end{array}$ & 7,07 & 10,82 & 9,67 & 11,89 & 9,59 & 7,05 & 3,72 & 6,12 & 6,01 & 5,56 & 14,60 & 6,65 & 6,08 & 6,26 \\
\hline $\begin{array}{l}\text { 3- Radioimp-referencial- } \\
\text { escaner }\end{array}$ & 7,07 & 10,82 & 9,68 & 11,88 & 9,59 & 7,05 & 3,72 & 6,11 & 6,00 & 5,56 & 14,60 & 6,65 & 6,08 & 6,26 \\
\hline $\begin{array}{l}\text { 4- Radioimp-referencial- } \\
\text { câmera }\end{array}$ & 7,06 & 10,81 & 9,67 & 11,87 & 9,58 & 7,04 & 3,71 & 6,10 & 6,00 & 5,55 & 14,60 & 6,64 & 6,07 & 6,25 \\
\hline $\begin{array}{l}\text { 5- Planimp-resolução- } \\
\text { escaner }\end{array}$ & 7,06 & 10,83 & 9,68 & 11,89 & 9,60 & 7,06 & 3,72 & 6,11 & 6,01 & 5,56 & 14,60 & 6,66 & 6,07 & 6,25 \\
\hline $\begin{array}{l}\text { 6- Planimp-referencial- } \\
\text { escaner }\end{array}$ & 7,06 & 10,82 & 9,67 & 11,88 & 9,60 & 7,06 & 3,72 & 6,12 & 6,01 & 5,56 & 14,60 & 6,66 & 6,07 & 6,25 \\
\hline $\begin{array}{l}\text { 7- Planimp-referencial- } \\
\text { câmera }\end{array}$ & 7,05 & 10,81 & 9,67 & 11,87 & 9,58 & 7,05 & 3,71 & 6,10 & 6,00 & 5,55 & 14,60 & 6,64 & 6,06 & 6,25 \\
\hline
\end{tabular}


Anexo 47- Tabela com as medidas das 14 distâncias anatômicas obtidas pelos sete grupos experimentais para a radiografia 47

\begin{tabular}{|c|c|c|c|c|c|c|c|c|c|c|c|c|c|c|}
\hline \multirow[b]{2}{*}{ RX 47} & \multicolumn{14}{|c|}{ Distâncias anatômicas } \\
\hline & $\begin{array}{c}\text { D1 } \\
\text { MSD }\end{array}$ & $\begin{array}{c}\text { D2 } \\
\text { PMSD }\end{array}$ & $\begin{array}{c}\text { D3 } \\
\text { CSD }\end{array}$ & $\begin{array}{c}\text { D4 } \\
\text { ICS }\end{array}$ & $\begin{array}{c}\text { D5 } \\
\text { CSE }\end{array}$ & $\begin{array}{c}\text { D6 } \\
\text { PMSE }\end{array}$ & $\begin{array}{c}\text { D7 } \\
\text { MSE }\end{array}$ & $\begin{array}{c}\text { D8 } \\
\text { MID }\end{array}$ & $\begin{array}{c}\text { D9 } \\
\text { PMID }\end{array}$ & $\begin{array}{l}\text { D10 } \\
\text { CID }\end{array}$ & $\begin{array}{l}\text { D11 } \\
\text { ICI }\end{array}$ & $\begin{array}{l}\text { D12 } \\
\text { CIE }\end{array}$ & \begin{tabular}{|c|} 
D13 \\
PMI \\
E \\
\end{tabular} & $\begin{array}{l}\text { D14 } \\
\text { MIE }\end{array}$ \\
\hline 1- Paquímetro & 7,54 & 10,50 & 14,35 & 13,35 & 15,41 & 7,65 & 5,80 & 9,08 & 8,24 & 10,26 & 24,41 & 6,91 & 5,50 & 6,08 \\
\hline $\begin{array}{l}\text { 2- Radioimp-resolução- } \\
\text { escaner }\end{array}$ & 7,56 & 10,53 & 14,36 & 13,36 & 15,44 & 7,66 & 5,81 & 9,09 & 8,26 & 10,28 & 24,41 & 6,92 & 5,50 & 6,09 \\
\hline $\begin{array}{l}\text { 3- Radioimp-referencial- } \\
\text { escaner }\end{array}$ & 7,55 & 10,53 & 14,36 & 13,36 & 15,43 & 7,66 & 5,80 & 9,08 & 8,25 & 10,27 & 24,41 & 6,91 & 5,50 & 6,09 \\
\hline $\begin{array}{l}\text { 4- Radioimp-referencial- } \\
\text { câmera }\end{array}$ & 7,54 & 10,51 & 14,36 & 13,35 & 15,42 & 7,65 & 5,79 & 9,08 & 8,24 & 10,27 & 24,41 & 6,91 & 5,50 & 6,08 \\
\hline $\begin{array}{l}\text { 5- Planimp-resolução- } \\
\text { escaner }\end{array}$ & 7,56 & 10,52 & 14,37 & 13,37 & 15,44 & 7,67 & 5,80 & 9,10 & 8,26 & 10,29 & 24,41 & 6,91 & 5,50 & 6,08 \\
\hline $\begin{array}{l}\text { 6- Planimp-referencial- } \\
\text { escaner }\end{array}$ & 7,55 & 10,52 & 14,36 & 13,36 & 15,43 & 7,67 & 5,80 & 9,09 & 8,25 & 10,29 & 24,41 & 6,91 & 5,51 & 6,08 \\
\hline $\begin{array}{l}\text { 7- Planimp-referencial- } \\
\text { câmera }\end{array}$ & 7,54 & 10,51 & 14,35 & 13,35 & 15,42 & 7,65 & 5,79 & 9,09 & 8,24 & 10,27 & 24,41 & 6,91 & 5,50 & 6,08 \\
\hline
\end{tabular}

Anexo 48- Tabela com as medidas das 14 distâncias anatômicas obtidas pelos sete grupos experimentais para a radiografia 48

\begin{tabular}{|c|c|c|c|c|c|c|c|c|c|c|c|c|c|c|}
\hline \multirow[b]{2}{*}{ RX 48} & \multicolumn{14}{|c|}{ Distâncias anatômicas } \\
\hline & $\begin{array}{c}\text { D1 } \\
\text { MSD }\end{array}$ & $\begin{array}{c}\text { D2 } \\
\text { PMSD }\end{array}$ & $\begin{array}{l}\text { D3 } \\
\text { CSD }\end{array}$ & $\begin{array}{l}\text { D4 } \\
\text { ICS }\end{array}$ & $\begin{array}{l}\text { D5 } \\
\text { CSE }\end{array}$ & $\begin{array}{c}\text { D6 } \\
\text { PMSE }\end{array}$ & $\begin{array}{l}\text { D7 } \\
\text { MSE }\end{array}$ & $\begin{array}{l}\text { D8 } \\
\text { MID }\end{array}$ & $\begin{array}{c}\text { D9 } \\
\text { PMID }\end{array}$ & $\begin{array}{l}\text { D10 } \\
\text { CID }\end{array}$ & $\begin{array}{l}\text { D11 } \\
\text { ICI }\end{array}$ & $\begin{array}{l}\text { D12 } \\
\text { CIE }\end{array}$ & \begin{tabular}{|c|} 
D13 \\
PMI \\
E
\end{tabular} & $\begin{array}{l}\text { D14 } \\
\text { MIE }\end{array}$ \\
\hline 1- Paquímetro & 10,32 & 13,49 & 12,65 & 11,97 & 13,54 & 12,27 & 7,20 & 5,55 & 5,95 & 6,57 & 17,21 & 7,05 & 5,87 & 6,50 \\
\hline $\begin{array}{l}\text { 2- Radioimp-resolução- } \\
\text { escaner }\end{array}$ & 10,32 & 13,49 & 12,65 & 11,98 & 13,55 & 12,28 & 7,20 & 5,56 & 5,95 & 6,59 & 17,21 & 7,06 & 5,88 & 6,51 \\
\hline $\begin{array}{l}\text { 3- Radioimp-referencial- } \\
\text { escaner }\end{array}$ & 10,32 & 13,49 & 12,65 & 11,98 & 13,55 & 12,28 & 7,20 & 5,56 & 5,95 & 6,58 & 17,21 & 7,06 & 5,88 & 6,51 \\
\hline $\begin{array}{l}\text { 4- Radioimp-referencial- } \\
\text { câmera }\end{array}$ & 10,32 & 13,49 & 12,65 & 11,97 & 13,54 & 12,27 & 7,20 & 5,55 & 5,94 & 6,57 & 17,21 & 7,06 & 5,87 & 6,50 \\
\hline $\begin{array}{l}\text { 5- Planimp-resolução- } \\
\text { escaner }\end{array}$ & 10,32 & 13,50 & 12,65 & 11,97 & 13,55 & 12,28 & 7,21 & 5,55 & 5,95 & 6,58 & 17,21 & 7,06 & 5,87 & 6,51 \\
\hline $\begin{array}{l}\text { 6- Planimp-referencial- } \\
\text { escaner }\end{array}$ & 10,33 & 13,49 & 12,65 & 11,98 & 13,55 & 12,28 & 7,21 & 5,55 & 5,95 & 6,58 & 17,21 & 7,05 & 5,88 & 6,51 \\
\hline $\begin{array}{l}\text { 7- Planimp-referencial- } \\
\text { câmera }\end{array}$ & 10,32 & 13,49 & 12,65 & 11,97 & 13,54 & 12,27 & 7,20 & 5,55 & 5,94 & 6,57 & 17,21 & 7,05 & 5,87 & 6,50 \\
\hline
\end{tabular}


Anexo 49- Tabela com as medidas das 14 distâncias anatômicas obtidas pelos sete grupos experimentais para a radiografia 49

\begin{tabular}{|c|c|c|c|c|c|c|c|c|c|c|c|c|c|c|}
\hline \multirow{2}{*}{ RX 49} & \multicolumn{14}{|c|}{ Distâncias anatômicas } \\
\hline & $\begin{array}{l}\text { D1 } \\
\text { MSD }\end{array}$ & $\begin{array}{c}\text { D2 } \\
\text { PMSD }\end{array}$ & $\begin{array}{l}\text { D3 } \\
\text { CSD }\end{array}$ & $\begin{array}{l}\text { D4 } \\
\text { ICS }\end{array}$ & $\begin{array}{l}\text { D5 } \\
\text { CSE }\end{array}$ & $\begin{array}{c}\text { D6 } \\
\text { PMSE }\end{array}$ & $\begin{array}{c}\text { D7 } \\
\text { MSE }\end{array}$ & $\begin{array}{l}\text { D8 } \\
\text { MID }\end{array}$ & \begin{tabular}{|c|} 
D9 \\
PMID
\end{tabular} & $\begin{array}{l}\text { D10 } \\
\text { CID }\end{array}$ & $\begin{array}{l}\text { D11 } \\
\text { ICI }\end{array}$ & $\begin{array}{l}\text { D12 } \\
\text { CIE }\end{array}$ & \begin{tabular}{|c|} 
D13 \\
PMIE
\end{tabular} & $\begin{array}{l}\text { D14 } \\
\text { MIE }\end{array}$ \\
\hline 1- Paquímetro & 3,29 & 5,58 & 10,61 & 8,36 & 7,01 & 7,03 & 4,46 & 6,14 & 5,86 & 7,11 & 16,66 & 9,20 & 7,64 & 7,02 \\
\hline $\begin{array}{l}\text { 2- Radioimp-resolução- } \\
\text { escaner }\end{array}$ & 3,29 & 5,59 & 10,62 & 8,37 & 7,03 & 7,04 & 4,47 & 6,16 & 5,87 & 7,13 & 16,66 & 9,21 & 7,65 & 7,02 \\
\hline $\begin{array}{l}\text { 3- Radioimp-referencial- } \\
\text { escaner }\end{array}$ & 3,29 & 5,59 & 10,62 & 8,37 & 7,03 & 7,04 & 4,46 & 6,15 & 5,87 & 7,13 & 16,66 & 9,20 & 7,65 & 7,02 \\
\hline $\begin{array}{l}\text { 4- Radioimp-referencial- } \\
\text { câmera }\end{array}$ & 3,29 & 5,59 & 10,62 & 8,36 & 7,02 & 7,03 & 4,46 & 6,14 & 5,86 & 7,12 & 16,66 & 9,20 & 7,64 & 7,02 \\
\hline $\begin{array}{l}\text { 5- Planimp-resolução- } \\
\text { escaner }\end{array}$ & 3,29 & 5,59 & 10,61 & 8,37 & 7,02 & 7,04 & 4,46 & 6,16 & 5,87 & 7,12 & 16,67 & 9,21 & 7,65 & 7,02 \\
\hline $\begin{array}{l}\text { 6- Planimp-referencial- } \\
\text { escaner }\end{array}$ & 3,29 & 5,59 & 10,61 & 8,37 & 7,02 & 7,04 & 4,46 & 6,15 & 5,87 & 7,12 & 16,67 & 9,20 & 7,65 & 7,03 \\
\hline $\begin{array}{l}\text { 7- Planimp-referencial- } \\
\text { câmera }\end{array}$ & 3,29 & 5,58 & 10,61 & 8,36 & 7,01 & 7,03 & 4,46 & 6,14 & 5,86 & 7,11 & 16,66 & 9,20 & 7,64 & 7,02 \\
\hline
\end{tabular}

Anexo 50- Tabela com as medidas das 14 distâncias anatômicas obtidas pelos sete grupos experimentais para a radiografia 50

\begin{tabular}{|c|c|c|c|c|c|c|c|c|c|c|c|c|c|c|}
\hline \multirow{2}{*}{$\mathrm{RX} 50$} & \multicolumn{14}{|c|}{ Distâncias anatômicas } \\
\hline & $\begin{array}{c}\text { D1 } \\
\text { MSD }\end{array}$ & $\begin{array}{c}\text { D2 } \\
\text { PMSD }\end{array}$ & $\begin{array}{l}\text { D3 } \\
\text { CSD }\end{array}$ & $\begin{array}{l}\text { D4 } \\
\text { ICS }\end{array}$ & $\begin{array}{l}\text { D5 } \\
\text { CSE }\end{array}$ & $\begin{array}{c}\text { D6 } \\
\text { PMSE }\end{array}$ & \begin{tabular}{|l} 
D7 \\
MSE
\end{tabular} & \begin{tabular}{|c|} 
D8 \\
MID
\end{tabular} & \begin{tabular}{|c|} 
D9 \\
PMID
\end{tabular} & $\begin{array}{l}\text { D10 } \\
\text { CID }\end{array}$ & $\begin{array}{l}\text { D11 } \\
\text { ICI }\end{array}$ & $\begin{array}{l}\text { D12 } \\
\text { CIE }\end{array}$ & \begin{tabular}{|c|} 
D13 \\
PMIE
\end{tabular} & $\begin{array}{l}\text { D14 } \\
\text { MIE }\end{array}$ \\
\hline 1- Paquímetro & 8,25 & 11,73 & 15,56 & 13,00 & 16,60 & 12,80 & 7,51 & 7,99 & 8,85 & 8,99 & 16,13 & 9,47 & 8,67 & 8,35 \\
\hline $\begin{array}{l}\text { 2- Radioimp-resolução- } \\
\text { escaner }\end{array}$ & 8,26 & 11,74 & 15,57 & 13,01 & 16,60 & 12,82 & 7,53 & 7,98 & 8,86 & 8,99 & 16,15 & 9,48 & 8,69 & 8,35 \\
\hline $\begin{array}{l}\text { 3- Radioimp-referencial- } \\
\text { escaner }\end{array}$ & 8,26 & 11,74 & 15,57 & 13,01 & 16,60 & 12,81 & 7,52 & 7,98 & 8,86 & 8,99 & 16,14 & 9,48 & 8,69 & 8,35 \\
\hline $\begin{array}{l}\text { 4- Radioimp-referencial- } \\
\text { câmera }\end{array}$ & 8,25 & 11,74 & 15,56 & 13,00 & 16,60 & 12,81 & 7,51 & 7,99 & 8,85 & 8,99 & 16,13 & 9,47 & 8,68 & 8,35 \\
\hline $\begin{array}{l}\text { 5- Planimp-resolução- } \\
\text { escaner }\end{array}$ & 8,26 & 11,73 & 15,57 & 13,01 & 16,60 & 12,83 & 7,53 & 7,99 & 8,86 & 8,99 & 16,14 & 9,48 & 8,69 & 8,35 \\
\hline $\begin{array}{l}\text { 6- Planimp-referencial- } \\
\text { escaner }\end{array}$ & 8,26 & 11,73 & 15,57 & 13,02 & 16,60 & 12,82 & 7,52 & 7,98 & 8,86 & 8,99 & 16,14 & 9,47 & 8,69 & 8,35 \\
\hline $\begin{array}{l}\text { 7- Planimp-referencial- } \\
\text { câmera }\end{array}$ & 8,25 & 11,73 & 15,56 & 13,00 & 16,60 & 12,81 & 7,51 & 7,98 & 8,85 & 8,98 & 16,13 & 9,47 & 8,68 & 8,35 \\
\hline
\end{tabular}

